\title{
THE ROLE OF THE GRASSLAND BIOME IN THE GLOBAL CARBON CYCLE
}

\section{BJÖRN DIRKS}





\section{PROPOSITIONS}

1. $\mathrm{CO}_{2}$ flux measurements without process analysis at the proper time scale have no generic value.

(this thesis)

2. Anthropogenic $\mathrm{CO}_{2}$ emissions are effectively mitigated by strengthening bioecosystems in the natural carbon cycle.

(this thesis)

3. A virus epidemic does not evolve to restore degraded ecosystems.

4. Advocacy of biomass as an energy source cannot be justified on basis of the processes of primary production.

5. More information does not result in more balanced opinions.

6. We are not living through extraordinary times.

Propositions belonging to the thesis, entitled

THE ROLE OF THE GRASSLAND BIOME

IN THE GLOBAL CARBON CYCLE

Björn Dirks

Wageningen, 17 September 2021 



\title{
THE ROLE OF THE GRASSLAND BIOME IN THE GLOBAL CARBON CYCLE
}

\author{
Björn Dirks
}




\section{Thesis committee}

\section{Promotor}

Prof. Dr M.K. van Ittersum

Personal Chair, Plant Production Systems

Wageningen University \& Research

\section{Co-promotors}

em. Prof. Dr R. Rabbinge

University Professor

Wageningen University \& Research

em. Dr E.A. Lantinga

Associate Professor, Farming Systems Ecology Group

Wageningen University \& Research

\section{Other members}

Prof. Dr N.P.R. Anten, Wageningen University \& Research

Prof. Dr N. Buchmann, Swiss Federal Institute of Technology Zürich, Switzerland

Dr K. Klumpp, National Research Institute for Agriculture, Food and Environment, Chamalières, France

Prof. Dr W. Peters, Wageningen University \& Research 


\title{
The role of the grassland biome in the global carbon cycle
}

\author{
Björn Dirks
}

Thesis

submitted in fulfillment of the requirements for the degree of doctor at Wageningen University by the authority of the Rector Magnificus

Prof. Dr A.P.J. Mol,

in the presence of the

Thesis Committee appointed by the Academic Board

to be defended in public

on Friday 17 September 2021

at 1.30 p.m. in the Aula. 
Björn Dirks

The role of the grassland biome in the global carbon cycle 228 pages

PhD thesis, Wageningen University, Wageningen, the Netherlands (2021)

With references, with summary in English

ISBN 978-94-6395-873-8

DOI https://doi.org/10.18174/549484 


\section{Table of Contents}

Chapter 1 General introduction

Chapter 2 Temperature sensitivity of photosynthesis in Lolium perenne swards: a comparison of two methods for deriving photosynthetic parameters from in vivo measurements

Chapter 3 Surface $\mathrm{CO}_{2}$ exchange in an intensively managed peat pasture 47

Chapter 4 Energy exchange and surface conductance in an intensively managed peat pasture

Chapter 5 The effect of drainage on $\mathrm{CO}_{2}$ exchange patterns in an intensively managed peat pasture

Appendix A Addenda to Chapters 3-5

Chapter 6 Patterns of monthly and annual $\mathrm{CO}_{2}$ exchange in a drained peat grassland

Chapter 7 General discussion

References

Summary

Acknowledgments

About the author 


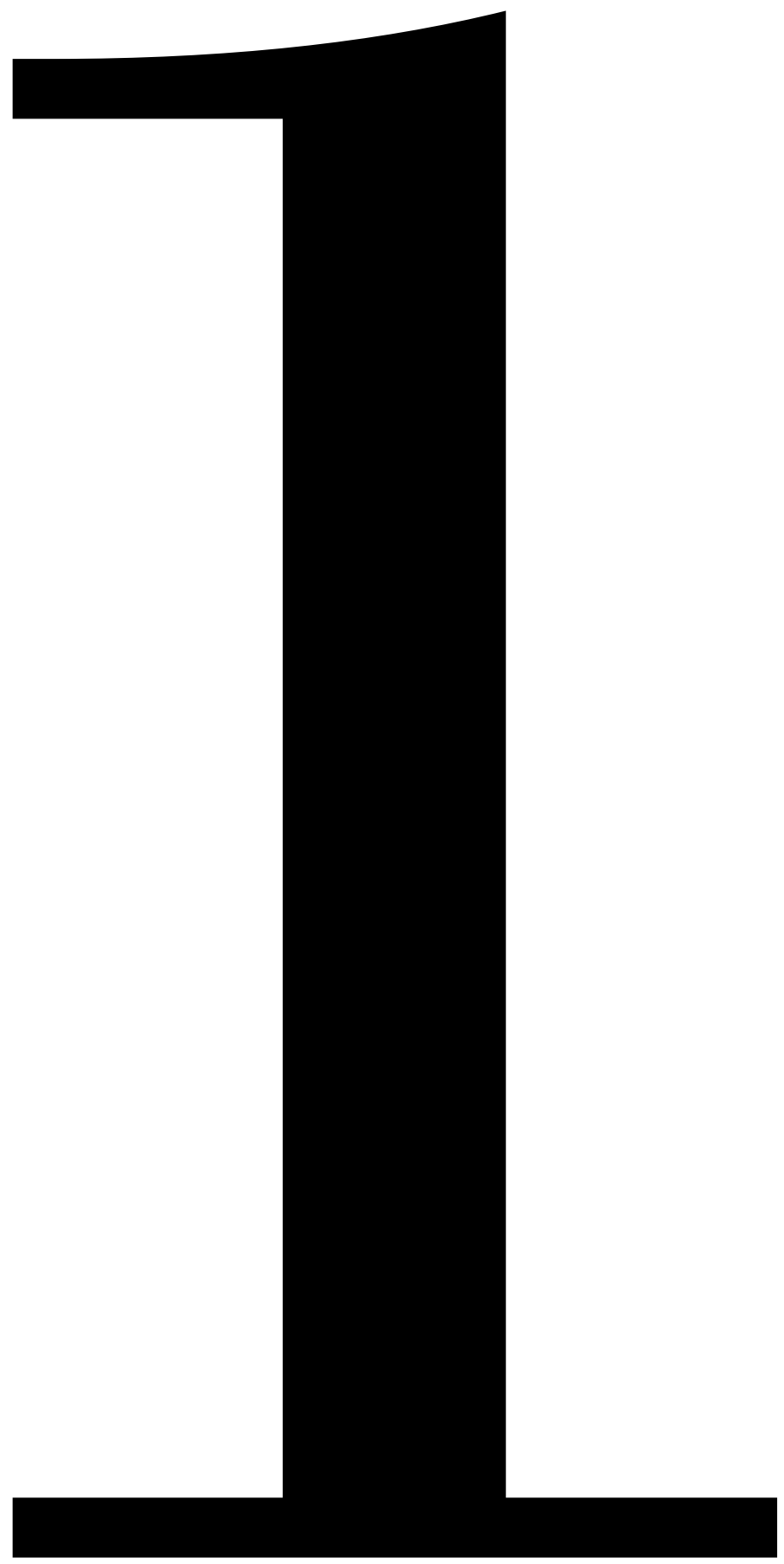


Chapter 1

General introduction 
Atmospheric $\mathrm{CO}_{2}$ has been widely recognised as an effective climate agent and is the most important resource in the autotrophic production of organic matter. It constitutes a small but significant part of the global $\mathrm{C}$ cycle and is subject to various negative feedback mechanisms which stabilise its concentration (Archer 2010, Schlesinger \& Bernhardt 2013). One of these mechanisms is the sequestration of $\mathrm{CO}_{2}$ in organic matter and the consequential early increase in and later stabilisation of the atmospheric $\mathrm{O}_{2}$ concentration. Whereas the atmospheric $\mathrm{O}_{2}$ concentration itself has a time coefficient of more than one million years (Canfield 2014), the $\mathrm{CO}_{2}$ concentration - in its relative minuteness - is characterised by a time coefficient of less than a decade. Photosynthetic activity in the biosphere exerts a large influence on the atmospheric $\mathrm{CO}_{2}$ concentration, which is reflected in its daily and annual cycles (Boden et al. 1994, Keeling et al. 2001). Seasonal changes in the atmospheric $\mathrm{CO}_{2}$ concentration are related to cycles of net primary productivity, where assimilatory and respiratory processes come largely full circle. A gradually increasing background $\mathrm{CO}_{2}$ concentration since the onset of the industrial revolution constitutes a clear signal in the atmospheric $\mathrm{CO}_{2}$ concentration and has proved to be of largely anthropogenic origins (Ciais et al. 2013). Although the combustion of fossil fuels, the cement industry and changes in land use release large amounts of $\mathrm{CO}_{2}$, the increase in atmospheric $\mathrm{CO}_{2}$ only accounts for approximately $50 \%$ of this release (Eldering et al. 2017). This discrepancy points at a large net $\mathrm{CO}_{2}$ sink in both biosphere and oceans, which mitigates anthropogenic emissions (Ciais et al. 1995, Griscom et al. 2017). In the terrestrial biosphere, grasslands represent one of the world's largest biomes and their surface area and physiology are conducive to substantial levels of $\mathrm{CO}_{2}$ sequestration (Gibson \& Newman 2019). Grasslands on organic soils share several characteristics with wetlands and exhibit less unequivocal $\mathrm{CO}_{2}$ exchange patterns than grasslands on mineral soils. Their anaerobic soil profiles immobilise large amounts of C, but drainage exposes the organic soil to conditions which accelerate decomposition and $\mathrm{CO}_{2}$ release (Couwenberg 2009). Whereas atmospheric-biospheric $\mathrm{CO}_{2}$ exchange is an instantaneous process at high spatial resolutions, its larger-scale significance and longerterm implications should be considered in the context of the global C cycle.

\subsection{ATMOSPHERIC $\mathrm{CO}_{2}$}

Interest in the atmospheric $\mathrm{CO}_{2}$ concentration and the consequences of its gradual rise dates back to the late $19^{\text {th }}$ century. The International Geophysical Year and attempts in the early 1950 s to measure the atmospheric $\mathrm{CO}_{2}$ concentration to investigate equilibria in the global $\mathrm{C}$ cycle led to the start of measurements of the atmospheric $\mathrm{CO}_{2}$ concentration (Revelle \& Suess 1957). Measurements began in 1958 on Hawaii's Mauna Loa volcano and continue to date. The site's remoteness and its altitude at 3,396 m ensure the absence of short-term disturbances by anthropogenic activity. It also avoids diurnal effects of a 
low night-time boundary layer accumulating $\mathrm{CO}_{2}$ respired by the terrestrial biosphere; measurements made during temperature inversions above the ground which trap volcanic $\mathrm{CO}_{2}$ are excluded from analysis. Mauna Loa's atmospheric $\mathrm{CO}_{2}$ concentration is often considered to be the global reference atmospheric $\mathrm{CO}_{2}$ concentration, in particular because of its time series. The so-called Keeling curve shows the atmospheric $\mathrm{CO}_{2}$ concentration gradually increasing from $315 \mu \mathrm{mol} \mathrm{mol}^{-1}$ in 1958 to $408 \mu \mathrm{mol} \mathrm{mol}^{-1}$ in 2018 (Ciais et al. 2019, Le Quéré et al. 2018, Schlesinger \& Bernhardt 2013). This amounts to an average annual increase of $1.5 \mu \mathrm{mol} \mathrm{mol}^{-1}$, although the annual increase accelerated to $2-2.5 \mu \mathrm{mol} \mathrm{mol}^{-1}$ in the $2010 \mathrm{~s}$. The increase has been largely attributed to anthropogenic $\mathrm{CO}_{2}$ emissions in the form of combustion of fossil fuels, cement production and land use change (Ciais et al. 2013). The slope of the Keeling curve and other measurements indicate that the pre-industrial $\mathrm{CO}_{2}$ concentration was around 280 $\mu \mathrm{mol} \mathrm{mol}{ }^{-1}$ or even less (Salinger 2007). $\mathrm{CO}_{2}$ concentrations measured in Antarctic ice cores date back 800,000 years and suggest that the atmospheric $\mathrm{CO}_{2}$ concentration ranged from $180 \mu \mathrm{mol} \mathrm{mol}^{-1}$ in glacial periods to $300 \mu \mathrm{mol} \mathrm{mol}^{-1}$ in interglacial periods (Ciais et al. 2013). Ice core measurements also indicate that the atmospheric $\mathrm{CO}_{2}$ concentration throughout the pre-industrial Holocene gradually increased from 265 to $280 \mu \mathrm{mol} \mathrm{mol}^{-1}$. The significance of atmospheric $\mathrm{CO}_{2}$ lies in its roles as (1) a climate agent through the absorption of infrared radiation and (2) an important resource in biospheric productivity.

Atmospheric $\mathrm{CO}_{2}$ is a significant component in the global climate system, primarily through its capability to absorb and emit infrared radiation. The resulting radiative forcing renders the atmosphere warmer than it would be without $\mathrm{CO}_{2}$ (Ciais et al. 2013, Forster et al. 2007, Scafetta et al. 2017). More $\mathrm{CO}_{2}$ thus results in more of the infrared radiation emitted by the earth surface to be captured and retained by the atmosphere. In ice core data from the past four glacial and interglacial cycles, Salinger (2007) found a positive correlation between northern hemisphere summer insolation and atmospheric $\mathrm{CO}_{2}$ concentration, with changes in temperature 'reasonably' synchronised with changes in $\mathrm{CO}_{2}$ concentration. This pattern was interrupted 8,000 years ago with both temperatures and $\mathrm{CO}_{2}$ concentrations reaching higher than could be expected on basis of solar insolation, which Salinger (2007) attributed to early land use change contributing to increasing $\mathrm{CO}_{2}$ concentrations and therefore higher temperatures. Concerns about the rapid increase in the atmospheric $\mathrm{CO}_{2}$ concentration in the second half of the $20^{\text {th }}$ century, increasing emissions of other greenhouse gases such as methane and nitrous oxide and their potential consequences for climate led to the establishment in 1988 of the Intergovernmental Panel on Climate Change (IPCC). IPCC has since drawn much attention to the enhanced greenhouse effect and methods to mitigate its consequences (Ciais et al. 2013, Forster et al. 2007, Proctor et al. 2018). The enhanced greenhouse effect has been defined as climate warming caused by the anthropogenic increase of atmospheric concentrations of $\mathrm{CO}_{2}$ and other greenhouse gases (Schlesinger \& Bernhardt 
2013) and stands in a somewhat arbitrary distinction to the natural greenhouse effect, i.e. the same process at pre-industrial levels of these gases. The interest in the effect of $\mathrm{CO}_{2}$ on climate dates back to the late $19^{\text {th }}$ century, when the first observations of a gradually increasing atmospheric $\mathrm{CO}_{2}$ concentration were made. Considered to be an improbable hypothesis, the increase in earth surface temperature observed during the first half of the $20^{\text {th }}$ century was then largely attributed to solar activity (Spencer 2008). With the advent of more advanced mathematical analysis and measurement techniques, the second half of the $20^{\text {th }}$ century saw a sharp rise in the interest in the role of $\mathrm{CO}_{2}$ as a climatic factor. The development of the first General Circulation Models in the 1960s (Edwards 2010) reinforced the theory that $\mathrm{CO}_{2}$ has a significant part in atmospheric temperatures and global circulation patterns.

Atmospheric $\mathrm{CO}_{2}$ is also one of the most important resources in the autotrophic production of organic matter and is at the base of biospheric productivity. In one of the most abundant biological processes, mostly photoautotrophic terrestrial and marine organisms sequester $\mathrm{CO}_{2}$ into complex organic compounds. The largely photosynthesised organic matter cascades through multiple heterotrophic levels and maintains a complex food web (Raven et al. 1981). The dependence of photosynthetic activity on the atmospheric $\mathrm{CO}_{2}$ concentration has been demonstrated at many levels of aggregation (Farquhar \& Von Caemmerer 1982, Harley et al. 1992, Pearcy \& Björkman 1983, Schapendonk et al. 1997, Suter et al. 2002). The effect of atmospheric $\mathrm{CO}_{2}$ primarily works at the cellular level in the photosynthetic $\mathrm{C}_{3}$ pathway or Calvin cycle where $\mathrm{O}_{2}$ competes with $\mathrm{CO}_{2}$. In this pathway, a higher $\mathrm{CO}_{2}$ concentration suppresses the photorespiration and increases the amount of $\mathrm{CO}_{2}$ entering the photosynthetic reaction chain (Lawlor 1987, Peisker \& Apel 1981). The (alternative) $C_{4}$ pathway or Hatch-Slack cycle prevents competition between $\mathrm{O}_{2}$ and $\mathrm{CO}_{2}$ and is therefore much less sensitive to the atmospheric $\mathrm{CO}_{2}$ concentration. The degree to which a higher atmospheric $\mathrm{CO}_{2}$ concentration increases photosynthetic activity in $\mathrm{C}_{3}$ plants depends on its interaction with other factors (Jarvis 1981, Jones 1992, Lüscher et al. 2000). If higher atmospheric $\mathrm{CO}_{2}$ concentrations concur with higher air temperatures, an enhancing effect of temperature on photorespiratory processes may offset part of the suppressing effect of $\mathrm{CO}_{2}$ (Kirschbaum \& Farquhar 1984, Long 1991). Moreover, plants are known to decrease their stomatal conductivity in response to a higher $\mathrm{CO}_{2}$ concentration (Jarvis $\&$ McNaughton 1986), thereby reducing the transpiration relative to the photosynthetic activity. Atmospheric $\mathrm{CO}_{2}$ is thus of significance to global food security, as it can increase photosynthetic activity both absolutely and relative to water use. 


\subsection{ATMOSPHERIC $\mathrm{CO}_{2}$ AND THE GLOBAL C CYCLE}

The global C cycle can be characterised by three major C cycle processes (Archer 2010). They constitute a system of consistent negative feedbacks on the atmospheric $\mathrm{CO}_{2}$ concentration and respond at vastly different time coefficients. These processes meet in the atmosphere, which exchanges $\mathrm{C}$ with lithosphere, oceans and biosphere. They all exhibit a certain degree of negative feedback, in which a higher concentration of $\mathrm{C}$ in the atmosphere - largely present as $\mathrm{CO}_{2}$ - ultimately results in a higher $\mathrm{C}$ sequestration from the atmosphere. The sequestration of $\mathrm{CO}_{2}$ into $\mathrm{CaCO}_{3}$ through its reaction with $\mathrm{CaSiO}_{3}$ - the basis of igneous rocks and therefore abundant - has an estimated time coefficient of approximately 100,000 years (Archer 2010, Archer et al. 2009). This sedimentation of atmospheric $\mathrm{CO}_{2}$ in the lithosphere is known as the atmospheric or weathering $\mathrm{CO}_{2}$ thermostat, where more atmospheric $\mathrm{CO}_{2}$ results in increased levels of weathering. $\mathrm{CO}_{2}$ and terrestrial $\mathrm{CaCO}_{3}$ - the major component of limestone - dissolve in the oceans where it ultimately deposits on the ocean floor to be transported to the inner part of the earth mantle at the point where tectonic plates collide. The dissolution of $\mathrm{CO}_{2}$ in the oceans controls the ocean's $\mathrm{pH}$ through a shifting equilibrium of carbonic acid $\left(\mathrm{H}_{2} \mathrm{CO}_{3}\right)$, bicarbonate $\left(\mathrm{HCO}_{3}^{-}\right)$and carbonate $\left(\mathrm{CO}_{3}^{2-}\right)$, which in turn reacts with $\mathrm{CaCO}_{3}$ (Feely et al. 2004, Sarmiento \& Gruber 2006, Schlesinger \& Bernhardt 2013). This feedback is known at the $\mathrm{CaCO}_{3} \mathrm{pH}$-stat. The ocean's acidity adjusts over a time period of several thousands of years (Archer 2010).

The gradual increase and later stabilisation of the atmospheric $\mathrm{O}_{2}$ concentration is the result of the cumulative net sequestration of $\mathrm{CO}_{2}$ by autotrophic processes in the biosphere and subsequent sedimentation as fossilised organic matter. Since the advent of complex life forms approximately 600 million years ago the atmospheric $\mathrm{O}_{2}$ concentration has remained relatively constant (Archer 2010, Schlesinger \& Bernhardt 2013). A higher atmospheric $\mathrm{CO}_{2}$ concentration increases its sequestration into organic matter through autotrophic activity and the concomitant formation of $\mathrm{O}_{2}$. Whereas the atmospheric $\mathrm{O}_{2}$ concentration has a time coefficient of approximately 2 million years (Archer 2010), atmospheric $\mathrm{CO}_{2}$ has a much smaller time coefficient because of its minute concentration. This small time coefficient is reflected in its short-term fluctuations. The negative feedback in the $\mathrm{C}$ cycle through autotrophic processes appears therefore more prominently in the $\mathrm{CO}_{2}$ concentration than in the $\mathrm{O}_{2}$ concentration.

Figure 1.1 represents an outline of the global $\mathrm{C}$ cycle and is based on a more detailed diagram published by IPCC (Ciais et al. 2013). It distinguishes between the cycle's major $\mathrm{C}$ reservoirs and shows the annual gross $\mathrm{C}$ fluxes. Moreover, it locates the three major C cycle processes as identified by Archer (2010) and shows how biosphere (I), oceans (II) and lithosphere (III) interact with atmospheric C. It illustrates how the atmosphere 


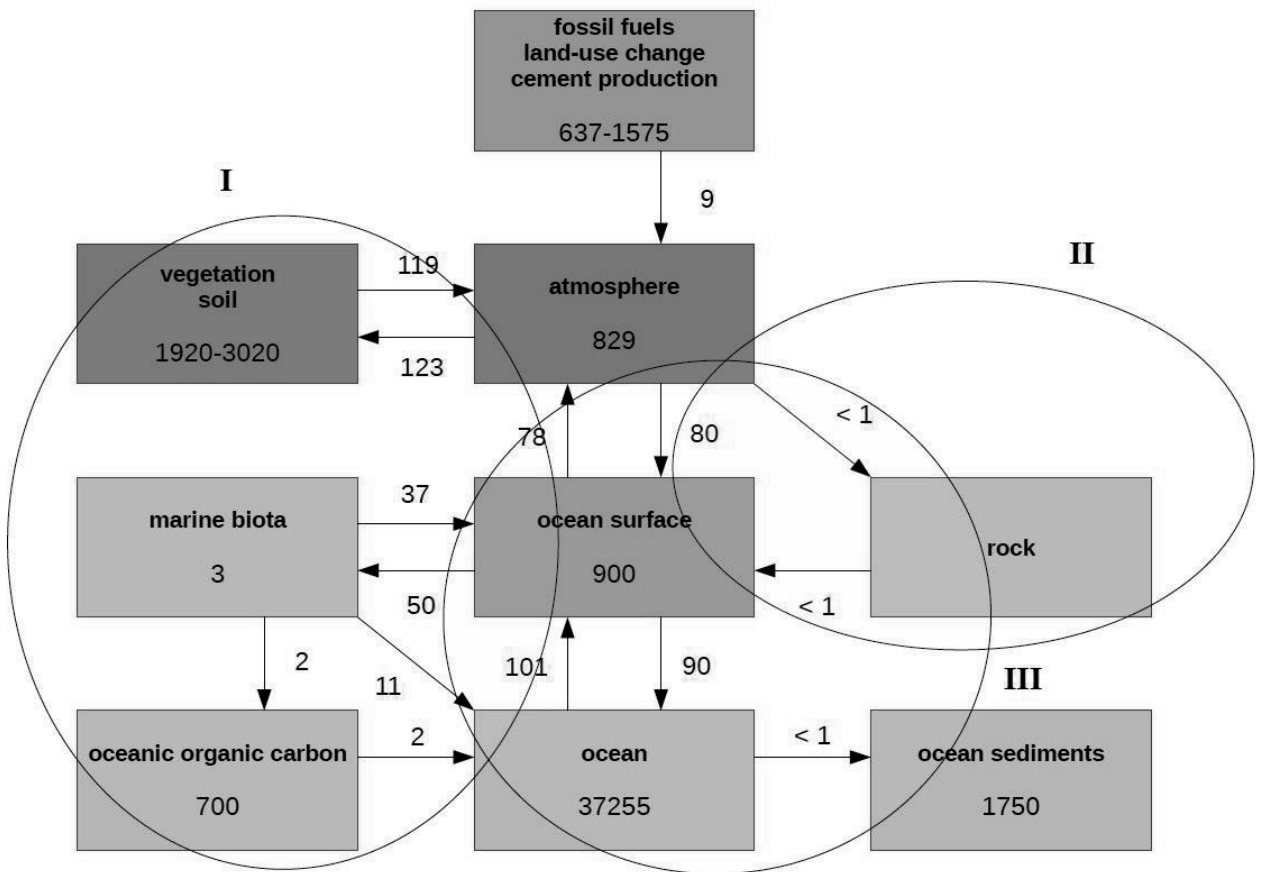

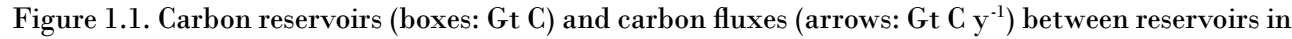
the global carbon cycle, adapted from a more detailed diagram by Ciais et al. (2013). Circles enclose the major carbon cycle processes identified by Archer (2010) in the biosphere (I), the lithosphere (II) and the oceans (III).

itself is a relatively small $\mathrm{C}$ reservoir at approximately $830 \mathrm{Gt} \mathrm{C}$. Discounting $\mathrm{C}$ held in sedimentary rocks - largely present as $\mathrm{CaSiO}_{3}$ (Archer 2010) and for all practical purposes unlimited - the amount of $\mathrm{C}$ present in the atmosphere constitutes less than $2 \%$ of its total. C incorporated in organic compounds in the marine (practically negligible) and terrestrial biosphere amounts to 1920-3020 Gt, which equates an almost equally modest $5 \%$. Up to $4 \%$ of total C lies sequestered in organic sediments, i.e. fossilised algae and plants which at some point may be partly or completely exploited as fossil fuel. $80 \%$ of $\mathrm{C}$ is thus held in inorganic forms in the oceans.

The diagram shows how multiple $\mathrm{C}$ reservoirs exchange $\mathrm{C}$ through the atmosphere (Ciais et al. 2013). The net exchanges between the atmosphere on the one hand and the oceans and the terrestrial biosphere on the other hand are relatively small at approximately 1 and $3 \mathrm{Gt} \mathrm{C}^{-1}$, however are the net result of much larger actual gross $\mathrm{C}$ fluxes. Oceans and atmosphere exchange approximately $90 \mathrm{Gt} \mathrm{C}^{-1}$ bidirectionally; terrestrial biosphere and atmosphere exchange approximately $120 \mathrm{Gt} \mathrm{C}^{-1}$. This all results in a time coefficient of approximately 4 years for the residence time of $\mathrm{C}$ in the atmosphere, i.e. the time required for a $\mathrm{C}$ atom to be exchanged. The small time coefficient reflects the sensitivity 
of atmospheric $\mathrm{C}$ to changes in the net $\mathrm{C}$ exchange with oceans and terrestrial biosphere. It contrasts with the large time coefficients of the main $\mathrm{C}$ cycle processes in sediments and oceans. The small time coefficient of atmospheric $\mathrm{CO}_{2}$ contrasts with the much larger, complementary time coefficient of atmospheric $\mathrm{O}_{2}$ as both largely cycle through the same instant biological and diffusive processes with the $\mathrm{O}_{2}$ concentration being much higher.

\subsection{ATMOSPHERIC $\mathrm{CO}_{2}$ AND ANTHROPOGENIC CO $\mathrm{CO}_{2}$ EMISSIONS}

The combustion of fossil fuels results in the release of $\mathrm{CO}_{2}$ from an anomalously fast oxidation of fossil $\mathrm{C}$ sediments, whereas changes in land use release $\mathrm{C}$ from biospheric $\mathrm{C}$ reservoirs. Urban areas contribute for more than $70 \%$ to these anthropogenic emissions (Schwandner et al. 2017). Anthropogenic $\mathrm{CO}_{2}$ accounts for most of the steady increase in the atmospheric $\mathrm{CO}_{2}$ concentration, which currently amounts to approximately $2-3 \mu \mathrm{mol}$ $\mathrm{mol}^{-1} \mathrm{y}^{-1}$ (Eldering et al. 2017). An important indication of the origin of atmospheric $\mathrm{CO}_{2}$ is provided by its ${ }^{13} \mathrm{C} /{ }^{12} \mathrm{C}$ isotope ratio. Photosynthesis processes discriminate between ${ }^{13} \mathrm{CO}_{2}$ and ${ }^{12} \mathrm{CO}_{2}$, by tending to favour the assimilation of the isotopically lighter ${ }^{12} \mathrm{C}$ over the heavier ${ }^{13} \mathrm{C}$ (Ciais et al. 1995, Griffiths 1993). The ${ }^{13} \mathrm{C} /{ }^{12} \mathrm{C}$ ratio in fossil $\mathrm{C}$ sediments is thus relatively low. A distinct decrease in the ${ }^{13} \mathrm{C} /{ }^{12} \mathrm{C}$ isotope ratio of atmospheric $\mathrm{CO}_{2}$ occurring since 1850 - as observed in tree rings, marine carbonate shells and ice cores supports the thesis that $\mathrm{CO}_{2}$ originating from fossil $\mathrm{C}$ deposits contributes significantly to the increasing atmospheric $\mathrm{CO}_{2}$ concentration (Keeling et al. 2001, 2005; Piper et al. 2001). The amounts of $\mathrm{CO}_{2}$ in the atmosphere and $\mathrm{CO}_{2}$ released from fossil fuels are well established and indicate that the increase in the amount of $\mathrm{CO}_{2}$ in the atmosphere on average only accounts for $50 \%$ of the amount of $\mathrm{CO}_{2}$ released from fossil fuels (Keeling et al. 2001, Le Quéré et al. 2018). This implies that an amount of $\mathrm{CO}_{2}$ which on average equals $50 \%$ of the $\mathrm{CO}_{2}$ released from fossil fuels is sequestered within the global $\mathrm{C}$ cycle. This amount of $\mathrm{CO}_{2}-$ the difference between the increase in the amount of atmospheric $\mathrm{CO}_{2}$ and $\mathrm{CO}_{2}$ released from fossil fuels - is occasionally referred to as the missing $\mathrm{CO}_{2}$ sink. Attempts have been made to differentiate this $\mathrm{CO}_{2}$ sink (e.g. Ciais et al. 2013, Le Quéré et al. 2018). Figure 1.1. shows how the biosphere could sequester $4 \mathrm{Gt} \mathrm{C}$ annually and the oceans could exhibit an annual net $\mathrm{C}$ uptake of $2 \mathrm{Gt} \mathrm{C}$. At an annual release of $6 \mathrm{Gt} C$ from the oxidation of fossil $\mathrm{C}$ deposits, this leaves $2 \mathrm{Gt} \mathrm{C}$ remaining in the atmosphere. The annual net $\mathrm{C}$ fluxes may be small as compared to their constituent gross fluxes, but are a substantial percentage of the atmospheric $\mathrm{C}$ reservoir. The biosphere has thus drawn increasing interest as a natural regulator of the atmospheric $\mathrm{CO}_{2}$ concentration (Griscom et al. 2017).

\subsection{THE BIOSPHERE AND THE ANNUAL CYCLE OF ATMOSPHERIC $\mathrm{CO}_{2}$}

The role of biospheric activity in the exchange of $\mathrm{C}$ is first shown in the variation in the amount of $\mathrm{CO}_{2}$ which is sequestered annually by biosphere and oceans. Whereas 
this amount of $\mathrm{CO}_{2}$ equates on average $50 \%$ of the anthropogenic $\mathrm{CO}_{2}$ emissions, it actually varies from 20 to $80 \%$ (Eldering et al. 2017). Piper et al. (2001) deduced a strong inter-annual variation in terrestrial biospheric $\mathrm{CO}_{2}$ fluxes. Ciais et al. (1995) identified a strong terrestrial $\mathrm{C}$ sink in the temperate latitudes of the Northern Hemisphere based on the seasonal pattern of atmospheric ${ }^{13} \mathrm{C}$ and ${ }^{12} \mathrm{C}$. This $\mathrm{C}$ sink was prevalent between latitudes $30^{\circ}$ and $60^{\circ}$ from June to September and is probably related to the regrowth of forest but also to $\mathrm{CO}_{2}$ fertilisation of temperate and sub-boreal ecosystems (Ciais et al. 1995). This seasonality in the balance of assimilatory and respiratory activity is also reflected in the atmospheric $\mathrm{CO}_{2}$ concentration as such (Denning et al. 2002, Keeling et al. 2001). The annual cycle of the atmospheric $\mathrm{CO}_{2}$ concentration is approximately sinusoidal and follows the growing season (Boden et al. 1994), which can be interpreted as a signature for a dominant role of the biosphere in the observed $\mathrm{C}$ sequestration. Its amplitude increases with the proportion of terrestrial to marine ecosystems. It can reach up to $15-20 \mu \mathrm{mol} \mathrm{mol}^{-1}$ at coordinates and altitudes where variable atmospheric boundary layer conditions play a minor role (Boden et al. 1994, Keeling et al. 2001). The atmospheric $\mathrm{CO}_{2}$ concentration in the Northern Hemisphere is characterised by a build-up during winter when respiratory activity exceeds assimilatory activity and a rapid decrease during spring when the biosphere's assimilatory activity rapidly exceeds the respiratory activity (Eldering et al. 2017). The decrease in atmospheric $\mathrm{CO}_{2}$ during spring coincides with an increase in Solar Induced Chlorophyll Fluorescence (Eldering et al. 2017), which proves to be a good measure for Gross Primary Productivity (Sun et al. 2017). The magnitude of the annual cycle is indicative for the role of the biosphere in the atmospheric $\mathrm{CO}_{2}$ balance. The annual atmospheric-biospheric $\mathrm{CO}_{2}$ exchange components add up to substantial sums but also come largely full circle, as most of the assimilatory activity is compensated for by respiratory activity. The gross sums are larger still if they come to include the atmospheric-oceanic $\mathrm{CO}_{2}$ exchange. The annual net $\mathrm{CO}_{2}$ exchange at the earth's surface - a net $\mathrm{CO}_{2}$ sequestration - is then relatively small (Figure 1.1) but nevertheless compares to on average $50 \%$ of the anthropogenic $\mathrm{CO}_{2}$ emissions.

Studies of biospheric-atmospheric $\mathrm{CO}_{2}$ exchange have been done in various ecosystems at various spatial scales. $\mathrm{CO}_{2}$ exchange studies are generally done at relatively small spatial scales using the aerodynamic gradient or eddy covariance techniques (Baldocchi 1994, 2003, Goulden et al. 1996, Luyssaert et al. 2009, Monteith \& Unsworth 1990). $\mathrm{CO}_{2}$ flux measurements are also done at larger spatial scales such as from aircrafts (Gioli et al. 2004), but the composite nature of the ecosystem measured and a discrepancy between spatial and temporal scales may make these measurements hard to analyse. Short-term fluctuations at large spatial scales compare to noise as they cannot be meaningfully attributed to specific processes or biome components. The Orbiting Carbon Observatory mission (OCO-2) by NASA's Jet Propulsion Laboratory (Crisp et al. 2004) allows the calculation of surface $\mathrm{CO}_{2}$ exchange from spectral measurements of the $\mathrm{CO}_{2}$ 
concentration in the atmospheric air column at much larger spatial scales over multiple years (Chatterjee et al. 2017, Eldering et al. 2017, Liu et al. 2017, Schwandner et al. 2017). These satellite measurements cannot yield detailed information about ecosystem processes. However, they can identify patterns of $\mathrm{CO}_{2}$ exchange in entire biomes provided the surface area has a certain degree of homogeneity and measurements are carried out long enough to average out temporal differences in environmental conditions.

When differentiating the terrestrial biosphere into degrees of primary productivity, natural biomes are often grouped into grasslands and forests (Foley et al. 1996, Haxeltine \& Prentice 1996, Prentice et al. 1992, Warant et al. 1994). In the context of their often alleged role as a major net source of $\mathrm{O}_{2}$ tropical rainforests have been considered a substantial sink of $\mathrm{CO}_{2}$. Grace et al. (1995) measured $\mathrm{CO}_{2}$ exchange in an undisturbed Amazonian rainforest and calculated an annual net $\mathrm{C}$ uptake of $0.10-0.24 \mathrm{~kg} \mathrm{C} \mathrm{m}^{-2}$ or 0.5-1.2 Gt C for the entire Amazon basin at a surface cover of $5 \times 10^{6} \mathrm{~km}^{2}$. Fan et al. (1990) found a strong response of net $\mathrm{CO}_{2}$ uptake to irradiance in an Amazonian rainforest during the wet season. However, they argued that the canopy itself stores a substantial amount of $\mathrm{CO}_{2}$ and that under conditions prevalent in the humid tropics much of a net $\mathrm{CO}_{2}$ uptake may be lost through the emission of volatile carbohydrates. Moreover, a net $\mathrm{CO}_{2}$ release during the dry season may thus go unaccounted for. The $\mathrm{C}$ sequestration in an Amazonian rainforest measured by Grace et al. (1995) compares to the $\mathrm{C}$ sink of $1.19 \mathrm{Mg} \mathrm{ha}^{-1} \mathrm{y}^{-1}$ measured using the eddy covariance technique by Tan $e t$ al. (2010) in an old-growth tropical seasonal rainforest in China. Sullivan et al. (2020) found $\mathrm{C}$ storage in both biomass and soil organic matter in tropical rainforests to be negatively affected by high temperature. As much of the tropical rainforest does not (anymore) qualify as an undisturbed climax vegetation, its role in the global $\mathrm{C}$ balance remains inconclusive. Based on satellite imagery, Baccini et al. (2017) observed tropical rainforest to exhibit a net $\mathrm{C}$ loss globally, but found this to be caused by the $\mathrm{C}$ loss from deforestation and degradation exceeding the $\mathrm{C}$ gain from growth. Temporal patterns of losses in $\mathrm{C}$ density were related to an alternation of degradation and regrowth, where increases in $\mathrm{C}$ gain were driven by prior $\mathrm{C}$ losses. They found the rate of net $\mathrm{C}$ gain to decrease going from natural secondary and managed forests to intact old-growth forest. Asner et al. (2010) observed a large variation in C stock in tropical rainforest depending on terrain and forest type, and deforestation and degradation to be also responsible for net $\mathrm{C}$ emissions. Secondary regrowth partially compensated for these losses, but had a $60-70 \%$ lower $\mathrm{C}$ density than intact forest. It remains to be seen whether the spatially low resolution OCO-2 measurements (Crisp et al. 2004, Eldering et al. 2017) will be able to disentangle these complex patterns of primary growth, degradation, deforestation and secondary growth. 
Ciais et al. (1995) identified a distinct $C$ sink between latitudes $30^{\circ}$ and $60^{\circ}$ in the Northern Hemisphere and related this to forest regrowth and a $\mathrm{CO}_{2}$ fertilisation effect. This hypothesis was corroborated by Wu et al. (2013) after analysing 13 years of net $\mathrm{CO}_{2}$ exchange measurements in a temperate deciduous forest in Denmark and concluding that the forest's $\mathrm{C}$ sink and light use efficiency had increased over this time period. In 15 European forests Van Dijk \& Dolman (2004) found a latitudinal trend in the net $\mathrm{CO}_{2}$ sequestration, decreasing from approximately $6.0 \mathrm{MgC} \mathrm{ha}^{-1} \mathrm{y}^{-1}$ at $41^{\circ}$ to $0.5 \mathrm{Mg} \mathrm{C} \mathrm{ha}^{-1}$ $\mathrm{y}^{-1}$ at $64^{\circ}$. This trend is a consequence of the gross primary productivity decreasing faster than the respiratory activity. It thus indicates that forests in the temperate zones exhibit a substantially higher net $\mathrm{CO}_{2}$ sequestration rate than tropical rainforests, although the forests' different stages of development make for an uneasy comparison. The extent of the contribution to the biosphere's net $\mathrm{CO}_{2}$ sequestration by (particularly tropical) forests which transcends cycles of deforestation and regrowth, however, remains uncertain.

\subsection{GRASSLANDS AND ATMOSPHERIC-BIOSPHERIC $\mathrm{CO}_{2}$ EXCHANGE}

\subsubsection{Grassland distribution}

Models of the global distribution of vegetation as a function of latitude, soil characteristics, climate and plant functional types correctly predict that grasses will compete successfully against woody plants in drier environments with precipitation in summer and conditions warm and dry enough to benefit $\mathrm{C}_{4}$ over $\mathrm{C}_{3}$ plants (Foley et al. 1996, Haxeltine \& Prentice 1996, Prentice et al. 1992). This applies particularly to the transition from tropical seasonal forest to savanna and to the temperate steppes of America and Asia. However, the models prove to be inadequate in predicting the occurrence of grasslands or forests elsewhere because of low functional resolution. The geological expansion of grasslands is thus often considered a result of a drier and more seasonal climate. But Retallack (2001) uses palaeontological, palaeosolic and isotopic evidence to suggest that during the Neogene era of the Cenozoic - approximately 6-7 million years ago - it was the co-evolution of grasses and grazers which may have driven the migration of grasslands into increasingly wetter climatic regions. Grasslands could thus have drastically expanded their climatic and geographical range beyond that of the original desert vegetation to regions with higher primary productivity. It is probable that the biogeography of grasslands will also in the future be dynamic particularly under conditions of a changing climate (Gibson \& Newman 2019). Grasslands have meanwhile come to constitute the biosphere's dominant ecosystem by surface area, although more detailed distributions are open to interpretation due to an arbitrary classification of shrubland, tundra and ecosystems which represent a transition between forest and grassland. 
Table 1.1. Global grassland distributions as provided by Gibson (Pilot Analysis of Global Ecosystems Classification 2009) and Ojima et al. (1993).

\begin{tabular}{llll}
\hline Gibson (2009) & & Ojima et al. (1993) & \\
\hline description & $\begin{array}{l}\text { surface } \\
\left(10^{6} \mathrm{~km}^{2}\right)\end{array}$ & description & $\begin{array}{l}\text { surface } \\
\left(10^{6} \mathrm{~km}^{2}\right)\end{array}$ \\
\hline tundra & 7.4 & semi desert & 5.0 \\
savannas & 17.9 & cool grasslands and shrublands & 2.7 \\
open and closed shrublands & 16.5 & warm grasslands and shrublands & 10.2 \\
non-woody grasslands & 10.7 & hot desert & 19.5 \\
& 52.5 & & 37.4 \\
\hline
\end{tabular}

Two contrasting grassland classifications are presented in Table 1.1. Gibson (2009) categorised grasslands by botanical characteristics and arrived at a total surface area of $52.5 \times 10^{6} \mathrm{~km}^{2}$. Ojima et al. (1993) categorised grasslands by climate zones and calculated a total surface area of $37.4 \times 10^{6} \mathrm{~km}^{2}$, the much lower surface area being a consequence of a restriction to drylands. The nature and degree of management of grassland ecosystems varies widely and ranges from natural hardly managed savanna in the Sahelian zone (Verhoef et al. 1996) to intensively managed pastureland in temperate climates reminiscent of cropland (Lantinga 1985, Lüscher et al. 2004). Although grasslands naturally occur under conditions which are less conducive to high primary productivity as a result of drought or low temperature (Gibson 2009), grassland reality appears more differentiated. Many natural grasslands have long been subject to at least some form of agricultural management - drainage, fertilisation or improvement of species composition - to increase primary productivity and forage quality (Penning de Vries \& Djitèye 1982). Many permanent grasslands also occur in regions where forests instead of grasslands constitute the natural climax vegetation and where primary productivity is higher because of conditions of less drought, less extreme temperatures and more intensive grassland management (Jones \& Donnelly 2004, Smit et al. 2008). European grasslands cover more than 90 million ha or approximately $40 \%$ of its agricultural area (Gilmanov et al. 2007).

\subsubsection{Grasslands as a $\mathrm{CO}_{2} \operatorname{sink}$}

The terrestrial C sink observed by Ciais et al. (1995) between $30^{\circ}$ and $60^{\circ}$ in the Northern Hemisphere also coincides with the location of the world's most productive grasslands. Retallack (2001) suggests that the expanding grasslands in the Cenozoic contributed to a decreasing atmospheric $\mathrm{CO}_{2}$ concentration and possibly climate cooling as a result of their particular characteristics in sequestering C. He points out that the erosion of soil organic matter to sedimentary basins is much more effective in pastureland than in the dry woodland which it replaced. Moreover, organic $\mathrm{C}$ reaches much deeper in grassland than in woodland soils, the former thus having a much higher total $\mathrm{C}$ content than the 
latter (Retallack 2001, Scurlock et al. 2002). Jones and Donnelly (2004) showed that the deeper parts of temperate grassland soil profiles are relatively rich in $\mathrm{C}$ and that the intermediate microaggregate-protected $\mathrm{C}$ pool (with a particle size of up to $0.1 \mathrm{~mm}$ ) has a particularly important role in long-term grassland $\mathrm{C}$ storage. Grasslands thus generally function as a $\mathrm{C}$ sink as a result of the accumulation of soil $\mathrm{C}$ rather than the accumulation of biomass (Jones \& Donnelly 2004, Lauenroth et al. 2006, Parton et al. 1987). What aboveground may thus appear to be a steady-state situation, is in fact not. Soussana et al. (2007) determined the greenhouse gas budgets of nine European grasslands based on flux measurements and found each of them to be a net sink for $\mathrm{CO}_{2}$ averaged over a period of two years. Flux measurements are made at surface of the ecosystem to the atmosphere and are thus not limited to a certain depth of the soil profile. The ecosystems' average annual net $\mathrm{CO}_{2}$ sequestration amounted to $108 \mathrm{~g} \mathrm{C} \mathrm{m}^{-2}$ or $47 \mathrm{~g} \mathrm{C} \mathrm{m}^{-2}$ when accounting for $\mathrm{C}$ migration across system boundaries. The semi-natural grasslands showed an average annual net $\mathrm{CO}_{2}$ sequestration of $140 \mathrm{~g} \mathrm{C} \mathrm{m}^{-2}(n=4)$, the intensively managed permanent grasslands $165 \mathrm{~g} \mathrm{C} \mathrm{m}^{-2}(n=2)$ and the sown grass/clover pastures $26 \mathrm{~g} \mathrm{C} \mathrm{m}^{-2}(n=3)$.

Although natural grasslands tend to occur under conditions which are less conducive to high primary productivity as a result of drought or low temperature (Jones \& Donnelly 2004), they have the potential to sequester significant amounts of $\mathrm{CO}_{2}$ and play an important role in the global $\mathrm{C}$ cycle. Grasslands are characterised by an aboveground vegetation cover which is mostly renewed annually and exhibits an efficient assimilatory system. Relatively low maintenance requirements result in a relatively high net primary productivity (Sala et al. 1988). Zhang et al. (2009) used imaging spectroradiometry to determine the global pattern of net (NPP) and gross primary productivity (GPP) in relation to 30-year averages of temperature and precipitation. They found the NPP/GPP ratio to increase across and within ecosystems with both decreasing temperatures between 10 and $-20^{\circ} \mathrm{C}$ and decreasing precipitation. Correspondingly, Zhang et al. (2009) found herbaceous ecosystems to have higher NPP/GPP ratios than forest ecosystems. Although high productivity as such is generally associated with densely vegetated ecosystems in warm and moist climates (Foley et al. 1996), grasslands retain a higher proportion of the assimilated dry matter. Scurlock et al. (2002) even suggest that many grassland NPP data underestimate actual productivity because of inadequate measurement methodology. Warnant et al. (1994) calculated average NPP for various biomes and arrived at 341 and $649 \mathrm{~g} \mathrm{C} \mathrm{m}^{-2} \mathrm{y}^{-1}$ for grassland and tropical savanna, respectively, a difference probably at least partially related to the length of the growing season. For boreal forest, temperate forest and tropical forest they calculated 419, 659 and $711 \mathrm{~g} \mathrm{C} \mathrm{m}^{-2} \mathrm{y}^{-1}$, respectively. Although forests are thus characterised by a higher net productivity, grasslands hold a higher proportion of their biomass belowground (Gibson 2009). Jones and Donnelly (2004) point out how belowground organic matter becomes more protected against decomposition than organic matter which is not encapsulated within soil aggregates or 
locked in by clay minerals. Moreover, chemical composition results in lower levels of decomposability in root organic matter. Howlett et al. (2013) found soil C in a seminatural grassland in southern Japan to date back 12,000 years, which indicates over what time scales grassland soils can sequester $\mathrm{C}$. Boreal forests seem to share this particular aspect with grasslands, with their organic matter of such a chemical composition that it has lower levels of decomposition than organic matter in other forest biomes. The high level of allocation of biomass to the root system, the roots' chemical composition, the physical protection of soil organic matter to decomposition and the vast surface cover of grasslands thus render the global grassland biome a potentially significant $\mathrm{C}$ sink, the size and dynamics of which are still to be resolved.

Whereas terrestrial $\mathrm{C}$ is mostly located belowground and rooting systems in general have an important role in the $\mathrm{C}$ cycle (Nepstad et al. 1994), this applies to a greater extent to grasslands (Jones \& Donnelly 2004). Grasslands which are part of a crop rotation and therefore of a temporary nature would see lower levels of belowground $\mathrm{C}$ sequestration as both their root system and their organic soil profile get disturbed. However, these non-permanent grasslands demonstrate how the conversion of arable land to grassland has a tendency to increase the amount of soil organic matter (Conant et al. 2001). In their inventory of C budgets in various grassland ecosystems Soussana et al. (2007) identified the highest level of net $\mathrm{C}$ sequestration in a grassland which was part of a crop rotation. However, high levels of $\mathrm{C}$ sequestration in temporary grassland do not necessarily compare well with $\mathrm{C}$ sequestration in permanent grasslands. Conversion of temporary grassland back to arable land may subsequently undo this pattern and again reduce levels of $\mathrm{C}$ storage. In much of Europe - the climax vegetation not being grassland - the distinction between permanent and temporary grassland can be indistinct. However, many of these grasslands lean towards a permanent character.

\subsubsection{Patterns of $\mathrm{CO}_{2}$ exchange in grasslands}

The role of grasslands in the global $\mathrm{C}$ cycle and their annual net $\mathrm{CO}_{2}$ exchange have drawn substantial interest. For any ecosystem the net $\mathrm{CO}_{2}$ exchange is the relatively small difference between the much larger downward ecosystem gross assimilatory $\mathrm{CO}_{2}$ flux and the upward ecosystem respiratory $\mathrm{CO}_{2}$ flux. The constituent processes of photosynthesis (Lawlor 1987, Long \& Hällgren 1993, Šesták et al. 1971) and respiratory activity (Kruse et al. 2011) have long been subject to intensive research and are comparatively well understood. However, the composite processes of entire ecosystem $\mathrm{CO}_{2}$ assimilatory and respiratory activity are less clear in their response to environmental factors because of their heterogeneity in both space and time. In addition to any instant response to the physical environment the ecosystem respiratory activity is characterised by a partially asynchronous dependence on the ecosystem assimilatory activity. It is tempting to see the annual cycle of assimilatory and respiratory $\mathrm{CO}_{2}$ exchange come largely full circle - with the remaining 
difference being the net $\mathrm{CO}_{2}$ exchange - but this is not entirely correct. Whereas a close relation between assimilatory and respiratory activity holds for autotrophic respiration, processes of heterotrophic respiration have a much larger time coefficient. Soil organic matter is characterised by an origin continuum - when undisturbed with ages of up to millennia (Howlett et al. 2013) - and the organic matter's decomposition stems from all these organic matter age fractions. Even though most of the heterotrophic respiration is associated with recent soil organic matter age fractions it can be seen that there is no distinct dependency of instant heterotrophic respiratory activity on instant assimilatory activity. This tail of heterotrophic respiration reflects the ecosystem's history of assimilatory activity and contributes to the complexity of the ecosystem respiratory $\mathrm{CO}_{2}$ flux. It can be seen that minor variations in ecosystem assimilatory and respiratory activity can have a relatively large effect on the ecosystem net $\mathrm{CO}_{2}$ flux. The analysis of the C balance in multiple grasslands by Soussana et al. (2007) shows that differences in net $\mathrm{CO}_{2}$ exchange between years can be substantial, occasionally switching between sequestration and release. The variation is such that it is difficult to determine an order of magnitude for annual net $\mathrm{CO}_{2}$ exchange even in individual ecosystems.

Seasonal eddy correlation measurements of $\mathrm{CO}_{2}$ and energy exchange in various grassland ecosystems have been done to analyse the relationship between latent heat flux and assimilatory activity (Hammerle et al. 2007, Krishnan et al. 2012, Ryu et al. 2008, Saigusa et al. 1998, Verhoef et al. 1996). Much of this research is driven by the relationship between surface conductance and grassland productivity, and generally shows that particularly under conditions of low soil moisture a reduced latent heat flux and surface conductance are associated with a reduced assimilatory $\mathrm{CO}_{2}$ flux. Patterns of atmosphericbiospheric energy exchange at a larger scale can equally affect mesoscale atmospheric circulations (Combe et al. 2015).

Analysis of the annual net $\mathrm{CO}_{2}$ exchange requires at least a full year of observations to complete an annual cycle of assimilation and respiration. Ma et al. (2007) measured net $\mathrm{CO}_{2}$ exchange in a Californian Mediterranean-type open grassland ecosystem over a period of 6 years and arrived at an average annual release of $193 \mathrm{~g} \mathrm{CO}_{2} \mathrm{~m}^{-2}$, ranging from a sequestration of $323 \mathrm{~g} \mathrm{CO}_{2} \mathrm{~m}^{-2} \mathrm{y}^{-1}$ to a release of $693 \mathrm{~g} \mathrm{CO}_{2} \mathrm{~m}^{-2} \mathrm{y}^{-1}$. They found the gross assimilatory and respiratory $\mathrm{CO}_{2}$ fluxes as well as the net $\mathrm{CO}_{2}$ exchange to be related to the length of the growing season as largely determined by the onset of the rains in spring. Although leaning towards being a $\mathrm{CO}_{2}$ source, the Mediterranean-type grassland ecosystem turned into a $\mathrm{CO}_{2}$ sink under conditions of high spring precipitation. The litter resulting from a high productivity in one year could lead to a late start of the growth in the next year, providing an unexpected twist to the tail of heterotrophic respiration spilling over into the following years. This $\mathrm{CO}_{2}$ release contrasts with a consistent annual $\mathrm{CO}_{2}$ sequestration in nine European grassland ecosystems measured 
by Soussana et al. (2007), averaging $381 \mathrm{~g} \mathrm{CO}_{2} \mathrm{~m}^{-2} \mathrm{y}^{-1}$. Gilmanov et al. (2007) compared net $\mathrm{CO}_{2}$ exchange measurements in multiple European grasslands and found 15 out of 19 grassland ecosystems to act as a net $\mathrm{CO}_{2}$ sink. The net $\mathrm{CO}_{2}$ sequestration in these grasslands ranged from 22 to $2394 \mathrm{~g} \mathrm{CO}_{2} \mathrm{~m}^{-2} \mathrm{y}^{-1}$ and the net $\mathrm{CO}_{2}$ release in the remainder from 96 to $627 \mathrm{~g} \mathrm{CO}_{2} \mathrm{~m}^{-2} \mathrm{y}^{-1}$. Across the grassland ecosystems they found net $\mathrm{CO}_{2}$ exchange most strongly correlated with irradiance and to a lesser extent with various measures of temperature, i.e. a higher net sequestration at higher irradiance and higher temperature. The highest of these net sequestration values was reported earlier by Jacobs et al. (2003) in a Dutch grassland on an alluvial clay soil during a particularly productive year. Later, Jacobs et al. (2007) measured net $\mathrm{CO}_{2}$ exchange in eight different grassland ecosystems in The Netherlands and found an average annual net $\mathrm{CO}_{2}$ sequestration of $330 \mathrm{~g} \mathrm{CO}_{2} \mathrm{~m}^{-2}$ in grasslands on mineral soils. Ammann et al. (2007) measured net $\mathrm{CO}_{2}$ exchange during 3 years in an intensively and an extensively managed grassland in Switzerland, both after conversion from arable rotation. They found an average annual net $\mathrm{CO}_{2}$ sequestration of $539 \mathrm{~g} \mathrm{CO}_{2} \mathrm{~m}^{-2}$ in the intensively managed grassland and an average annual net $\mathrm{CO}_{2}$ release of $209 \mathrm{~g} \mathrm{CO}_{2} \mathrm{~m}^{-2}$ in the extensively managed grassland, the latter related to higher rates of soil organic matter decomposition.

Many grasslands in agricultural use are characterised by $\mathrm{C}$ flows across system boundaries. It is inevitably arbitrary where boundaries are to be drawn, but much of the $\mathrm{C}$ flow concerns $\mathrm{C}$ taken out of the system in the form of dairy produce and harvested grass. If unaccounted for, it will result in an overestimation of a net $\mathrm{CO}_{2}$ sequestration as any further decomposition associated with the exported $\mathrm{C}$ will go unnoticed. As the $\mathrm{C}$ flows across system boundaries are usually determined at a lower time resolution than the ecosystem $\mathrm{CO}_{2}$ fluxes, the annual ecosystem net $\mathrm{CO}_{2}$ flux is often adjusted with the amount of $\mathrm{C}$ registered as exported. This is an improvement over many flux measurements in tropical forest ecosystems where analogously harvested biomass tends to escape both measurement and calculation.

A general pattern appears in which grasslands are a $\mathrm{CO}_{2}$ sink, although not exclusively. Grasslands which on average sequester $\mathrm{CO}_{2}$ occasionally turn into a $\mathrm{CO}_{2}$ source. Other grasslands exhibit $\mathrm{CO}_{2}$ release on a more permanent basis. Across grassland ecosystems primary productivity appears to be consistently correlated with net $\mathrm{CO}_{2}$ sequestration, which in turn is more unequivocally related to irradiance than to temperature. On a more speculative note, annual net $\mathrm{CO}_{2}$ exchange may even be subject to negative feedback, as levels of net $\mathrm{CO}_{2}$ exchange in one year occasionally make a grassland ecosystem switch between being a $\mathrm{CO}_{2}$ sink and source in the next year. Newly sown grassland - e.g. in a crop rotation - may exhibit high levels of $\mathrm{CO}_{2}$ sequestration, but this appears to depend on the degree of soil disturbance. Hirata et al. (2013) measured $\mathrm{CO}_{2}$ exchange in several grassland ecosystems in Japan over 3 years on starting different intensive fertilisation 
regimes (combinations of manure and chemical fertiliser) and found all experimental plots to be net $\mathrm{CO}_{2}$ sources. Although the experiment lacked a control $-\mathrm{CO}_{2}$ exchange before application of the fertiliser regimes - it suggests that suddenly higher levels of fertiliser may have increased soil organic matter decomposition to such an extent that the grassland ecosystem exhibited a net $\mathrm{CO}_{2}$ release.

\subsubsection{Grasslands on organic soils}

Although grasslands on mineral soils are not an entirely consistent $\mathrm{CO}_{2}$ sink, the tendency is clear. One cause for grasslands on mineral soils to be an occasional $\mathrm{CO}_{2}$ source appears to be a disturbance in the soil profile, resulting in increased levels of soil organic matter decomposition. Patterns of $\mathrm{CO}_{2}$ exchange in grassland ecosystems on organic soils are less unequivocal. Grasslands on organic soils (histosols) - or peat grasslands - resulting from poor drainage used to cover substantial surface areas, but massive grassland improvement efforts have reduced their occurrence to such an extent that they now frequently qualify as threatened wetlands (Couwenberg 2009). Peat grasslands typically contain large amounts of $\mathrm{C}$ under anaerobic conditions, which make them potentially very significant to the global $\mathrm{C}$ cycle. The distinction between peat grasslands and open peatlands is not very clear as they are characterised by the same $\mathrm{C}$ cycle processes and both dominated by grass species. Tundras can be considered part of these open peatlands (Burton et al. 1996, Tenhunen et al. 1995), as can be nutrient-poor bogs and nutrient-rich fens (Funk et al. 1994). Pastures on organic soil have now become of minor importance globally, but remain a significant factor in the grasslands' $\mathrm{C}$ balance in the Netherlands. This organic soil is a historical C deposit which accumulated in the Holocene period (roughly from 10,000 BC) and has remained immobilised ever since. Approximately 20\% of the productive grasslands in the Netherlands are constituted by these peat grasslands (Langeveld $e t$ al. 1997), which are being drained to various extents for grassland management purposes.

Whereas peat grassland ecosystems have the potential to sequester large amounts of $\mathrm{C}$ and indeed have until recently been doing so for thousands of years - their drainage has increasingly led to the decomposition of peat organic matter (Beetz et al. 2013, Hooijer et al. 2010). While aiming at increasing both primary productivity and carrying capacity, drainage of organic soil has the unintended side-effect of soil subsidence as a result of the decomposition of peat. This process of land management and drainage has been ongoing for several centuries as it is self-perpetuating: the soil subsidence necessitates further drainage measures. The oxidation of soil organic matter into $\mathrm{CO}_{2}$ once exposed to aerobic conditions partly or completely negates the net $\mathrm{CO}_{2}$ sequestration in the actual grassland system which resides on the organic soil and may even result in a net $\mathrm{CO}_{2}$ release from the peat grassland system as a whole. Veenendaal et al. (2007) measured the annual net $\mathrm{CO}_{2}$ exchange in an intensively and an extensively managed peat grassland ecosystem in the Netherlands during one year and found both similarly drained peat grasslands to 
be a substantial C source at $420 \mathrm{~g} \mathrm{C} \mathrm{m}^{-2}$. It was also accounted for the contribution of methane $\left(\mathrm{CH}_{4}\right)$ to $\mathrm{C}$ emissions from wetland soils. Jacobs et al. (2007) arrived at a mean annual net $\mathrm{C}$ release of $220 \mathrm{~g} \mathrm{C} \mathrm{m}^{-2}$ from an intensively managed peat grassland in the Netherlands based on 4 years of $\mathrm{CO}_{2}$ flux measurements.

Impaired lateral water movement in drained peat grasslands is an important factor in both decomposition and soil subsidence during the warmer and drier parts of the growing season as it results in an aerobic soil profile which reaches deeper than is required for optimum land management. Improved drainage techniques - which enhance lateral water movement - could avoid much of the decomposition of peat as has been shown by a reduced $\mathrm{CO}_{2}$ emission (Van Zandvoort et al. 2017) and soil subsidence (Pleijter \& Van den Akker 2007). Hendriks et al. (2007) found a 3 year average annual net $\mathrm{CO}_{2}$ sequestration of $330 \mathrm{~g} \mathrm{C} \mathrm{m}^{-2}$ in a Dutch peat grassland turned into a nature reserve after raising water levels. The role of wetlands in general and grasslands on organic soils in particular in the global $\mathrm{C}$ cycle is ambiguous. Primarily through root senescence, wetlands can accumulate vast amounts of $\mathrm{C}$ in their anaerobic soil profiles and in principle retain this $\mathrm{C}$ over long periods of time. Progressively higher levels of drainage can undo this net $\mathrm{CO}_{2}$ sequestration by the oxidation of the organic matter on its exposure to aerobic conditions.

\subsection{THIS THESIS}

The balance of $\mathrm{C}$ released as anthropogenically emitted $\mathrm{CO}_{2}$ on the one hand and atmospheric $\mathrm{C}$ on the other shows the existence of a large $\mathrm{CO}_{2}$ sink. The atmospheric $\mathrm{CO}_{2}$ concentration increases by only half as much as it would do without this $\mathrm{CO}_{2}$ sink. The difference is most probably constituted by a combination of a net dissolution in the oceans and a net sequestration by the terrestrial biosphere. The annual cycle of the atmospheric $\mathrm{CO}_{2}$ concentration shows a strong correlation with the growing season, with lower concentrations in the warm or wet season and higher concentrations in the cold or dry season. This pattern points at a strong role for the terrestrial biosphere, exhibiting a seasonal differentiation into net $\mathrm{CO}_{2}$ sequestration and net $\mathrm{CO}_{2}$ release.

The possible role of forests in this global net $\mathrm{CO}_{2}$ sequestration has been investigated in relative detail. It indicates that particularly boreal forests in the colder climate zone sequester $\mathrm{CO}_{2}$. Low irradiance and low temperature in the boreal zone are suboptimal to assimilatory activity, but low temperature also reduces respiratory activity. High temperature and high humidity in the tropics increase respiratory activity to such an extent that little $C$ remains sequestered for long (Luo et al. 2019). A contribution of grasslands to the global net $\mathrm{CO}_{2}$ sequestration has remained somewhat underexposed, 
albeit decreasingly so. The grasslands' large surface cover, their relatively low maintenance requirements, the high root proportion and the often dry or cold climatic conditions which bear resemblance to the boreal zone where forests sequester $\mathrm{CO}_{2}$ add up to a potentially significant role for grasslands in the observed global net $\mathrm{CO}_{2}$ sink. Actual measurement of the grassland biome's net $\mathrm{CO}_{2}$ exchange is unfeasible as it would require a virtually infinite number of measurement sites in often remote locations operating over a very long period of time. Moreover, the added value of the analysis of a costly number of measurements for insight into the $\mathrm{C}$ cycle processes - required to extrapolate beyond the time frame of the measurements - may be limited. To explore the role of grasslands in the global $\mathrm{C}$ cycle it is therefore necessary to focus on the fundamental $\mathrm{CO}_{2}$ exchange processes which are shared across the grassland biome rather than on a large number of $\mathrm{CO}_{2}$ exchange measurements at various locations over a limited period of time. Only insight into these processes can contribute to the estimation of the grassland biome's net $\mathrm{CO}_{2}$ exchange and the exploration of its role in time. It is an assumption underlying this thesis that the role of grasslands in the $\mathrm{C}$ cycle should not be determined by disaggregation of the biome into a large number of ecosystems but by aggregation on basis of its shared $\mathrm{CO}_{2}$ exchange processes.

The aim of this thesis is to determine how the diurnal cycles of grasslands' instant $\mathrm{CO}_{2}$ exchange processes aggregate to an annual cycle of net $\mathrm{CO}_{2}$ exchange and thus cause inter-annual differences in this net $\mathrm{CO}_{2}$ exchange. It elaborates the case for drained peat grassland ecosystems. Based on these processes, it subsequently seeks to qualitatively explore the role of the biosphere in the course of the atmospheric $\mathrm{CO}_{2}$ concentration and the role of the grassland biome in a biospheric net $\mathrm{CO}_{2}$ sequestration. This thesis investigates in detail the assimilatory and respiratory $\mathrm{CO}_{2}$ fluxes as the constituent processes in the atmospheric-biospheric $\mathrm{CO}_{2}$ exchange of grasslands on organic soils. It illustrates how these processes aggregate from lower to higher levels of aggregation, and how this aggregation can contribute to an assessment of the contribution of grasslands to the biospheric net $\mathrm{CO}_{2}$ sequestration. The approach emphasises process-based analysis and synthesis over statistical treatment, as to be able to make more general assertions about the role of ecosystems in the $\mathrm{C}$ cycle.

Chapters 2 to 6 analyse the $\mathrm{CO}_{2}$ exchange processes at increasing levels of aggregation, directly based on the different measurements. In the second part of the general discussion (Chapter 7), the potential role of biosphere in general and grasslands in particular in the global C cycle is discussed.

Chapter 2 investigates the measured instantaneous photosynthetic $\mathrm{CO}_{2}$ flux in an in vivo grass sward in its response to irradiance, temperature and ambient $\mathrm{CO}_{2}$ concentration. It compares the photosynthetic response on basis of cellular electron transport processes as 
theorised by Farquhar and Von Caemmerer (1982) and aggregated asymptotic response curves. Chapters 3, 4 and 5 analyse instantaneous energy and $\mathrm{CO}_{2}$ fluxes at ecosystem level. Chapter 3 analyses the response of the instantaneous assimilatory and respiratory $\mathrm{CO}_{2}$ fluxes in a drained peat grassland ecosystem to irradiance, temperature and air humidity, from two years of aerodynamic gradient flux measurements. For the same drained peat grassland ecosystem, Chapter 4 analyses how the instantaneous dissipation of the net irradiance into latent and sensible heat fluxes is a measure for the canopy's surface conductance and how this affects the assimilatory $\mathrm{CO}_{2}$ flux. Chapter 5 analyses instantaneous assimilatory and respiratory $\mathrm{CO}_{2}$ fluxes in a drained peat grassland ecosystem at two settled levels of drainage, from one growing season of eddy covariance measurements. Addenda to Chapters 3, 4 and 5 in Appendix A subsequently synthesise the instantaneous ecosystem $\mathrm{CO}_{2}$ fluxes to diurnal and seasonal cycles of ecosystem $\mathrm{CO}_{2}$ exchange and how these $\mathrm{CO}_{2}$ flux components aggregate to an ecosystem net $\mathrm{CO}_{2}$ flux. It uses the ecosystem net $\mathrm{CO}_{2}$ flux at different levels of drainage to estimate the difference in respiratory $\mathrm{CO}_{2}$ exchange related to enhanced decomposition in the aerobic soil profile as a result of deeper drainage.

Chapter 6 aggregates the diurnal cycles of ecosystem $\mathrm{CO}_{2}$ exchange from Chapters 3, 4 and 5 and Appendix A to annual cycles of ecosystem $\mathrm{CO}_{2}$ exchange. An annual $\mathrm{CO}_{2}$ balance emerges only in the annual cycle of $\mathrm{CO}_{2}$ exchange, and only there it can be established why $\mathrm{CO}_{2}$ balances vary among years. This aggregation emphasises processes over exact annual values. In the first half of the general discussion (Chapter 7), it is discussed how the processes at the successive levels of aggregation in the preceding chapters result in an explanation of an annual $\mathrm{CO}_{2}$ balance. This part of the discussion touches both general processes in grassland ecosystems and the effect of various levels of drainage on the $\mathrm{CO}_{2}$ balance in grasslands on organic soils. The second half of the general discussion takes the general processes from the first half and explores to which extent they can be used to explain inter-annual patterns in the global atmospheric $\mathrm{CO}_{2}$ concentration and the contribution of grasslands to the net $\mathrm{C}$ sequestration which can be deduced for the biosphere. It discusses a dominant role for the biosphere in an enhanced $\mathrm{CO}_{2}$ sequestration from the atmosphere, thereby building on processes in the natural $\mathrm{C}$ cycle. The methodology used in this study is evaluated and its results are presented. 


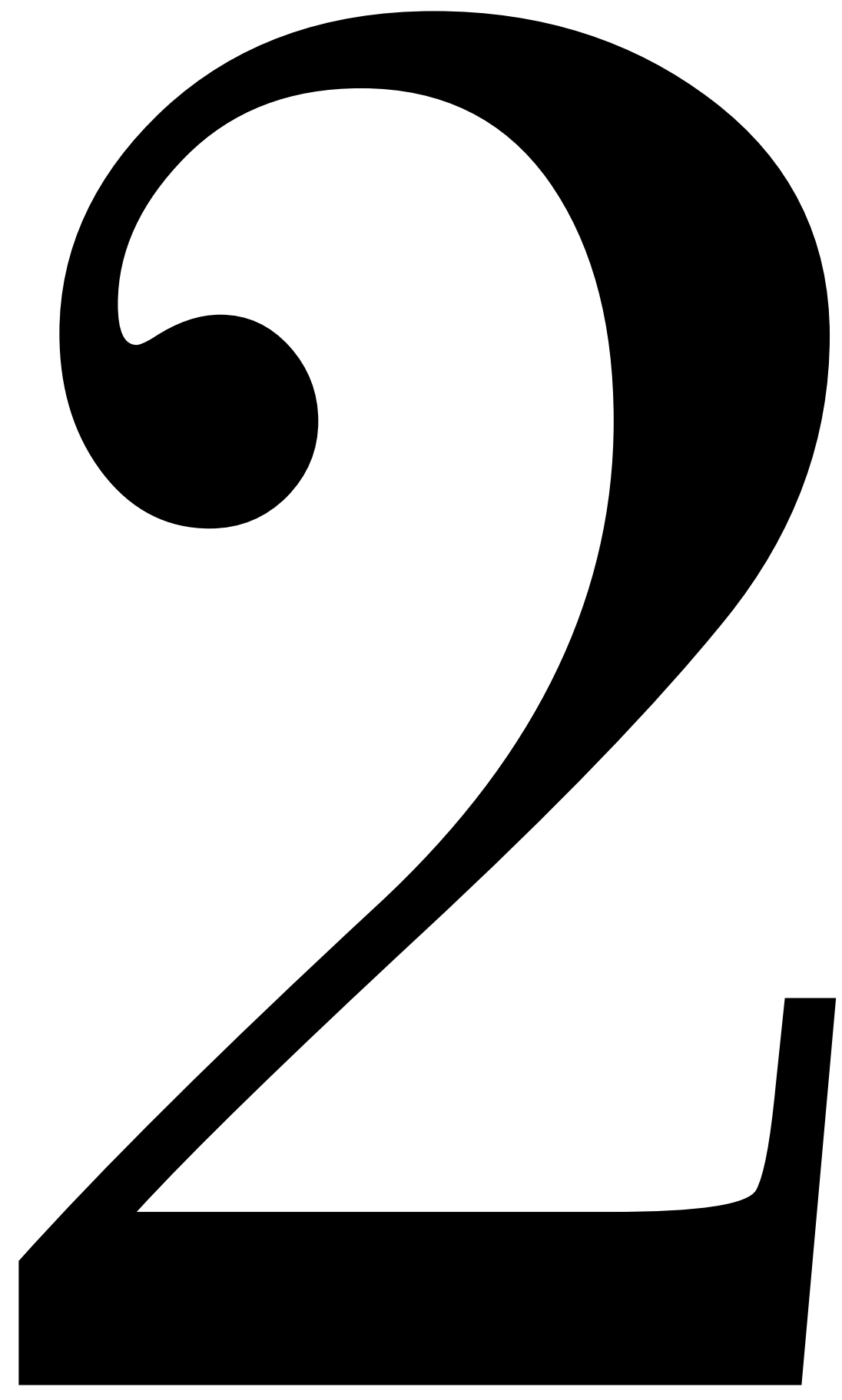




\section{Chapter 2}

\section{Temperature sensitivity of photosynthesis in Lolium perenne swards: a comparison of two methods for deriving photosynthetic parameters from in vivo measurements}

Originally published as B.O.M. Dirks, M. van Oijen, A.H.C.M. Schapendonk, J. Goudriaan \& J. Wolf, 2002. Temperature sensitivity of photosynthesis in Lolium perenne swards: A comparison of two methods for deriving photosynthetic parameters from in vivo measurements. Photosynthetica 40: 405-413. 


\section{SUMMARY}

The seasonal variation in photosynthetic rate of grass swards is partly the result of changes in the environment and partly the result of changes in the photosynthetic capacity of the sward itself. We evaluated two types of photosynthesis equations regarding their capacity to analyse seasonal and short-term temperature effects on the photosynthesis of ryegrass (Lolium perenne L.). Intact cores of a field-grown ryegrass sward were taken to the laboratory 10 days after cutting for measurements of photosynthesis under controlled conditions. This was done during a 4-week period in summer and a 3-week period in autumn at an ambient $\mathrm{CO}_{2}$ concentration range of $200-700 \mu \mathrm{mol} \mathrm{mol}^{-1}$ and air temperature ranges of $15-30{ }^{\circ} \mathrm{C}$ and $10-25^{\circ} \mathrm{C}$, respectively. Net photosynthetic rate $\left(P_{\mathrm{N}}\right)$ of the sward was lower in autumn than in summer. Both a negatively exponential photosynthesis irradiance-response curve and the Farquhar algorithm for photosynthesis (Caemmerer \& Farquhar 1981) were applied to the in vivo sward measurements. Application of the irradiance-response curve showed that irradiance-saturated gross photosynthetic rate increased modestly but not significantly with temperature and was higher in summer than in autumn. The initial radiation use efficiency did not differ between the seasons but decreased significantly with the temperature rise. This explains the observation that total canopy photosynthetic rate decreased after short-term temperature increases in both seasons. The parameters in the Farquhar algorithm which represent the temperature sensitivity of the maximum electron transport rate and of the Michaelis-Menten constants for $\mathrm{CO}_{2}$ and $\mathrm{O}_{2}$ fixation could not be derived from these instantaneous measurements. Parametrisation of the Farquhar equations was hampered by a lack of appropriate information on many biochemical parameters. Aggregated response-functions proved to be more adequate when scaling from single to composite photosynthetic processes in in vivo canopy measurements.

\subsection{INTRODUCTION}

Photosynthetic rate can be differentiated into three main processes (Lawlor 1987). The photochemical process is the only strictly light-dependent process. In the photochemical process the cells' chlorophyll captures the radiation and transforms it into ATP and $\mathrm{NADPH}$ while gaining an electron from (i.e. oxidising) an $\mathrm{H}_{2} \mathrm{O}$ molecule. This energy can be used by the subsequent light-independent biochemical process in which NADPH is the main reducing agent for $\mathrm{CO}_{2}$. The diffusive process in which $\mathrm{CO}_{2}$ diffuses through the leaf's stomata and cell membranes into the cells which contain the chlorophyll is entirely physical and supplies the biochemical process with the required $\mathrm{CO}_{2}$. The biochemical process uses the ATP and NADPH generated in the photochemical process to reduce the diffused $\mathrm{CO}_{2}$ to form a $\mathrm{C}_{3}$ carbohydrate in the Calvin cycle (a process 
which is somewhat, but at this level not fundamentally different in the $\mathrm{C}_{4}$ photosynthetic pathway). The biochemical process as such is light-independent.

Leaf net photosynthetic rate $\left(P_{\mathrm{N}}\right)$ has often been described by semi-empirical response curves (Goudriaan 1979, Thornley 1998), which are a function of nutritional status, crop morphology, temperature, $\mathrm{CO}_{2}$ concentration and irradiance (Peisker \& Apel 1981). These response curves typically integrate all three photosynthetic processes. Caemmerer and Farquhar (1981) provided a widely accepted biochemically-based mechanistic approach for analysing the photosynthetic process which reduces $\mathrm{CO}_{2}$ to $\mathrm{C}_{3}$ carbohydrates. They defined the process of $\mathrm{CO}_{2}$ assimilation as a Blackman relationship, which successively depends on (1) energy supply and reducing power through electron transport at low irradiance and (2) availability and activity of the ribulose-1,5-biphosphate carboxylase/ oxygenase (RuBPCO) enzyme at high irradiance. The Farquhar approach makes explicit the effects of irradiance, $\mathrm{CO}_{2}$ concentration and temperature on photosynthetic rate.

In photosynthesis at the cellular level, particularly the effect of temperature has proven to be complex and uncertain. For example, Brooks and Farquhar (1985) found an instantaneous temperature effect on the $\mathrm{CO}_{2} / \mathrm{O}_{2}$ specificity of RuBPCO. Long (1991) pointed at the strong interaction between ambient $\mathrm{CO}_{2}$ concentration and temperature on photorespiration and photosynthesis. The complexity of such interactions has resulted in many modifications to the Farquhar approach (e.g. Harley et al. 1992, Leuning 1995), but thus far no attempts have been made to relate the dynamic response to temperature at canopy level to the calculated response from the Farquhar equation.

In the present experiments we studied the effect of temperature changes on grass photosynthesis and quantified the values beyond the steady-state conditions, for which the Farquhar model is principally valid. We took intact cores of a field-grown grass (Lolium perenne L.) sward to the laboratory for photosynthetic measurement under controlled conditions during a four-week period in summer and a three-week period in autumn. These measurements were made under different levels of irradiance, temperature and ambient $\mathrm{CO}_{2}$ concentration. Only in a few other studies were $\mathrm{CO}_{2}$ assimilation measurements done in intact grass swards (e.g. Woledge \& Parsons 1986, Nijs et al. 1989). Both the detailed Farquhar algorithm and an aggregated function are applied to analyse these canopy responses of $P_{\mathrm{N}}$ to irradiance, $\mathrm{CO}_{2}$ concentration and, notably, temperature. This aims to answer two key questions: (1) What are the seasonal long-term changes in the photosynthetic characteristics of the sward, and how do these changes affect the response to environmental transitions, particularly short-term changes in temperature? (2) Which method for analysing photosynthetic rate is most appropriate in the case of in vivo measurements on intact grass swards? 


\subsection{MATERIAL AND METHODS}

\subsubsection{Field conditions and experimental lay-out}

Perennial ryegrass (Lolium perenne L. cv. Herbie) was sown $\left(4 \mathrm{~g} \mathrm{~m}^{-2}\right)$ in rows in a former wheat field on an alluvial clay soil in Wageningen, the Netherlands, in November 1994. Until the start of the experiment in July 1995, the sward was fertilised four times with calcium ammonium nitrate at $6.5 \mathrm{~g} \mathrm{~N} \mathrm{~m}^{-2}$ for every application, which corresponds to a nitrogen fertilisation of $260 \mathrm{~kg} \mathrm{~N} \mathrm{ha}^{-1} \mathrm{y}^{-1}$. During July, the sward was regularly irrigated at night to maintain permanently moist soil conditions.

For the gas exchange measurements two periods in 1995 were chosen: a 4-week period in summer and a 3 -week period in autumn. Figure 2.1 shows the weather conditions in the field during the experiments. Shortwave irradiance decreased from $25 \mathrm{MJ} \mathrm{m}^{-2} \mathrm{~d}^{-1}$ in summer to $10 \mathrm{MJ} \mathrm{m}^{-2} \mathrm{~d}^{-1}$ in autumn. The temperature maximum decreased from over $30{ }^{\circ} \mathrm{C}$ to below $20^{\circ} \mathrm{C}$. Temperature set points in the laboratory measurements (15-30 ${ }^{\circ} \mathrm{C}$ in summer and $10-25^{\circ} \mathrm{C}$ in autumn) matched the outside temperature ranges. Aerial vapour pressure decreased from 1.75 to $1.50 \mathrm{kPa}$.

For the measurements the sward was cut to a height of $5 \mathrm{~cm}$ and fertilised with calcium ammonium nitrate $\left(8 \mathrm{~g} \mathrm{~m}^{-2}\right)$. Three days later, cores with a depth of $0.3 \mathrm{~m}$ and a diameter of $0.2 \mathrm{~m}$ (i.e. a surface area of $0.0315 \mathrm{~m}^{2}$ of grass sward), were taken from the field. The cores were transferred to cylinders that were closed on the lower side and contained a layer of gravel and an aeration and drainage valve at the bottom. These cylinders were subsequently put in the original holes for another seven days to allow for recovery from damage due to intrusion. They were later taken to the laboratory for measurement of both the irradiance response and the dark respiration at four temperatures and four $\mathrm{CO}_{2}$ concentrations (16 treatments). Each day, measurements were done in the laboratory for four treatments. The successive experimental weeks served as replicates (four in summer: 17-21 July, 24-28 July, 31 July-4 August, 7-11 August; and three in autumn: 18-22 September, 25-29 September, 9-13 October). Measurements were randomly distributed over the week.

\subsubsection{Laboratory measurements}

In the early morning, the cylinders with grass sward were transported to the laboratory. The $P_{\mathrm{N}}$-irradiance response of the sward was measured by exposing it to five successively higher and next to five successively lower levels of photosynthetically active radiation (from 0 up to 800 and back to $0 \mu \mathrm{mol} \mathrm{m}{ }^{-2}$ (ground) $\mathrm{s}^{-1}$ ). The applied $\mathrm{CO}_{2}$ concentrations were 200, 350, 500 and $700 \mu \mathrm{mol} \mathrm{mol}^{-1}$. The applied air temperatures were 15, 20, 25 and $30^{\circ} \mathrm{C}$ for the summer series and $10,15,20$ or $25^{\circ} \mathrm{C}$ for the autumn series. 

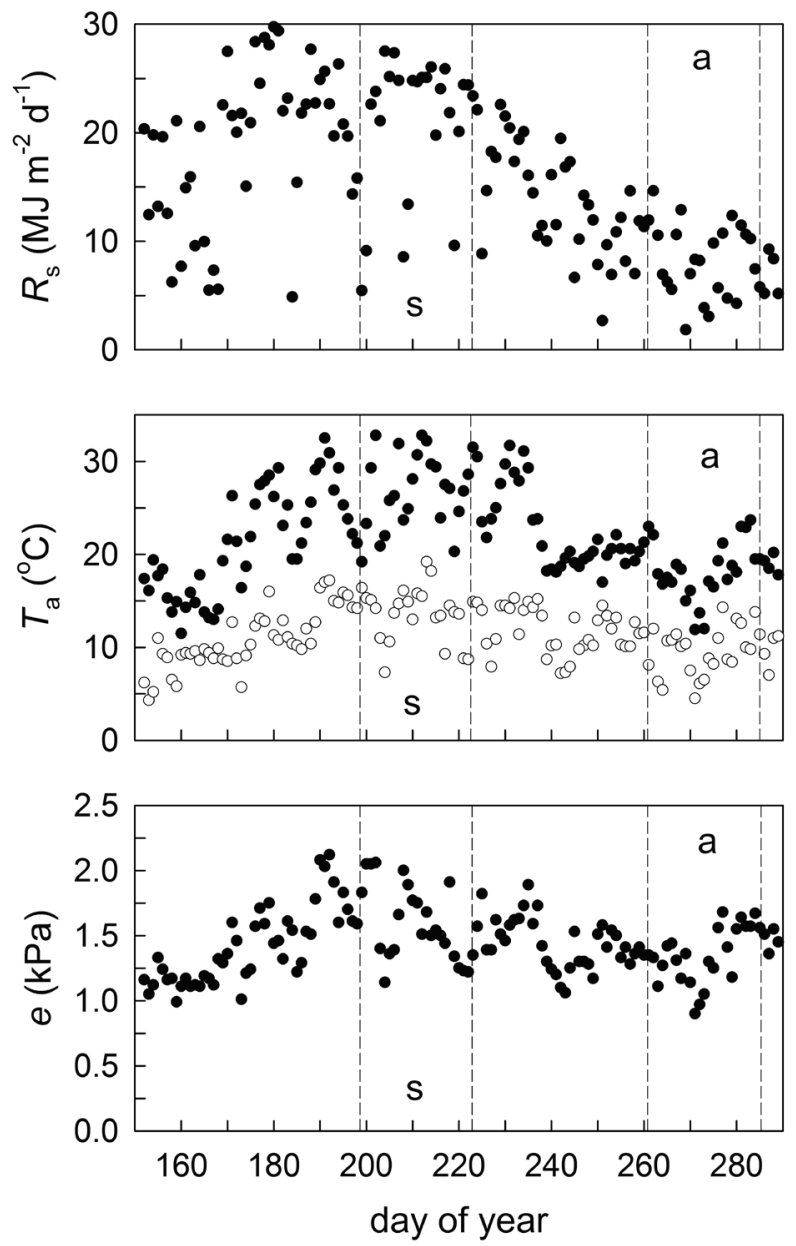

Figure 2.1. Daily shortwave irradiance $\left(R_{\mathrm{s}}\right)$, daily vapour pressure $(e)$, and daily minimum (open symbols) and maximum (closed symbols) air temperature $\left(T_{\mathrm{a}}\right)$ in Wageningen in 1995, during summer (s) and autumn (a).

Temperature and $\mathrm{CO}_{2}$ concentration were kept within $2.5^{\circ} \mathrm{C}$ and $10 \%$ of their target values, respectively.

In the laboratory, the cylinders were attached to the bottom plates of polycarbonate plant cuvettes. Measurements were done in parallel at four treatments (i.e. specific combination of temperature and $\mathrm{CO}_{2}$ concentration). Whole shoot photosynthesis and dark respiration were measured in an open system by comparing the $\mathrm{CO}_{2}$ concentrations of the in-going and out-going air of the plant cuvette and multiplying their difference by the flow rate in the cuvette. The flow rate in the cuvette was $1.0 * 10^{-4} \mathrm{~m}^{3} \mathrm{~s}^{-1} . \mathrm{CO}_{2}$ fluxes from root and soil respiration were excluded by a slight overpressure in the cuvette (at $10 \mathrm{~mm}$ water 
column). $\mathrm{CO}_{2}$ concentrations were measured every minute with an infra-red gas analyser (IRGA Series 225, The Analytical Development Co., Hoddesdon, UK). The air velocity over the canopy was approximately $1.5 \mathrm{~m} \mathrm{~s}^{-1}$.

While measuring the irradiance-response curves during the temperature- $\mathrm{CO}_{2}$ concentration treatments, the successive radiation levels were maintained during approximately 30 minutes each. A complete sequence of photosynthesis measurements thus required approximately $5 \mathrm{~h}$ per treatment; a dark period completed a $24 \mathrm{~h}$ measurement period. Leaf area indices $(L A I)$ of the cores were determined at the end of this measurement period.

\subsubsection{Analysis of the photosynthesis measurements}

We used two methods for analysing sward photosynthetic rate: (1) a negatively exponential photosynthesis irradiance-response curve (Goudriaan 1979) and (2) the algorithm described by Farquhar and Caemmerer (1982). Both express rate of photosynthesis per unit leaf area, whereas our measurements quantified photosynthesis per unit ground area in sward cores. We converted these measurements to leaf-scale estimates by dividing by $L A I$. This simple conversion, which does not apply in situations with a complete or even saturating interception of radiation, was justified by the erect and relatively open canopy structure which minimised differences in photon absorption between upper and lower leaves in the sward. This was further supported by the observed linear relationship between leaf area index and canopy $\mathrm{CO}_{2}$ assimilation rate (Figure 2.2). Therefore, this relatively simple experimental situation did not require a more complex scaling from canopy to leaf photosynthesis (e.g. De Pury \& Farquhar 1997).

\subsubsection{Method (1) - aggregated photosynthesis-irradiance response function}

The leaf $\mathrm{CO}_{2}$ photosynthetic rate was related to irradiance in an aggregated photosynthesisirradiance response curve as a negatively exponential asymptotic function (Goudriaan 1979):

$P_{\mathrm{Nl}}=P_{\mathrm{Gl}(\max )} \times\left(1-\mathrm{e}^{-\varepsilon \times f \times 10 / P \mathrm{Gl}(\max )}\right)-R_{\mathrm{D}}$

where $P_{\mathrm{Nl}}$ is the leaf net photosynthetic rate $\left(\mu \mathrm{mol} \mathrm{m} \mathrm{m}^{-2}(\mathrm{leaf}) \mathrm{s}^{-1}\right), P_{\mathrm{Gl}(\max )}$ is the asymptotic value of the leaf gross photosynthetic rate at saturating irradiance $\left(\mu \mathrm{mol} \mathrm{m} \mathrm{m}^{-2}\right.$ (leaf) $\left.\mathrm{s}^{-1}\right)$, $\varepsilon$ is the initial net radiation use efficiency $\left(\mu \mathrm{mol} \mu \mathrm{mol}^{-1}\right), I_{0}$ is the irradiance ( $\mu \mathrm{mol}$ $\mathrm{m}^{-2}$ (ground) $\left.\mathrm{s}^{-1}\right), f_{\mathrm{r}}$ is the relative leaf exposure ( $\mathrm{m}^{2}$ (ground) $\mathrm{m}^{-2}($ leaf $)$ ), and $R_{\mathrm{D}}$ is the rate of respiration other than photorespiratory $\left(\mu \mathrm{mol} \mathrm{m}{ }^{-2}(\right.$ leaf $\left.) \mathrm{s}^{-1}\right) . R_{\mathrm{D}}$ was derived from the observed respiration rate at the end of the dark period. Leaf gross photosynthetic rate $\left(P_{\mathrm{Gl}}\right)$ was the sum of the measured values for leaf net photosynthetic rate $\left(P_{\mathrm{Nl}}\right)$ and respiration 


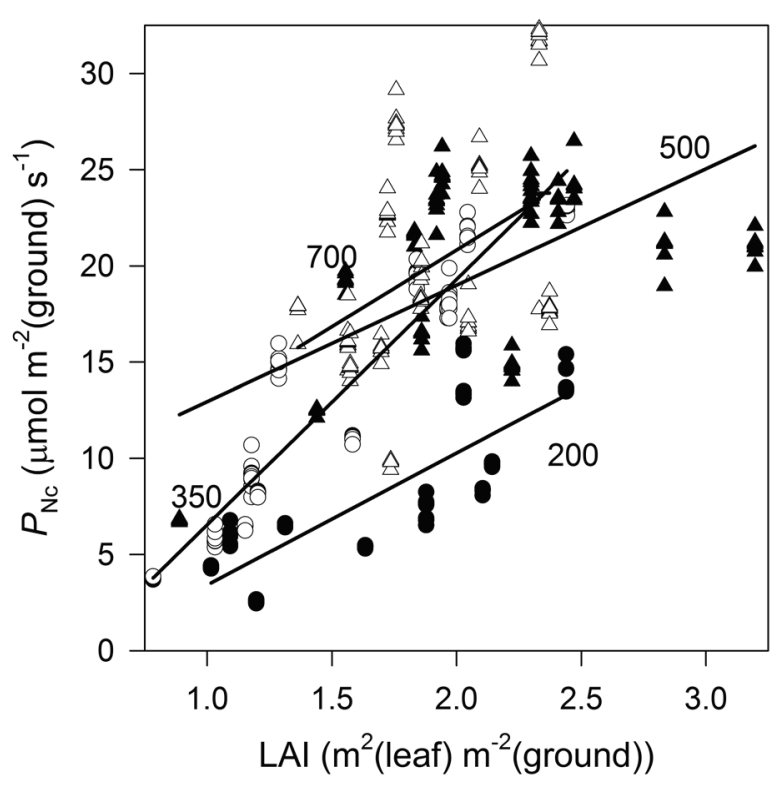

Figure 2.2. Canopy net photosynthetic rate $\left(P_{\mathrm{Nc}}\right)$ as a function of leaf area index $(L A I)$ in summer at applied $\mathrm{CO}_{2}$ concentrations of 200 (closed circles), 350 (open circles), 500 (closed triangles) and $700 \mu \mathrm{mol} \mathrm{mol}^{-1}$ (open triangles). Irradiance $800 \mu \mathrm{mol} \mathrm{m}^{-2} \mathrm{~s}^{-1}$.

rate $\left(R_{\mathrm{D}}\right)$. Since $\varepsilon$ and $f_{\mathrm{r}}$ cannot be separated, a compound initial radiation use efficiency $\Phi\left(=\varepsilon \times f_{\mathrm{r}}\right)$ was calculated.

Equation 2.1 was applied to the experimental data to derive leaf-scale parameters $P_{\mathrm{Gl}(\max )}$ and $\Phi$. No hysteresis was observed when increasing and subsequently decreasing irradiance. Therefore, the two irradiance-response series ( 0 to 800 and 800 to $0 \mu \mathrm{mol} \mathrm{m}{ }^{-2}$ $\mathrm{s}^{-1}$ ) were analysed as a single response. Differences in $P_{\mathrm{Gl}(\max )}$ and $\Phi$ values were analysed statistically (Fox et al. 1994).

\subsubsection{Method (2) - Farquhar algorithm}

A more detailed process-based approach for analysing the photosynthetic rate is given by Caemmerer and Farquhar (1981) and Farquhar and Caemmerer (1982). They distinguish between photosynthetic rate limited by the electron transport rate in the thylakoid membrane (at lower irradiance) and photosynthetic rate limited by the availability and activity of RuBPCO (at higher irradiance). Since the photon absorption rate per unit leaf area was relatively low in our grass swards as a result of the erect canopy structure, we assume that photosynthesis was limited by electron transport exclusively. Under these conditions, $P_{\mathrm{Gl}}$ can be described by the following equation (Farquhar \& Caemmerer 1982): 


$$
P_{\mathrm{Gl}}=J \times\left(C_{\mathrm{i}}-\Gamma\right) /\left(4.5 \times C_{\mathrm{i}}+10.5 \times \Gamma\right)
$$

where $J$ is the rate of electron transport $\left(\mu \mathrm{mol} \mathrm{m}{ }^{-2}(\right.$ leaf $\left.) \mathrm{s}^{-1}\right), \Gamma$ is the $\mathrm{CO}_{2}$ compensation concentration in the absence of dark respiration $\left(\mu \mathrm{mol} \mathrm{mol}^{-1}\right)$, and $C_{\mathrm{i}}$ is the intercellular $\mathrm{CO}_{2}$ concentration $\left(\mu \mathrm{mol} \mathrm{mol}{ }^{-1}\right) . C_{\mathrm{i}}$ was assumed to equal 0.7 times the ambient $\mathrm{CO}_{2}$ concentration $C_{\mathrm{a}}$ (Nijs et al. 1989, Pearcy \& Björkman 1983).

$\Gamma$ and the rate of electron transport $(/)$ were calculated as follows (Farquhar \& Caemmerer 1982, Harley et al. 1986):

$\Gamma=0.5 \times 0.21 \times O_{\mathrm{i}} \times K_{\mathrm{C}} / K_{\mathrm{O}}$

$J=J_{\max } \times f_{\mathrm{r}} \times I_{0} /\left(f_{\mathrm{r}} \times I_{0}+2.1 \times J_{\max }\right)$

where $K_{\mathrm{C}}$ and $K_{\mathrm{O}}$ are the Michaelis-Menten constants for $\mathrm{CO}_{2}$ and $\mathrm{O}_{2}$ fixation $(\mu \mathrm{mol}$ $\left.\mathrm{mol}^{-1}\right), J_{\max }$ is the maximum rate of electron transport $\left(\mu \mathrm{mol} \mathrm{m}{ }^{-2}(\right.$ leaf $\left.) \mathrm{s}^{-1}\right), f_{\mathrm{r}}$ is the relative leaf exposure ( $\mathrm{m}^{2}$ (ground) $\mathrm{m}^{-2}$ (leaf)), $I_{0}$ is the irradiance $\left(\mu \mathrm{mol} \mathrm{m}^{-2}\right.$ (ground) $\left.\mathrm{s}^{-1}\right)$, and $O_{\mathrm{i}}$ is the intercellular $\mathrm{O}_{2}$ concentration $\left(\mu \mathrm{mol} \mathrm{mol}{ }^{-1}\right)$.

$K_{\mathrm{C}}, K_{\mathrm{O}}$ and $J_{\max }$ in turn depend on temperature (Harley et al. 1985, 1986, 1992; Kirschbaum \& Farquhar 1984, Leuning 1995). $K_{\mathrm{C}}$ and $K_{\mathrm{O}}$ represent single-step biochemical processes and depend on temperature in an Arrhenius dependency, characterised by the respective values at reference temperature $\left(20^{\circ} \mathrm{C}\right)$ and the activation energies $\left(E_{\mathrm{a}}\right) . J_{\max }$ reflects a compound biological process and depends on temperature in an Arrhenius dependency which includes a temperature optimum (Harley et al. 1992, Leuning 1995):

$J_{\max }=J_{\max (20)} \times \mathrm{e}^{(1 / 293-1 /(273+T)) \times E a / R} /\left(1+\mathrm{e}^{(S \times T-E \mathrm{~d}) /(R \times T)}\right)$

where $J_{\max (20)}$ is $J_{\max }$ at $20{ }^{\circ} \mathrm{C}$ (if no enzymatic deactivation occurs), $T$ is the temperature $\left({ }^{\circ} \mathrm{C}\right), E_{\mathrm{a}}$ is the activation energy $\left(\mathrm{J} \mathrm{mol}^{-1}\right), E_{\mathrm{d}}$ is the deactivation energy $\left(\mathrm{J} \mathrm{mol}^{-1}\right), R$ is the universal gas constant $\left(8.314 \mathrm{~J} \mathrm{~K}^{-1} \mathrm{~mol}^{-1}\right)$, and $S$ is an entropy term $\left(650 \mathrm{~J} \mathrm{~mol}^{-1}\right.$ : Harley et al. 1992).

Equations 2.2 to 2.5 were applied to the experimental data. $P_{\mathrm{Gl}}$ was again derived from the measured values for $P_{\mathrm{Nl}}$ and $R_{\mathrm{D}}$. For the temperature dependencies of $K_{\mathrm{C}}$ and $K_{\mathrm{O}}$, parameter values provided by Harley et al. (1986) and Long (1991) were used for comparison, as presented in Table 2.1. For the temperature sensitivity of $J_{\max }$ activation and deactivation energy values provided by Harley et al. (1992) were used: $E_{\mathrm{a}}=80 \mathrm{~kJ}$ $\mathrm{mol}^{-1}, E_{\mathrm{d}}=201 \mathrm{~kJ} \mathrm{~mol}^{-1}$. 
Table 2.1. Arrhenius parameters for the Michaelis-Menten constants for $\mathrm{CO}_{2}$ and $\mathrm{O}_{2}$ binding: values at $20^{\circ} \mathrm{C}\left(K_{20}\right)$ and activation energies $\left(E_{\mathrm{a}}\right)$.

\begin{tabular}{llllll}
\hline reference & species & \multicolumn{2}{c}{$\begin{array}{c}\boldsymbol{K}_{\mathbf{2 0}} \\
\left(\boldsymbol{\mu \text { mol mol }} \mathbf{~}^{-\mathbf{1}}\right)\end{array}$} & \multicolumn{2}{c}{$\begin{array}{c}\boldsymbol{E}_{\mathbf{a}} \\
\left(\mathbf{J ~ m o l}^{-1}\right)\end{array}$} \\
\cline { 3 - 6 } & & $\mathrm{CO}_{2}$ & $\mathrm{O}_{2}$ & $\mathrm{CO}_{2}$ & $\mathrm{O}_{2}$ \\
\hline Harley et al. 1986 & Arbutus unedo $\left(T<15^{\circ} \mathrm{C}\right)$ & 424 & $25510^{3}$ & 109700 & 36000 \\
Harley et al. 1986 & Arbutus unedo $\left(T>15^{\circ} \mathrm{C}\right)$ & 299 & $25510^{3}$ & 59430 & 36000 \\
Long 1991 & general terms & 460 & $33010^{3}$ & 65800 & 1400 \\
Harley et al. 1992 & cotton (at elevated $\left.\mathrm{CO}_{2}\right)$ & 155 & $37710^{3}$ & 80470 & 14510 \\
Leuning 1995 & Eucalyptus grandis & 302 & $25610^{3}$ & 59430 & 36000 \\
\hline
\end{tabular}

In parallel to the use of the parameter values provided by Long (1991) and Harley et al. (1986), the effects of temperature on $J_{\max }$ and $\Gamma$ were benchmarked by fitting $3^{\text {rd }}$ order polynomial curves to the experimental data. For $\Gamma$, this means combining $K_{\mathrm{C}}$ and $K_{\mathrm{O}}$ into a single compound variable (the $K_{\mathrm{C}} / K_{\mathrm{O}}$ ratio) which is a measure for the relative affinity of RuBPCO to $\mathrm{O}_{2}$.

\subsubsection{Response of photosynthetic rate to $\mathrm{CO}_{2}$}

The response curves of $P_{\mathrm{Nl}}$ to $C_{\mathrm{i}}$ at different irradiance levels intersect with the x-axis theoretically at the same point for a set temperature (Brooks \& Farquhar 1985). The corresponding $C_{\mathrm{i}}$ value provides an estimate of $\Gamma$ and respiration rate $R_{\mathrm{D}}$. This approach was used to explore the assumption of a fixed ratio of 0.7 between $C_{\mathrm{i}}$ and $C_{\mathrm{a}}$.

\subsection{RESULTS}

\subsubsection{Measurements of grass sward photosynthetic rate}

Table 2.2 provides a summary of the measurement data at the highest level of irradiance applied $\left(800 \mu \mathrm{mol} \mathrm{m} \mathrm{m}^{-2} \mathrm{~s}^{-1}\right)$. It lists the averages and standard deviations over the $2-4$ replications for each treatment of $P_{\mathrm{N}}, L A I$, irradiance, $C_{\mathrm{a}}$ and temperature. The values for each replication in turn typically average 10-15 successive measurements over a time interval of approximately 30 minutes. $P_{\mathrm{N}}$ values were generally higher in summer than in autumn. $P_{\mathrm{N}}$ decreased with increasing temperatures, by approximately $50 \%$ over a temperature range of $20^{\circ} \mathrm{C}$ and largely independently of the ambient $\mathrm{CO}_{2}$ concentration. The measurements of autumn indicate a slightly suboptimal temperature at $10{ }^{\circ} \mathrm{C}$ as compared to $15^{\circ} \mathrm{C}$. The highest $P_{\mathrm{Nl}}$ values were approximately $13.5 \mu \mathrm{mol} \mathrm{m}{ }^{-2}$ (leaf) $\mathrm{s}^{-1}$ in summer and $12 \mu \mathrm{mol} \mathrm{m}{ }^{-2}$ (leaf) $\mathrm{s}^{-1}$ in autumn, at an ambient $\mathrm{CO}_{2}$ concentration of $700 \mu \mathrm{mol} \mathrm{mol}{ }^{-1}$ and a temperature of $15^{\circ} \mathrm{C}$. Figure 2.2 shows how the sward net photosynthetic rate increased linearly with $L A I$. 
Table 2.2. Measurement values at highest irradiance, averaged over 2-4 replications $(n)$ where each replication is the average of $10-15$ values within a 30 minute time interval: $P_{\mathrm{Nl}}=$ net leaf photosynthetic rate $\left(\mu \mathrm{mol} \mathrm{m} \mathrm{m}^{-2}(\right.$ leaf $\left.) \mathrm{s}^{-1}\right), L A I=$ leaf area index $\left(\mathrm{m}^{2}(\right.$ leaf $) \mathrm{m}^{-2}$ (ground), $I=$ irradiance $(\mu \mathrm{mol}$ $\mathbf{m}^{-2}$ (ground) $\left.\mathrm{s}^{-1}\right), C=\mathrm{CO}_{2}$ concentration $\left(\mu \mathrm{mol} \mathrm{CO} \mathrm{mol}^{-1}\right), T=$ temperature $\left({ }^{\circ} \mathrm{C}\right)$. Values between brackets represent standard deviation.

\begin{tabular}{|c|c|c|c|c|c|}
\hline & variable & C200 & C350 & $\mathrm{C500}$ & C700 \\
\hline \multicolumn{6}{|c|}{ summer: } \\
\hline T15 & $\begin{array}{l}P_{\mathrm{Nl}} \\
L A I \\
I \\
C \\
T \\
n\end{array}$ & $\begin{array}{l}\mathbf{6 . 1 2}(\mathbf{0 . 6 8 )} \\
1.7(0.5) \\
790(76) \\
191(8) \\
15.6(0.6) \\
4\end{array}$ & $\begin{array}{l}\mathbf{1 0 . 5 8}(\mathbf{0 . 7 8 )} \\
1.9(0.4) \\
852(34) \\
330(18) \\
16.1(0.2) \\
4\end{array}$ & $\begin{array}{l}12.04(0.71) \\
1.6(0.4) \\
844(84) \\
492(13) \\
16.5(1.2) \\
4\end{array}$ & $\begin{array}{l}13.35(\mathbf{1 . 6 9}) \\
1.9(0.2) \\
832(56) \\
686(15) \\
16.7(0.8) \\
4\end{array}$ \\
\hline T20 & $\begin{array}{l}P_{\mathrm{Nl}} \\
L A I \\
I \\
C \\
T \\
n\end{array}$ & $\begin{array}{l}4.60(\mathbf{0 . 3 1}) \\
1.5(0.5) \\
863(38) \\
194(12) \\
22.6(1.4) \\
3\end{array}$ & $\begin{array}{l}7.62(\mathbf{1 . 0 1}) \\
1.6(0.3) \\
807(68) \\
334(15) \\
22.4(1.0) \\
3\end{array}$ & $\begin{array}{l}9.61(\mathbf{1 . 8 8}) \\
1.9(0.4) \\
816(67) \\
494(16) \\
21.6(1.0) \\
4\end{array}$ & 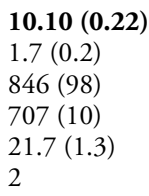 \\
\hline T25 & $\begin{array}{l}P_{\mathrm{Nl}} \\
L A I \\
I \\
C \\
T \\
n\end{array}$ & $\begin{array}{l}3.44(\mathbf{0 . 7 2}) \\
1.8(0.3) \\
798(86) \\
192(10) \\
26.0(0.3) \\
3\end{array}$ & $\begin{array}{l}\mathbf{6 . 8 7}(\mathbf{1 . 8 0}) \\
1.3(0.4) \\
840(93) \\
356(11) \\
25.9(0.2) \\
4\end{array}$ & $\begin{array}{l}8.72(\mathbf{0 . 7 4}) \\
1.7(0.6) \\
834(37) \\
500(5) \\
26.2(0.7) \\
4\end{array}$ & $\begin{array}{l}10.49(2.17) \\
1.9(0.4) \\
878(41) \\
691(15) \\
26.4(0.5) \\
4\end{array}$ \\
\hline T30 & $\begin{array}{l}P_{\mathrm{Nl}} \\
L A I \\
I \\
C \\
T \\
n \\
\end{array}$ & $\begin{array}{l}2.74(\mathbf{0 . 5 7}) \\
1.4(0.2) \\
879(68) \\
199(1) \\
30.9(0.3) \\
2\end{array}$ & $\begin{array}{l}5.22(\mathbf{0 . 4 0 )} \\
1.0(0.2) \\
881(49) \\
354(9) \\
31.0(0.5) \\
2\end{array}$ & $\begin{array}{l}7.01(\mathbf{0 . 4 3}) \\
3.0(0.2) \\
869(62) \\
493(5) \\
30.9(0.1) \\
2\end{array}$ & $\begin{array}{l}7.02(\mathbf{1 . 3 6}) \\
1.9(0.2) \\
859(50) \\
703(7) \\
30.9(0.2) \\
2\end{array}$ \\
\hline \multicolumn{6}{|c|}{ autumn: } \\
\hline T10 & $\begin{array}{l}P_{\mathrm{Nl}} \\
L A I \\
I \\
C \\
T \\
n\end{array}$ & $\begin{array}{l}\mathbf{5 . 8 6}(\mathbf{0 . 8 0}) \\
1.0(0.2) \\
793(4) \\
193(3) \\
10.8(0.2) \\
3\end{array}$ & $\begin{array}{l}8.01(\mathbf{2 . 4 2}) \\
0.9(0.2) \\
795(4) \\
343(1) \\
10.6(0.1) \\
2\end{array}$ & $\begin{array}{l}9.92(1.77) \\
1.0(0.1) \\
791(0) \\
495(2) \\
10.7(0.2) \\
2\end{array}$ & $\begin{array}{l}\mathbf{1 0 . 5 6}(\mathbf{1 . 6 5}) \\
0.9(0.2) \\
799(5) \\
693(5) \\
10.9(0.4) \\
3\end{array}$ \\
\hline T15 & $\begin{array}{l}P_{\mathrm{Nl}} \\
L A I \\
I \\
C \\
T \\
n\end{array}$ & $\begin{array}{l}5.04(\mathbf{0 . 4 8}) \\
1.1(0.1) \\
796(7) \\
193(6) \\
16.6(0.1) \\
3\end{array}$ & $\begin{array}{l}8.19(\mathbf{1 . 9 8}) \\
1.0(0.3) \\
798(1) \\
339(7) \\
15.6(0.3) \\
3\end{array}$ & $\begin{array}{l}\mathbf{1 0 . 9 8}(\mathbf{1 . 8 1}) \\
1.1(0.4) \\
792(8) \\
493(6) \\
15.5(0.3) \\
3\end{array}$ & $\begin{array}{l}11.71(\mathbf{0 . 7 0}) \\
0.9(0.2) \\
796(4) \\
690(1) \\
15.6(0.1) \\
3\end{array}$ \\
\hline T20 & $\begin{array}{l}P_{\mathrm{Nl}} \\
L A I \\
I \\
C \\
T \\
n\end{array}$ & $\begin{array}{l}2.39(\mathbf{0 . 2 4}) \\
1.1(0.7) \\
767(11) \\
203(4) \\
20.4(0.1) \\
3\end{array}$ & $\begin{array}{l}3.93(\mathbf{1 . 0 5}) \\
1.1(0.4) \\
782(11) \\
351(4) \\
20.3(0.3) \\
3\end{array}$ & $\begin{array}{l}7.33(1.04) \\
1.1(0.3) \\
779(18) \\
500(4) \\
20.4(0.3) \\
3\end{array}$ & $\begin{array}{l}7.15(2.02) \\
1.2(0.3) \\
783(14) \\
696(0) \\
20.5(0.4) \\
3\end{array}$ \\
\hline T25 & $\begin{array}{l}P_{\mathrm{Nl}} \\
L A I \\
I \\
C \\
T \\
n\end{array}$ & $\begin{array}{l}3.06(1.58) \\
0.7(0.1) \\
792(3) \\
203(4) \\
25.2(0.1) \\
3\end{array}$ & $\begin{array}{l}4.27(\mathbf{0 . 3 9}) \\
1.1(0.3) \\
773(11) \\
350(8) \\
25.3(0.2) \\
3\end{array}$ & $\begin{array}{l}7.74(1.40) \\
0.9(0.1) \\
785(9) \\
509(11) \\
25.2(0.0) \\
3\end{array}$ & $\begin{array}{l}\mathbf{6 . 8 1}(\mathbf{1 . 6 4 )} \\
1.2(0.2) \\
779(11) \\
698(2) \\
25.3(0.2) \\
3\end{array}$ \\
\hline
\end{tabular}




\subsubsection{Method (1) - aggregated photosynthesis-irradiance response function}

Table 2.3 shows that the average fitted asymptotic value of $P_{\mathrm{Gl}(\max )}$ at saturating irradiance, using Equation 2.1, was higher in summer than in autumn (respectively 22 and $18 \mu \mathrm{mol}$ $\mathrm{m}^{-2} \mathrm{~s}^{-1}$ at $\left.25^{\circ} \mathrm{C}\right) . P_{\mathrm{Gl}(\max )}$ responded to temperature positively, but this was significant in autumn only, increasing from 13 to $18 \mu \mathrm{mol} \mathrm{m}^{-2} \mathrm{~s}^{-1}$ between 10 and $25^{\circ} \mathrm{C}$. The difference in $P_{\mathrm{Gl}(\max )}$ between summer and autumn was larger at lower temperatures. With the ambient $\mathrm{CO}_{2}$ concentration $\left(C_{\mathrm{a}}\right)$ increasing from 200 to $700 \mu \mathrm{mol} \mathrm{mol}^{-1}, P_{\mathrm{Gl}(\max )}$ tripled from 10 to $30 \mu \mathrm{mol} \mathrm{m}^{-2} \mathrm{~s}^{-1}$ in summer and doubled from 10 to $20 \mu \mathrm{mol} \mathrm{m} \mathrm{m}^{-2} \mathrm{~s}^{-1}$ in autumn. The positive response of $P_{\mathrm{Gl}(\max )}$ to $C_{\mathrm{a}}$ was maintained across almost its entire range; saturation could only be observed in autumn at $C_{\mathrm{a}} \geq 500 \mu \mathrm{mol} \mathrm{mol}{ }^{-1}$.

The initial radiation use efficiency $(\Phi)$ was similar in summer and autumn at 20-21 $\mu \mathrm{mol} \mathrm{mol}{ }^{-1}$ (at $350 \mu \mathrm{mol} \mathrm{CO} \mathrm{mol}^{-1}$ ). From 15 to $25^{\circ} \mathrm{C}, \Phi$ decreased from 25 to 18 $\mu \mathrm{mol} \mathrm{mol}{ }^{-1}$. Between 200 and $700 \mu \mathrm{mol} \mathrm{CO}_{2} \mathrm{~mol}^{-1}$, $\Phi$ increased from 19 to $22 \mu \mathrm{mol}$ $\mathrm{mol}^{-1}$. There was no significant interaction between the effects of temperature and $\mathrm{CO}_{2}$ concentration on either $P_{\mathrm{Gl}(\max )}$ or $\Phi$.

Table 2.3. Asymptotic value of grass sward gross leaf photosynthetic rate $\left(P_{\mathrm{Gl}(\max )}\right)$ and initial radiation use efficiency $(\Phi)$, fitted as a function of temperature (from $10^{\circ} \mathrm{C}(\mathrm{T} 10)$ to $30^{\circ} \mathrm{C}(\mathrm{T} 30)$ ) and $\mathrm{CO}_{2}$ concentration (from $200 \mu \mathrm{mol} \mathrm{mol}{ }^{-1}(\mathrm{C} 200)$ to $700 \mu \mathrm{mol} \mathrm{mol}^{-1}(\mathrm{C} 700)$ ). Different superscripts indicate significant differences between the effects of concentrations of $\mathrm{CO}_{2}$ and temperature as determined by analysis of variance $(P<0.05$; Student-Newman-Keuls test $)$.

\begin{tabular}{|c|c|c|c|c|c|c|c|c|c|c|}
\hline & \multicolumn{5}{|c|}{ 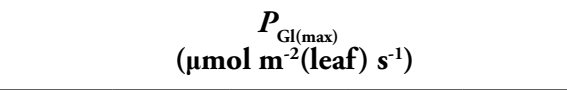 } & \multicolumn{5}{|c|}{$\begin{array}{c}\Phi \\
\left(\mathrm{mmol} \mathrm{mol}^{-1}\right) \\
\end{array}$} \\
\hline & C200 & C350 & $\mathrm{C} 500$ & C700 & C & C200 & C350 & $\mathrm{C} 500$ & C700 & C \\
\hline \multicolumn{11}{|c|}{ summer: } \\
\hline T15 & 10.6 & 19.2 & 23.4 & 29.0 & $20.5^{a}$ & 20.9 & 24.0 & 25.6 & 26.8 & $24.3^{\mathrm{a}}$ \\
\hline T20 & 10.2 & 19.1 & 26.5 & 29.5 & $21.3^{\mathrm{a}}$ & 17.3 & 20.1 & 20.3 & 22.5 & $20.0^{b}$ \\
\hline T25 & 8.9 & 21.9 & 25.1 & 33.2 & $22.3^{a}$ & 18.3 & 17.9 & 20.1 & 19.9 & $19.1^{\mathrm{b}}$ \\
\hline T30 & 9.3 & 23.0 & 26.8 & 30.5 & $22.4^{\mathrm{a}}$ & 13.9 & 17.5 & 15.0 & 16.4 & $15.7^{c}$ \\
\hline $\mathbf{T}$ & $9.8^{\mathrm{a}}$ & $20.8^{b}$ & $25.5^{\mathrm{c}}$ & $30.5^{d}$ & & $17.6^{a}$ & $19.8^{a b}$ & $20.3^{\mathrm{ab}}$ & $21.4^{b}$ & \\
\hline \multicolumn{11}{|c|}{ autumn: } \\
\hline T10 & 8.3 & 12.0 & 15.4 & 16.4 & $13.0^{\mathrm{a}}$ & 22.9 & 25.3 & 24.9 & 28.9 & $25.5^{\mathrm{a}}$ \\
\hline T15 & 8.4 & 14.6 & 20.4 & 22.3 & $16.4^{\mathrm{ab}}$ & 19.5 & 23.3 & 26.2 & 28.9 & $24.5^{\mathrm{a}}$ \\
\hline T20 & 8.7 & 13.0 & 19.8 & 22.5 & $16.0^{\mathrm{ab}}$ & 16.6 & 18.3 & 19.7 & 18.2 & $18.2^{\mathrm{b}}$ \\
\hline T25 & 11.1 & 13.9 & 24.1 & 22.3 & $17.9^{b}$ & 19.4 & 16.5 & 20.9 & 16.3 & $18.3^{b}$ \\
\hline $\mathbf{T}$ & $9.1^{\mathrm{a}}$ & $13.4^{\mathrm{b}}$ & $19.9^{c}$ & $20.9^{c}$ & & $19.6^{a}$ & $20.8^{a}$ & $22.9^{a}$ & $23.1^{\mathrm{a}}$ & \\
\hline
\end{tabular}


Figure 2.3 combines $\Phi$ and $P_{\mathrm{Gl}(\max )}$ in the actual fitted responses of the leaf gross photosynthetic rate $\left(P_{\mathrm{Gl}}\right)$ to the applied levels of irradiance. Figure 2.3A shows how the response of $P_{\mathrm{Gl}}$ to irradiance in summer decreased consistently with short-term increases in temperature from 15 to $30^{\circ} \mathrm{C}$. The effect of temperature on the response of $P_{\mathrm{Gl}}$ to irradiance in autumn (Figure 2.3B) was less clear. A temperature of $10^{\circ} \mathrm{C}$ proved to be suboptimal as the response at $15^{\circ} \mathrm{C}$ was substantially higher. The responses were lower again at 20 and $25^{\circ} \mathrm{C}$, indicating a temperature optimum at around $15^{\circ} \mathrm{C} . P_{\mathrm{Gl}}$ was generally lower in autumn than in summer. Figures $2.3 \mathrm{C}$ and $2.3 \mathrm{D}$ show that the response of $P_{\mathrm{Gl}}$ to irradiance responded consistently and positively to increases in ambient $\mathrm{CO}_{2}(C)$ from 200 to $700 \mu \mathrm{mol} \mathrm{mol}^{-1}$ in both summer and autumn. In autumn, however, the response of $P_{\mathrm{Gl}}$ to irradiance increased only marginally beyond a $C_{\mathrm{a}}$ value of $500 \mu \mathrm{mol}$ $\mathrm{mol}^{-1}$. As light-saturation was not attained in any of the experimental combinations $\Phi$ was more indicative of the response of $P_{\mathrm{Gl}}$ to irradiance than $P_{\mathrm{Gl}(\max )}$. In fact, the course of the somewhat hypothetical values of $P_{\mathrm{Gl}(\max )}$ is more likely to be forced by the course of the real, actually observed values of $\Phi$, i.e. the initial slope of the response curve.
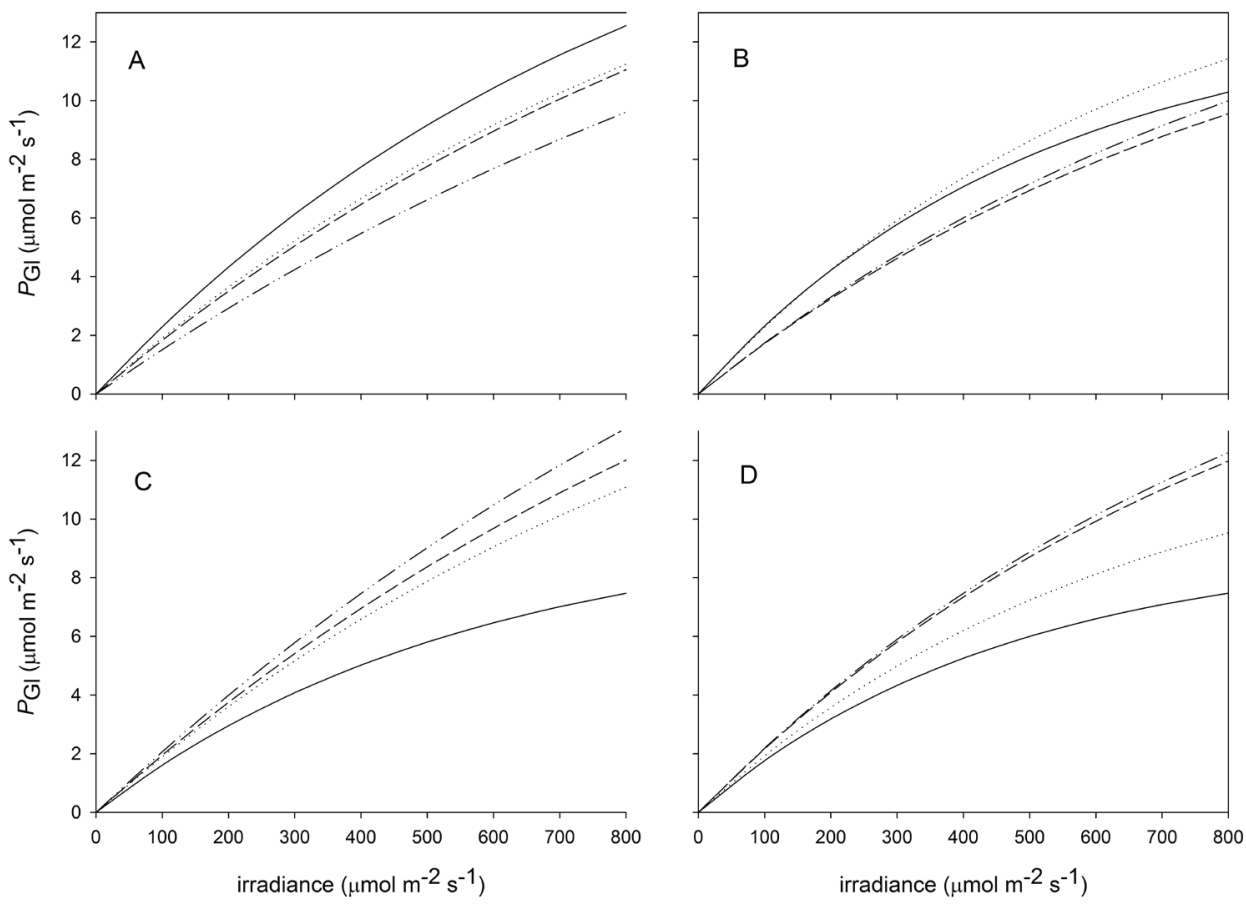

Figure 2.3. Fitted negatively exponential asymptotic response of the leaf gross photosynthetic rate $\left(P_{\mathrm{Gl}}\right)$ as a function of irradiance: $(\mathrm{A})$ in summer at 15 (drawn), 20 (dotted), 25 (dashed) and $30^{\circ} \mathrm{C}$ (alternating); (B) in autumn at 10 (drawn), 15 (dotted), 20 (dashed) and $25{ }^{\circ} \mathrm{C}$ (alternating); (C) in summer at 200 (drawn), 350 (dotted), 500 (dashed) and $700 \mu \mathrm{mol} \mathrm{CO}_{2} \mathrm{~mol}^{-1}$ (alternating); and (D) in autumn at 200 (drawn), 350 (dotted), 500 (dashed) and $700 \mu \mathrm{mol} \mathrm{CO}_{2} \mathrm{~mol}^{-1}$ (alternating). 


\subsubsection{Method (2) - Farquhar equations}

Application of the experimental data to Equation 2.2 and its constituent Equations 2.3 to 2.5 resulted in a fitted value of $f_{\mathrm{r}}$ in the range $0.25-0.30$, a measure for the erect canopy structure. From this value for $f_{\mathrm{r}}$ and the fitted values for $\Phi$ from method (1) as shown in Table 2.3, the initial radiation use efficiency on a single leaf basis $(\varepsilon)$ was calculated at $55-101 \mu \mathrm{mol} \mathrm{mol}^{-1}$ (at a $C_{\mathrm{a}}$ value of $350 \mu \mathrm{mol} \mathrm{mol}^{-1}$ ). For the subsequent analysis of the temperature dependence of photosynthetic processes, fixed $f_{\mathrm{r}}$ values of both 0.25 and 0.30 were used.

Table 2.4 shows the results of the fit of Equations 2.2 to 2.5 to the experimental data. First, it shows the difference resulting from the two sets of Arrhenius parameters $\left(K_{\mathrm{C}(20)}\right.$, $K_{\mathrm{O}(20)}, E_{\mathrm{aC}}$ and $\left.E_{\mathrm{aO}}\right)$ in the temperature dependencies of RuBPCO as shown in Table 2.1, as given by Long (1991) and by Harley et al. (1986). Maximum electron transport rate at $20^{\circ} \mathrm{C} J_{\max (20)}$ (see Equation 2.5) was the only variable which resulted from this fitting to the experimental data, assuming standard values for Arrhenius parameters $S, E_{\text {aj }}$, and $E_{\mathrm{dJ}}$ (Harley et al. 1992). Table 2.4 shows that the parameter values of Long (1991) gave both a closer fit (higher $r^{2}$ ) and a higher $J_{\max (20)}$ than the values of Harley et al. (1986). $J_{\max (20)}$ values were higher in summer than in autumn.

Second, Table 2.4 also shows the result of drawing $3^{\text {rd }}$ order polynomial relationships between $J_{\max }$ and $K_{\mathrm{C}} / K_{\mathrm{O}}$ on the one hand and temperature on the other. These polynomial relationships are to be compared to the derived Arrhenius dependencies for $J_{\max }$ (Harley et al. 1992) and $K_{\mathrm{C}}$ and $K_{\mathrm{O}}$ (Harley et al. 1986, Long 1991). Having more degrees of freedom, the polynomials provide a closer fit to the experimental data than the Arrhenius dependencies. The fitted parameters of the polynomial relationships corresponded more

Table 2.4. Fitted parameters for irradiance-limited photosynthesis following Equations 2.2 to 2.5. For the relationship between on the one hand $J_{\max }$ and $K_{\mathrm{C}} / K_{\mathrm{o}}$ and on the other hand temperature, fixed Arrhenius parameters (Harley et al. 1986, 1992, Long, 1991), and $3^{\text {rd }}$ order polynomials are shown. " fixed values.

\begin{tabular}{|c|c|c|c|c|c|c|c|}
\hline & \multicolumn{3}{|c|}{$f_{\mathrm{r}}=0.25$} & \multicolumn{3}{|c|}{$f_{\mathrm{r}}=\mathbf{0 . 3 0}$} & \multirow[t]{2}{*}{$n$} \\
\hline & $J_{\max (20)}$ & $\left(K_{\mathrm{C}} / K_{\mathrm{O}}\right)_{(20)}$ & $r^{2}$ & $J_{\max (20)}$ & $\left(K_{\mathrm{C}} / K_{\mathrm{O}}\right)_{(20)}$ & $r^{2}$ & \\
\hline \multicolumn{8}{|l|}{ summer: } \\
\hline Harley et al. (1986) & 272 & $1.17^{*}$ & 0.90 & 148 & $1.17^{*}$ & 0.85 & 5760 \\
\hline Long (1991) & 453 & $1.39^{*}$ & 0.95 & 233 & $1.39^{*}$ & 0.94 & 5760 \\
\hline $3^{\text {rd }}$ order polynomial & 387 & 1.41 & 0.96 & 239 & 1.57 & 0.96 & 5760 \\
\hline \multicolumn{8}{|l|}{ autumn: } \\
\hline Harley et al. (1986) & 270 & $1.17^{*}$ & 0.86 & 166 & $1.17^{*}$ & 0.81 & 5166 \\
\hline Long (1991) & 297 & $1.39^{*}$ & 0.89 & 190 & $1.39^{*}$ & 0.86 & 5166 \\
\hline $3^{\text {rd }}$ order polynomial & 311 & 1.90 & 0.92 & 219 & 2.16 & 0.92 & 5166 \\
\hline
\end{tabular}



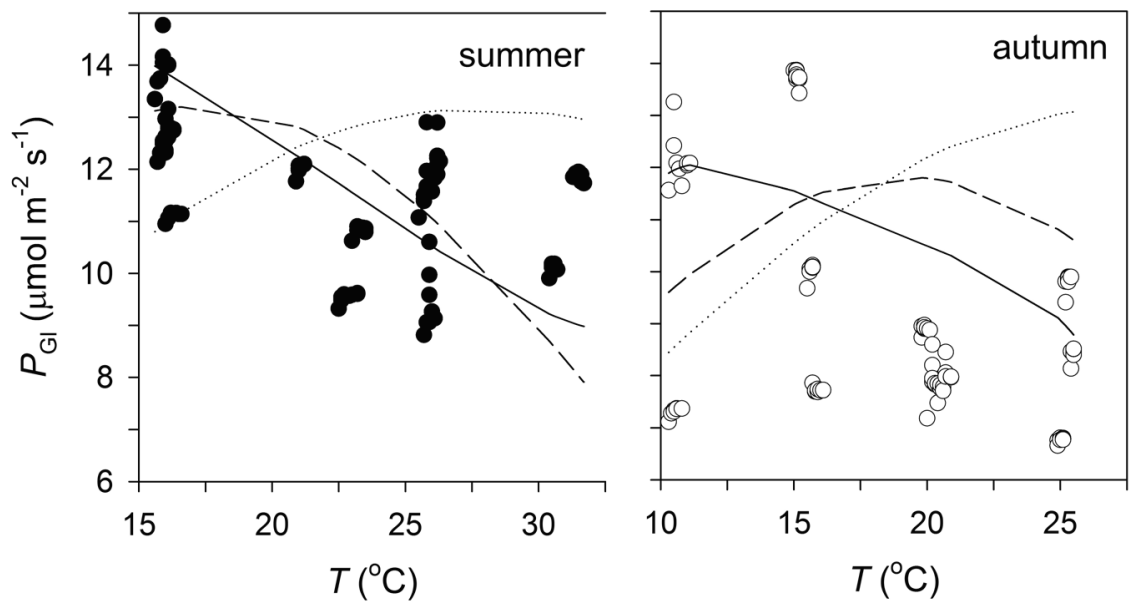

Figure 2.4. Leaf gross photosynthetic rate $\left(P_{G 1}\right)$ as a function of temperature $(T)$ in summer and autumn. Symbols represent measurements, lines represent fitted curves for Equation 3.2 with temperature dependencies of Harley et al. (1986; dotted), Long (1991; dashed), and polynomial (solid). Irradiance of $800 \mu \mathrm{mol} \mathrm{m} \mathrm{m}^{-2} \mathrm{~s}^{-1}$ and applied $\mathrm{CO}_{2}$ concentration of $350 \mu \mathrm{mol} \mathrm{mol}^{-1}$.

closely with those of the Arrhenius dependencies by Long (1991) than with those by Harley et al. (1986) (comparison also in Table 2.4).

Figure 2.4 shows the actual leaf gross photosynthetic rate values $\left(P_{\mathrm{Gl}}\right)$ which were directly calculated from the observations made at an irradiance of $800 \mu \mathrm{mol} \mathrm{m}^{-2} \mathrm{~s}^{-1}$ and an ambient $\mathrm{CO}_{2}$ concentration of $350 \mu \mathrm{mol} \mathrm{mol}^{-1}$. Figure 2.4 also displays the curves that were fitted to the experimental data at these conditions with the parameter values which are given in Table 2.4. The observations represent only a limited part of all observations made, whereas the curves were fitted to all observations simultaneously. Figure 2.4 illustrates the observation in Table 2.4 that the Arrhenius dependencies between $J_{\max }, K_{\mathrm{C}} / K_{\mathrm{O}}$ and $T_{\mathrm{a}}$ as established by Long (1991) corresponded more closely with the benchmark polynomial fit than the Arrhenius dependencies found by Harley et al. (1986). In both summer and autumn the polynomial fit between $J_{\max }, K_{\mathrm{C}} / K_{\mathrm{O}}$ and $T_{\mathrm{a}}$ resulted in a steady decrease of $P_{\mathrm{Gl}}$ with $T_{\mathrm{a}}$. This almost linear decrease in $\mathrm{CO}_{2}$ assimilation with temperature concurs with the observations. The Arrhenius dependencies of $J_{\max }$ and $K_{\mathrm{C}} / K_{\mathrm{O}}$ on $T_{\mathrm{a}}$ as established by Long (1991) also resulted in a steady decrease of $P_{\mathrm{Gl}}$ with $T_{\mathrm{a}}$ in summer, but leaned towards a temperature optimum at $15-20^{\circ} \mathrm{C}$ in autumn. The large variation in observed rates of photosynthesis at low temperatures in autumn makes the temperature response difficult to assess (Figure 2.4).

Whereas Figure 2.4 shows the various responses of the leaf gross photosynthetic rate $\left(P_{\mathrm{Gl}}\right)$ to temperature, Figure 2.5 instead shows the responses of its constituent processes. The 

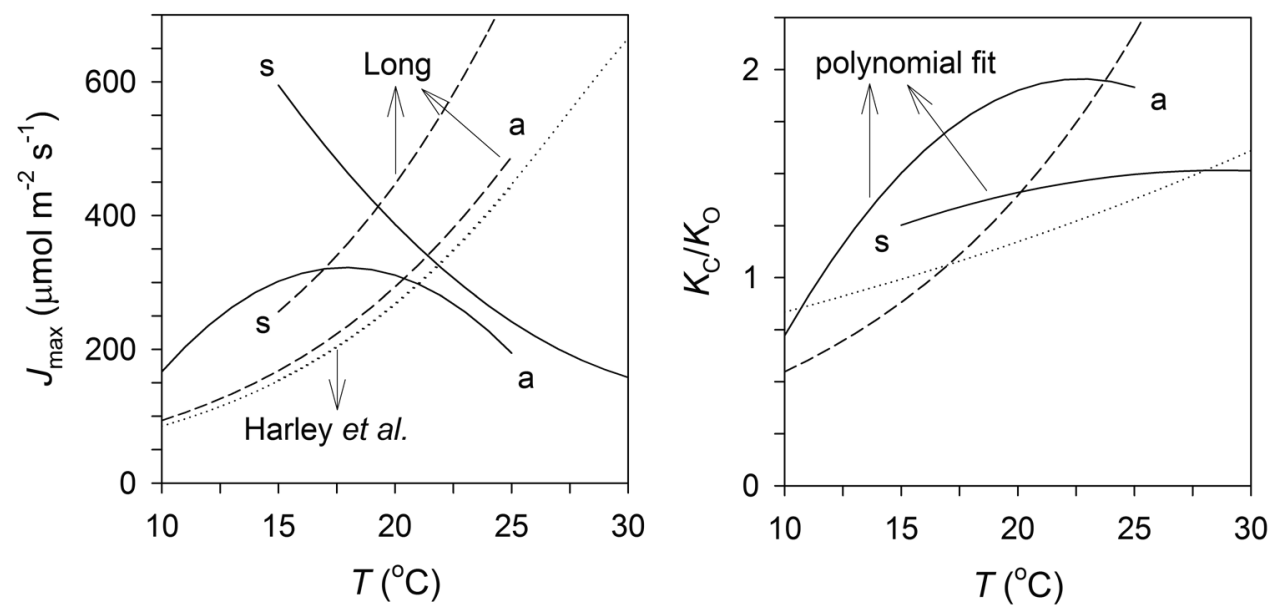

Figure 2.5. Maximum electron transport rate $\left(J_{\max }\right)$ and the ratio of the Michaelis-Menten constants for $\mathrm{CO}_{2}$ and $\mathrm{O}_{2}\left(K_{\mathrm{C}} / K_{\mathrm{o}}\right)$ as fitted (to observations from measurements at irradiance of $800 \mu \mathrm{mol} \mathrm{m} \mathrm{m}^{-2} \mathrm{~s}^{-1}$ ) functions of temperature $(T)$ in summer $(\mathrm{s})$ and autumn $(\mathrm{a})\left(T=15-30^{\circ} \mathrm{C}\right.$ and $10-25^{\circ} \mathrm{C}$, respectively). Equations with temperature dependencies of Harley et al. (1986: dotted), Long (1991: dashed), and polynomial (solid) were applied.

relationships between $J_{\max }, K_{\mathrm{C}} / K_{\mathrm{O}}$ and temperature are much more speculative, as the processes could not be directly observed. It shows large differences between the Arrhenius dependencies found by Harley et al. (1986) and Long (1991) on the one hand and the fitted $3^{\text {rd }}$ order polynomial relationships on the other. Whereas any Arrhenius dependency predicts an increase in the maximum electron transport rate $\left(J_{\max }\right)$ with temperature $\left(T_{\mathrm{a}}\right)$, the fitted polynomial shows a decrease in $J_{\max }$ with $T_{\mathrm{a}}$ in summer and a temperature optimum at $15-20^{\circ} \mathrm{C}$ in autumn. For the relative affinity of RuBPCO to $\mathrm{O}_{2}$ (the $K_{\mathrm{C}} / K_{\mathrm{O}}$ ratio) the Arrhenius dependencies by Harley et al. (1986) and Long (1991) predict an increase with temperature, whereas the fitted polynomial shows an asymptotic response. Although the response of $P_{\mathrm{Gl}}$ as a whole to $T_{\mathrm{a}}$ as found by Long (1991) agreed modestly with the observations in this study - as reflected in the fitted $3^{\text {rd }}$ order polynomial - this was not supported by the responses of its constituent processes of $J_{\max }$ and $K_{\mathrm{C}} / K_{\mathrm{O}}$.

Figure 2.6 plots the response of the observed leaf net photosynthetic rate $\left(P_{\mathrm{Nl}}\right)$ to the intercellular $\mathrm{CO}_{2}$ concentration $\left(C_{\mathrm{i}}\right)$ at different levels of irradiance, where $C_{\mathrm{i}}$ was calculated as $70 \%$ of the ambient $\mathrm{CO}_{2}$ concentration $\left(C_{\mathrm{a}}\right)$. The responses were similar in summer and autumn. Whereas $P_{\mathrm{Nl}}$ appeared to respond linearly to $C_{\mathrm{i}}$ initially, the response levelled off beyond $C_{\mathrm{i}} 350-400 \mu \mathrm{mol} \mathrm{mol}^{-1}$. The different response functions did not intersect at any specific value of $C_{\mathrm{i}}$. 

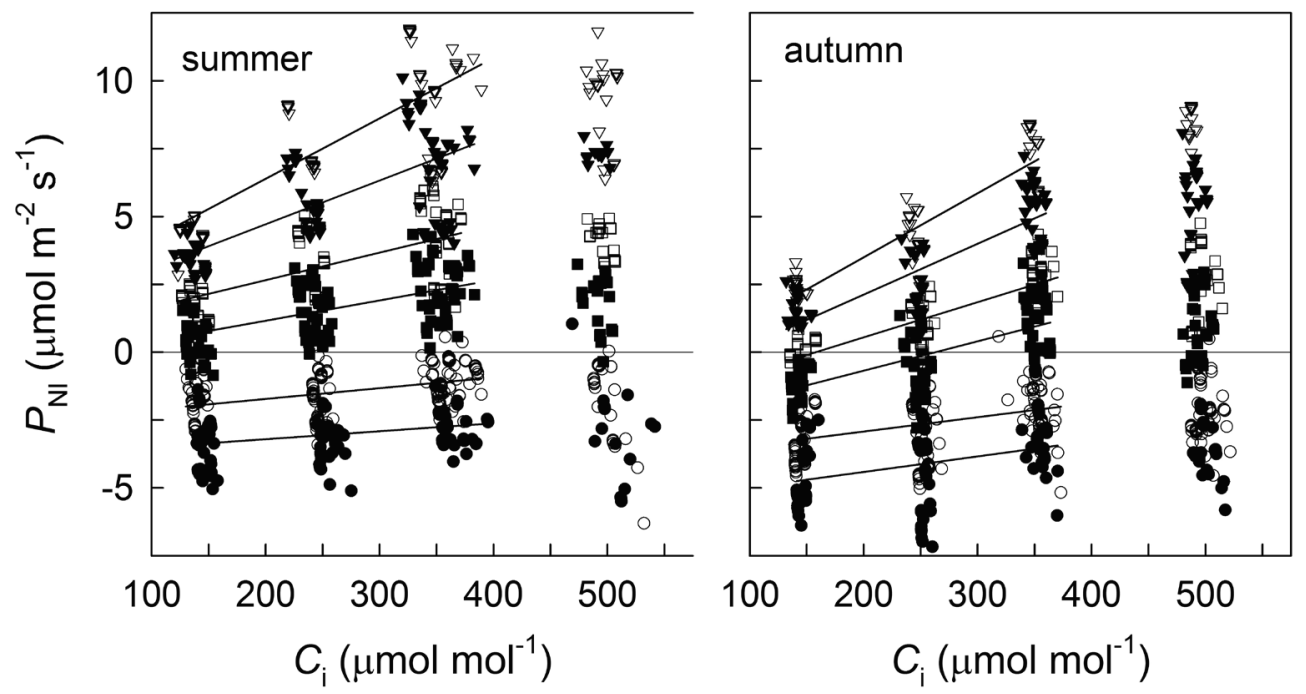

Figure 2.6. Measured leaf net photosynthetic rate $\left(P_{\mathrm{N}}\right)$ as a function of intercellular $\mathrm{CO}_{2}$ concentration $\left(C_{\mathrm{i}}\right)$ at $20^{\circ} \mathrm{C}$, assuming a fixed relationship with ambient $\mathrm{CO}_{2}$ concentration $\left(C_{\mathrm{i}}=0.7 \times C_{\mathrm{a}}\right)$. Irradiances of 0 (closed circles), 100 (open circles), 200 (closed squares), 350 (open squares), 500 (closed triangles) and $800 \mu \mathrm{mol} \mathrm{m}^{-2} \mathrm{~s}^{-1}$ (open triangles).

\subsection{DISCUSSION}

\subsubsection{Seasonality and temperature sensitivity}

The decrease in irradiance from late summer to autumn has consequences for morphophysiological characteristics of the canopy. At low irradiance, common adaptive morphological responses - increased leaf area ratio, increased shoot-to-root ratio, decreased leaf thickness, reduction in mesophyll cell number and stomatal density - and a decline in photosynthetic capacity are frequently observed in grasses (Huylenbroeck et al. 1999).

Climate change research in grassland swards has focused much on the effects of $\mathrm{CO}_{2}$ (Schapendonk et al. 1996, Chen et al. 1996). Long-term effects of temperature have less been taken into account (Casella et al. 1996), although Woledge and Dennis (1982) found that leaves can acclimate to the temperature environment in which they develop. They found maximum photosynthetic rates to be both higher and more responsive after acclimation to higher temperatures, which would agree with the strong response to irradiance of the grass sward in this study in summer relative to autumn. It nonetheless seems that acclimation to irradiance could have a larger effect than acclimation to temperature. Woledge and Parsons (1985) reported that ryegrass canopy photosynthesis at $20{ }^{\circ} \mathrm{C}$ increased to 1.8 times the rate at $10{ }^{\circ} \mathrm{C}$ under conditions of bright irradiance, whereas under conditions of low irradiance this factor declined to 1.3 . 
The effect of temperature on single leaf photosynthesis shifts to higher values with increasing irradiance. In a multilayer canopy individual leaves have acclimated to a broad range of levels of irradiance, meaning that the temperature optimum of the whole canopy photosynthesis is much broader than the optimum of a single leaf. It also means that canopies with a high $L A I$ respond less to temperature because the shape of the temperature response curve gets flatter as more leaves become shaded. In contrast, the respiration enhancing effect of temperature will increase its relative impact at low irradiance. As such, measurements of canopy photosynthesis are difficult to unravel but they are nonetheless useful to confront expectations from models with real data.

\subsubsection{Photosynthetic rate limited by electron transport}

Equation 2.2 assumes that the rate of photosynthesis in the measurements was exclusively limited by electron transport, meaning that photosynthesis is mainly limited by the regeneration of $\mathrm{RuBP}$ and not by the carboxylation rate. This is supported by the low fitted $f_{\mathrm{r}}$ values of $0.25-0.30$, which are a consequence of the relatively erect and open canopy structure in this particular sward, diluting photons over a larger leaf area. Figure 2.2 corroborates this assumption by illustrating an absence of notable photon saturation in photosynthetic rate at increasing $L A I$.

\subsubsection{Photosynthesis-temperature responses}

$\Phi$ decreased with rising temperatures, which is shown in Table 2.3. The calculated value for $\varepsilon\left(=\Phi / f_{\mathrm{r}}\right)$ of $60-100 \mu \mathrm{mol} \mathrm{mol}^{-1}$ is in agreement with a value of $80 \mu \mathrm{mol} \mathrm{mol}^{-1}$ found by Peisker and Apel (1981). Although the asymptotic leaf gross photosynthetic rate at saturating irradiance $\left(P_{\mathrm{Gl}(\max }\right)$ simultaneously increased, this increase was only apparent and an arithmetical consequence of the real decrease in $\Phi$. Leaf gross photosynthetic rate $P_{\mathrm{Gl}}$ itself decreased at increasing temperature (Figure 2.4). Whereas the temperature dependencies parameterised by Harley et al. (1986) predicted an increase in $P_{\mathrm{Gl}}$ with temperature rise, the dependencies parameterised by Long (1991) came closer to our observations, although with an optimum at low temperatures not seen in the measured data. Our data fitted by the benchmark $3^{\text {rd }}$ order polynomials resulted in a simple nearly linear decrease in $P_{\mathrm{Gl}}$ with temperature rise.

At first sight, the appreciably good linear fits listed in Table $2.4\left(r^{2}=0.80-0.95\right)$ appear to much disagree with the observations shown in Figure 2.4. The fits shown in Table 2.4 apply to the full scope of the Farquhar equations (i.e. all treatments of temperature, $\mathrm{CO}_{2}$ and irradiance, with $n \approx 5500$ ). However, the observations in Figure 2.4 represent only part of these treatments $(n<<5500)$, with photosynthetic rate as a function of temperature at one particular combination of irradiance and ambient $\mathrm{CO}_{2}$ concentration. Figure 2.4 also demonstrates how a large number of observations is needed to limit the 
variance in experimental results. Differences in photosynthetic rate were probably largely caused by differences in irradiance and ambient $\mathrm{CO}_{2}$ concentration.

Figure 2.5 shows how the differences in temperature response of $P_{\mathrm{Gl}}$ as fitted to observed data in Figure 2.4, were caused by different temperature dependencies for the maximum electron transport rate $\left(J_{\max }\right)$ and $K_{\mathrm{C}} / K_{\mathrm{O}}$, the ratio of Michaelis-Menten constants for $\mathrm{CO}_{2}$ and $\mathrm{O}_{2}$ fixation being a measure for the relative affinity of $\mathrm{RuBPCO}$ to $\mathrm{O}_{2}$. The predicted increase in the maximum electron transport rate $J_{\max }$ with temperature was similar for the parameter sets of Harley et al. (1986) and Long (1991). But whereas Harley et al. (1986) predicted a modest increase in $K_{\mathrm{C}} / K_{\mathrm{O}}$ - i.e. an increase in the relative affinity of RubBPCO to $\mathrm{O}_{2}$ over $\mathrm{CO}_{2}$ - Long (1991) predicted a strong increase using a lower activation energy $E_{\mathrm{a}}$ of $1400 \mathrm{~J} \mathrm{~mol}^{-1}$ for $\mathrm{O}_{2}$ binding (Table 2.1). The fitted benchmark $3^{\text {rd }}$ order polynomials for the temperature dependencies of $J_{\max }$ and $K_{\mathrm{C}} / K_{\mathrm{O}}$ provided different dynamics: the decrease in $P_{\mathrm{Gl}}$ with temperature rise originated for a substantial part from a decrease in $J_{\max }$ at high temperatures. This behaviour is consistent with an optimum curve for the response of $J_{\max }$ to temperature proposed by Farquhar \& Caemmerer (1982).

\subsubsection{Response of photosynthetic rate to $C_{\mathrm{i}}$}

Application of Equation 2.2 and its constituent parts to in vivo systems is paired with many assumptions. One major assumption is an often applied fixed proportionality between intercellular $\left(C_{\mathrm{i}}\right)$ and ambient $\mathrm{CO}_{2}$ concentration $\left(C_{\mathrm{a}}\right)$. Nijs et al. (1989) calculated a value of approximately 0.75 for $L$. perenne, whereas Pearcy and Björkman (1983) found $C_{\mathrm{i}} / C_{\mathrm{a}}$ ratios ranging from 0.6 to 0.8 . Photosynthesis theory (e.g. Brooks and Farquhar 1985) predicts a linear relationship between $C_{\mathrm{i}}$ (the actual photosynthesis substrate) and $P_{\mathrm{Nl}}$. Figure 2.6 shows that a linear relationship between $C_{\mathrm{i}}$ and $P_{\mathrm{Nl}}$ in which $C_{\mathrm{i}}$ is calculated as a fixed proportion of 0.7 of $C_{\mathrm{a}} \operatorname{did}$ not hold at $C_{\mathrm{i}}$ values higher than $400 \mu \mathrm{mol} \mathrm{mol}{ }^{-1}$. This implies that either the response of $P_{\mathrm{Nl}}$ to $C_{\mathrm{i}}$ saturates at higher levels of $C_{\mathrm{i}}$ or the $C_{\mathrm{i}} / C_{\mathrm{a}}$ ratio becomes smaller at high $C_{\mathrm{a}}$ as a result of stomatal adjustment to higher levels of ambient $\mathrm{CO}_{2}$. As the effect at high $C_{\mathrm{i}}$ was consistent across all irradiance levels, a saturation effect seems less plausible than stomatal adjustment resulting in a lower stomatal conductance under conditions of high $C_{\mathrm{a}}$.

\subsubsection{The Farquhar algorithm and the canopy photosynthetic rate}

The question of the applicability of the Farquhar algorithm to the calculation of canopy photosynthetic rate touches two points: (1) the uncertainty in the applied relationships as such (represented by Figures 2.4 and 2.5) and (2) the scaling of a cellular process (as represented by the Farquhar algorithm) to the canopy level. The second point is beyond the scope of this study. The scaling of photosynthesis from leaf to canopy has been considered comprehensively by other authors (e.g. Leuning 1995). 
Figure 2.4 shows a substantial disagreement among parameter sets and the resulting responses of photosynthetic rate to temperature. The observed decrease in initial radiation use efficiency $\Phi$ with increasing temperature agrees with the course of the benchmark's polynomial responses of $J_{\text {max }}$ and $K_{\mathrm{C}} / K_{\mathrm{O}}$ to temperature as shown in Figure 2.5: $J_{\max }$ (the maximum electron transport rate) decreases and $K_{\mathrm{C}} / K_{\mathrm{O}}$ (the relative affinity of RuBPCO to $\mathrm{O}_{2}$ over $\mathrm{CO}_{2}$ ) increased with increasing temperature. This is reflected in Figure 2.4, where $P_{\mathrm{Gl}}$ as calculated on basis of these polynomial responses decreases with increasing temperature. However, it proved not to be possible to replicate this polynomial response by applying either the parameters provided by Harley et al. (1986) or the parameters provided by Long (1991). Even though the responses of $P_{\mathrm{GI}}$ to temperature were comparably similar for the $3^{\text {rd }}$ order polynomial fit and the parameter set of Long (1991), this was much less evident for the constituent processes, which were very different.

Farquhar and Caemmerer (1980) and Harley et al. (1992) suggested that the variation in photosynthetic rate may be largely explained by the reference rates of electron transport $\left(J_{\max (20)}\right)$ and carboxylation, as the reference Michaelis-Menten constants and the activation and deactivation energies would be relatively constant. But Harley et al. (1985) encountered difficulties in parameterisation of the different processes on basis of in vitro experimentation. This problem is reflected in the on-going attempts to determine these parameter values (e.g. Harley et al., 1985, 1986, 1992, Kirschbaum \& Farquhar 1984, and see Table 2.1). Parameterisation is particularly significant once the equations are used for calculations rather than for conceptual study. Parameter uncertainties then put restrictions on the application of the Farquhar algorithm, particularly for the calculation of canopy photosynthetic rate and dry matter accumulation. It could be argued that the parameter uncertainty on basis of in vivo experimentation is in fact a reflection of a limitation on the scaling from a single biochemical process (i.e. the Farquhar algorithm) to the composite process of photosynthesis which integrates photochemical, diffuse and biochemical processes which all exhibit different responses to temperature. Unlike for the aggregated irradiance-response function for photosynthetic rate, the temperature sensitivities in the Farquhar algorithm of $P_{\mathrm{Gl}}$ and particularly of its underlying processes in this study could thus not be derived with any degree of certainty. Because of the uncertainty in biochemical parameters and in the scaling from a single to a composite photosynthetic process, application of an aggregated response function is preferable in case of in vivo canopy measurements on grass swards. Biochemical processes take part in explaining leaf photosynthetic rate, but the scaling of biochemical processes from leaf to canopy introduces much complexity. Aggregated leaf response functions are more accessible and connect better to the scaling from leaf to canopy photosynthetic rate. 


$$
3
$$




\section{Chapter 3}

\section{Surface $\mathrm{CO}_{2}$ exchange in an intensively managed peat pasture}

Originally published as B.O.M. Dirks, A. Hensen \& J. Goudriaan, 1999. Surface $\mathrm{CO}_{2}$ exchange in an intensively managed peat pasture. Climate Research 13:

115-123. 


\section{SUMMARY}

Aerodynamic gradient measurements of net $\mathrm{CO}_{2}$ exchange $\left(F_{\mathrm{n}}\right)$ and latent heat exchange $(\lambda E)$ were done in an intensively managed peat pasture during two consecutive years at a fetch of approximately $2 \mathrm{~km}$ distance. $F_{\mathrm{n}}$ was separated into an instantaneous respiratory $\mathrm{CO}_{2}$ flux $\left(F_{\mathrm{r}}\right)$ and an instantaneous gross assimilatory $\mathrm{CO}_{2}$ flux $\left(F_{\mathrm{a}}\right)$. Surface conductance $\left(g_{s}\right)$ was calculated on basis of the Penman-Monteith equation. $F_{\mathrm{r}}$ responded to air temperature $(T)$ in several $Q_{10}$ type of relationships, both on a monthly basis and while emerging annually on basis of all monthly responses. $F_{\text {a }}$ responded to shortwave irradiance $(R)$ in a hyperbolic relationship, which was characterised by the radiation use efficiency at zero irradiance $(\varepsilon)$ and the assimilatory $\mathrm{CO}_{2}$ flux at saturating irradiance $\left(F_{\mathrm{a}(\max )}\right)$. Low $T_{\mathrm{a}}$ proved to be an important limiting factor in $F_{\mathrm{a}}$. After accounting for the effect of $T_{\mathrm{a}}$ the monthly responses of $F_{\mathrm{a}}$ to $R_{\mathrm{s}}$ converged, with $\varepsilon$ ranging from 4.2 to $8.5 \mu \mathrm{g} \mathrm{CO} \mathrm{J}^{-1}$ and $F_{\mathrm{a}(\max )}$ ranging from 0.96 to $1.77 \mathrm{mg} \mathrm{CO}_{2} \mathrm{~m}^{-2} \mathrm{~s}^{-1}$. Neither $g_{\mathrm{s}}$ nor aerial vapour pressure deficit $(D)$ appeared to have a discernible effect on $F_{\mathrm{a}}$, which was possibly related to the ambiguous relationship between $g_{\mathrm{s}}$ and $F_{\mathrm{a}}$ and to a limited variation in these particular environmental conditions. $F_{\mathrm{a}(\max )}$ is a composite measure for the system's assimilatory capacity and responded positively to seasonal patterns in $R_{s}$. The reference respiratory $\mathrm{CO}_{2}$ flux at $0{ }^{\circ} \mathrm{C}$ is a composite measure for the system's metabolically active biomass and showed a seasonal dependence on $F_{\mathrm{a}(\max )}$.

\subsection{INTRODUCTION}

General Circulation Models support the view that the atmospheric $\mathrm{CO}_{2}$ concentration is an important climatic factor (Manabe et al. 1991, Sellers et al. 1986). Atmospheric $\mathrm{CO}_{2}$ constitutes the most significant interface between most large pools of the global $\mathrm{C}$ cycle (Sundquist 1993) and has a relatively small time coefficient. Annual oscillations in the atmospheric $\mathrm{CO}_{2}$ concentration - which reach an amplitude of up to $20 \mu \mathrm{mol}$ $\mathrm{mol}^{-1}$ in the Northern Hemisphere - illustrate seasonal shifts in terrestrial biospheric respiratory and assimilatory activity (Fung et al. 1983, 1987, Kaduk \& Heimann 1996, Nemry et al. 1996). Long-term trends in these oscillations suggest a gradually increasing amplitude and a progressively earlier draw-down of the atmospheric $\mathrm{CO}_{2}$ concentration in spring (Bacastow et al. 1985, Cleveland et al. 1983). These changes reflect the interaction between a changing atmospheric $\mathrm{CO}_{2}$ concentration, climate and biospheric activity (Keeling et al. 1996, Kohlmaier et al. 1989).

On the balance sheet of global C flows, a net biospheric $\mathrm{CO}_{2}$ uptake (Goudriaan 1994, Hudson et al. 1994, King et al. 1995, Tans et al. 1990) is thought to mitigate anthropogenic $\mathrm{CO}_{2}$ emissions (Houghton et al. 1996, Sundquist 1993). However, global 
sinks and sources of $\mathrm{CO}_{2}$ show large differences in their spatial and temporal arrangement (Box 1988). Measurements of atmospheric-biospheric $\mathrm{CO}_{2}$ exchange have been done in many ecosystems (Anderson et al. 1984, Anderson \& Verma 1986, Baldocchi 1994, Baldocchi et al. 1981, Dunin et al. 1989, McGinn \& King 1990, Verma \& Rosenberg 1976). For a long period of time few of these measurements extended beyond the growing season, as the measurements were often done in a crop physiological context rather than for the characterisation of the role of the biosphere in the $\mathrm{C}$ cycle. From $\mathrm{CO}_{2}$ exchange measurements in an undisturbed Amazonian rainforest and subsequent analysis in relation to environmental factors Fan et al. (1990) and Grace et al. (1995) calculated an annual net C uptake, although Fan et al. (1990) were to point out that much of this net uptake would be lost through the emission of volatile carbohydrates.

This study reports on micrometeorological $\mathrm{CO}_{2}$ flux measurements in intensively managed peat pasture done during two consecutive years. Firstly, the analysis separates the instantaneous flux in respiratory and assimilatory $\mathrm{CO}_{2}$ flux components. Secondly, the analysis investigates the relationships between on the one hand the $\mathrm{CO}_{2}$ flux components and on the other hand irradiance, temperature and vapour pressure deficit, and assesses their seasonal course.

\subsection{MATERIALS AND METHODS}

\subsubsection{Experimental site}

Measurements were done at the experimental site of the Royal Netherlands Meteorological Institute (KNMI) near Cabauw in the Netherlands ( $\left.51^{\circ} 58^{\prime} \mathrm{N}, 4^{\circ} 55^{\prime} \mathrm{E}\right)$. The site was surrounded by pasture, orchards, minor roads and some built-up area. The pastures predominantly consisted of Lolium perenne and were used for productive dairy farming at 2.5 heads of cattle per ha, with mixed grazing and mowing.

The soil consisted of a 0.6-0.8 m thick layer of alluvial clay on top of a massive peat layer. The land was composed of long strips of pastureland alternated by waterways at every $50 \mathrm{~m}$, which covered approximately $5 \%$ of the total surface. The vertical distance between land and waterway surface amounted to approximately $0.8 \mathrm{~m}$. This does not translate into an actual drainage depth of $0.8 \mathrm{~m}$, as the lateral conductivity to water in these grasslands is very low. Active water management in drained peat grasslands is not uniform in time but runs counter to the naturally occurring course of groundwater levels. The winter period sees above-average drainage, as this time of the year is characterised by high precipitation, low evapotranspiration and naturally high groundwater levels. This drainage results in relatively low groundwater levels and higher soil temperatures in early spring, allowing for an earlier start of plant growth. More polder reservoir water is let in 
during the summer period, because of lower precipitation, high evapotranspiration and naturally low groundwater levels. The resulting higher groundwater levels reduce both drought and the exposure of the peat layer to aerobic conditions.

Although flux measurements were made at all wind directions, only measurements at incident wind angles $195-250^{\circ}$ (westerly to south-westerly winds) were analysed. In this range the footprint exclusively consisted of pasture over a distance of approximately 2 $\mathrm{km}$. It was thus possible to unequivocally attribute the measured fluxes to the grassland vegetation, which is of particular significance when analysing the grassland's $\mathrm{C}$ flow processes.

\subsubsection{Flux measurements}

Aerodynamic gradient measurements of latent heat $(\lambda E)$ - required to calculate the surface conductivity - and $\mathrm{CO}_{2}$ (Hensen et al. 1997) covered most of the periods from March 1993 up to February 1994 (from here on '1993') and from March 1994 up to February 1995 (from here on '1994'). The Netherlands Energy Research Foundation $(\mathrm{ECN})$ measured the $\mathrm{CO}_{2}$ concentration profiles, whereas KNMI measured the profiles of the other variables. Data processing was done by ECN.

Temperature measurements were obtained at 0.6, 2 and $5 \mathrm{~m}$ height. Thermocouples measured the direct differences between the successive levels at an accuracy of 0.05 ${ }^{\circ} \mathrm{C}$; at $0 \mathrm{~m}$ they were measured against a $0{ }^{\circ} \mathrm{C}$ ice bath. Wind speed and direction were determined at $10 \mathrm{~m}$ height using a Gill propeller vane $8002 \mathrm{dx}$ modified by KNMI at an accuracy of $1 \%$. Air humidity followed from temperature and wet bulb temperature; the set-up of latter measurement was similar to that of temperature, but the sensor was kept wet using peristaltic pumps.

Air sampling for determination of the $\mathrm{CO}_{2}$ concentration gradient was done at 1 , 2 and $10 \mathrm{~m}$ height (Hensen et al. 1997). The air was transported through $50 \mathrm{~m}$ of polyethylene tubing, heated to $5{ }^{\circ} \mathrm{C}$ above ambient to avoid condensation of water vapour. $\mathrm{CO}_{2}$ concentrations were measured using a NDIR (Siemens Ultramat 5e) with a $\mathrm{N}_{2}$-filled reference cell. Before entering the measurement cell, the air was led through a humidifier and a Peltier cooling element maintaining dew point at $5{ }^{\circ} \mathrm{C}$. The monitor was calibrated daily using $\mathrm{N}_{2}$ as zero gas; the span was calibrated using commercially available $\mathrm{CO}_{2}$ standards, in their turn calibrated against standards of the National Ocean and Atmospheric Administration (NOAA).

The different heights were sampled for 2 minutes: the monitor was flushed for $20 \mathrm{~s}$ and the $\mathrm{CO}_{2}$ concentration was calculated from the measurements during the remaining 100 s. A full $\mathrm{CO}_{2}$ profile was obtained every 8 minutes. The concentration data were clustered 
to 30 minute averages, excluding measurements at drag coefficients $\left(C_{\text {drag }}\right)$ higher than 0.02 and at malfunctioning. High stability situations (with differences of up to $500 \mu \mathrm{mol}$ $\mathrm{mol}^{-1}$ between 1 and $2 \mathrm{~m}$ height) were rejected. Errors in the calculation of the $\mathrm{CO}_{2}$ flux occur when the requirements for the gradient technique are not met. Inhomogeneities in terms of upwind obstacles can cause errors, but their frequency was low. The absence of local $\mathrm{CO}_{2}$ sources avoided horizontal $\mathrm{CO}_{2}$ gradients, which constitute a potential source of error. The effect of $\mathrm{CO}_{2}$ storage below the sampling inlet was generally small, since a profile was measured every 8 minutes and the lower inlet was at $1 \mathrm{~m}$ height. The limited resolution of the monitor $\left(0.5 \mu \mathrm{mol} \mathrm{mol}^{-1}\right)$ would have led to a $25 \%$ uncertainty in the calculated $\mathrm{CO}_{2}$ fluxes if one profile would have been used. The three subsequent 8 minute profiles in a 30 minute average had a standard deviation of about $40 \%$ depending on the meteorological conditions.

From the measured variables, the net $\mathrm{CO}_{2}$ flux $\left(F_{\mathrm{n}}\right)\left(\mathrm{mg} \mathrm{m}^{-2} \mathrm{~s}^{-1}\right)$, the latent heat flux $(\lambda E)$ $\left(\mathrm{W} \mathrm{m}{ }^{-2}\right)$, the wind speed at $10 \mathrm{~m}$ height $\left(u_{10}\right)\left(\mathrm{m} \mathrm{s}^{-1}\right)$, the air temperature at $0.6 \mathrm{~m}$ height $\left(T_{\mathrm{a}}\right)\left({ }^{\circ} \mathrm{C}\right)$ and the vapour pressure deficit at $0.6 \mathrm{~m}$ height $\left(D_{0.6}\right)(\mathrm{kPa})$ were subject of this analysis. The mass and energy fluxes were an implicit average of all conditions met within the fetch of $2 \mathrm{~km}$.

\subsubsection{Meteorological measurements}

Meteorological measurements and data processing were done by KNMI. Shortwave irradiance $(0.3-3 \mu \mathrm{m})$ was measured using a Kipp CM11 pyranometer, ventilated to prevent condensation on the dome. For diffuse irradiance the pyranometer was equipped with a shadow band. Longwave irradiance $(3-50 \mu \mathrm{m})$ was measured using a ventilated Eppley radiometer. Measurement of net radiation $(0.3-50 \mu \mathrm{m})$ was done by a Funk radiometer. The values were reduced to 30 minute averages $\left(\mathrm{W} \mathrm{m}^{-2}\right)$ of shortwave irradiance $(R)$ and outgoing longwave radiation $\left(L_{\text {out }}\right)$.

\subsubsection{Surface conductance}

The grassland's surface conductance is a measure for its stomatal conductance. By regulating the fluxes of $\mathrm{CO}_{2}$ (assimilation) and $\mathrm{H}_{2} \mathrm{O}$ (transpiration) it has a pronounced effect on the system's mass and energy exchange. To analyse its role in the grassland's $\mathrm{CO}_{2}$ exchange, the surface conductance to water vapour was calculated from the PenmanMonteith equation (Monteith \& Unsworth 1990):

$g_{\mathrm{s}}=\lambda E \times \gamma \times g_{\mathrm{a}} /\left(s \times\left(R_{\mathrm{n}}-G\right)+\rho \times c_{\mathrm{p}} \times D_{0.6} \times g_{\mathrm{a}}-\lambda E \times(s+\gamma)\right)$

where $g_{s}$ is the canopy's surface conductance to water vapour $\left(\mathrm{m} \mathrm{s}^{-1}\right), \lambda E$ is the latent heat flux $\left(\mathrm{W} \mathrm{m}^{-2}\right), \gamma$ is the psychrometer constant $\left(66 \mathrm{~Pa} \mathrm{~K}^{-1}\right), g_{\mathrm{a}}$ is the aerodynamic conductance to water vapour $\left(\mathrm{m} \mathrm{s}^{-1}\right), s$ is the change of saturation vapour pressure with 
temperature $\left(\mathrm{Pa} \mathrm{K}^{-1}\right), R_{\mathrm{n}}$ is the net irradiance $\left(\mathrm{W} \mathrm{m}^{-2}\right), G$ is the soil heat flux (assumed to be $\left.0 \mathrm{~W} \mathrm{~m}^{-2}\right), \rho$ is the density of dry air $\left(1246 \mathrm{~g} \mathrm{~m}^{-3}\right), c_{\mathrm{p}}$ is the specific heat capacity of air $\left(1.01 \mathrm{~J} \mathrm{~g}^{-1} \mathrm{~K}^{-1}\right)$ and $D_{0.6}$ is the vapour pressure deficit at $0.6 \mathrm{~m}$ height $(\mathrm{Pa}) . g_{\mathrm{s}}$ integrates both leaf area and leaf physiological characteristics (Kelliher et al. 1995, Mascart et al. 1991, Saugier \& Katerji 1991).

The change of saturation vapour pressure with temperature $(s)$ is a familiar micrometeorological quantity (Monteith \& Unsworth 1990):

$s=\lambda \times M_{\mathrm{w}} /\left(R \times T^{2}\right) \times e_{\mathrm{s}}(T)$

where $\lambda$ is the latent heat of vapourisation $\left(2477 \mathrm{~J} \mathrm{~g}^{-1}\right), M_{\mathrm{w}}$ is the molecular weight of water, $R$ is the molar gas constant $\left(8.314 \mathrm{~J} \mathrm{~mol}^{-1} \mathrm{~K}^{-1}\right), T$ is temperature $(\mathrm{K})$ and $e_{\mathrm{s}}(T)$ is the saturation vapour pressure at temperature $T(\mathrm{~Pa})$. The aerodynamic conductance to water vapour $\left(g_{\mathrm{a}}\right)$ was calculated as:

$g_{\mathrm{a}}=\left(u_{0.6} / u_{*}^{2}+5.31 \times u_{*}^{-2 / 3}\right)^{-1}$

where $u_{*}$ is the friction velocity $\left(\mathrm{m} \mathrm{s}^{-1}\right.$ ), which follows from $0.141 \times u_{10}$ (where $u_{10}$ is the measured wind speed at $10 \mathrm{~m}$ height) (Lhomme 1991, Monteith \& Unsworth 1990, Saugier \& Katerji 1991, Thom 1972, 1975, Verma et al. 1986). $u_{0.6}$ is the wind speed at $0.6 \mathrm{~m}$ height and follows from the logarithmic wind profile (Monteith \& Unsworth 1990):

$u_{\mathrm{x}}=\left(u_{*} / k\right) \times \ln \left(\left(z_{\mathrm{x}}-d\right) / z_{0}\right)$

where $u_{\mathrm{x}}$ is the wind speed at height $\mathrm{x}\left(\mathrm{m} \mathrm{s}^{-1}\right), k$ is the von Karman constant (a dimensionless 0.41$), z_{\mathrm{x}}$ is height $\mathrm{x}(\mathrm{m}), d$ is the zero plane displacement (assumed 0.05 $\mathrm{m}$ ) and $z_{0}$ is the roughness length (assumed $0.03 \mathrm{~m}$ ).

Measurements made under conditions with wet surfaces were excluded by only considering values where both latent heat flux $(\lambda E)$ and equilibrium latent heat flux $\left(\lambda E_{\text {eq }}\right)$ were higher than $0 \mathrm{~W} \mathrm{~m} \mathrm{~m}^{-2}$. The equilibrium latent heat flux is the latent heat flux under conditions where the aerodynamic conductance $\left(g_{\mathrm{a}}\right)$ approaches 0 and equals (Jones 1992):

$\lambda E_{\mathrm{eq}}=s \times R_{\mathrm{n}} /(s+\gamma)$

Measurements made under conditions with a low degree of coupling between atmosphere and surface (Jarvis \& McNaughton 1986) were excluded by only considering values where the decoupling coefficient $(\Omega)$ was less than 0.70 : 
$\left.\Omega=(s / \gamma+1) \times\left(s / \gamma+1+g_{\mathrm{a}} / g_{\mathrm{s}}\right)^{-1}\right)$

\subsection{5. $\mathrm{CO}_{2}$ flux}

To analyse the system's $\mathrm{CO}_{2}$ flux processes, the measured net $\mathrm{CO}_{2}$ flux $\left(F_{\mathrm{n}}\right)$ was separated into a respiratory $\mathrm{CO}_{2}$ flux $(F)$ and a gross assimilatory $\mathrm{CO}_{2}$ flux $\left(F_{\mathrm{a}}\right)$. To this end a distinction was made between night-time and daytime $\mathrm{CO}_{2}$ fluxes. As assimilatory activity does not or almost not occur in the absence of radiation, the night-time $\mathrm{CO}_{2}$ flux was assumed to exclusively represent an (upward) respiratory $\mathrm{CO}_{2}$ flux. The daytime $\mathrm{CO}_{2}$ flux was assumed to be the sum of a (downward) gross assimilatory $\mathrm{CO}_{2}$ flux and an (upward) respiratory $\mathrm{CO}_{2}$ flux (Ruimy et al. 1995).

The proper establishment of the respiratory $\mathrm{CO}_{2}$ flux throughout the night-time and daytime period thus is the basis for this analysis. The gross assimilatory $\mathrm{CO}_{2}$ flux is calculated as the difference between the measured net $\mathrm{CO}_{2}$ flux $\left(F_{\mathrm{n}}\right)$ and the calculated respiratory $\mathrm{CO}_{2}$ flux $(F)$. While characterising the respiratory $\mathrm{CO}_{2}$ flux, night-time $\mathrm{CO}_{2}$ flux values within 30 minutes from sunset and before sunrise were excluded from analysis to avoid anomalous effects due to twilight. The instantaneous respiratory $\left(F_{\mathrm{r}}\right)$ and gross assimilatory $\mathrm{CO}_{2}$ fluxes $\left(F_{\mathrm{a}}\right)$ were derived from the daytime and night-time fluxes and used for analysis. Linear regression was done by the least squares technique, whereas non-linear regression analysis was done using the Marquardt-Levenberg algorithm (Fox et al. 1994).

\subsubsection{Respiratory $\mathrm{CO}_{2}$ flux}

The positive response of biological activity to temperature is well established. Lloyd and Taylor (1994) developed a semi-empirical relationship that effectively accounts for a decrease in activation energy at increasing temperature:

$F_{\mathrm{r}}=F_{\mathrm{r}(0)} \times \mathrm{e}^{a 1 \times T a /((T \mathrm{a}+273-a 2) *(273-a 2))}$

where $F_{\mathrm{r}(0)}$ is the reference respiratory $\mathrm{CO}_{2}$ flux at $0{ }^{\circ} \mathrm{C}\left(\mathrm{mg} \mathrm{CO}_{2} \mathrm{~m}^{-2} \mathrm{~s}^{-1}\right), T_{\mathrm{a}}$ is the air temperature $\left({ }^{\circ} \mathrm{C}\right)$, and $a_{1}$ and $a_{2}$ are parameters that characterise the temperature response.

The monthly responses of the system's composite respiratory $\mathrm{CO}_{2}$ flux $\left(F_{\mathrm{r}}\right)$ to air temperature were calculated by fitting Equation 3.7 to the populations of night-time $\mathrm{CO}_{2}$ fluxes and air temperatures at $0.6 \mathrm{~m}$ height $\left(T_{0.6}\right)$. As the reference respiratory $\mathrm{CO}_{2}$ flux includes the effect of biomass, $F_{\mathrm{r}(0)}$ was left to vary but response parameters $a_{1}$ and $a_{2}$ were taken to be constant (Lloyd \& Taylor 1994). It was assumed that the validity of the fitted responses is maintained during the day, i.e. that the daytime respiratory $\mathrm{CO}_{2}$ flux can be calculated from the daytime temperature and the fitted response of the nighttime $\mathrm{CO}_{2}$ flux to temperature. 


\subsubsection{Assimilatory $\mathrm{CO}_{2}$ flux}

The response of the night-time $\mathrm{CO}_{2}$ flux to temperature in Equation 3.7 is generalised to represent the response of the respiratory $\mathrm{CO}_{2}$ flux to temperature. The grassland system's gross assimilatory $\mathrm{CO}_{2}$ flux $\left(F_{\mathrm{a}}\right)$ can now be calculated as the difference between the measured daytime net $\mathrm{CO}_{2}$ flux $\left(F_{\mathrm{n}}\right)$ and the calculated daytime respiratory $\mathrm{CO}_{2}$ flux $\left(F_{\mathrm{r}}\right)$. As the assimilatory activity primarily depends on radiation, the monthly populations of the calculated gross assimilatory $\mathrm{CO}_{2}$ flux $\left(F_{\mathrm{a}}\right)$ were fitted to shortwave irradiance $\left(R_{\mathrm{s}}\right)$ while applying a conventional rectangular hyperbola:

$F_{\mathrm{a}}=-\varepsilon \times F_{\mathrm{a}(\max )} \times R_{\mathrm{s}} /\left(\varepsilon \times R_{\mathrm{s}}+F_{\mathrm{a}(\max )}\right)$

where $F_{a(\max )}$ is the asymptotic value of the gross assimilatory $\mathrm{CO}_{2}$ flux at saturating irradiance $\left(\mathrm{mg} \mathrm{m}^{-2} \mathrm{~s}^{-1}\right)$ and $\varepsilon$ is the initial radiation use efficiency at zero irradiance $\left(\mu \mathrm{g} \mathrm{J} \mathrm{J}^{-1}\right)$.

The primary effect of radiation on gross $\mathrm{CO}_{2}$ assimilation is known to be mediated by several other both environmental and physiological quantities. These effects were assessed by including multipliers to the asymptotic gross assimilatory $\mathrm{CO}_{2}$ flux $\left(F_{\mathrm{a}(\max )}\right)$ while fitting Equation 3.8. Low temperature $\left(T_{\mathrm{a}}\right)$ early in the growing season may limit assimilatory activity. It is accounted for by imposing a linear increase on $F_{\mathrm{a}(\max )}$ between temperatures $T_{0}$ and $T_{1}$ as illustrated in Figure 3.1A. Also vapour pressure deficit $(D)$ is known to have a substantial effect on $\mathrm{CO}_{2}$ assimilation (e.g. Leuning 1995), either as a measure for limiting soil water conditions or through a direct effect on stomatal conductance. An indirect or direct effect of $D$ was evaluated by imposing a linear decrease on $F_{\mathrm{a}(\max )}$ beyond a vapour pressure deficit inflection point $\left(D_{\mathrm{i}}\right)$ with a limiting effect per unit of vapour pressure deficit $\left(b_{\mathrm{D}}\right)$ as shown in Figure 3.1B. Surface conductance $\left(g_{\mathrm{s}}\right)$ itself may limit assimilatory activity. An effect of surface conductance was assessed by imposing a linear decrease on $F_{\mathrm{a}(\max )}$ below a surface conductance inflection point $\left(g_{\mathrm{s}(\mathrm{i})}\right)$ with a limiting effect per unit of surface conductance $\left(b_{\mathrm{g}}\right)$ as illustrated in Figure 3.1C.

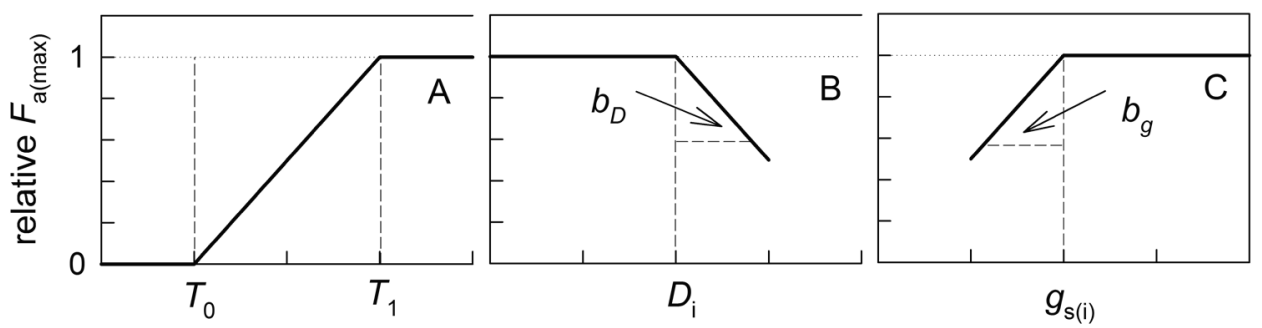

Figure 3.1. Asymptotic value of the assimilatory $\mathrm{CO}_{2} f l u x\left(F_{a, m x}\right)$ : effect of (a) temperature $\left(T_{\mathrm{a}}\right) ;(\mathrm{b})$ vapour pressure deficit $(D)$; and $(c)$ surface conductance $\left(g_{s}\right)$. 


\subsubsection{Additional $\mathrm{CO}_{2}$ sources}

Occasional traffic occurred on a road at a distance of 750-1500 m. In the distance to the mast, its $\mathrm{CO}_{2}$ emission appears in a homogeneously mixed increase of the upward $\mathrm{CO}_{2}$ flux. It was evaluated that the fitted relationships between shortwave irradiance and assimilatory $\mathrm{CO}_{2}$ flux did not differ for different incident wind angles.

To assess $\mathrm{CO}_{2}$ sources and $\mathrm{C}$ flows other than those related to the vegetation, a survey was made in April 1993 of the 5 dairy farms which held most of the land at incident wind angles $195-250^{\circ}$. The survey found a stocking density of 1.7 cows ha ${ }^{-1}$ and 0.9 young animals ha-1 . With respiratory $\mathrm{CO}_{2}$ emissions by cattle set at $3.9 \mathrm{~kg} \mathrm{C} \mathrm{d}^{-1}$ for a cow and $2.4 \mathrm{~kg} \mathrm{C} \mathrm{d}^{-1}$ for a young animal (Langeveld et al. 1997), this resulted in an average $\mathrm{CO}_{2}$ emission of $0.038 \mathrm{mg} \mathrm{CO}_{2} \mathrm{~m}^{-2} \mathrm{~s}^{-1}$. Due to a clustered appearance of cattle, their actual emissions may have been higher and discontinuous in time. The cattle produced approximately 180 ton $\mathrm{C}^{-1}$ in manure (Langeveld et al. 1997). At a humification coefficient of 0.58 (Kolenbrander 1974), this results in an average $\mathrm{CO}_{2}$ emission from manure of $0.006 \mathrm{mg} \mathrm{CO}_{2} \mathrm{~m}^{-2} \mathrm{~s}^{-1}$, which is negligible as compared to the entire respiratory $\mathrm{CO}_{2}$ flux $(F)$. At the scale of these flux measurements there is little conceptual difference between manure and soil organic matter.

\subsection{RESULTS}

\subsubsection{Respiratory $\mathrm{CO}_{2}$ flux}

Equation 3.7 represents a positive response of the grassland ecosystem's composite respiratory activity to temperature at a gradually decreasing activation energy. This equation was fitted to two years of instantaneous night-time $\mathrm{CO}_{2}$ flux $\left(F_{\mathrm{n}}\right)$ and air temperature $\left(T_{\mathrm{a}}\right)$ values measured at incident wind angles $195-250^{\circ}$. Both response parameters $a_{1}$ and $a_{2}$ were held constant, but the reference respiratory $\mathrm{CO}_{2}$ flux at $0{ }^{\circ} \mathrm{C}$ $\left(F_{\mathrm{r}(0)}\right)$ was allowed to vary on a monthly basis. This resulted in fitted values of 765 and $180 \mathrm{~K}$ for $a_{1}$ and $a_{2}$, respectively $\left(r^{2}=0.62, n=2345\right)$. The reference respiratory $\mathrm{CO}_{2}$ flux can be interpreted as a measure for biomass and soil microbial activity - with soil organic matter as substrate - per unit of surface area as it excludes the effect of temperature. Table 3.1 lists the fitted monthly $F_{\mathrm{r}(0)}$ values and Figure 3.2A plots its annual course. It shows that the reference respiratory $\mathrm{CO}_{2}$ flux was generally higher in 1993 than in 1994 at averages of 0.103 and $0.083 \mathrm{mg} \mathrm{CO}_{2} \mathrm{~m}^{-2} \mathrm{~s}^{-1}$, respectively. Its seasonal pattern was similar for both years, with $F_{\mathrm{r}(0)}$ being highest in spring and summer at approximately 0.10-0.13 $\mathrm{mg} \mathrm{CO} \mathrm{m}^{-2} \mathrm{~s}^{-1}$, and sharply dropping from late summer to late autumn to approximately 0.05-0.06 $\mathrm{mg} \mathrm{CO}_{2} \mathrm{~m}^{-2} \mathrm{~s}^{-1}$. 


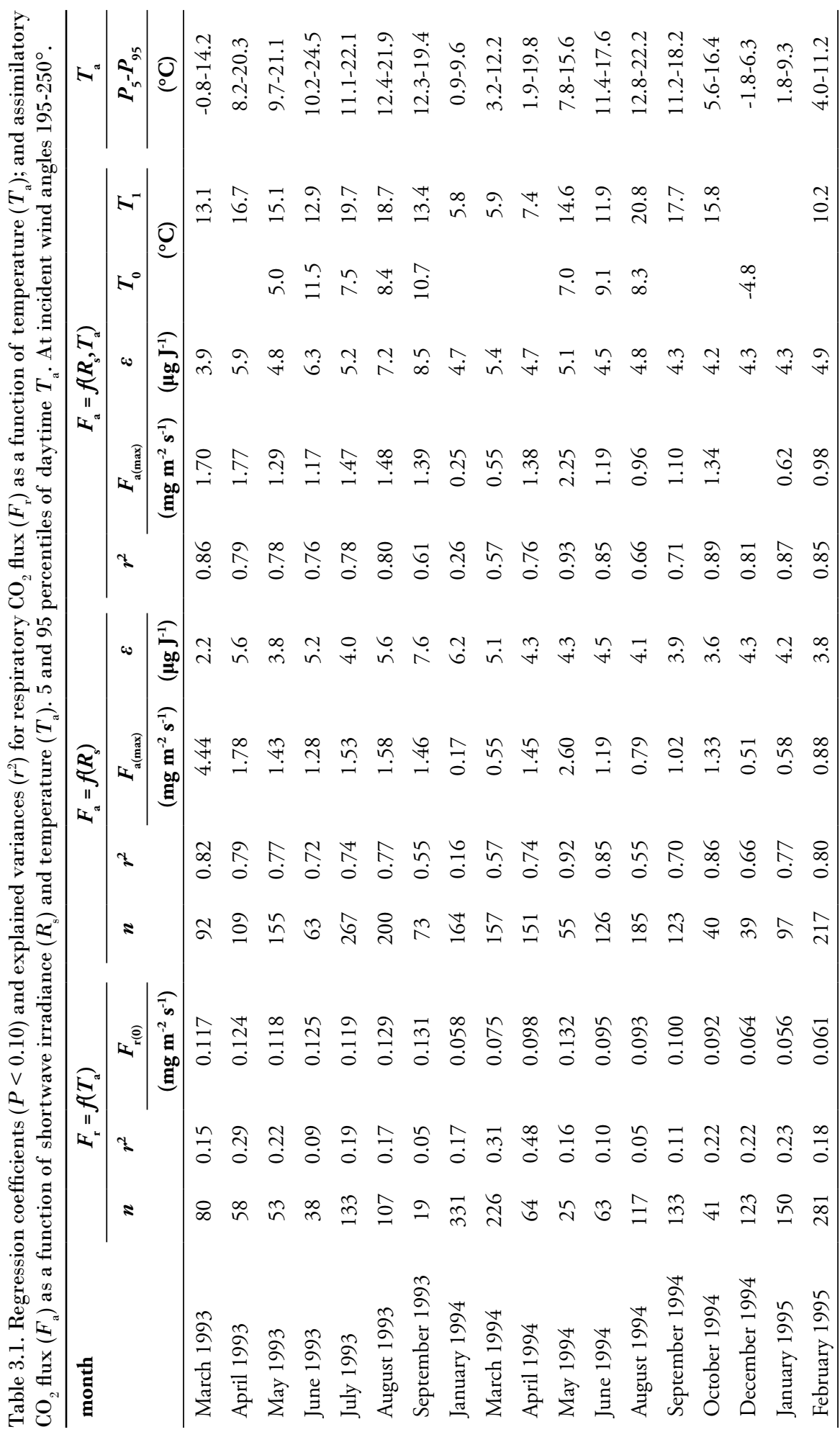



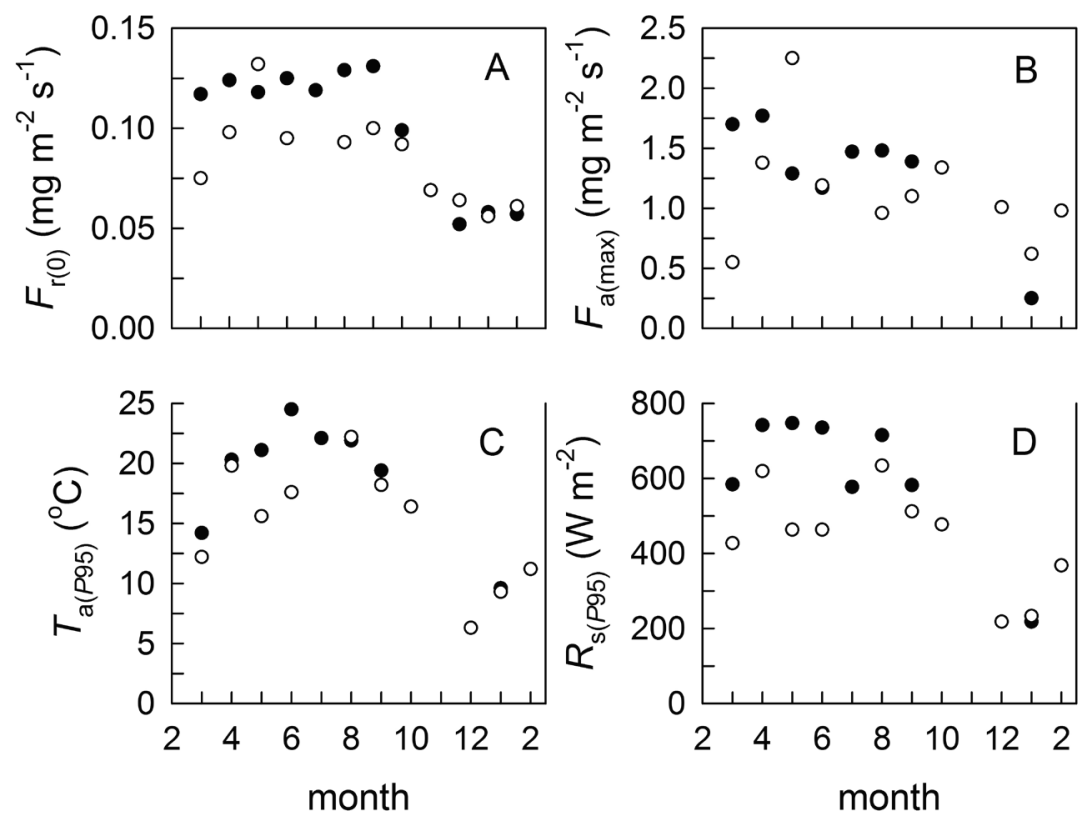

Figure 3.2. Annual pattern of monthly fitted: (a) reference respiratory $\mathrm{CO}_{2}$ flux $\left(F_{\mathrm{r}(0)}\right) ;(\mathrm{b})$ asymptotic value of the assimilatory $\mathrm{CO}_{2}$ flux $\left(F_{\mathrm{a}, \mathrm{mx}}\right.$ at optimum $\left.T_{\mathrm{a}}\right)$; (c) 95 percentile of temperature $\left(T_{\mathrm{a}}\right)$; and (d) 95 percentile of short-wave irradiance $\left(R_{)}\right)$; in 93 (closed circles) and 94 (open circles).

Table 3.1 and Figure 3.3 show the fitted monthly responses of the night-time $\mathrm{CO}_{2}$ flux $\left(F_{\mathrm{n}}\right)$ to air temperature $\left(T_{\mathrm{a}}\right)$. Explained variance $\left(r^{2}\right)$ was limited, which the graph demonstrates for May 1994. The response curves include the annual course of $F_{\mathrm{r}(0)}$. They also illustrate that the response of the night-time $\mathrm{CO}_{2}$ flux to temperature became stronger as temperature increased, which is reflected in an increasingly steeper slope of the curve. Whereas the progressively stronger responses to temperature are enforced by fitted Equation 3.7, the annual pattern of progressively steeper curves as temperature increases emerges from the fitted responses themselves.

\subsubsection{Assimilatory $\mathrm{CO}_{2}$ flux}

The instantaneous gross assimilatory $\mathrm{CO}_{2}$ flux $\left(F_{2}\right)$ was calculated as the difference between the measured daytime net $\mathrm{CO}_{2}$ flux $\left(F_{\mathrm{n}}\right)$ and the calculated respiratory $\mathrm{CO}_{2}$ flux $\left(F_{\mathrm{r}}\right)$. The instantaneous respiratory $\mathrm{CO}_{2}$ flux in its turn was calculated from the fitted monthly response of the night-time $\mathrm{CO}_{2}$ flux to temperature and the current air temperature $(T)$. The response of $F_{\mathrm{a}}$ to irradiance is characterised by its asymptotic value $\left(F_{\mathrm{a}(\max )}\right)$ and the initial slope $\varepsilon$ at zero irradiance. Equation 3.8 was fitted to both years of instantaneous gross assimilatory $\mathrm{CO}_{2}$ flux $\left(F_{\mathrm{a}}\right)$ and shortwave irradiance $\left(R_{\mathrm{s}}\right)$ at incident wind angles $195-250^{\circ}$, which is shown in Figure 3.4. The fitted annual asymptotic gross assimilatory $\mathrm{CO}_{2}$ flux $\left(F_{\mathrm{a}(\max }\right)$ was higher in 1993 than in 1994 and amounted to 1.68 and $0.99 \mathrm{mg} \mathrm{CO}_{2} \mathrm{~m}^{-2} \mathrm{~s}^{-1}$, respectively. However, neither annual response seemed to 

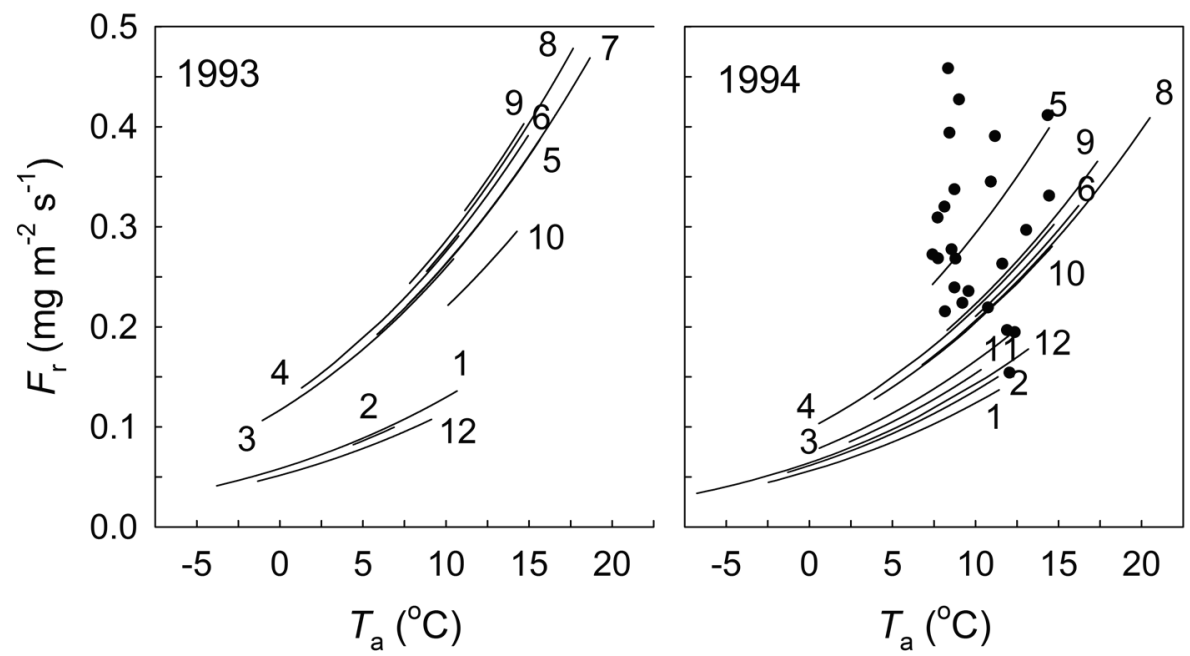

Figure 3.3. Monthly fitted relationships between air temperature $\left(T_{\mathrm{a}}\right)$ and respiratory $\mathrm{CO}_{2}$ flux $\left(F_{\mathrm{r}}\right)$; at $195-250^{\circ}$. Actual observations: May 94 .

exhibit actual light-saturation. The fitted annual initial radiation use efficiency at zero irradiance $\varepsilon$ was lower in 1993 than in 1994 and was calculated as 3.4 and $3.9 \mu \mathrm{g} \mathrm{CO}_{2}$ $\mathrm{J}^{-1}$, respectively.

Table 3.1 lists the fitted monthly asymptotic gross assimilatory $\mathrm{CO}_{2}$ fluxes $\left(F_{\mathrm{a}(\max )}\right)$. It shows that $F_{\text {a(max })}$ ranged substantially, from 0.51 to $4.44 \mathrm{mg} \mathrm{CO}_{2} \mathrm{~m}^{-2} \mathrm{~s}^{-1}$. The difference between 1993 and 1994 as a whole is reflected in their monthly $F_{\text {a(max) }}$ values in the growing season where light-saturation was often approached or even attained. In 1993 they ranged from 1.28 to $1.78 \mathrm{mg} \mathrm{CO}_{2} \mathrm{~m}^{-2} \mathrm{~s}^{-1}$, whereas in 1994 they ranged lower from 0.79 to $1.45 \mathrm{mg} \mathrm{CO}_{2} \mathrm{~m}^{-2} \mathrm{~s}^{-1}$ (with a notable outlier at $2.60 \mathrm{mg} \mathrm{CO}_{2} \mathrm{~m}^{-2} \mathrm{~s}^{-1}$ ).

Table 3.1 also shows that the fitted monthly initial radiation use efficiencies $\varepsilon$ ranged from 2.2 to $7.6 \mu \mathrm{g} \mathrm{CO}_{2} \mathrm{~J}^{-1}$. Unlike the annual initial radiation use efficiency $\varepsilon$, which was higher in 1994 than in 1993, its monthly values proved to be generally higher in 1993 than in 1994. In the growing season of 1993 it ranged from 3.8 to $7.6 \mu \mathrm{g} \mathrm{CO}$ $\mathrm{J}^{-1}$ and in the growing season of 1994 from 3.9 to $4.3 \mu \mathrm{g} \mathrm{CO}_{2} \mathrm{~J}^{-1}$. Figure 3.5 shows the fitted monthly responses of the gross assimilatory $\mathrm{CO}_{2}$ flux $\left(F_{\mathrm{a}}\right)$ to shortwave irradiance $(R)$. For May 1994 (the month with the highest $F_{\mathrm{a}(\max )}$ value) it is demonstrated how the fitted curve relates to the actual values of $F_{\mathrm{a}}$. Figure 3.5 clearly shows that the asymptotic assimilatory $\mathrm{CO}_{2}$ flux $\left(F_{\mathrm{a}(\text { max })}\right)$ was generally higher in 1993 than in 1994 and it can also be seen that the initial slopes of the response curves were mostly steeper in 1993 than in 1994. It also shows that levels of irradiance were generally higher in 1993 than in 1994. 

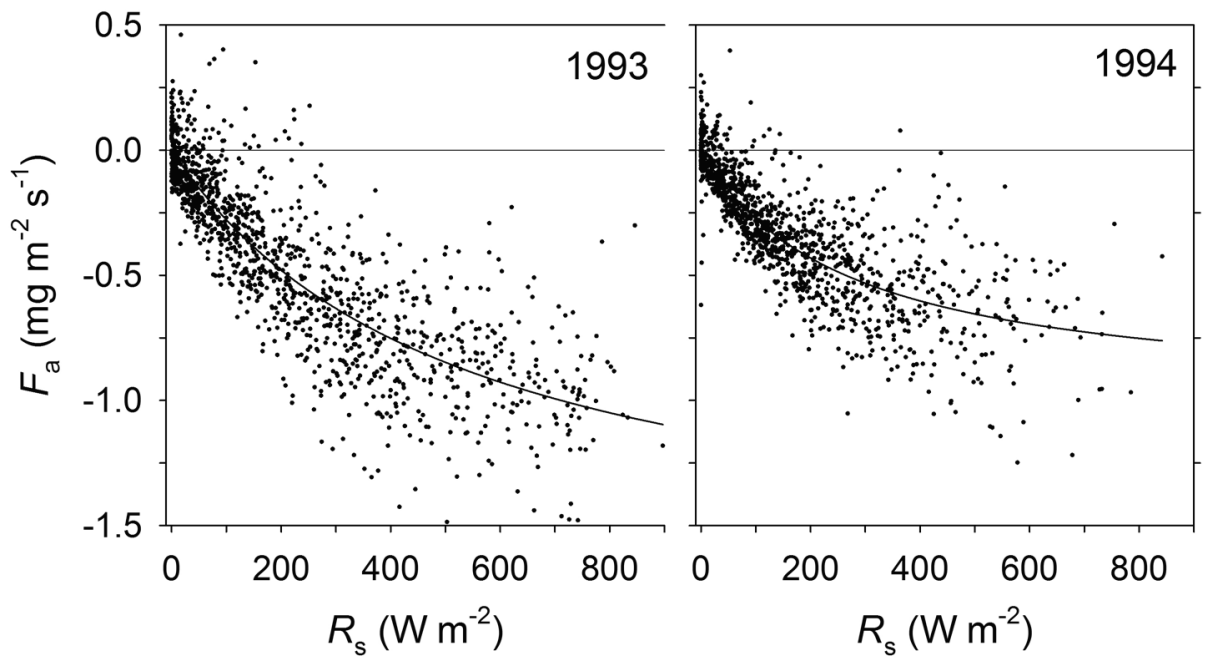

Figure 3.4. Assimilatory $\mathrm{CO}_{2}$ flux $\left(F_{\mathrm{a}}\right)$ as a function of short-wave irradiance $\left(R_{\mathrm{s}}\right)$ and fitted hyperbolic relationships in 93 and 94 ; at $195-250^{\circ}$.
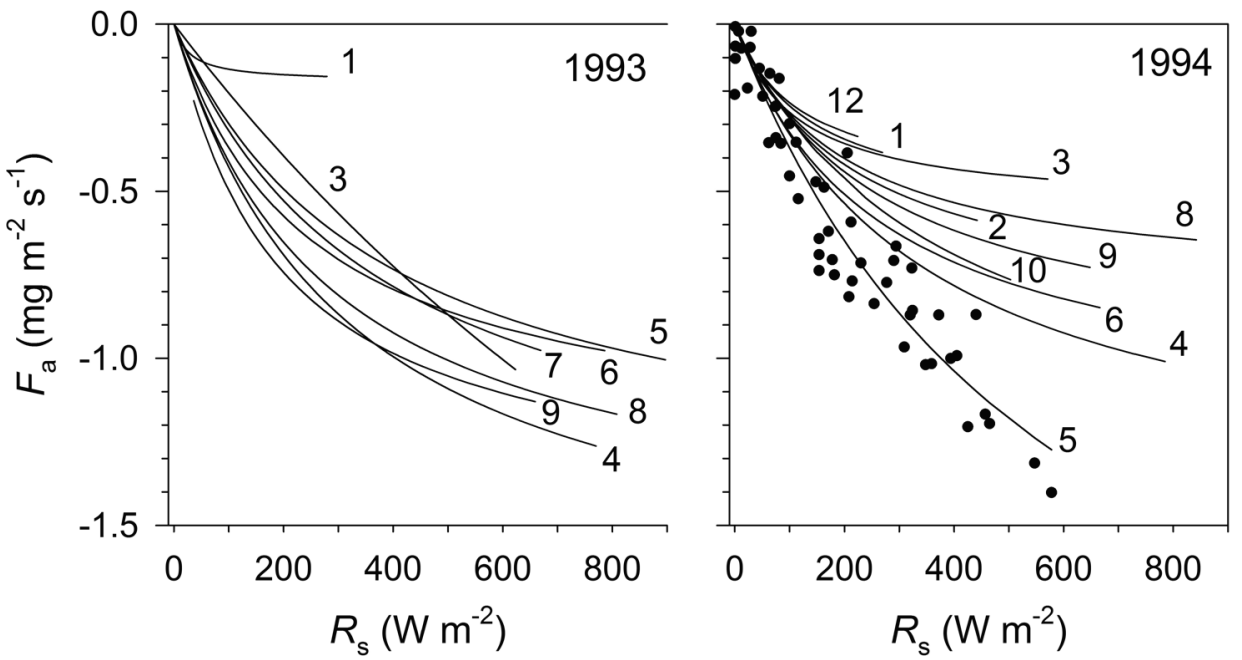

Figure 3.5. Monthly fitted relationships between short-wave irradiance $\left(R_{\mathrm{s}}\right)$ and assimilatory $\mathrm{CO}_{2}$ flux $\left(F_{\mathrm{a}}\right)$; at $195-250^{\circ}$. Actual observations: May 94 .

Table 3.1 and Figures 3.4 and 3.5 illustrate that 1993 was more abundant in terms of biomass and productivity than 1994 . The gross assimilatory $\mathrm{CO}_{2}$ flux $\left(F_{\mathrm{a}}\right)$ was higher, as determined by both the initial radiation use efficiency $(\varepsilon)$ and the asymptotic assimilatory $\mathrm{CO}_{2}$ flux $\left(F_{a(\max )}\right)$. This coincided with generally higher levels of irradiance.

Figure 3.5 also illustrates how the course of $F_{\mathrm{a}}$ and $F_{\mathrm{a}(\max )}$ varies from month to month seemingly without a discernible pattern. In an attempt to assess the role of suboptimal air 
temperature $\left(T_{\mathrm{a}}\right)$ in the course of $F_{\mathrm{a}}$, the effect of $T_{\mathrm{a}}$ was included as a linear multiplier to the asymptotic assimilatory $\mathrm{CO}_{2}$ flux $\left(F_{\text {a(max) }}\right)$ in Equation 3.8 as displayed in Figure 3.1A. Although the proposed model of a linear increase in relative $F_{\mathrm{a}(\max )}$ from 0 to 1 between air temperatures $T_{0}$ and $T_{1}$ cannot do justice to the complexity of the role of temperature in $\mathrm{CO}_{2}$ assimilation, it allows the relationship between irradiance and assimilatory $\mathrm{CO}_{2}$ flux to respond to temperature. Table 3.1 shows the result of the inclusion of this straightforward multiplication. It generally modifies the shape of the hyperbola by increasing the fitted initial slope and decreasing the asymptotic value in the growing season and slightly increasing the asymptotic value during the remainder of the year. The initial radiation use efficiency $(\varepsilon)$ in the growing season now ranged from 4.8 to $8.5 \mu \mathrm{g} \mathrm{J}^{-1}$ in 1993 and from 4.2 to $5.1 \mu \mathrm{g} \mathrm{J}^{-1}$ in 1994 . The asymptotic assimilatory $\mathrm{CO}_{2} \mathrm{flux}\left(F_{\mathrm{a}(\max )}\right)$ in the growing season now ranged from 1.17 to $1.77 \mathrm{mg} \mathrm{CO}_{2} \mathrm{~m}^{-2} \mathrm{~s}^{-1}$ in 1993 and from 0.96 to $1.38 \mathrm{mg}$ $\mathrm{CO}_{2} \mathrm{~m}^{-2} \mathrm{~s}^{-1}$ in 1994 (with one outlier at $2.25 \mathrm{mg} \mathrm{CO}_{2} \mathrm{~m}^{-2} \mathrm{~s}^{-1}$ ).

Figure 3.6A goes into more detail and illustrates the effect of temperature $\left(T_{\mathrm{a}}\right)$ on assimilatory $\mathrm{CO}_{2}$ flux $(F)$ for the case of March 1993. In Figure 3.5 the response of $F_{\mathrm{a}}$ to shortwave irradiance $(R)$ for March 1993 stands out as it appears to be almost linear at the lowest of initial radiation use efficiencies $(\varepsilon)$ and consequentially highest of asymptotic assimilatory $\mathrm{CO}_{2}$ fluxes $\left(F_{\mathrm{a}(\max )}\right)$. In the response of assimilatory $\mathrm{CO}_{2}$ flux $\left(F_{\mathrm{a}}\right)$ to shortwave irradiance $\left(R_{\mathrm{s}}\right)$ Figure 3.6A distinguishes between $F_{\mathrm{a}}$ values determined at $T_{\mathrm{a}}$ lower than $7.5^{\circ} \mathrm{C}$ and $F_{\mathrm{a}}$ values determined at $T_{\mathrm{a}}$ higher than $7.5^{\circ} \mathrm{C}$. It shows that most $F_{\mathrm{a}}$ values which represent a limited response to $R_{\mathrm{s}}$ were determined at $T_{\mathrm{a}}$ values lower than $7.5^{\circ} \mathrm{C}$, i.e. $\mathrm{CO}_{2}$ assimilation at clearly suboptimal temperatures. The particular data set results in a hyperbola which appears to be practically linear for the data range available. By adding air temperature as a quantity to Equation 3.8 the hyperbola now turns to a
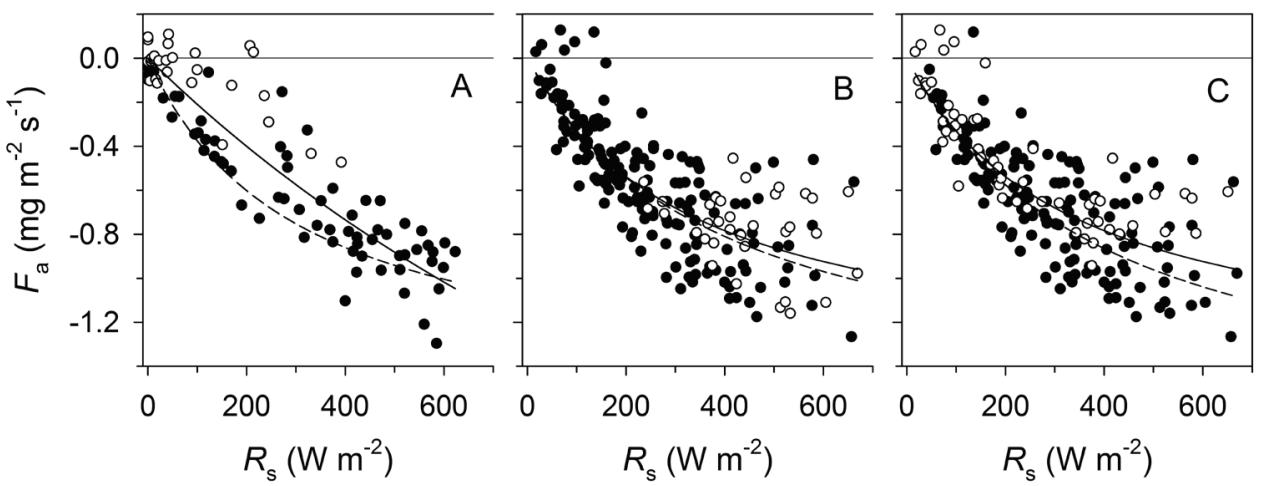

Figure 3.6. Assimilatory $\mathrm{CO}_{2}$ flux $\left(F_{\mathrm{a}}\right)$ as a function of short-wave irradiance $\left(R_{\mathrm{s}}\right)$ : (a) March 93: $T_{\mathrm{a}}$ $>7.5$ (closed circles) and $<7.5^{\circ} \mathrm{C}$ (open circles); (b) July 93: $D<0.75$ (closed circles) and $>0.75 \mathrm{kPa}$ (open circles); (c) July 93: $g_{s}>0.75$ (closed circles) and $<0.75 \mathrm{~cm} \mathrm{~s}^{-1}$ (open circles). Curves: average (drawn line) and non-limiting $T_{\mathrm{a}}, D$ and $g_{\mathrm{s}}$ (dashed line). 

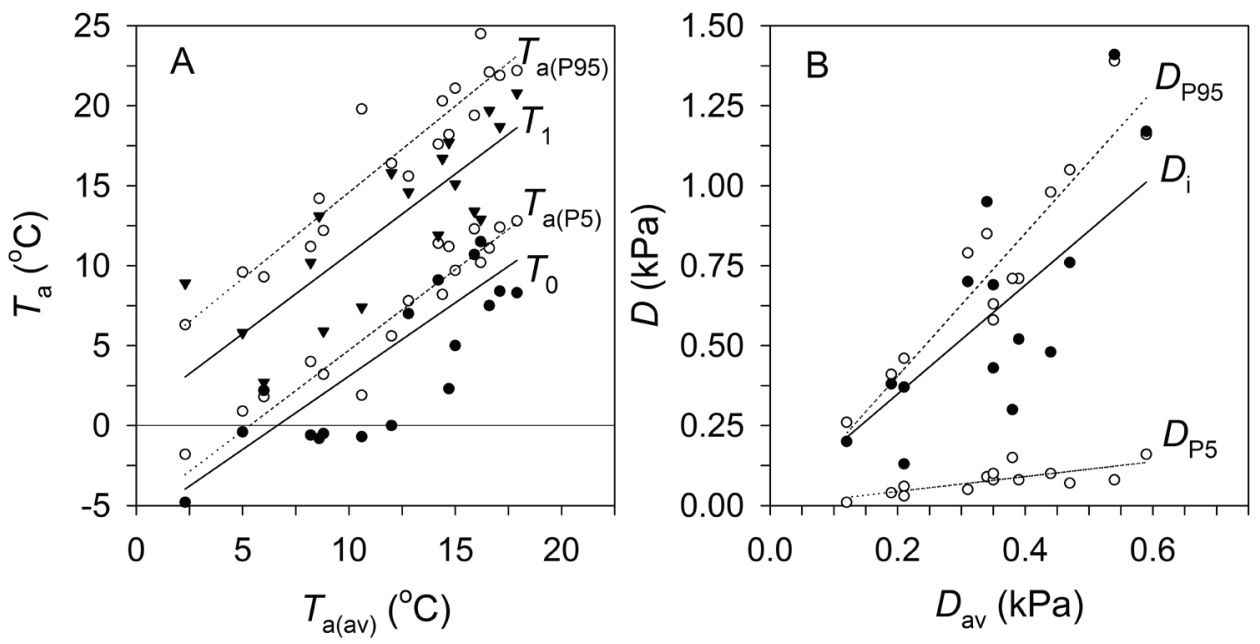

Figure 3.7. (a) monthly 5 and 95 percentiles of daytime $T_{\mathrm{a}}$ (open circles and dashed line) as a function of average $T_{\mathrm{a}}$ : monthly $T_{0}$ (closed circles) and $T_{1}$ (open circles); (b) monthly 5 and 95 percentiles of daytime $D$ (open circles and dashed line) as a function of average $D$ : monthly $D_{\mathrm{i}}$ (closed circles). Drawn lines at $P<0.10$.

curve which can also be visually recognised as a hyperbola: $\varepsilon$ increases from 2.2 to $3.9 \mu \mathrm{g}$ $\mathrm{CO}_{2} \mathrm{~J}^{-1}$ and $F_{\text {a(max) }}$ decreases from 4.44 to $1.70 \mathrm{mg} \mathrm{CO}_{2} \mathrm{~m}^{-2} \mathrm{~s}^{-1}$. Whereas March 1993 is the most obvious case where low temperatures inhibited $\mathrm{CO}_{2}$ assimilation, it is less clear to what extent this was the case for the remaining responses of $F_{\mathrm{a}}$ to $R_{\mathrm{s}}$ listed in Table 3.1. The typical simultaneous increase in $\varepsilon$ and decrease in $F_{a(\max )}$ could be observed for multiple months, including for several months in summer. Figure 3.7A shows that the fitted boundaries $T_{0}$ and $T_{1}$ for the temperature response range (Figure 3.1A) practically coincided with the lower and upper boundaries of the observed air temperatures, which suggests that a temperature effect was always present. However, this observation can also be related to the correlation between radiation and temperature.

The proposed models for the effect of vapour pressure deficit $(D)$ and surface conductance $\left(g_{s}\right)$ on the asymptotic assimilatory $\mathrm{CO}_{2}$ flux $\left(F_{\mathrm{a}(\max }\right)$ as proposed in Figures $3.1 \mathrm{~B}$ and 3.1C did not fit the data. Inclusion of the effects of $D$ and of $g_{\mathrm{s}}$ as a linear multiplier to $F_{\text {a(max) }}$ in Equation 3.8 slightly modified only some of the hyperbolic relationships between shortwave irradiance $\left(R_{s}\right)$ and assimilatory $\mathrm{CO}_{2}$ flux $\left(F_{\mathrm{a}}\right)$. Figure 3.6B shows this in more detail for the response of $F_{\mathrm{a}}$ to $R_{\mathrm{s}}$ in July 1993 as mediated by $D$. It distinguishes between $F_{\mathrm{a}}$ values determined at $D$ lower than $750 \mathrm{~Pa}$ and $F_{\mathrm{a}}$ values determined at $D$ higher than $750 \mathrm{~Pa} . F_{\mathrm{a}}$ at $D$ higher than $750 \mathrm{~Pa}$ seems to be hardly lower than $F_{\mathrm{a}}$ at $D$ lower than 750 $\mathrm{Pa}$, which is reflected in an only minor change of the fitted hyperbola towards higher $\varepsilon$ and higher $F_{\text {a(max) }}$. Figure $3.7 \mathrm{~B}$ suggests that the vapour pressure deficit inflection point beyond which $F_{\mathrm{a}(\max )}$ started to be limited $\left(D_{\mathrm{i}}\right)$ generally coincided with the upper reaches of the $D$ range, i.e. that there was little discernible effect of $D$ on $F_{\text {a(max) }}$. 
Figure 3.6C illustrates that the effect of $g_{\mathrm{s}}$ on the response of $F_{\mathrm{a}}$ to $R_{\mathrm{s}}$ was slightly more discernible than the effect of $D$. It distinguishes between $F_{\mathrm{a}}$ values determined at $g_{\mathrm{s}}$ higher than $0.75 \mathrm{~cm} \mathrm{~s}^{-1}$ and $F_{\mathrm{a}}$ values determined at $g_{\mathrm{s}}$ lower than $0.75 \mathrm{~cm} \mathrm{~s}^{-1}$. It clearly shows that $F_{\mathrm{a}}$ values associated with $g_{\mathrm{s}}$ lower than $0.75 \mathrm{~cm} \mathrm{~s}^{-1}$ were suboptimal relative to $F_{\mathrm{a}}$ values associated with $g_{\mathrm{s}}$ higher than $0.75 \mathrm{~cm} \mathrm{~s}^{-1}$. The change of the fitted hyperbolic relationship towards both higher $\varepsilon$ and higher $F_{\text {a(max })}$ was therefore more pronounced after accounting for low $g_{\text {s }}$ than after accounting for high $D$ (Figure 3.6B).

\subsubsection{Diurnal patterns and hysteresis}

Hysteresis in the response of the assimilatory $\mathrm{CO}_{2}$ flux to environmental quantities can shed light on mediating factors in their primary responses. To characterise hysteresis, the daytime net $\mathrm{CO}_{2}$ flux $\left(F_{\mathrm{n}}\right)$, the gross assimilatory $\mathrm{CO}_{2}$ flux $\left(F_{\mathrm{a}}\right)$, the air temperature $\left(T_{\mathrm{a}}\right)$, the aerial $\mathrm{CO}_{2}$ concentration at $1 \mathrm{~m}$ height $\left(C_{\mathrm{a}}\right)$ and the surface conductance $\left(g_{\mathrm{s}}\right)$ were clustered to monthly average diurnal patterns. Figure 3.8 compares the responses to shortwave irradiance $(R)$ (the $\mathrm{CO}_{2}$ assimilation's main driving variable) before noon and after noon. The comparison was done for August 1993 and August 1994, the latter being one of the driest months in the experimental period.

For August 1993 little hysteresis was observed. The response of the assimilatory $\mathrm{CO}_{2}$ flux $\left(F_{\mathrm{a}}\right)$ to shortwave irradiance $\left(R_{\mathrm{s}}\right)$ was unequivocal, with surface conductance $\left.g_{\mathrm{s}}\right)$ closely matching $F_{\mathrm{a}} \cdot g_{\mathrm{s}}$ followed rather than limited $F_{\mathrm{a}}$. The net assimilatory activity during the day was reflected in a steady decrease in the aerial $\mathrm{CO}_{2}$ concentration $\left(C_{\mathrm{a}}\right)$ from $390 \mu \mathrm{mol} \mathrm{mol}^{-1}$ at sunrise to a background concentration of $350 \mu \mathrm{mol} \mathrm{mol}^{-1}$ at noon, afterwards gradually increasing again to $360 \mu \mathrm{mol} \mathrm{mol}^{-1}$. August 1994 exhibited a counter-intuitive case of modest hysteresis, as $F_{\mathrm{a}}$ was somewhat higher after noon than before noon, despite lower $g_{s}$. A higher $F_{\mathrm{a}}$ in the afternoon seems to be reflected in afternoon $C_{a}$, which was sustained at a background concentration of $350 \mu \mathrm{mol} \mathrm{mol}^{-1}$ for a longer period of time. No hysteresis could be observed for February 1995, where the response of $F_{\mathrm{a}}$ to $R_{\mathrm{s}}$ was unequivocal and actually comparable to the response in August 1993, although at lower levels of $R_{s}$. The course of $C_{\mathrm{a}}$ was comparable to the other months, although the background concentration which was attained in the afternoon amounted to approximately $365 \mu \mathrm{mol} \mathrm{mol}{ }^{-1}$.

\subsection{DISCUSSION}

\subsubsection{Respiratory $\mathrm{CO}_{2}$ flux}

The plant-based respiration in the calculated respiratory $\mathrm{CO}_{2}$ flux $\left(F_{\mathrm{r}}\right)$ is largely confined to maintenance respiration. However, the generalisation of night-time $F_{\mathrm{n}}$ to daytime maintenance respiration is not undisputed (Woledge \& Parsons 1986). Robson et al. 


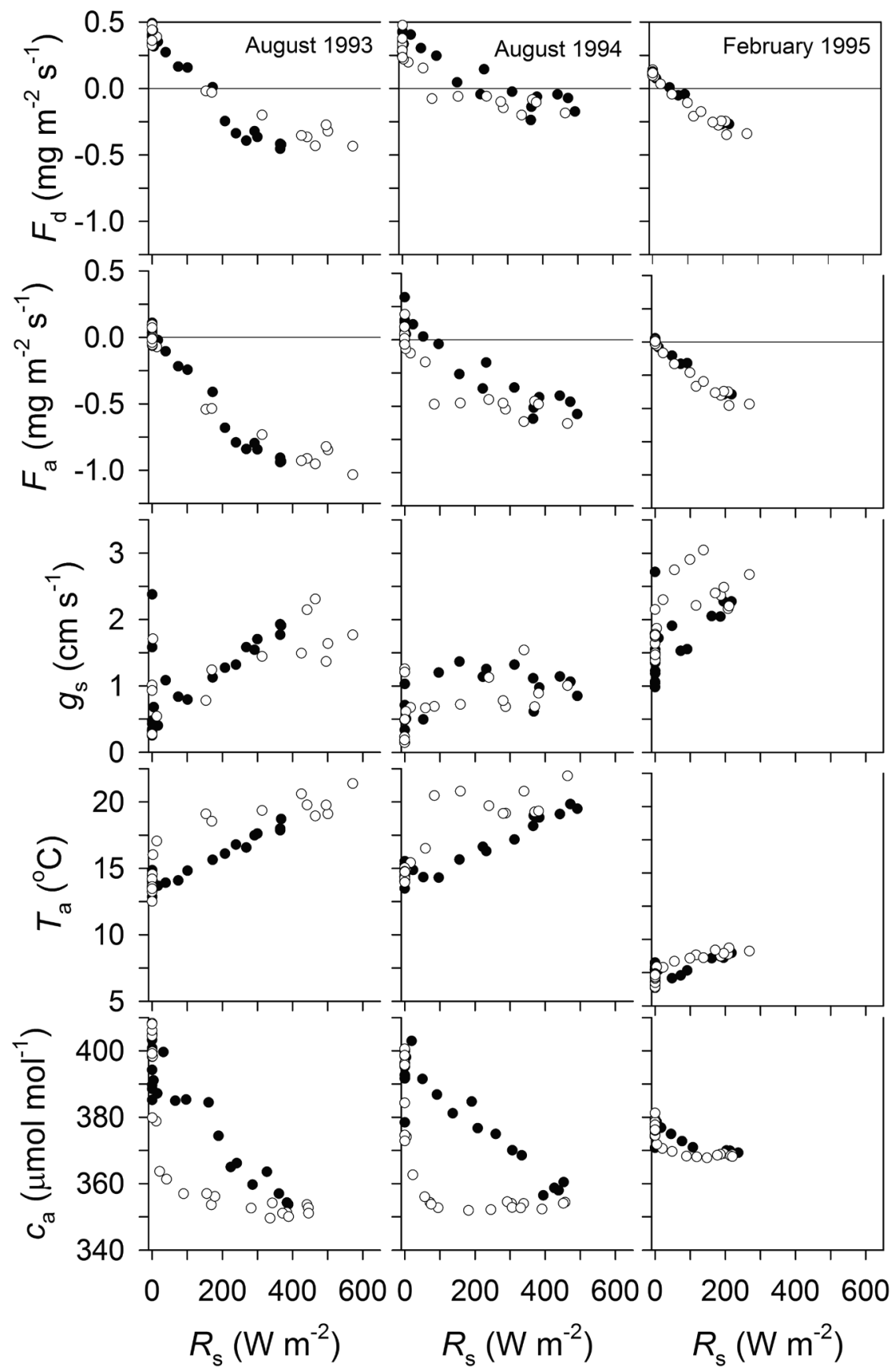

Figure 3.8. Average diurnal response to short-wave irradiance $\left(R_{\mathrm{s}}\right)$ of the day-time net $\mathrm{CO}_{2}$ flux $\left(F_{\mathrm{d}}\right)$, assimilatory $\mathrm{CO}_{2}$ flux $\left(F_{\mathrm{a}}\right)$, surface conductance $\left(g_{\mathrm{s}}\right)$, air temperature $\left(T_{\mathrm{a}}\right)$ and aerial $\mathrm{CO}_{2}$ concentration at $1 \mathrm{~m}$ height $\left(c_{\mathrm{a}}\right)$ before (closed circles) and after noon (open circles), at $195-250^{\circ}$; for each 30 minute average $n \geq 3$. 
(1988) argued that dark respiration in grass may be partly suppressed under illumination, but also noted that under high irradiance the dark respiration in grass is generally less than $10 \%$ of its net photosynthesis. Reekie and Redman (1987) found a daily maintenance requirement of only $3.7 \%$ in the root system of a semi-arid grassland.

The entire respiratory $\mathrm{CO}_{2}$ flux $F_{\mathrm{r}}$ in this study is of a composite nature and consists of the vegetation's maintenance respiration, the decomposition of soil organic matter and the decomposition of peat in the aerobic soil profile. It increased linearly from approximately 0.25-0.30 $\mathrm{mg} \mathrm{CO}_{2} \mathrm{~m}^{-2} \mathrm{~s}^{-1}$ at zero $F_{\mathrm{a}}$ to approximately $0.40-0.50 \mathrm{mg} \mathrm{CO}_{2} \mathrm{~m}^{-2} \mathrm{~s}^{-1}$ at $F_{\text {a }}$ values of $1.00 \mathrm{mg} \mathrm{CO}_{2} \mathrm{~m}^{-2} \mathrm{~s}^{-1}$. An important factor in the variation in the respiratory $\mathrm{CO}_{2}$ flux is soil moisture as it affects soil microbial respiratory activity (Hanson et al. 1993, Kim et al. 1992, Raich \& Schlesinger 1992, Rochette et al. 1991). In peat soils, drainage results in better aeration and often increases below-ground respiration (Raich $\&$ Schlesinger 1992, Silvola et al. 1996). In this experiment's peat pasture, a limited lateral diffusivity causes a fluctuating groundwater table in its subsoil (Schothorst 1982) as high evapotranspiration or precipitation cannot be sufficiently compensated for by drainage. This could have caused suboptimal soil moisture for microbial activity and may have added to a heterogeneous response of the respiratory $\mathrm{CO}_{2}$ flux to temperature. Varying contributions from soil organic matter, litter and vegetation to the respiratory $\mathrm{CO}_{2}$ flux can have resulted in a varying ecosystem response to temperature. The below-ground part in the respiratory $\mathrm{CO}_{2}$ flux responds to soil temperature rather than to air temperature, which itself is subject to a vertical profile. Rainfall affects soil $\mathrm{CO}_{2}$ flows by additional dissolution, reduced diffusivity and upward flushes (Rochette et al. 1991). In this composite system it is difficult to establish an unequivocal response to the environment. The vegetation's maintenance respiration is relatively straightforward and a function of biomass and air temperature. However, soil microbial respiration resulting from the decomposition of soil organic matter and drained peat is a function of a continuum of organic matter fractions with a range of decomposition characteristics which are exposed to dynamic profiles of soil temperature and soil moisture. Yet, the correlation between the reference respiratory activity $F_{\mathrm{r}(0)}$ and the system's assimilatory capacity $F_{\mathrm{a}(\max )}$ indicates that the vegetation's maintenance respiration and the decomposition of newly senesced organic matter have a dominant part in the system's respiratory $\mathrm{CO}_{2}$ flux.

\subsubsection{Assimilatory $\mathrm{CO}_{2}$ flux}

The response of the gross assimilatory $\mathrm{CO}_{2}$ flux $\left(F_{\mathrm{a}}\right)$ to irradiance $\left(R_{\mathrm{s}}\right)$ is characterised by its asymptotic value $F_{\text {a(max })}$ and its initial slope at zero irradiance $\varepsilon$. Throughout the year, suboptimal temperatures proved to be an important factor in the response of $F_{\mathrm{a}}$ to $R_{s}$. Low temperature primarily reduces $\varepsilon$ and as a side-effect modifies the response such that this results in an apparent increase in $F_{\text {a(max) }}$. The positive effect of temperature on $F_{\text {a }}$ over much of the actual temperature range as illustrated in Figure 3.7A is consistent with 
observations at plant level (Wilson \& Cooper 1969, Woledge \& Dennis 1982, Woledge $\&$ Parsons 1986). An in vivo interaction of temperature and vapour pressure deficit often causes an apparent absence of a sustained effect of temperature on $\mathrm{CO}_{2}$ assimilation (Woledge et al. 1989). Suboptimal temperatures may thus occur throughout much of the response of $F_{\mathrm{a}}$ to $R_{\mathrm{s}}$ before noon.

A distinct effect of surface conductance $\left(g_{\mathrm{s}}\right)$ on the assimilatory $\mathrm{CO}_{2}$ flux $\left(F_{\mathrm{a}}\right)$ could not be observed. In part this may be a statistical artefact as the variation in surface conductance at higher irradiance was relatively small, which reduces the possibility for regression analysis to detect a signal - even if surface conductance actually limits the assimilatory $\mathrm{CO}_{2}$ flux. Also, the proposed model for the effect of surface conductance on the assimilatory $\mathrm{CO}_{2}$ flux shown as a single inflection point in Figure 3.1C may well have been too simple. Vapour pressure deficit may serve as an alternative environmental quantity for surface conductance (Collatz et al. 1991, Jarvis 1981). Vapour pressure deficit does not possess the ambiguity which characterises the role of surface conductance in the assimilatory $\mathrm{CO}_{2}$ flux at low and high irradiance, as vapour pressure deficit correlates with irradiance. However, a distinct effect of vapour pressure deficit on the assimilatory $\mathrm{CO}_{2}$ flux was not observed either. Leuning (1995) found a limiting effect of vapour pressure deficit on surface conductance and thus $\mathrm{CO}_{2}$ assimilation, but only up from $1 \mathrm{kPa}$. In our observations vapour pressure deficit was generally below $1-1.5 \mathrm{kPa}$.

The correlation between monthly levels of irradiance and $F_{a(\max )}$ shows that the annual pattern of the asymptotic gross $\mathrm{CO}_{2}$ assimilation (after accounting for the effect of temperature) as shown in Figure 3.2 is related to the annual pattern in leaf area or even to adjustment of the assimilatory capacity to irradiance. The correlation between the reference respiratory $\mathrm{CO}_{2}$ flux $\left(F_{\mathrm{r}(0)}\right)$ and the asymptotic gross $\mathrm{CO}_{2}$ assimilation $\left(F_{\mathrm{a}(\max )}\right)$ indicates that both quantities constitute a measure for metabolically active biomass. The annual patterns in Figure 3.2 compare well with general patterns of grassland productivity (Corrall \& Fenlon 1978). Fung et al. (1987) found a proportionality between the Net Primary Productivity and the soil $\mathrm{CO}_{2}$ flux. Annual differences in the asymptotic assimilatory $\mathrm{CO}_{2}$ flux - as shown in Figure 3.2B - are ultimately a consequence of differences in levels of radiation and temperature: low irradiance decreases the $\mathrm{CO}_{2}$ assimilation and temperature modifies the response of the $\mathrm{CO}_{2}$ assimilation to irradiance. These effects accumulate into different leaf areas. 


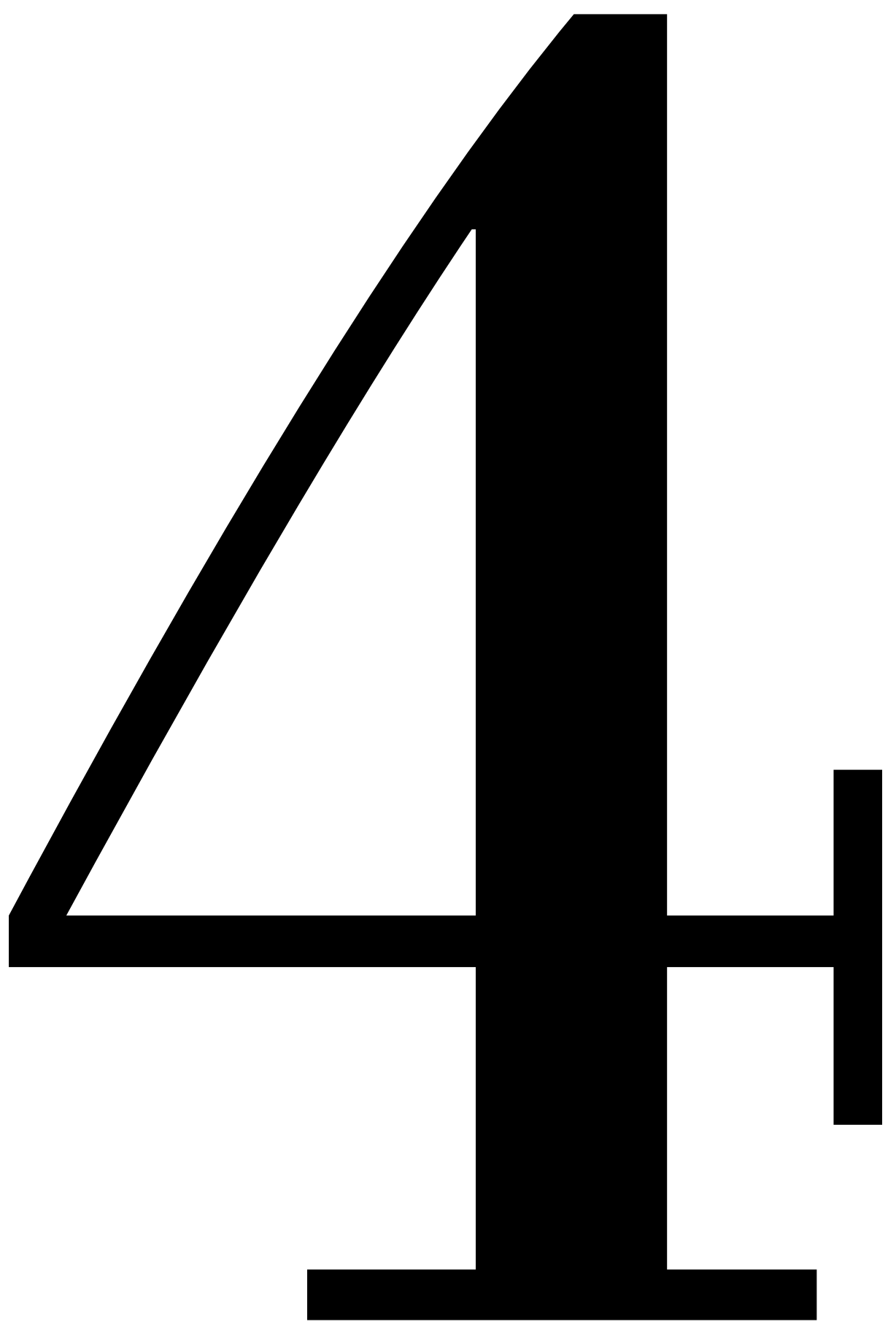




\section{Chapter 4}

\section{Energy exchange and surface conductance in an intensively managed peat pasture}

Originally published as B.O.M. Dirks \& A. Hensen, 1999. Energy exchange and surface conductance in intensively managed peat pasture. Climate Research 12: 29-

37. 


\section{SUMMARY}

Aerodynamic gradient measurements of latent $(\lambda E)$ and sensible heat $(H)$ exchange were done in an intensively managed peat pasture during two consecutive years at a fetch of approximately $2 \mathrm{~km}$. The surface conductance $\left(g_{\mathrm{s}}\right)$ was calculated from the PenmanMonteith equation. It was shown that $g_{s}$ responded negatively to the aerial vapour pressure deficit $(D)$. Its effect was hypothesised to consist of the so-called inflection point $\left(D_{\mathrm{i}}\right)$ at which the effect of $D$ started to be felt, and the relative effect per unit of $D$. The analysis showed that $D_{\mathrm{i}}$ moved up with average $D$ and that the relative effect decreased. This suggests that a negative effect of $D$ on $g_{\mathrm{s}}$ was present over the greater part of the $D$ range and that $g_{\mathrm{s}}$ was sensitive to $D . g_{\mathrm{s}}$ proved to be a strong mediator in the pasture's energy balance. $\lambda E$ initially increased with $D$, but the effect of $D$ was increasingly offset by an increasing $g_{s}$. Impairment of $\lambda E$ by $g_{s}$ increased the surface to air temperature difference $(\Delta T)$ and consequently $H$. At increasing $g_{s}, \lambda E$ and $H$ added up to progressively lower values, which indicates an increased soil heat flux. Impaired $\lambda E$ as a result of limiting $g_{\text {s }}$ clearly increased the Bowen ratio $(\beta)$ as the dissipation of energy shifts away from $\lambda E$ to $H$. $\beta$ ranged from 0.37 to 0.75 and proved to be a good measure for $g_{s}$. It was possible to identify several months with limiting $g_{s}$. It is hypothesised that if $g_{s}$ limits $\lambda E$ it also limits the system's assimilatory $\mathrm{CO}_{2}$ flux.

\subsection{INTRODUCTION}

The canopy or surface conductance $\left(g_{s}\right)$ is an important factor in the mass and energy exchange between atmosphere and biosphere. It is one of the driving variables in canopy $\mathrm{CO}_{2}$ assimilation and directly determines the latent heat flux $(\lambda E)$, more so than it determines the sensible heat flux $(H)$ and the soil heat flux $(G)$. In the energy balance of a biospheric surface area, the surface conductance is the only biological quantity, whereas the remaining mainly physical quantities are imposed upon the surface. The effect of surface conductance and environment on the latent heat flux varies widely among vegetation types and environmental conditions (Baldocchi 1994). Hiyama et al. (1995) found substantial differences in the partitioning of the net irradiance $\left(R_{\mathrm{n}}\right)$ into latent heat flux $(\lambda E)$, sensible heat flux $(H)$ and soil heat flux $(G)$ at different surface types. Jarvis and McNaughton (1986) showed that the impact of $g_{\mathrm{s}}$ on $\lambda E$ depends on the ratio between $g_{\mathrm{s}}$ and aerodynamic conductance $\left(g_{\mathrm{a}}\right)$ as a result of the feedback of the canopy's microclimate on $\lambda E$.

Changes in surface conductance $\left(g_{s}\right)$ and latent heat flux $(\lambda E)$ are reflected in the Bowen ratio, the ratio between sensible and latent heat fluxes $(\beta=H / \lambda E)$. Lower $g_{s}$ leads to reduced $\lambda E$, which in turn leads to elevated surface temperatures. The increased 
temperature difference between surface cover and aerial environment increases $H$ but also increases $\lambda E$. Simulation studies have shown that the Bowen ratio can have a pronounced effect on the development of mesoscale circulations in the atmospheric boundary layer, primarily as a result of a differential distribution of $H$ over the land surface (Avissar \& Pielke 1991, Mascart et al. 1991, Segal et al. 1988).

The surface conductance $\left(g_{s}\right)$ is generally derived from measurements of the latent heat flux. The best established component of $g_{s}$ is stomatal conductance, which is determined by multiple factors. The stomatal conductance is known to respond to $\mathrm{CO}_{2}$ assimilation (Collatz et al. 1991), irradiance and temperature (Avissar et al. 1985, Baldocchi et al. 1991, Lindroth \& Halldin 1986), vapour pressure deficit (Leuning 1995, Price \& Black 1990, Verhoef et al. 1996), relative air humidity (Collatz et al. 1991), leaf water potential (Lynn \& Carlson 1990), latent heat flux (Mott \& Parkhurst 1991) and soil moisture.

This study reports on micrometeorological energy flux measurements in an intensively managed peat pasture done during two consecutive years. As an important factor in both energy balance and assimilatory $\mathrm{CO}_{2}$ fluxes, it seeks to establish the surface conductance $(g)$ and how it is affected by environmental conditions. It is assessed how the dynamics in $g_{s}$ affect the latent heat flux $(\lambda E)$ and how this interacts with other components in the energy balance.

\subsection{MATERIALS AND METHODS}

\subsubsection{Experimental site}

Measurements were done at the experimental site of the Royal Netherlands Meteorological Institute (KNMI) near Cabauw in the Netherlands ( $51^{\circ} 58^{\prime} \mathrm{N}, 4^{\circ} 55^{\prime} \mathrm{E}$ ). The site was surrounded by pasture, orchards, minor roads and some built-up area. The soil consisted of a 0.6-0.8 m thick layer of alluvial clay on top of a massive peat layer. The land was composed of long strips of pastureland alternated by waterways at every $50 \mathrm{~m}$, covering approximately $5 \%$ of the total surface. The vertical distance between land and waterway surface amounted to approximately $0.8 \mathrm{~m}$, although this does not translate into a uniform drainage depth of $0.8 \mathrm{~m}$ as the lateral conductivity to water was low. The pastures predominantly consisted of Lolium perenne and were used for intensive dairy farming at 2.5 heads of cattle per ha, with mixed grazing and mowing.

Only measurements made at incident wind angles $195-250^{\circ}$ were analysed. In this range the footprint almost exclusively consisted of pasture over a distance of approximately $2 \mathrm{~km}$. By restricting the analysis to measurements made at westerly to south-westerly winds, an implicit selection for climate type was introduced. Table 4.1 shows significant 
Table 4.1. Average, minimum and maximum values of environmental variables measured at two incident wind angle ranges at site Cabauw from March 1993 up to February 1995.

\begin{tabular}{lllllll}
\hline \multirow{2}{*}{ quantity } & \multicolumn{3}{c}{$\mathbf{1 - 3 6 0}^{\circ}$} & \multicolumn{3}{c}{$\mathbf{1 9 5 - 2 5 0}^{\circ}$} \\
\cline { 2 - 7 } & $\mathbf{a v g}$ & $\mathbf{m i n}$ & $\mathbf{m a x}$ & $\mathbf{a v g}$ & $\mathbf{m i n}$ & $\mathbf{m a x}$ \\
\hline air temperature $\left({ }^{\circ} \mathrm{C}\right)$ & 9.8 & -8.2 & 32.6 & 9.9 & -6.8 & 25.7 \\
shortwave irradiance $\left(\mathrm{W} \mathrm{m}{ }^{-2}\right)$ & 115 & - & 985 & 94 & - & 954 \\
fraction diffuse radiation $(-)$ & 0.68 & - & - & 0.80 & - & - \\
air humidity $\left(\mathrm{g} \mathrm{kg}^{-1}\right)$ & 6.74 & - & - & 6.87 & - & - \\
precipitation $\left(\mathrm{mm}^{1 / 2} \mathrm{~h}^{-1}\right)$ & 0.049 & - & - & 0.058 & - & - \\
\hline
\end{tabular}

$(P<0.10)$ climatic differences between the ranges with incident wind angles $1-360^{\circ}$ and $195-250^{\circ}$. More clouds and precipitation and fewer extremes in irradiance and temperature indicate that we considered a climate that was slightly more maritime than the actual average.

\subsubsection{Flux measurements}

Aerodynamic gradient energy exchange measurements (Hensen et al. 1997) covered most of the periods from March 1993 up to February 1994 (from here on '1993') and from March 1994 up to February 1995 (from here on '1994'). Measurements and data processing were done by the Netherlands Energy Research Foundation (ECN). Measurements under wind-still conditions were excluded.

The aerodynamic gradient technique used wind speed measured at $10 \mathrm{~m}$ height. The wind speed was determined at an accuracy of $1 \%$ using a Gill propeller vane type $8002 \mathrm{dx}$, modified by KNMI. Temperature measurements were obtained at 0.6, 2 and $10 \mathrm{~m}$ height. Thermocouples measured the direct differences between the successive levels. At $0 \mathrm{~m}$ height the thermocouples were measured against a $0{ }^{\circ} \mathrm{C}$ ice bath. The thermocouples were shielded and ventilated, whereas the accuracy of the temperature differences was approximately $0.05^{\circ} \mathrm{C}$. The air humidity followed from the air temperature and the wet bulb temperature. The set-up of the wet bulb temperature measurements was similar to that of the air temperature, but the sensor was kept wet using peristaltic pumps.

The measurements were clustered to 30 minute averages and comprised the latent heat flux $\left(\lambda E\right.$ in $\left.\mathrm{W} \mathrm{m}^{-2}\right)$, the sensible heat flux $\left(H\right.$ in $\left.\mathrm{W} \mathrm{m}^{-2}\right)$, the wind speed at $10 \mathrm{~m}$ height $\left(u_{10}\right.$ in $\left.\mathrm{m} \mathrm{s}^{-1}\right)$, the air temperature at $0.6 \mathrm{~m}$ height $\left(T_{\mathrm{a}}\right.$ in $\left.{ }^{\circ} \mathrm{C}\right)$, the specific air humidity at $0.6 \mathrm{~m}$ height $\left(q\right.$ in $\left.\mathrm{g} \mathrm{kg}^{-1}\right)$ and the vapour pressure deficit at $0.6 \mathrm{~m}$ height $\left(D_{0.6}\right.$ in $\left.\mathrm{kPa}\right)$. The fluxes were an implicit average of all conditions met within the fetch of $2 \mathrm{~km}$.

Linear regression was done by the least squares technique, whereas non-linear regression analysis was done applying the Marquardt-Levenberg algorithm (Fox et al. 1994). 


\subsubsection{Meteorological measurements}

Meteorological measurements and data processing were done by KNMI. Shortwave irradiance $(0.3-3 \mu \mathrm{m})$ was measured using a Kipp CM11 pyranometer, ventilated to prevent condensation on the dome. For diffuse irradiance the pyranometer was equipped with a shadow band. Long-wave irradiance $(3-50 \mu \mathrm{m})$ was measured using a ventilated Eppley radiometer. Measurement of net radiation $(0.3-50 \mu \mathrm{m})$ was done by a Funk radiometer. The soil heat flux was measured using flux plates developed by the TNO Institute of Applied Physics: 3 heat flux plates, $3 \mathrm{~m}$ apart, at 0,5 and $10 \mathrm{~cm}$ depth. The values were clustered to 30 minute averages $\left(\mathrm{W} \mathrm{m}^{-2}\right)$ and included the shortwave irradiance $(R)$, the diffuse shortwave irradiance, the outgoing longwave radiation $\left(L_{\text {our }}\right)$, the net radiation $\left(R_{\mathrm{n}}\right)$ and the surface soil heat flux $(G)$.

The surface temperature $\left(T_{s}\right.$ in $\left.{ }^{\circ} \mathrm{C}\right)$ was calculated by applying the Stefan-Boltzmann Law to $L_{\text {out }}$ and assuming a surface emissivity of 0.975 (Ripley \& Redmann 1976). The surface to air temperature difference $(\Delta T)$ was calculated as the difference between $T_{\mathrm{s}}$ and $T_{\mathrm{a}}$. Though $\Delta T$ holds several uncertainties, it was supposed to be indicative for the actual surface to air temperature difference.

\subsubsection{Energy balance}

In this grassland ecosystem's energy balance, both advection and its biochemical and physical energy storage were neglected. The energy available for upward dissipation $\left(R_{\mathrm{in}}\right)$ then is the difference between net radiation $\left(R_{\mathrm{n}}\right)$ and the surface soil heat flux $(G)$. The upwardly dissipated energy $\left(R_{\text {out }}\right)$ is the sum of the latent heat flux $(\lambda E)$ and the sensible heat flux $(H)$. Figure 4.1 shows a close correspondence of $R_{\mathrm{in}}$ and $R_{\text {our }}$, despite the different spatial scales for their components. $\lambda E$ and $H$ were measured at the scale of the footprint of the aerodynamic gradient technique, whereas $R_{\mathrm{n}}$ and $G$ were measured at the much smaller scale of meteorological instruments. No significant difference between $R_{\mathrm{in}}$ and $R_{\text {out }}$ was observed during either year.

\subsubsection{Latent heat flux and surface conductance}

An important factor in the surface energy balance is the relation between surface conductance $\left(g_{s}\right)$ and latent heat flux $(\lambda E) . g_{s}$ constitutes a largely biological surface factor that operates in a system of otherwise external aerial and radiative factors. $g_{s}$ as such cannot be measured as it is a compound quantity which incorporates multiple factors. Instead it is calculated from measurements of $\lambda E$. We applied the latent heat loss equation to characterise the latent heat flux $(\lambda E)$. The Penman-Monteith equation was used to calculate the surface conductance $\left(g_{s}\right)$, which was subsequently analysed in its response to irradiance and vapour pressure deficit. 


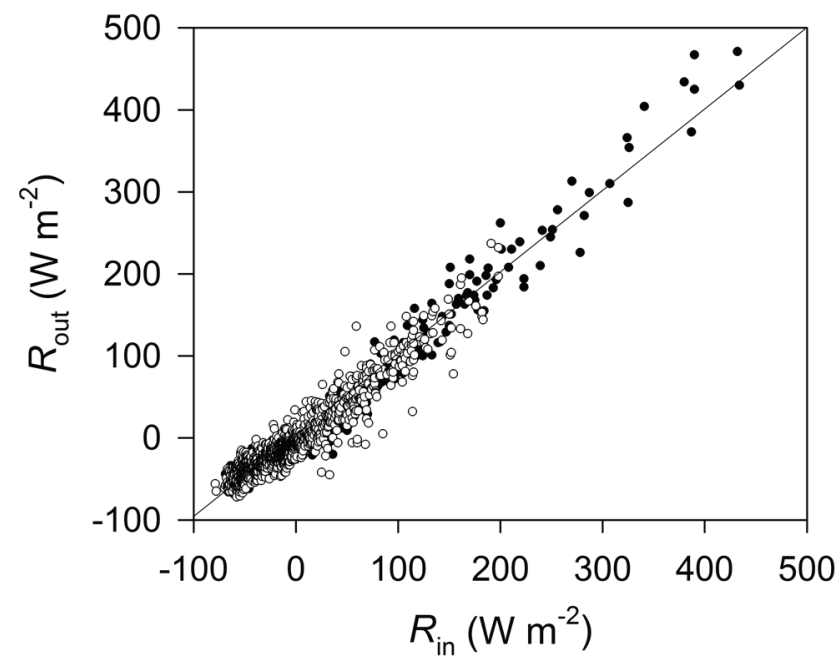

Figure 4.1. Energy balance in 1993 (closed symbols) and 1994 (open symbols): comparison of available energy $\left(R_{\text {in }}=R_{\mathrm{n}}-G\right)$ and outgoing energy $\left(R_{\text {out }}=\lambda E+H\right)$ at incident wind angles $195-250^{\circ}$.

In an analogy to an electrical circuit, the original latent heat loss equation (Monteith \& Unsworth 1990) relates the latent heat flux $(\lambda E)$ to the difference in vapour pressure between air and surface cover (the numerator term: $D+s \times \Delta T$ ) and the resistance to water vapour transfer (the denominator term: $r_{\mathrm{a}}+r_{\mathrm{s}}$ ):

$\lambda E=\left(0.622 \times \lambda \times \rho_{\mathrm{a}} / p\right)(D+s \times \Delta T) /\left(r_{\mathrm{a}}+r_{\mathrm{s}}\right)$

where $\rho_{\mathrm{a}}$ is the density of dry air $\left(\mathrm{g} \mathrm{m}^{-3}\right), p$ is the air pressure $(\mathrm{kPa}), D$ is the aerial vapour pressure deficit $(\mathrm{kPa}), \Delta T$ is the difference between surface temperature $\left(T_{\mathrm{s}}\right)$ and $T_{\mathrm{a}}\left({ }^{\circ} \mathrm{C}\right)$, $s$ is the slope of the saturation vapour pressure curve at $T_{\mathrm{a}}\left(\mathrm{kPa} \mathrm{K}^{-1}\right), r_{\mathrm{a}}$ and $r_{\mathrm{s}}$ are the aerodynamic and surface resistances to water vapour transfer $\left(\mathrm{s} \mathrm{m}^{-1}\right)$ and $\lambda$ is the latent heat of vapourisation $\left(\mathrm{J} \mathrm{g}^{-1}\right)$.

Equation 4.1 was only used to characterise $\lambda E$, as it includes an uncertainty in the application of $\Delta T$. The Penman-Monteith equation is derived from Equation 4.1 and eliminates the need for surface temperature and surface vapour pressure (Monteith \& Unsworth 1990):

$\lambda E=\left(s \times\left(R_{\mathrm{n}}-G\right)+\rho_{\mathrm{a}} \times c_{\mathrm{p}} \times D / r_{\mathrm{a}}\right) /\left(s+\gamma \times\left(r_{\mathrm{a}}+r_{\mathrm{s}}\right) / r_{\mathrm{a}}\right)$

where $\gamma$ is the psychrometer constant $\left(\mathrm{kPa} \mathrm{K}^{-1}\right)$ and $c_{\mathrm{p}}$ is the specific heat of air at constant pressure $\left(\mathrm{J} \mathrm{g}^{-1} \mathrm{~K}^{-1}\right)$. Equation 4.2 was used to calculate the surface conductance $\left(g_{\mathrm{s}}\right)$. 


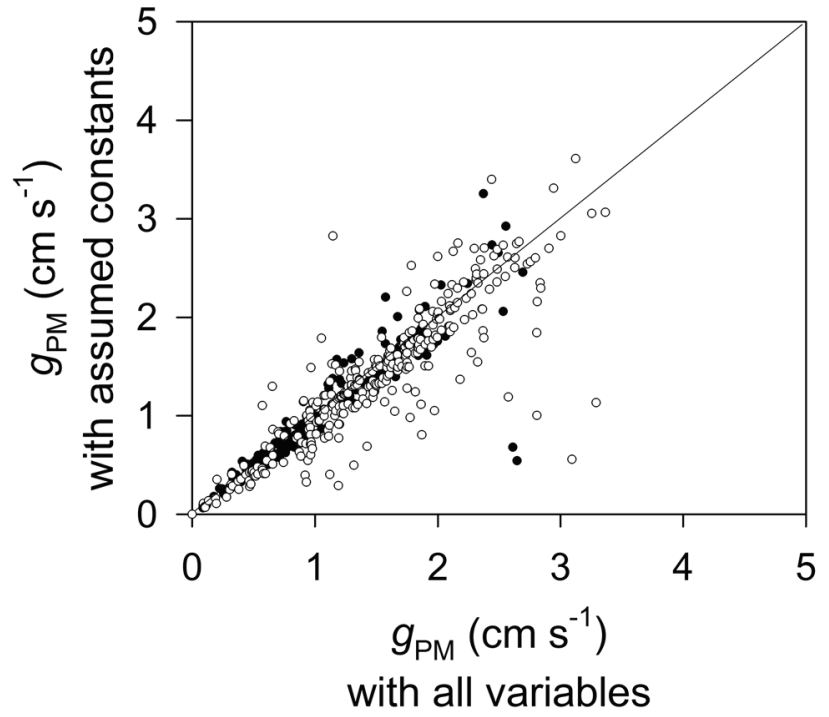

Figure 4.2. Comparison of daytime conductance to water vapour transfer ( $g$ ) with all variables and with several variables assumed constant; in 1993 (closed symbols) and 1994 (open symbols).

The aerodynamic conductance to water vapour $\left(g_{\mathrm{a}}\right)$ was calculated as (Lhomme 1991, Monteith \& Unsworth 1990, Saugier \& Katerji 1991, Thom 1972, 1975, Verma et al. 1986):

$g_{\mathrm{a}}=\left(u_{0.6} / u_{*}^{2}+5.31 \times u_{*}^{-2 / 3}\right)^{-1}$

where $u_{*}$ is the friction velocity $\left(\mathrm{m} \mathrm{s}^{-1}\right)$, which is calculated as $0.141{ }^{*} u_{10}$ (where $u_{10}$ is the measured wind speed at $10 \mathrm{~m}$ height). The wind speed at $0.6 \mathrm{~m}$ height $\left(u_{0.6}\right)$ was calculated from the logarithmic wind profile, assuming a zero plane displacement of 0.05 $\mathrm{m}$ and a roughness length of 0.021-0.066 $\mathrm{m}$.

The derivation of the surface conductance $\left(g_{s}\right)$ from Equation 4.2 entails the use of multiple dynamic parameters and quantities. A comparison was made between the derivation of $g_{s}$ which includes all these parameters and quantities as measured or calculated and the derivation of $g_{\text {s }}$ which assumes constant values for the surface soil heat flux $\left(G=0 \mathrm{~W} \mathrm{~m}^{-2}\right)$, air pressure $(p=101 \mathrm{kPa})$, psychrometer constant $(\gamma=0.066$ $\left.\mathrm{kPa} \mathrm{K} \mathrm{K}^{-1}\right)$, latent heat of vapourisation $\left(\lambda=2477 \mathrm{~J} \mathrm{~g}^{-1}\right)$, density of dry air $\left(\rho_{\mathrm{a}}=1246 \mathrm{~g} \mathrm{~m}^{-3}\right)$ and roughness length $\left(z_{0}=0.03 \mathrm{~m}\right)$. Both conductances $g_{\mathrm{s}}$ did not differ significantly; therefore it was decided to calculate $g_{s}$ with assumed constant values. Figure 4.2 compares the total conductances to water vapour transfer: $g=\left(\left(g_{\mathrm{a}}+g_{\mathrm{s}}\right) /\left(g_{\mathrm{a}} \times g_{\mathrm{s}}\right)\right)^{-1}$ and illustrates how both approaches to the calculation of $g_{s}$ gave comparable results. 


\subsubsection{Surface conductance and environment}

Surface conductance tends to follow the $\mathrm{CO}_{2}$ assimilation under non-limiting conditions. At high vapour pressure deficits the surface conductance itself becomes impaired, which in turn limits the $\mathrm{CO}_{2}$ assimilation. A multiplicative relationship was used to explore the effect of shortwave irradiance $\left(R_{s}\right)$ and surface vapour pressure deficit $\left(D_{0}\right)$ on surface conductance $\left(g_{\mathrm{s}}\right)$. For the effect of $R_{\mathrm{s}}$ a rectangular hyperbolic response of $g_{\mathrm{s}}$ to $R_{\mathrm{s}}$ was assumed (Kelliher $e t$ al. 1995, Schulze et al. 1995), characterised by a maximum surface conductance $\left(g_{s(\max }\right)$. For the effect of $D_{0}$ three different responses of $g_{s}$ to $D_{0}$ were evaluated: (a) a linear response, (b) a negatively exponential response (Jones 1992) and (c) a hyperbolic response (Leuning 1995, Schulze et al. 1995), as illustrated in Figure 4.3. For the three different models of the effect of $D_{0}$ on $g_{s}$ the relative effects $\left(f\left(D_{0}\right)\right)$ are described as follows:

$$
\begin{aligned}
& f\left(D_{0}\right)=1-\left(D_{0}-D_{\mathrm{i}}\right) / d_{\text {lin }} \\
& f\left(D_{0}\right)=\mathrm{e}^{-\left(D 0-D_{\mathrm{i}}\right) / d \exp } \\
& f\left(D_{0}\right)=\left(1+\left(D_{0}-D_{\mathrm{i}}\right) / d_{\text {hyp }}\right)^{-1}
\end{aligned}
$$

where $D_{0}$ is the surface vapour pressure deficit $(\mathrm{kPa})$ and $d_{\text {lin }}, d_{\text {exp }}$ and $d_{\text {hyp }}$ are equationspecific parameters which determine how much the relative effect $f\left(D_{0}\right)$ (and therefore $g_{s}$ ) changes per unit of $D_{0}$ (thus setting the slope of the curve). $D_{\mathrm{i}}$ is the vapour pressure deficit inflection point where $f\left(D_{0}\right)=1$ for $D_{0}<D_{\text {i }}$.

Measurements made under conditions with wet surfaces were excluded by only considering values where both latent heat flux $(\lambda E)$ and equilibrium latent heat flux $\left(\lambda E_{\text {eq }}\right)$ were higher than $0 \mathrm{~W} \mathrm{~m}^{-2} . \lambda E_{\text {eq }}$ equates $\lambda E$ under conditions where the aerodynamic conductance $\left(g_{\mathrm{a}}\right)$ approaches 0 and equals (Jones 1992):

$\lambda E_{\text {eq }}=s \times R_{\mathrm{n}} /(s+\gamma)$

Measurements made under conditions with a low degree of coupling between atmosphere and surface (Jarvis \& McNaughton 1986) were excluded by only considering values where the decoupling coefficient $(\Omega)$ was less than 0.70 :

$\left.\Omega=(s / \gamma+1) \times\left(s / \gamma+1+g_{\mathrm{a}} / g_{s}\right)^{-1}\right)$

The surface vapour pressure deficit $\left(D_{0}\right)$ was calculated from the vapour pressure deficit at $0.6 \mathrm{~m}$ height $\left(D_{0.6}\right)$, the aerodynamic conductance to water vapour $\left(g_{\mathrm{a}}\right)$, the latent heat flux $(\lambda E)$ and the equilibrium latent heat flux $\left(\lambda E_{\text {eq }}\right)$ as described by Kelliher et al. (1993). 


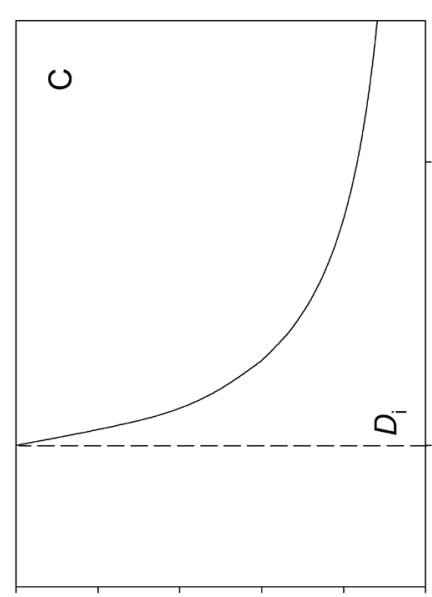

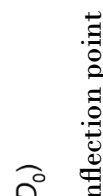

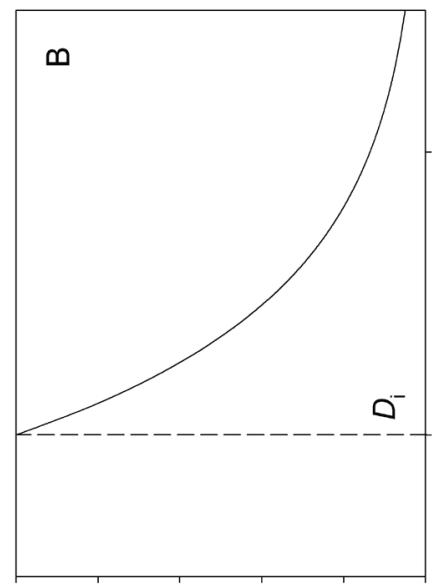

넌

ఏ)

क्ष

는

言

$>\frac{0}{3} \stackrel{2}{\circ}$

की

कos b

$\stackrel{\circlearrowright}{\Xi}$

ฮี

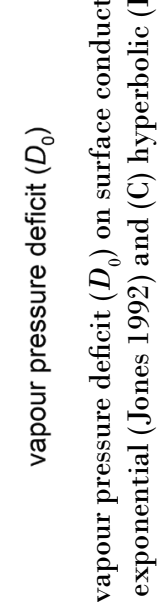

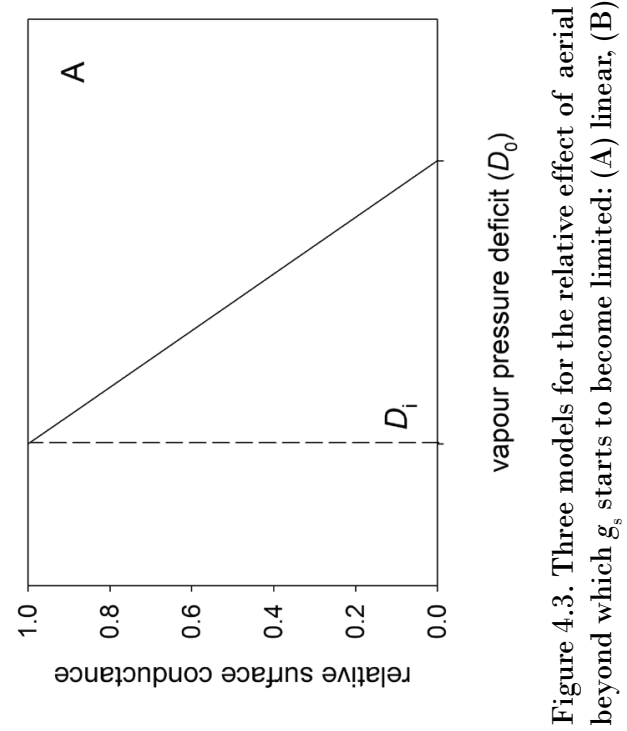




\subsection{RESULTS}

\subsubsection{Surface conductance}

Table 4.2 shows that shortwave irradiance $R_{\mathrm{s}}$ as such was generally able to explain surface conductance $g_{\mathrm{s}}$ only poorly $\left(r^{2}=0.05-0.10\right)$. Exceptions are August 1993, May 1994 and October 1994 where increasing $R_{\mathrm{s}}$ proved to be an important factor in explaining an increasing $g_{\mathrm{s}}\left(r^{2}=0.35-0.55\right)$. Accounting for surface vapour pressure deficit $D_{0}$ by applying Equations 4.4 to the surface conductance data increased the explained variance substantially. During most months $g_{\mathrm{s}}$ responded clearly to $D_{0}$, thereby generally increasing explained variance to the range of 0.25-0.55. Only in August 1993 and particularly in May 1994 the effect of $D_{0}$ on $g_{\mathrm{s}}$ was very limited. Altogether $D_{0}$ appeared to be an important factor in $g_{s}$. The functions for an exponential (4.4B) and a hyperbolic effect (4.4C) of $D_{0}$ on $g_{\mathrm{s}}$ provided the best description of $g_{\mathrm{s}}$, but differences were modest.

Table 4.2 shows that the fitted maximum surface conductance $g_{s(\max )}$ at non-limiting irradiance $R_{\mathrm{s}}$ and surface vapour pressure deficit $D_{0}$ ranged from $2.6-3.4 \mathrm{~cm} \mathrm{~s}^{-1}$ in spring, to $1.8-5.1 \mathrm{~cm} \mathrm{~s}^{-1}$ in summer, to $6.9 \mathrm{~cm} \mathrm{~s}^{-1}$ in autumn and to $4.5 \mathrm{~cm} \mathrm{~s}^{-1}$ in winter. Table 4.2 also indicates that the surface vapour pressure deficit beyond which the surface conductance became increasingly impaired (inflection point $D_{\mathrm{i}}$ ) was $0.25-0.40 \mathrm{kPa}$, with the exception of July and August 1993 where it was higher at $0.60-0.65 \mathrm{kPa}$.

Figure 4.4A illustrates in more detail the effect of the surface vapour pressure deficit $D_{0}$ on the surface conductance $g_{s}$. It plots the lower and upper boundaries of $D_{0}$ as well as

Table 4.2. Explained variance $\left(r^{2}\right)$ and fitted parameters $(P<0.10)$ for surface conductance $\left(g_{\mathrm{s}}\right)$ as a hyperbolic function of shortwave irradiance $\left(R_{\mathrm{s}}\right)$ and exponential function of vapour pressure deficit $\left(D_{0}\right)$. At incident wind angles $195-250^{\circ}, \lambda E$ and $\lambda E_{\text {eq }}>0 \mathrm{~W} \mathrm{~m}^{-2}$ and $\Omega<0.70$.

\begin{tabular}{|c|c|c|c|c|c|c|c|}
\hline \multirow[t]{2}{*}{ month } & \multirow{2}{*}{$\begin{array}{l}D_{0.6}\left(P_{95}\right) \\
(\mathbf{k P a})\end{array}$} & \multicolumn{2}{|c|}{$g_{s}=f\left(R_{s}\right)$} & \multicolumn{4}{|c|}{$g_{s}=f\left(R_{s}, D_{0}\right)$} \\
\hline & & $n$ & $r^{2}$ & $r^{2}$ & $\begin{array}{l}g_{s(\max )} \\
\left(\mathrm{cm} \mathrm{s}^{-1}\right)\end{array}$ & $d_{\text {exp }}$ & $\begin{array}{l}D_{\mathrm{i}} \\
(\mathbf{k P a})\end{array}$ \\
\hline April 93 & 0.79 & 47 & 0.04 & 0.56 & & 0.51 & \\
\hline June 93 & 1.39 & 42 & 0.04 & 0.50 & 3.0 & 0.78 & 0.21 \\
\hline July 93 & 1.05 & 204 & 0.08 & 0.27 & 2.3 & 0.57 & 0.60 \\
\hline August 93 & 0.98 & 141 & 0.40 & 0.52 & 2.7 & 1.11 & 0.64 \\
\hline September 93 & 0.71 & 58 & 0.11 & 0.38 & 5.1 & 0.63 & 0.24 \\
\hline April 94 & 0.84 & 94 & 0.04 & 0.23 & 3.4 & 0.38 & 0.34 \\
\hline May 94 & 0.63 & 39 & 0.33 & 0.35 & 2.6 & - & - \\
\hline August 94 & 1.16 & 106 & 0.02 & 0.38 & 1.8 & 0.72 & 0.40 \\
\hline October 94 & 0.58 & 31 & 0.56 & 0.77 & 6.9 & 0.46 & - \\
\hline January 95 & 0.41 & 70 & 0.06 & 0.18 & 4.5 & - & 0.27 \\
\hline
\end{tabular}



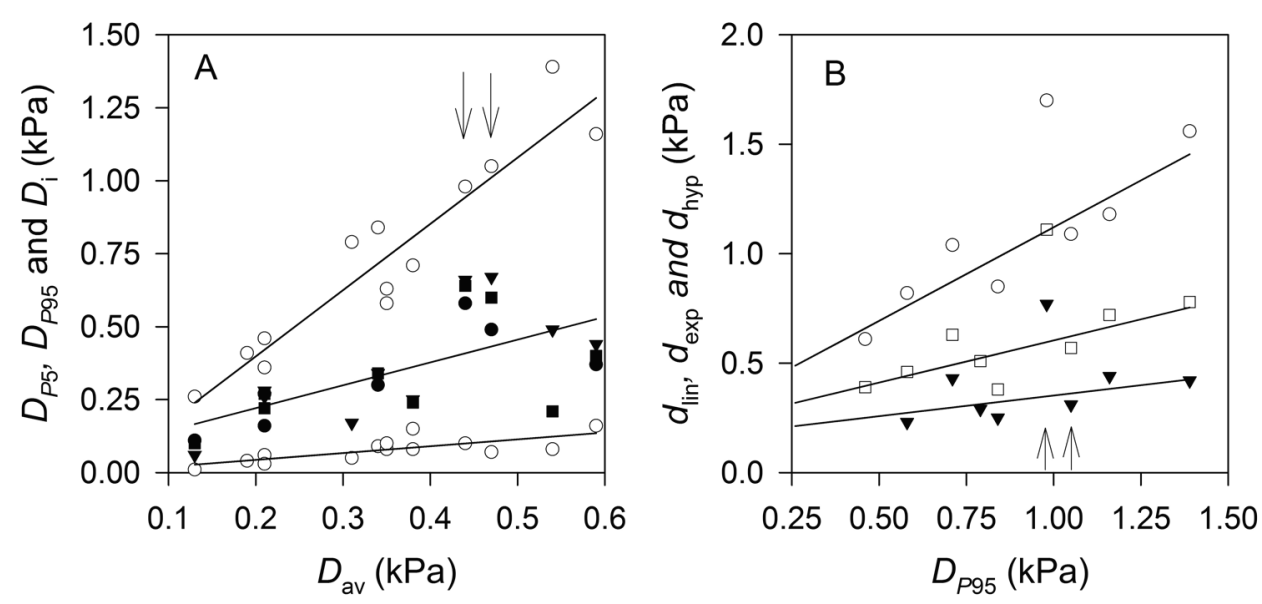

Figure 4.4. (A) Monthly $\boldsymbol{P}_{5}$ and $\boldsymbol{P}_{95}$ of vapour pressure deficit ( $D$ : open symbols), monthly fitted (closed symbols) and regressed inflection point $D_{\mathrm{i}}$ as a function of average vapour pressure deficit $\left(D_{\text {av }}\right)$. (B) Monthly fitted and regressed $d_{\text {lin }}, d_{\text {exp }}$ and $d_{\text {hyp }}$ as a function of the $P_{95}$ of vapour pressure deficit $\left(D_{P 95}\right)$. Arrows: July and August 1993. Equation 4.4A: circles; 4.4B: squares; 4.4C: triangles.

the fitted course of the surface vapour pressure deficit inflection point $\left(D_{\mathrm{i}}\right)$. It indicates that the vapour pressure deficit at which the surface conductance started to become impaired fell about halfway the full range of vapour pressure deficits. If vapour pressure deficit levels increased, so did the inflection point. July and August 1993 stand out as the vapour pressure deficit inflection point was higher than the trend, i.e. surface conductance remained unimpaired up to a higher vapour pressure deficit.

Figure $4.4 \mathrm{~B}$ shows that the equation-specific parameters $d_{\text {lin }}, d_{\text {exp }}$ and $d_{\text {hyp }}$ from Equations 4.4 - setting the rate of change in $g_{s}$ per unit of $D_{0}$ - increased with increasing vapour pressure deficit. This indicates that the response of the surface conductance to vapour pressure deficit becomes more moderate at increasing vapour pressure deficit. The differential response of $g_{s}$ to varying ranges of vapour pressure deficit could point at stomatal adjustment.

\subsubsection{Soil heat flux}

An upward soil heat flux $(G)$ of $3 \mathrm{~W} \mathrm{~m}^{-2}$ was fitted for zero net irradiance $\left(R_{\mathrm{n}}\right)$ in 1993. Figure 4.5 shows that the gradient of daytime $G$ against $R_{\mathrm{n}}$ was $0.1\left(r^{2}=0.56, n=962\right)$, indicating that $10 \%$ of the net radiation was absorbed by the soil.

\subsubsection{Latent heat flux}

Figure 4.5 shows that the gradient $b_{\lambda E}$ of the daytime latent heat flux $\lambda E$ against net irradiance $R_{\mathrm{n}}$ (the fraction of $R_{\mathrm{n}}$ which is being dissipated as $\lambda E$ ) was $0.55-0.65$ on a yearly basis. $b_{\lambda E}$ was significantly lower in 1994 than in $1993(P<0.001)$. Table 4.3 lists 

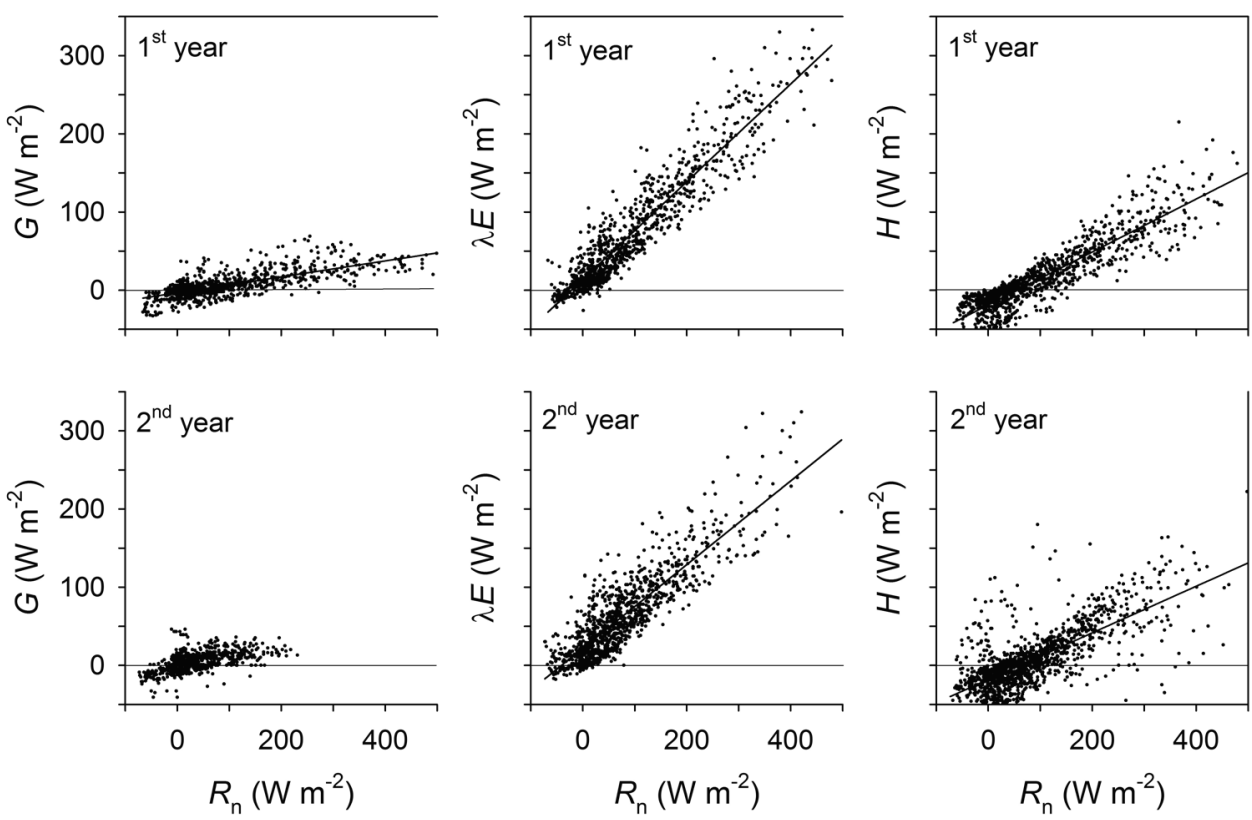

Figure 4.5. Daytime latent heat flux $(\lambda E)$, sensible heat flux $(H)$ and soil heat flux $(G)$ in 1993 and 1994 as a function of net irradiance $\left(R_{n}\right)$ at incident wind angles $195-250^{\circ}$.

the monthly gradients $b_{\lambda E^{*}}$. In spring and summer, $b_{\lambda E}$ ranged from 0.52 to 0.70 . The highest value was observed for August 1993. This month was characterised by high levels of vapour pressure deficit $D$ but also of high surface conductance $g_{s}$ at moderate levels of surface to air temperature difference $\Delta T$. Low values of $b_{\lambda E}$ fitted for June 1993 and August 1994 are associated with high levels of $D$ and $\Delta T$ and low levels of $g_{s}$. The period from June to August 1993 was characterised by drought and sustained high levels of $D$ but also progressively higher values of $g_{\mathrm{s}}$ and lower values of $\Delta T . b_{\lambda E}$ increased over this period.

Figure 4.6 and Table 4.4 illustrate the relationship between $R, \lambda E$ and $g_{\mathrm{s}}$ in more detail by comparing July 1993 and August 1994, having a high and a low value of $b_{\lambda E}$, respectively. For the dissipation of $R_{\mathrm{n}}$ as $\lambda E$ it is differentiated between three classes of $g_{s}$ : higher than $1.0 \mathrm{~cm} \mathrm{~s}^{-1}$, between 0.5 and $1.0 \mathrm{~cm} \mathrm{~s}^{-1}$ and lower than $0.5 \mathrm{~cm} \mathrm{~s}^{-1}$. The dissipation of $R_{\mathrm{n}}$ as $\lambda E$ was reduced significantly and markedly when $g_{\mathrm{s}}$ decreased from $>1.0$ to $0.5-1.0$ $\mathrm{cm} \mathrm{s}^{-1}$. A further decrease of $g_{\mathrm{s}}$ to $<0.5 \mathrm{~cm} \mathrm{~s}^{-1}$ (for August 1994) only marginally and not significantly further reduced $b_{\lambda E}$.

Figure 4.6 indicates a rather distinct lower boundary of $b_{\lambda E^{\prime}}$, which was already attained at $g_{s}$ values of $0.5-1.0 \mathrm{~cm} \mathrm{~s}^{-1}$. A further decrease in $g_{s}$ caused $\lambda E$ to be concentrated at this lower boundary level. On fitting linear curves through the values for $g_{\mathrm{s}}$ classes $0.5-1.0 \mathrm{~cm}$ $\mathrm{s}^{-1}$ and $<0.5 \mathrm{~cm} \mathrm{~s}^{-1}$ it appears that $b_{\lambda E}$ for $g_{\mathrm{s}}$ class $0.5-1.0 \mathrm{~cm} \mathrm{~s}^{-1}$ was somewhat higher. In 


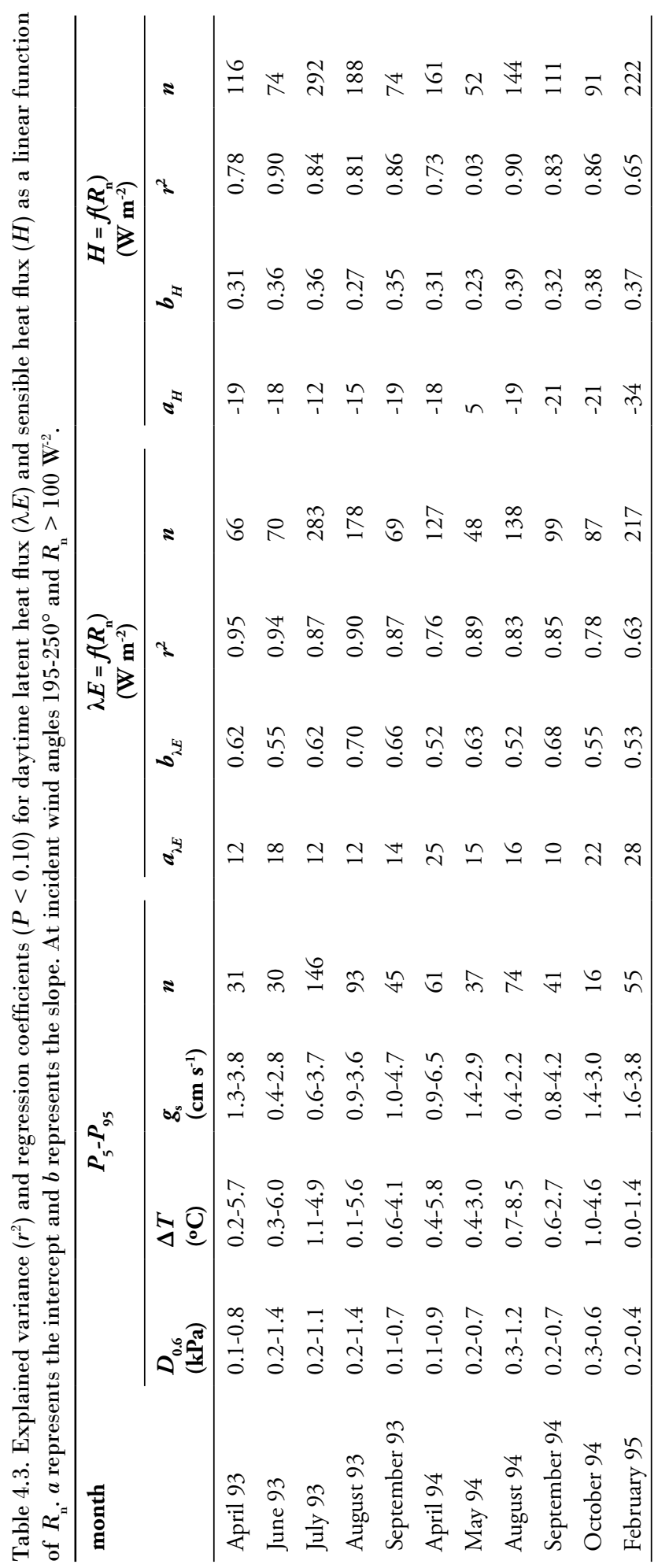


Table 4.4. Average aerodynamic conductance to water vapour $\left(g_{\mathrm{a}}\right)$ and regression coefficients $(P<$ $0.10)$ for daytime latent heat flux $(\lambda E)$, sensible heat flux $(H)$ and surface to air temperature difference $(\Delta T)$ as a linear function of net irradiance for different surface conductance $\left(g_{\mathrm{s}}\right)$ classes. At incident wind angles $195-250^{\circ}$. Superscripts indicate within-month significant differences $(P<0.10)$.

\begin{tabular}{|c|c|c|c|c|c|}
\hline \multirow[t]{2}{*}{ quantity } & \multicolumn{2}{|c|}{$\begin{array}{l}\text { July } 1993 \\
g_{\mathrm{s}}\left(\mathrm{cm} \mathrm{s}^{-1}\right)\end{array}$} & \multicolumn{3}{|c|}{$\begin{array}{c}\text { August } 1994 \\
g_{\mathrm{s}}\left(\mathrm{cm} \mathrm{s}^{-1}\right)\end{array}$} \\
\hline & $>1.0$ & $0.5-1.0$ & $>1.0$ & $0.5-1.0$ & $<0.5$ \\
\hline$g_{\mathrm{a}}\left(\mathrm{cm} \mathrm{s}^{-1}\right)$ & $3.6^{\mathrm{a}}$ & $3.2^{\mathrm{a}}$ & $3.0^{\mathrm{a}}$ & $3.1^{\mathrm{a}}$ & $2.2^{\mathrm{b}}$ \\
\hline$a_{\lambda E}\left(\mathrm{~W} \mathrm{~m}^{-2}\right)$ & $16^{\mathrm{a}}$ & $14^{a}$ & & $19^{a}$ & $17^{\mathrm{a}}$ \\
\hline$b_{\lambda E}(-)$ & $0.66^{\mathrm{a}}$ & $0.51^{\mathrm{b}}$ & $0.68^{a}$ & $0.44^{\mathrm{b}}$ & $0.39^{\mathrm{b}}$ \\
\hline$a_{H}\left(\mathrm{~W} \mathrm{~m}^{-2}\right)$ & $-16^{a}$ & $-20^{\mathrm{a}}$ & $-26^{a}$ & $-25^{a}$ & $-16^{\mathrm{b}}$ \\
\hline$b_{H}(-)$ & $0.33^{\mathrm{a}}$ & $0.49^{\mathrm{b}}$ & $0.36^{\mathrm{a}}$ & $0.47^{\mathrm{b}}$ & $0.41^{\mathrm{b}}$ \\
\hline$a_{\Delta T}\left({ }^{\circ} \mathrm{C}\right)$ & $0.5^{\mathrm{a}}$ & $0.4^{a}$ & & & \\
\hline$b_{\Delta T}\left({ }^{\circ} \mathrm{C}\left(\mathrm{W} \mathrm{m}^{-2}\right)^{-1}\right)$ & $0.010^{\mathrm{a}}$ & $0.011^{\mathrm{a}}$ & $0.014^{\mathrm{a}}$ & $0.015^{\mathrm{a}}$ & $0.022^{\mathrm{b}}$ \\
\hline
\end{tabular}

fact, this is an expression of a greater variation above the lower boundary of $b_{\lambda E}$ relative to the values in $g_{\mathrm{s}}$ class $<0.5 \mathrm{~cm} \mathrm{~s}^{-1}$, which all concentrate on or near that lower boundary. Table 4.4 shows that the aerodynamic conductance to water vapour $g_{a}$ was significantly lower at $g_{\mathrm{s}}$ values $<0.5 \mathrm{~cm} \mathrm{~s}^{-1}$, which may have compounded the effect of low $g_{\mathrm{s}}$. Figure 4.6 and Table 4.4 moreover show that the surface to air temperature difference $\Delta T$ was not significantly different between $g_{\mathrm{s}}$ classes $>1.0$ and $0.5-1.0 \mathrm{~cm} \mathrm{~s}^{-1}$, but occasionally tended to very high values at high $R_{\mathrm{n}}$ and $g_{\mathrm{s}}$ values $<0.5 \mathrm{~cm} \mathrm{~s}^{-1}$.

\subsubsection{Sensible heat flux}

Figure 4.5 shows that the gradient $b_{H}$ of the daytime sensible flux $H$ against net irradiance $R_{\mathrm{n}}$ (the fraction of $R_{\mathrm{n}}$ which is dissipated as $H$ ) was $0.30-0.35$ on a yearly basis. $b_{H}$ was significantly lower in 1994 than in $1993(P<0.01)$. Table 4.3 shows that in spring and summer monthly $b_{H}$ ranged from 0.23 to 0.39 . The lowest value of $b_{H}$ was observed for August 1993, at the same time as the highest value of $b_{\lambda E}$ and the lowest surface to air temperature difference $\Delta T$. High values of $b_{H}$ were found for June and July 1993 and August 1994, generally months with lower values of $b_{\lambda E}$ and relatively high levels of $\Delta T$.

When differentiating between the same three surface conductivity classes $g_{\mathrm{s}}$ as done for $b_{\lambda E}$ for July 1993 and August 1994, Figure 4.6 and Table 4.4 illustrate that the dissipation of $R_{\mathrm{n}}$ as $H$ increased significantly if $g_{\mathrm{s}}$ decreased from $>1.0$ to $0.5-1.0 \mathrm{~cm} \mathrm{~s}^{-1}$. For a further decrease of $g_{\mathrm{s}}$ to $<0.5 \mathrm{~cm} \mathrm{~s}^{-1}$ a similar observation could be made as done for $b_{\lambda E}$ Fitted $b_{H}$ was insignificantly lower than for $g_{\mathrm{s}}$ values $0.5-1.0 \mathrm{~cm} \mathrm{~s}^{-1}$, and Figure 4.6 shows that in fact $b_{H}$ was similar for both $g_{s}$ classes $0.5-1.0$ and $<0.5 \mathrm{~cm} \mathrm{~s}^{-1}$. Moreover, in analogy to $b_{\lambda E}$ a distinct dissipation of $R_{\mathrm{n}}$ as $H$ seems to emerge, but this time as the upper boundary of $b_{H}$. 

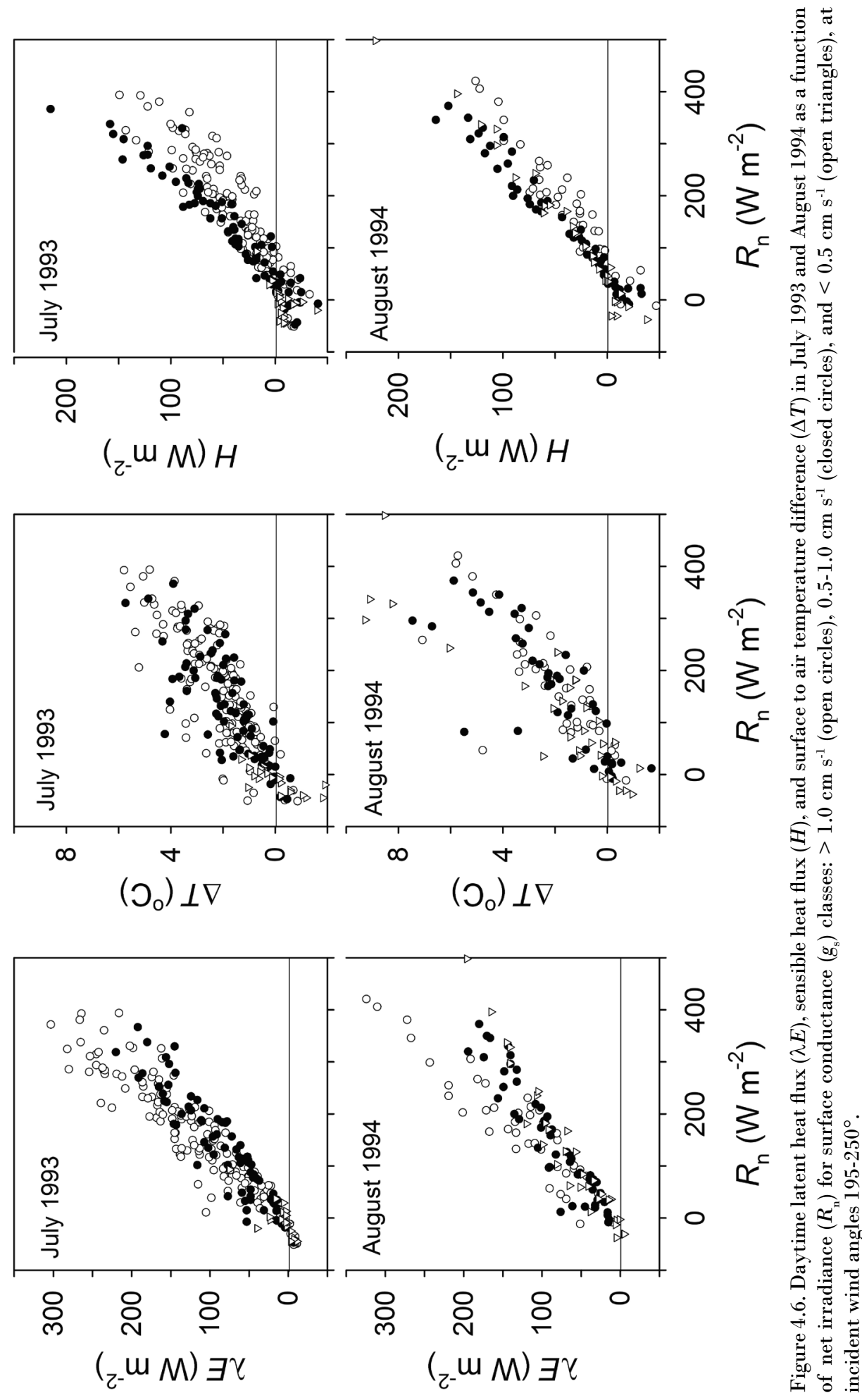


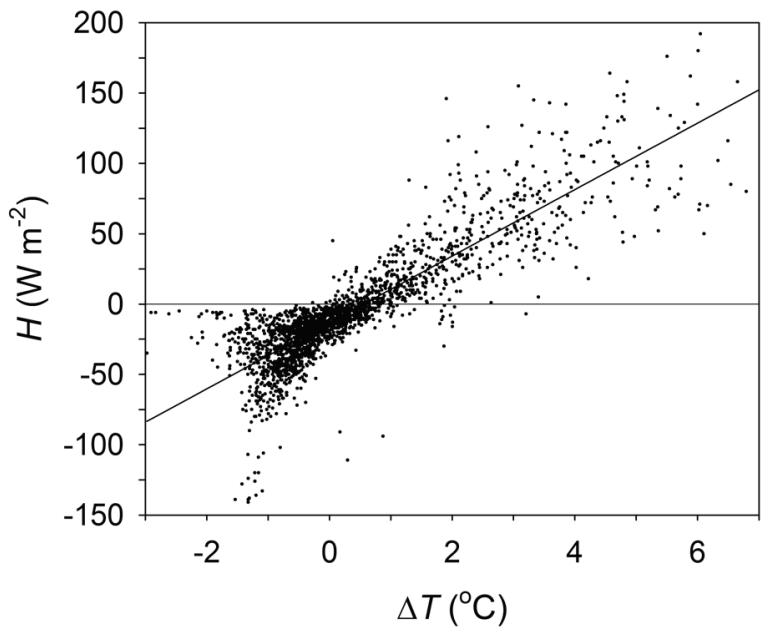

Figure 4.7. Sensible heat flux $(H)$ as a function of surface to air temperature difference $(\Delta T)$ in 1993 at incident wind angles $195-250^{\circ}$.

Figure 4.7 shows an apparently linear relationship between the surface to air temperature difference $\Delta T$ and sensible heat flux $H$. The fitted responses amounted to $24 \mathrm{~W} \mathrm{~m}^{-2}\left({ }^{\circ} \mathrm{C}\right)^{-1}$ in $1993\left(r^{2}=0.76, n=2105\right)$ and $21 \mathrm{~W} \mathrm{~m}^{-2}\left({ }^{\circ} \mathrm{C}\right)^{-1}$ in $1994\left(r^{2}=0.59, n=2701\right)$. However, many of the measurements were clustered in a less meaningful range of negative $\Delta T$ and negative $H$. In the data range of positive $\Delta T$ and positive $H$ the variation was substantial. When comparing the course of $\Delta T$ and $H$ for the different surface conductivity classes $g_{s}$, also Figure 4.6 indicates that the course of $H$ seemed only moderately related to $\Delta T$.

\subsubsection{Diurnal patterns and hysteresis}

To characterise hysteresis, latent heat flux $\lambda E$, sensible heat flux $H$, vapour pressure deficit $D$, surface to air temperature difference $\Delta T$ and surface conductance $g_{s}$ were clustered to monthly average diurnal patterns. Figure 4.8 compares the responses to net radiation $R_{\mathrm{n}}$ (the energy balance's driving force) before and after noon. The comparison was primarily done for August 1993 (a moderate summer month at an average air temperature of 15.6 ${ }^{\circ} \mathrm{C}$ ) and August 1994 (one of the driest months in the experimental period at an average air temperature of $17.4^{\circ} \mathrm{C}$ ).

$D$ in the afternoon was much higher than $D$ before noon, whereas general levels of $D$ - particularly in the afternoon - were higher in 1994 than in 1993. The course of $D$ was mirrored in the course of $g_{s}$, which was lower in the afternoon than before noon, particularly in 1994. In 1993 only modest hysteresis could be observed in $g_{s}$. In general, levels of $g_{s}$ were much lower in 1994 than in 1993. Lower $g_{s}$ in response to high levels of $D$ can be expected in the light of stomatal adjustment, but from the data it is not clear why hysteresis was so much more outspoken in 1994 than in 1993 and why $g_{\mathrm{s}}$ was 


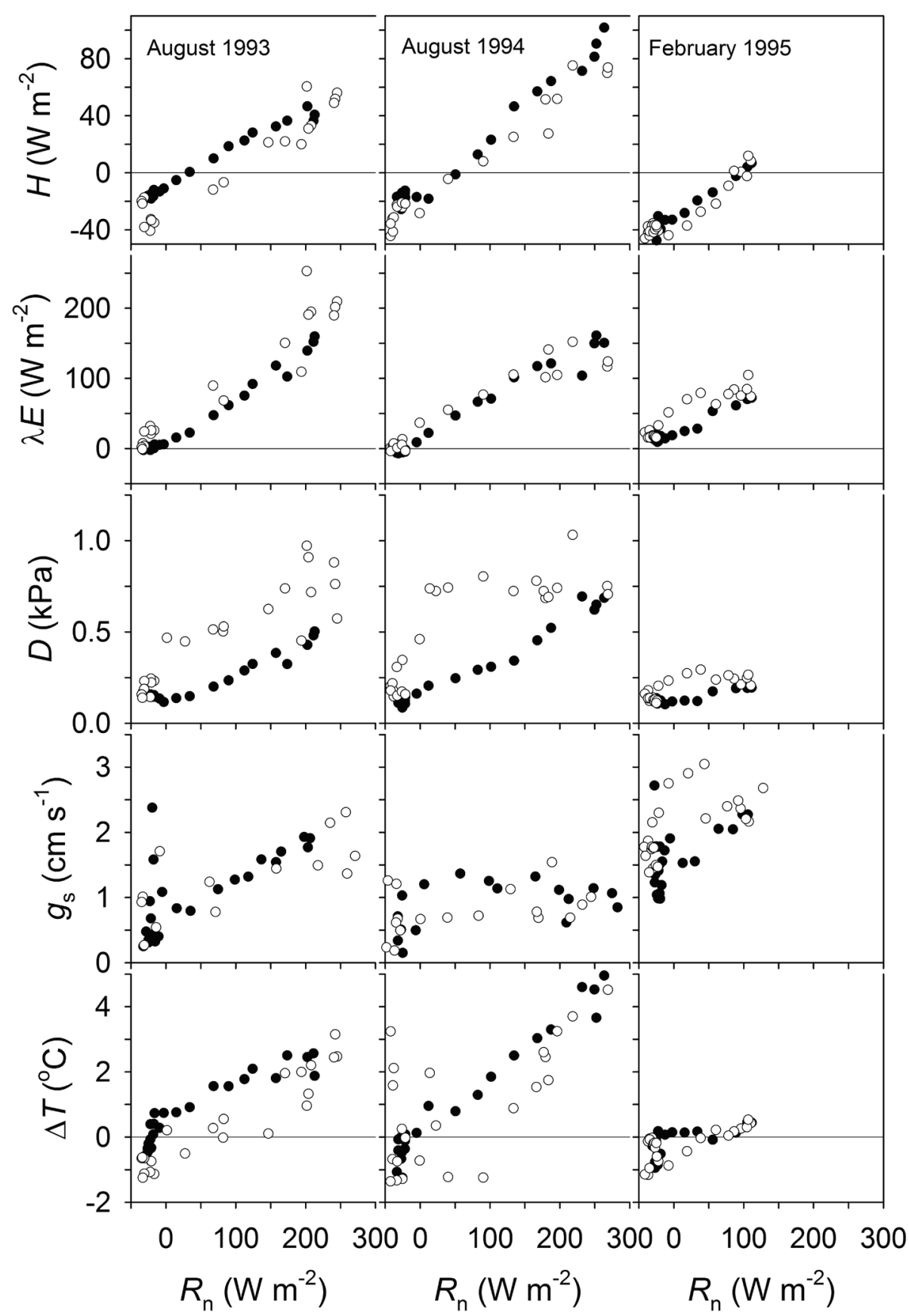

Figure 4.8. Average diurnal response to net irradiance $\left(R_{n}\right)$ of the sensible heat flux $(H)$, latent heat flux $(\lambda E)$, vapour pressure deficit $(D)$, surface conductance $\left(g_{\mathrm{s}}\right)$ and surface to air temperature difference $(\Delta T)$ before noon (closed symbols) and after noon (open symbols), at $195-250^{\circ}$; for each 30 minute average $n \geq 3$. 
generally much lower in 1994 than in 1993. Possibly 1994 was characterised by low soil moisture. $\lambda E$ followed $g_{\mathrm{s}}$ and particularly $D$, and was somewhat higher in the afternoon than before noon. The effects of $g_{\mathrm{s}}$ and $D$ on $\lambda E$ are opposed - decreasing and increasing $\lambda E$, respectively - and it appears that the lower afternoon $g_{s}$ effectively mitigated most but not all of the effect of high $D$. $H$ and $\Delta T$ mirrored the course of $\lambda E$. In the afternoon, a modestly elevated $\lambda E$ resulted in a modestly reduced $H$ as well as a lower $\Delta T$.

The pattern was slightly different in February 1995, such that a higher $D$ in the afternoon was associated with a higher $g_{s}$. The prevailing low levels of $D$ clearly did not affect $g_{s}$. But the effects of $D$ and $g_{\mathrm{s}}$ on the energy balance were consistent with those in August: a higher $D$ and higher $g_{s}$ in the afternoon combine to increase $\lambda E$ and decrease $H$ relative to the response before noon.

\subsection{DISCUSSION}

\subsubsection{Surface conductance}

The highest surface conductance $g_{\text {s(max) }}$ calculated in this study for conditions of nonlimiting irradiance and vapour pressure deficit in the spring and summer period ranged from approximately 2.0 to $5.0 \mathrm{~cm} \mathrm{~s}^{-1}$. Saugier and Katerji (1991) and Kelliher et al. (1995) found the maximum surface conductance to range from $0.9-1.7 \mathrm{~cm} \mathrm{~s}^{-1}$ in natural grasslands to $3.3-5.0 \mathrm{~cm} \mathrm{~s}^{-1}$ in crops. This agrees with the notion that productive pastureland in the Netherlands physiologically resembles cropland rather than natural grassland, at least from the viewpoint of productivity and grassland management.

Kelliher et al. (1995) noted that fitted $g_{\text {s(max })}$ values tend to be approximately $25 \%$ higher than observed $g_{s(\max )}$ values. $g_{s(\max )}$ values of $2.0-5.0 \mathrm{~cm} \mathrm{~s}^{-1}$ as calculated in this study by eliminating the effects of irradiance $R_{\mathrm{s}}$ and particularly vapour pressure deficit $D$ are theoretical as they are not actually attained. The study indicates an effect of $D$ on $g_{\text {s }}$ which is sustained through much of the growing season. But long-term patterns of $g_{s(\max )}$ also reflect the leaf area in a cut or grazed grass sward: it is high after the first period of regrowth in spring and gradually decreases towards late autumn. This could explain part of the observed pattern of $g_{s(\max )}$. More speculative were the fitted $g_{s(\max )}$ values of up to $7.0 \mathrm{~cm} \mathrm{~s}^{-1}$ for autumn as they were not nearly attained. In autumn, $\mathrm{CO}_{2}$ assimilation at lower irradiance may be limited by temperature and display low initial radiation use efficiency. Because of the close relationship between $\mathrm{CO}_{2}$ assimilation and $g_{\mathrm{s}}$ (Collatz et al. 1991, Leuning 1995) this limitation by temperature may also have resulted in a low initial response of $g_{s}$ to $R_{s}$ and in an apparent high $g_{s(\max )}$. 
The strong negative effect of vapour pressure deficit $D$ on surface conductance $g_{\text {s }}$ throughout much of the growing season as it emerges from this study agrees with other observations which show that stomatal conductance in grass is particularly sensitive to vapour pressure deficit (Woledge et al. 1989). It is possible that the effects of vapour pressure deficit and soil moisture on surface conductance were confounded as both are strongly correlated. However, a severe reduction in canopy $\mathrm{CO}_{2}$ assimilation and growth in a non-irrigated pasture on alluvial clay $50 \mathrm{~km}$ east of the site in August 1994, was largely alleviated by lowering $D$ (unpublished results).

The proposed effect of $D$ on $g_{s}$ consisted of (1) the range of $D$ over which $g_{s}$ was affected and (2) the relative effect on $g_{s}$ per unit of $D$. The analysis shows that an increasing $D$ and therefore increasing range of $D$ resulted in a concomitant increase in the vapour pressure deficit threshold where the effect on $g_{s}$ started to be felt. The range of $D$ over which $g_{s}$ was affected thus became larger and moved upwards. At the same time the relative effect on $g_{s}$ per unit of $D$ decreased. This pattern hints at a gradual adaptation of the grassland canopy's stomatal characteristics to changes in levels of vapour pressure deficit. As the negative effect of vapour pressure deficit on surface conductance was maintained over the greater part of the vapour pressure deficit range, it could be concluded that stomatal adjustment (Drake \& Salisbury 1972) permanently balanced between surface conductance requirements for both sustained $\mathrm{CO}_{2}$ assimilation (high surface conductance) and reduced transpiration (low surface conductance), occurring over the full range of irradiance. A deviation from this trend was observed for July and August 1993, where a negative effect of $D$ on $g_{s}$ was less outspoken. This may be related by the progressively lower levels of $D$ which characterised the period from June to August 1993.

\subsubsection{Energy balance}

Kim and Verma (1990) found a 10-25\% dissipation of net irradiance $\left(R_{\mathrm{n}}\right)$ as soil heat flux $(G)$ in a tallgrass prairie, where the variation was attributed to differences in surface cover and soil moisture. A $10 \%$ dissipation of $R_{\mathrm{n}}$ as $G$ in this study is modest, but in temperate pastures, surface cover and soil moisture are generally high and stable relative to $R_{\mathrm{n}}$ throughout much of the year.

Vapour pressure deficit $D$ has a direct unequivocally positive effect on the latent heat flux $\lambda E$. The surface conductance $\left(g_{s}\right)$ starts to negate this effect from a certain threshold value of $D$. Jarvis (1981) observed $g_{\text {s }}$ to moderate the effect of $D$ in Scots pine from 1.5 $\mathrm{kPa}$ onwards. Baldocchi et al. (1981) observed simultaneous increases in $D$ and $\lambda E$ and a decrease in downward $\mathrm{CO}_{2}$ flux in soybean under conditions of heat advection. Decreased $g_{\mathrm{s}}$ as a result of the heat possibly reduced $\mathrm{CO}_{2}$ assimilation but for $\lambda E$ was compensated for by $D$. In this study too, the direct and indirect effects of $D$ on $\lambda E$ increasingly offset each other, which was particularly visible in the patterns of hysteresis. This negating effect 
of $g_{\mathrm{s}}$ on the effect of $D$ was best observed for June 1993 and August 1994 (both months characterised by low $g_{s}$ ) and August 1993 (characterised by high $g_{s}$ ). Despite sustained high levels of $D, \lambda E$ increased less with $R_{\mathrm{n}}$ because of lower levels of $g_{\mathrm{s}}$, which was reflected in a low gradient of $\lambda E$ against $R_{\mathrm{n}}\left(b_{\lambda E}\right)$. Reduced $\lambda E$ resulted in an increased surface to air temperature difference $(\Delta T)$. August 1993 represented a situation where the effect of $D$ was only little affected by $g_{s}$, reflected in a high $b_{\lambda E}$ value of approximately 0.70 . Figure 4.6 indicates that $D$ may also increasingly override $g_{s}$. As $\lambda E$ was not further reduced at decreasing $g_{s}$ it may have been compensated for by high $D$.

The sensible heat flux $H$ complements the latent heat flux $\lambda E$. If low surface conductance $g_{s}$ occurring at high levels of vapour pressure deficit $D$ reduces $\lambda E$, the surface to air temperature difference $\Delta T$ increases. $H$ is the diffusion of heat and is primarily determined by $\Delta T$ and the aerodynamic conductance to water vapour $g_{a}$ as a measure for coupling between surface and atmosphere. This could be observed for June and July 1993 and August 1994, where reduced $\lambda E$ and increased $\Delta T$ increased the dissipation of net irradiance $R_{\mathrm{n}}$ as $H\left(b_{H}\right)$. August 1993 represents a situation with high levels of $g_{\mathrm{s}}$ and a low $b_{H}$ value of approximately 0.25 .

\subsubsection{Bowen ratio}

Impairment of the latent heat flux $\lambda E$ is reflected in the Bowen ratio $(\beta=H / \lambda E)$ as it increases with the sensible heat flux $H$. At a constant surface conductance $g_{s}$, Jarvis (1981) found $\beta$ to decrease when moving from a maritime to a continental climate. However, as high vapour pressure deficit $(D)$ started to reduce $g_{s}$, this progressively counteracted the increase in $\lambda E$ and thus increased $H$ through $\Delta T$. In a tallgrass prairie, Kim and Verma (1990) found $\beta$ to range from $0.3\left(D=1.8 \mathrm{kPa}\right.$ and $\left.g_{\mathrm{s}}=1.3 \mathrm{~cm} \mathrm{~s}^{-1}\right)$ to $1.3(D=4.3 \mathrm{kPa}$ and $g_{\mathrm{s}}=0.3 \mathrm{~cm} \mathrm{~s}^{-1}$, which shows that $\lambda E$ can be reduced substantially more than it was in the driest month in this experiment.

Table 4.3 also shows that at decreasing $g_{\mathrm{s}}$ (or increasing $\beta$ ) the dissipation of $R_{\mathrm{n}}$ into $\lambda E$ and $H$ added up to increasingly lower values. This may have resulted in an increased soil heat flux. To explore this phenomenon a simple calculation was done of an iterative energy balance of a hypothetical leaf (Jones 1992). It introduced Equation 4.1 for $\lambda E$, the standard equation for $H$ (Monteith \& Unsworth 1990) and the Stefan-Boltzmann Law for long-wave irradiance. This calculation suggests that for observed ranges of aerodynamic conductance $\left(g_{\mathrm{a}}\right)$ and surface conductance $\left(g_{\mathrm{s}}\right), \lambda E$ is only moderately affected by $g_{\mathrm{a}}$. As expected, a decrease in $g_{s}$ resulted in a decrease in $\lambda E$ and an increase in $\Delta T$ and $H$. The sum of $\lambda E$ and $H$ was positively correlated with $g_{s}$ : the lower $g_{s}$, the lower was the sum of $\lambda E$ and $H$. Low $g_{\mathrm{a}}$ reduced $H$ substantially and increased $\Delta T$, although in reality increased buoyancy may compensate to enhance $H$. 


$$
5
$$




\section{Chapter 5}

\section{The effect of drainage on $\mathrm{CO}_{2}$ exchange patterns in an intensively managed peat pasture}

Originally published as B.O.M. Dirks, A. Hensen \& J. Goudriaan, 2000. The effect of drainage on $\mathrm{CO}_{2}$ exchange patterns in an intensively managed peat pasture. Climate Research 14: 57-63. 


\section{SUMMARY}

Eddy covariance measurements of net $\mathrm{CO}_{2}$ exchange $\left(F_{\mathrm{n}}\right)$ were made during the growing season in an intensively managed peat pasture at drainage levels of 30 and $60 \mathrm{~cm}$ below surface. Deeper drainage was reflected in a stronger soil subsidence, which is hypothesised to be at least partly associated with higher levels of decomposition of organic matter in the aerobic soil profile. The experiment aimed to determine this difference in soil organic matter decomposition between both drainage levels. $F_{\mathrm{n}}$ was separated into a respiratory $\mathrm{CO}_{2}$ flux $(F)$ responding to temperature $\left(T_{\mathrm{a}}\right)$ and a gross assimilatory $\mathrm{CO}_{2}$ flux component $\left(F_{\mathrm{a}}\right)$ responding to shortwave irradiance $(R)$. The analysis shows that the reference respiratory $\mathrm{CO}_{2}$ flux at $20^{\circ} \mathrm{C}$ was consistently higher at the low than at the high groundwater table. The asymptotic gross assimilatory $\mathrm{CO}_{2}$ flux was higher at the low than at the high groundwater table during the growing season only. No such tendency was observed for the initial radiation use efficiency at zero irradiance $(\varepsilon)$. However, it is shown that the differences in $F_{\mathrm{a}}$ and $F_{\mathrm{r}}$ between both drainage levels could to a large extent be attributed to different weather patterns during measurement, as the experimental set-up included a weather bias due to the measurements for groundwater levels being associated with particular incident wind angles. $T_{\mathrm{a}}$ was an important factor in explaining patterns in both $F_{\mathrm{a}}$ and $F_{\mathrm{r}}$ by affecting $\varepsilon$ and levels of metabolic activity, respectively. At both drainage levels the peat pasture was a $\mathrm{CO}_{2}$ sink in spring and gradually turned into a $\mathrm{CO}_{2}$ source later in the season as the result of a simultaneously increasing $F_{\mathrm{r}}$ and decreasing $F$. A direct comparison of the $\mathrm{CO}_{2}$ fluxes between both drainage levels did not present a difference which could be attributed to a differential decomposition of peat soil in both aerobic soil profiles, although the temperature response of the respiratory $\mathrm{CO}_{2}$ flux as reflected in its activation energy was mildly stronger at the low groundwater table.

\subsection{INTRODUCTION}

A major $\mathrm{C}$ sink in the global $\mathrm{C}$ balance has been observed for the Northern Hemisphere (Ciais et al. 1995). A combination of ecosystem processes, land use changes and spatially explicit biomes has shown that this global $\mathrm{C}$ sink is the net result of a complex of smaller C sinks and sources (Box 1988, King et al. 1995, Klein Goldewijk et al. 1994, Schimel 1995). Land use has been seen as a major factor in the terrestrial C balance, in view of the large differences in typical biome C contents (Batjes \& Sombroek 1997, King et al. 1995, Wolf \& Janssen 1991). Over the last centuries, the conversion of large areas of natural and semi-natural grasslands and forests to arable land has constituted an important C source (Ojima et al. 1993, Schimel 1995). Management practices also affect the C balance in agroecosystems. Parton et al. (1987) showed that increased grazing reduced 
the $\mathrm{C}$ content in grasslands, whereas Fisher et al. (1994) suggested that the introduction of deeply rooting grasses increases the $\mathrm{C}$ content in savannas.

Peatland is a significant yet ambiguous biome in the global $\mathrm{C}$ cycle because of its high soil $\mathrm{C}$ content. Like many ecosystems, peatland accumulates $\mathrm{CO}_{2}$ under undisturbed (i.e. not drained) conditions but tends to emit $\mathrm{CO}_{2}$ under disturbed (i.e. drained) conditions (Francez \& Vasander 1995, Glenn et al. 1993, Laiho et al. 1996, Nykänen et al. 1995, Oades 1988, Silvola et al. 1996, Van Zandvoort et al. 2017). Peat soil subsidence at drainage is often seen as a rough measure for $\mathrm{CO}_{2}$ emissions, though little agreement exists on the fraction of the subsidence which can be attributed to the oxidation of $\mathrm{C}$ (Glenn et al. 1993, Schothorst 1982, Pleijter \& Van den Akker 2007). In the course of time, many peatlands have been partly drained and converted into productive grasslands or forests (Laiho et al. 1996).

In the Netherlands, $10 \%$ of the total land area consists of peat soils, whereas $20 \%$ of the pastureland is situated on peat soils that have been drained to varying extents (Langeveld et al. 1997). Most of this pastureland is centuries old, but several decades ago its drainage regime was intensified to increase productivity and improve management practices (Schothorst 1982). Deeper and more effective drainage has also been shown to increase soil subsidence. This study compares micrometeorological $\mathrm{CO}_{2}$ flux measurements done in an experimental peat pasture site during the growing season at two different levels of drainage. It quantifies and characterises the assimilatory and respiratory processes in relation to the drainage levels. The $\mathrm{CO}_{2}$ flux processes are used to discuss differences in the respiratory $\mathrm{CO}_{2}$ flux between both drainage levels which could be attributed to an enhanced decomposition of peat in the aerobic soil profile as a result of a deeper drainage.

\subsection{MATERIALS AND METHODS}

\subsubsection{Experimental site}

Measurements were done at the experimental farm ROC Zegveld near Zegveld in the Netherlands $\left(52^{\circ} 7^{\prime} \mathrm{N}, 4^{\circ} 52^{\prime} \mathrm{E}\right)$. The land use is characterised as pastureland, predominantly consisting of Lolium perenne and used for intensive dairy farming at a density of 1.5 heads of cattle per ha, with mixed grazing and mowing. The soil is a peat soil (Terric Histosol) with a massive peat layer (wood sedge peat) up to a depth of $7 \mathrm{~m}$. The soil top $0.2 \mathrm{~m}$ has a relatively high clay content of $30 \%$ (Velthof \& Oenema 1995). The land has been under cultivation since about the year $1000 \mathrm{AD}$. The pastures are situated in long strips of land alternated by small waterways of $2 \mathrm{~m}$ width at every 50 $\mathrm{m}$, covering approximately $5 \%$ of the total surface. Two different drainage regimes have been imposed since 1969. The pastureland characteristics are presented in Table 5.1. 
Table 5.1. Characteristics of the pastures in Zegveld at two different levels of drainage. Source: ROC Zegveld (pers.comm.), Velthof and Oenema (1995).

\begin{tabular}{llllll}
\hline $\begin{array}{l}\text { groundwater } \\
\text { table }\end{array}$ & $\begin{array}{l}\text { incident wind } \\
\text { angles }\end{array}$ & $\begin{array}{l}\text { vertical distance } \\
\text { waterway-land surface } \\
(\mathbf{c m})\end{array}$ & $\begin{array}{l}\text { soil } \\
\text { subsidence } \\
\left(\mathbf{c m ~ y}^{-1}\right)\end{array}$ & $\begin{array}{l}\mathbf{C} \text { content } \\
\text { top } \mathbf{0 . 2} \mathbf{~ m} \\
\left(\mathbf{k g ~ k g}_{\mathbf{~}} \mathbf{)}\right.\end{array}$ & $\begin{array}{l}\mathrm{C} / \mathrm{N} \text { ratio } \\
\text { top } \mathbf{0 . 2} \mathbf{~ m} \\
(-)\end{array}$ \\
\hline high & $7-74^{\circ} \& 187-272^{\circ}$ & 30 & 0.5 & 0.156 & 9.6 \\
low & $74-187^{\circ} \& 272-334^{\circ}$ & 60 & 1.1 & 0.223 & 12.0 \\
\hline
\end{tabular}

Fluxes at high groundwater tables (waterway $0.3 \mathrm{~m}$ below ground level) were measured at incident wind angles $7-74^{\circ}$ and $187-272^{\circ}$. Fluxes at low groundwater tables (waterway $0.6 \mathrm{~m}$ below ground level) were measured at incident wind angles $74-187^{\circ}$ and $272-334^{\circ}$.

\subsection{2. $\mathrm{CO}_{2}$ flux and meteorological measurements}

Eddy covariance measurements of $\mathrm{CO}_{2}$ exchange were done by the Netherlands Energy Research Foundation (ECN) in 1994, from April to June and from August to October. The measurements were made on an open frame tower at a height of $4 \mathrm{~m}$. The sonic anemometer (Applied Technologies, Inc., Boulder CO; model SWS-211/3K) and the $\mathrm{CO}_{2}$ sampling inlet were located at the south side. The tower was also equipped with temperature sensors and cup anemometers at 1,2 and $5 \mathrm{~m}$ height. $\mathrm{CO}_{2}$ and $\mathrm{H}_{2} \mathrm{O}$ concentrations were measured with a NDIR (LI-COR, Inc., Lincoln NE; model LI6262), using fast solid state detectors. The $\mathrm{CO}_{2}$ concentration was corrected for the density fluctuations due to $\mathrm{H}_{2} \mathrm{O}$ and temperature (Webb correction: Hensen et al. 1995). The air flow was $7.51 \mathrm{~min}^{-1}$, whereas the reference $\mathrm{N}_{2}$ flow was $50 \mathrm{ml} \mathrm{min}{ }^{-1}$. The $5 \mathrm{~m}$ long and 0.25 inch $(0.635 \mathrm{~cm})$ wide polyethylene tube was isolated with a $1 \mathrm{~cm}$ thick layer of foam to prevent condensation. The air sample and reference flows were regulated by mass flow controllers. Air pressure was measured and used for instantaneous pressure correction of the $\mathrm{CO}_{2}$ and $\mathrm{H}_{2} \mathrm{O}$ measurements.

Calibration of the NDIR was done every day at 10:00 h using $\mathrm{N}_{2}$ as zero gas; the standards were calibrated against NOAA station standards. The zero drift of the monitor was generally less than $1 \mu \mathrm{mol} \mathrm{mol}^{-1} \mathrm{~d}^{-1}$. The span drift was less than $0.5 \mu \mathrm{mol} \mathrm{mol}^{-1} \mathrm{~d}^{-1}$ (i.e. $0.1 \%$ ) and therefore negligible. The short-time reproducibility of the monitor at 360 $\mu \mathrm{mol} \mathrm{mol}^{-1}$ was $0.1 \mu \mathrm{mol} \mathrm{mol}^{-1}$. The $10 \mathrm{~Hz}$ analogue output of the NDIR was connected to the analogue input of the sonic anemometer. Since the $\mathrm{CO}_{2}$ concentration was monitored with a closed path sensor, a delay occurred between the fluctuating component of the vertical wind velocity $\left(w^{\prime}\right)$ and the corresponding $\mathrm{CO}_{2}$ signal $\left(c^{\prime}\right)$. This delay was determined by recalculating the $\mathrm{CO}_{2}$ flux with several time delays, thus optimising the correlation between $w^{\prime}$ and $c^{\prime}$. All measurements with a drag coefficient $\left(C_{\text {drag }}=u_{*}^{2} / u^{2}\right)$ higher than 0.02 ( $8 \%$ of the total) were discarded to avoid non-homogeneous flow. All measurements made between wind angles $350^{\circ}$ and $30^{\circ}$ (15\% of the total) were omitted 
because of disturbance by the tower. Between $30^{\circ}$ and $350^{\circ}$ an undisturbed footprint of more than $1 \mathrm{~km}$ distance was available, even though the technique only required a footprint of approximately $0.5 \mathrm{~km}$ (at a measurement height of $4 \mathrm{~m}$ ). Shortwave irradiance $(0.3-3 \mathrm{~mm})$ was measured using a Kipp CM11 pyranometer, which was ventilated to prevent condensation on the dome. The pyranometer was equipped with a shadow band to measure diffuse irradiance.

In the experimental setup four alternating pastures - with successively high, low, high and low groundwater tables - touched at the centrally located mast on which the flux and meteorological measurements were made. The two high groundwater table fields were located at incident wind angles $7-74^{\circ}$ and $187-272^{\circ}$, whereas the two low groundwater table fields were located at incident wind angles $74-187^{\circ}$ and $272-334^{\circ}$. Measurements at a specific groundwater table were thus made only at specific incident wind angles, which can introduce a weather bias. Measurements at the high groundwater table were thus made at the north-easterly and south-westerly wind direction quadrants, whereas measurements at the low groundwater table were made at the south-easterly and northwesterly wind direction quadrants. As the weather bias can introduce differences in levels of irradiance, temperature, air humidity and precipitation the $\mathrm{CO}_{2}$ fluxes at both drainage levels do not necessarily compare instantly. Comparison of the $\mathrm{CO}_{2}$ fluxes thus requires a process-based analysis, which normalises the $\mathrm{CO}_{2}$ fluxes for environmental conditions and levels of primary productivity.

\subsection{3. $\mathrm{CO}_{2}$ fluxes}

To calculate the system's respiratory $(F)$ and gross assimilatory $\mathrm{CO}_{2}$ fluxes $\left(F_{\mathrm{a}}\right)$ a distinction was made between the night-time and daytime $\mathrm{CO}_{2}$ fluxes (Ruimy et al. 1995). As assimilatory activity is largely absent during the night-time period the nighttime $\mathrm{CO}_{2}$ flux was assumed to exclusively represent the respiratory $\mathrm{CO}_{2}$ flux. The nighttime $\mathrm{CO}_{2}$ flux thus allows for characterisation of the respiratory $\mathrm{CO}_{2}$ flux. Subtraction of the (upward) respiratory $\mathrm{CO}_{2}$ flux $(F)$ from the (generally downward) daytime net $\mathrm{CO}_{2}$ flux $\left(F_{\mathrm{n}}\right)$ calculates the downward gross assimilatory $\mathrm{CO}_{2}$ flux $\left(F_{\mathrm{a}}\right)$. While characterising the respiratory $\mathrm{CO}_{2}$ flux, night-time $\mathrm{CO}_{2}$ flux values within 30 minutes from sunset and before sunrise were excluded from analysis to avoid anomalous effects as a result of twilight. Non-linear regression analysis was done using the Marquardt-Levenberg algorithm (Fox et al. 1994).

\subsubsection{Respiratory $\mathrm{CO}_{2}$ flux}

The dependence of respiratory activity on temperature is well established. To characterise the dependence of the night-time respiratory $\mathrm{CO}_{2}$ flux $(F)$ on temperature an Arrhenius temperature dependence was assumed: 
$F_{\mathrm{r}}=F_{\mathrm{r}(20)} \times \mathrm{e}^{(1 / 293-1 /(273+T \mathrm{a})) \times E / R}$

where $F_{\mathrm{r}(20)}$ is the reference respiratory $\mathrm{CO}_{2}$ flux at $20{ }^{\circ} \mathrm{C}\left(\mathrm{mg} \mathrm{CO}_{2} \mathrm{~m}^{-2} \mathrm{~s}^{-1}\right), T_{\mathrm{a}}$ is the temperature at $1 \mathrm{~m}$ height $\left({ }^{\circ} \mathrm{C}\right), E$ is the activation energy $\left(\mathrm{J} \mathrm{mol}^{-1}\right)$ and $R$ is the universal gas constant $\left(8.314 \mathrm{~J} \mathrm{~mol}^{-1} \mathrm{~K}^{-1}\right)$.

The monthly responses of the respiratory $\mathrm{CO}_{2}$ flux $\left(F_{\mathrm{r}}\right)$ to temperature were determined by fitting Equation 5.1 to the night-time $\mathrm{CO}_{2}$ fluxes and air temperatures $(T)$ of the entire experimental period simultaneously. The activation energy $(E)$ was assumed to be constant across months (Lloyd \& Taylor 1994). The reference respiratory $\mathrm{CO}_{2}$ flux $\left(F_{\mathrm{r}(20)}\right)$ is a measure for metabolically active biomass and was fitted to monthly values instead. It is subsequently assumed that the response of the instantaneous night-time $\mathrm{CO}_{2}$ flux to temperature equates the response of any instantaneous respiratory $\mathrm{CO}_{2}$ flux to temperature, which allows the calculation of the daytime respiratory $\mathrm{CO}_{2}$ flux by means of extrapolation.

\subsubsection{Assimilatory $\mathrm{CO}_{2}$ flux}

The daytime respiratory $\mathrm{CO}_{2}$ flux $(F)$ was calculated from the response of the night-time $\mathrm{CO}_{2}$ flux to temperature and the current air temperature $\left(T T_{\mathrm{a}}\right) \cdot F_{\mathrm{r}}$ was subtracted from the measured daytime net $\mathrm{CO}_{2}$ flux $\left(F_{\mathrm{n}}\right)$ to obtain the instantaneous gross assimilatory $\mathrm{CO}_{2}$ flux $\left(F_{\mathrm{a}}\right)$. As its primary environmental response $F_{\mathrm{a}}$ was fitted to the shortwave irradiance $(R)$ using a conventional rectangular hyperbola:

$F_{\mathrm{a}}=-\varepsilon \times F_{\mathrm{a}(\max )} \times R_{\mathrm{s}} /\left(\varepsilon \times R_{\mathrm{s}}+F_{\mathrm{a}(\max )}\right)$

where $F_{\mathrm{a}(\max )}$ is the asymptotic value of the gross assimilatory $\mathrm{CO}_{2}$ flux $\left(\mathrm{mg} \mathrm{CO} \mathrm{m}^{-2} \mathrm{~s}^{-1}\right)$ and $\varepsilon$ is the initial radiation use efficiency at zero irradiance $\left(\mathrm{mg} \mathrm{J}^{-1}\right)$.

\subsubsection{Data aggregation and analysis}

Instantaneous assimilatory and respiratory fluxes at both drainage levels are calculated on basis of Equations 5.1 and 5.2. The instantaneous flux values are evaluated in relation to their main environmental drivers and in relation to each other.

To further compare the monthly $\mathrm{CO}_{2}$ exchange fluxes between both groundwater tables, the instantaneous flux and meteorological measurements were aggregated into monthly average diurnal patterns of net $\mathrm{CO}_{2}$ exchange $\left(F_{\mathrm{n}}\right)$, air temperature $\left(T_{\mathrm{a}}\right)$ and irradiance $(R)$ each consisting of 48 half-hourly values. These diurnal patterns were derived directly from the measurements, i.e. 48 monthly averages of the original half-hourly averages (at $n$ $\geq 3$ ). Monthly average diurnal patterns of the respiratory $\left(F_{\mathrm{r}}\right)$ and gross assimilatory $\mathrm{CO}_{2}$ flux $\left(F_{\mathrm{a}}\right)$ were obtained by applying Equations 5.1 and 5.2 to the average diurnal patterns 
of $F_{\mathrm{n}}, T_{\mathrm{a}}$ and $R_{\mathrm{s}}$. The monthly average daily net, respiratory and gross assimilatory $\mathrm{CO}_{2}$ fluxes are then calculated as the numerical integrals of diurnal $F_{\mathrm{n}}, F_{\mathrm{r}}$ and $F_{\mathrm{a}}$.

\subsection{RESULTS}

\subsubsection{Respiratory $\mathrm{CO}_{2}$ flux}

On fitting Equation 5.1 to the instantaneous night-time $\mathrm{CO}_{2}$ flux and air temperature measurements, an activation energy $(E)$ of $66.7 \mathrm{~kJ} \mathrm{~mol}^{-1}$ was calculated for the high groundwater table $\left(r^{2}=0.25, n=668, P<0.0001\right)$ and $78.3 \mathrm{~kJ} \mathrm{~mol}^{-1}$ for the low groundwater table $\left(r^{2}=0.30, n=559, P<0.0001\right)$. This indicates that the response of the respiratory $\mathrm{CO}_{2}$ flux was stronger at the low groundwater table, which is reflected in the corresponding $Q_{10}$ values of 2.6 and 3.1, respectively. Figure 5.1 compares the responses of the respiratory $\mathrm{CO}_{2}$ flux $\left(F_{\mathrm{r}}\right)$ to air temperature $\left(T_{\mathrm{a}}\right)$ between both drainage levels for a constant activation energy $(E)$ and an activation energy decreasing with temperature (Lloyd \& Taylor 1994). A progressively decreasing $E$ has the effect of decreasing the fitted respiratory $\mathrm{CO}_{2}$ flux. At a $T_{\mathrm{a}}$ value of $20{ }^{\circ} \mathrm{C}$ the average difference in $F_{\mathrm{r}}$ between both groundwater tables was approximately $0.05 \mathrm{mg} \mathrm{CO}_{2} \mathrm{~m}^{-2} \mathrm{~s}^{-1}$ at constant $E$ and $0.03 \mathrm{mg}$ $\mathrm{CO}_{2} \mathrm{~m}^{-2} \mathrm{~s}^{-1}$ for the relationship proposed by Lloyd and Taylor (1994). Either response function leads to the conclusion that the low groundwater table resulted in the strongest response to air temperature.

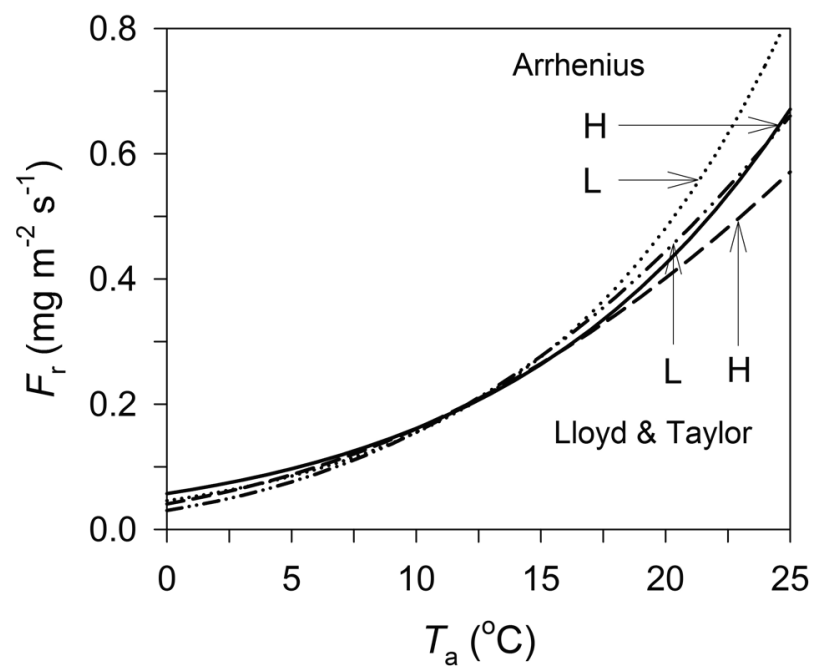

Figure 5.1. Fitted response of respiratory $\mathrm{CO}_{2}$ flux $\left(F_{\mathrm{r}}\right)$ to air temperature $\left(T_{\mathrm{a}}\right)$, at high $(\mathrm{H})$ and low groundwater table (L) for both the Arrhenius and Lloyd \& Taylor equations. 
The effect of drainage level on the response of the instantaneous night-time $\mathrm{CO}_{2}$ flux to $T_{\mathrm{a}}$ is plotted in Figure 5.2. The slopes of the curves show that $F_{\mathrm{r}}$ responded consistently stronger to $T_{\mathrm{a}}$ at the low than at the high groundwater table. In May and August the measured ranges of the night-time $\mathrm{CO}_{2}$ flux showed that $F_{\mathrm{r}}$ was higher at the low groundwater table, whereas in the other months the differences in $F_{\mathrm{r}}$ between both drainage levels became apparent only after extrapolation into the daytime temperature range.
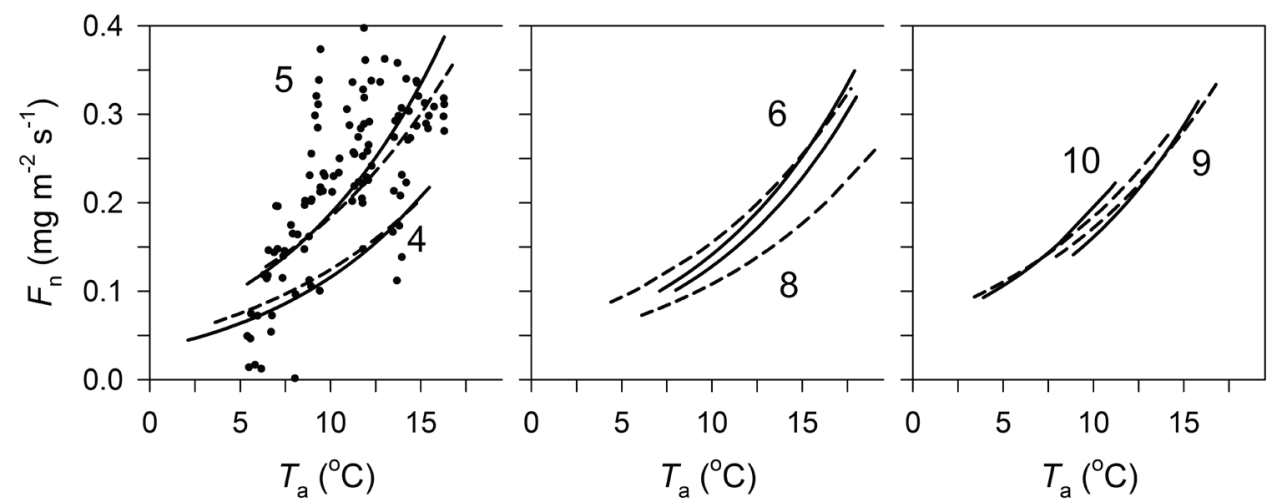

Figure 5.2. Fitted monthly responses of night-time $\mathrm{CO}_{2}$ flux $\left(F_{\mathrm{r}}\right)$ to air temperature $\left(T_{\mathrm{a}}\right)$, at high (broken line) and low groundwater tables (drawn line). Measurements at low groundwater table in May 1994 shown by dots.

The monthly reference respiratory $\mathrm{CO}_{2}$ flux $F_{\mathrm{r}(20)}$ is a measure for metabolically active biomass.

Table 5.2 shows that $F_{\mathrm{r}(20)}$ started at approximately $0.33-0.36 \mathrm{mg} \mathrm{CO}_{2} \mathrm{~m}^{-2} \mathrm{~s}^{-1}$ in April and increased to $0.48-0.59 \mathrm{mg} \mathrm{CO}_{2} \mathrm{~m}^{-2} \mathrm{~s}^{-1}$ in May. $F_{\mathrm{r}(20)}$ was maintained at $0.41-0.60 \mathrm{mg} \mathrm{CO}_{2}$ $\mathrm{m}^{-2} \mathrm{~s}^{-1}$ during most of the experimental period, whereas August saw a temporary decline to $0.28-0.40 \mathrm{mg} \mathrm{CO}_{2} \mathrm{~m}^{-2} \mathrm{~s}^{-1} . F_{\mathrm{r}(20)}$ was consistently higher at the low groundwater table. The biggest differences between both drainage levels were observed in May, August and October at $0.10-0.12 \mathrm{mg} \mathrm{CO}_{2} \mathrm{~m}^{-2} \mathrm{~s}^{-1}$. In the remaining months the difference in $F_{\mathrm{r}(20)}$ was smaller at $0.03-0.05 \mathrm{mg} \mathrm{CO} \mathrm{m}^{-2} \mathrm{~s}^{-1}$.

\subsubsection{Assimilatory $\mathrm{CO}_{2}$ flux}

The instantaneous gross assimilatory $\mathrm{CO}_{2}$ flux $\left(F_{\mathrm{a}}\right)$ was calculated from the daytime net $\mathrm{CO}_{2}$ flux $\left(F_{\mathrm{n}}\right)$, the response of the respiratory $\mathrm{CO}_{2}$ flux $\left(F_{\mathrm{r}}\right)$ to air temperature $\left(T_{\mathrm{a}}\right)$ and the current air temperature. On fitting Equation 5.2 to $F_{\mathrm{a}}$ and the shortwave irradiance $(R)$ the asymptotic assimilatory $\mathrm{CO}_{2}$ flux $\left(F_{\mathrm{a}(\max )}\right)$ and the initial radiation use efficiency at zero irradiance $(\varepsilon)$ were derived. Table 5.2 shows that $F_{a(\max )}$ ranged from 1.01 to $4.07 \mathrm{mg}$ 


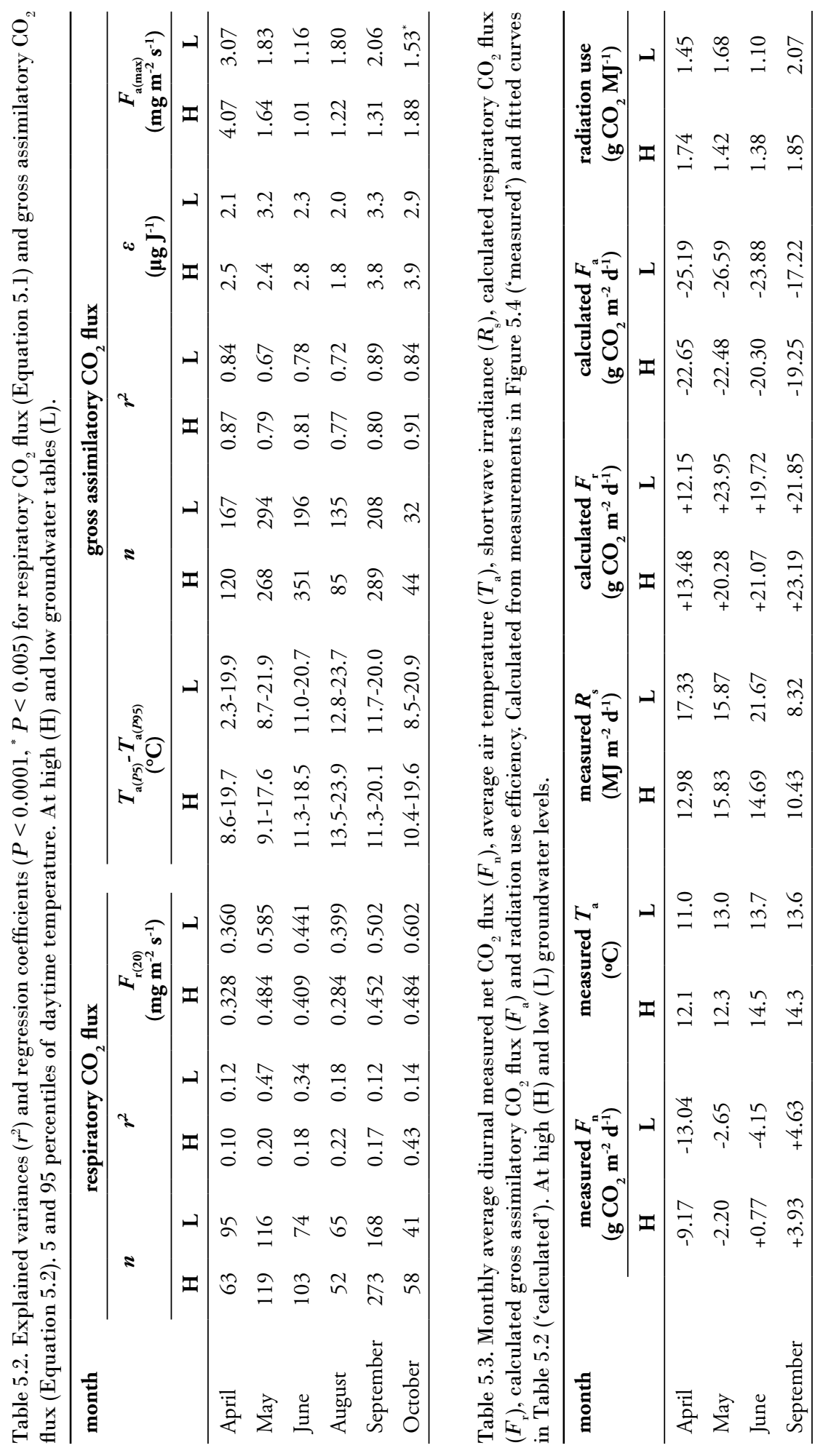



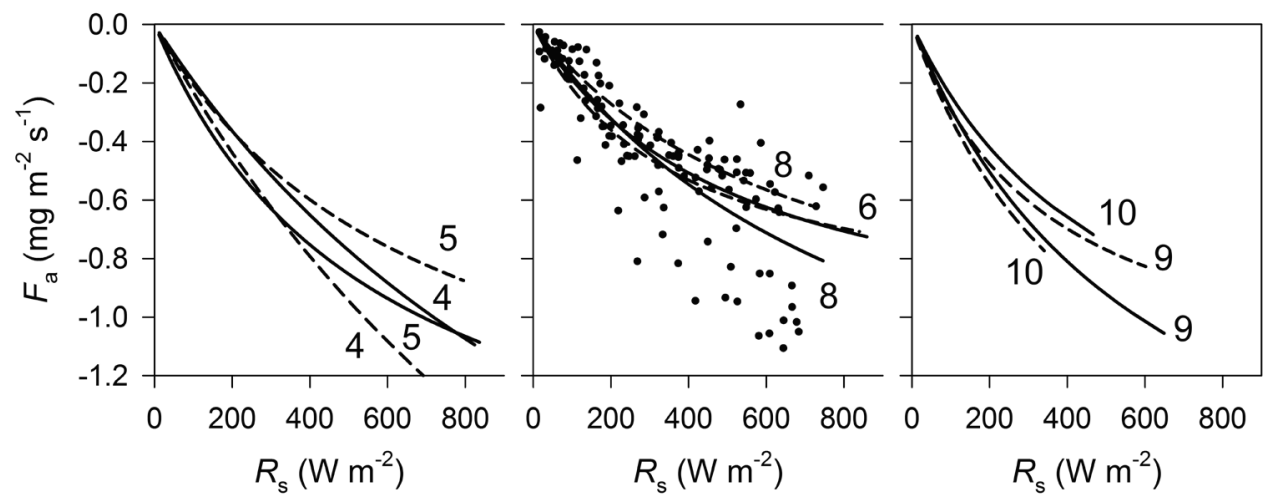

Figure 5.3. Fitted monthly responses of gross assimilatory $\mathrm{CO}_{2}$ flux $\left(F_{\mathrm{a}}\right)$ to shortwave irradiance $\left(R_{\mathrm{s}}\right)$, at high (broken line) and low groundwater tables (drawn line). Measurements at low groundwater table in August 1994 shown by dots.

$\mathrm{CO}_{2} \mathrm{~m}^{-2} \mathrm{~s}^{-1}$ and the initial radiation use efficiency from 1.8 to $3.9 \mu \mathrm{g} \mathrm{CO}_{2} \mathrm{~J}^{-1}$. However, Figure 5.3 indicates that $F_{\mathrm{a}}$ itself rarely exceeded $1.10 \mathrm{mg} \mathrm{CO}_{2} \mathrm{~m}^{-2} \mathrm{~s}^{-1}$.

Table 5.2 shows that levels of $F_{\mathrm{a}}$ were generally higher at the low groundwater table. Figure 5.3 also shows that the actual response of $F_{\mathrm{a}}$ to $R_{\mathrm{s}}$ was mostly stronger at the low groundwater table. Excepted from this trend was the growing season's periphery in April and October, where $F_{\mathrm{a}}$ was higher at the high groundwater table. This observation could be related to a weather bias in the measurements and its effect on the response of the assimilatory $\mathrm{CO}_{2}$ flux $\left(F_{\mathrm{a}}\right)$ to irradiance $(R)$. Fluxes at high groundwater tables were measured at north-easterly and south-westerly winds and fluxes at low groundwater tables at south-easterly and north-westerly winds, resulting in a correlation between drainage regime and weather type. It has been shown that the response of the assimilatory $\mathrm{CO}_{2}$ flux to radiation is strongly mediated by temperature, both a sward level (Woledge $\&$ Dennis 1982) and ecosystem level (Chapter 3). Table 5.2 shows that $\varepsilon$ was lower at the low groundwater table in April and October, indicating that measurements may have been done at limiting air temperature. The lower ends of the measured temperature spectrum were 2.3 and $8.5^{\circ} \mathrm{C}$, respectively, as opposed to 8.6 and $10.4^{\circ} \mathrm{C}$ at the high groundwater table. Limiting air temperature during measurement may thus have caused April and October to deviate from the general trend of a higher assimilatory $\mathrm{CO}_{2}$ flux at the low groundwater table.

\subsubsection{Diurnal patterns of $\mathrm{CO}_{2}$ exchange}

Figure 5.4 presents the aggregated monthly diurnal patterns for the measured net $\mathrm{CO}_{2}$ flux $\left(F_{\mathrm{n}}\right)$, shortwave irradiance $\left(R_{\mathrm{s}}\right)$ and air temperature $\left(T_{\mathrm{a}}\right)$ differentiated by drainage level for April, May, June and September 1994. The aggregated monthly daily net $\mathrm{CO}_{2}$ 


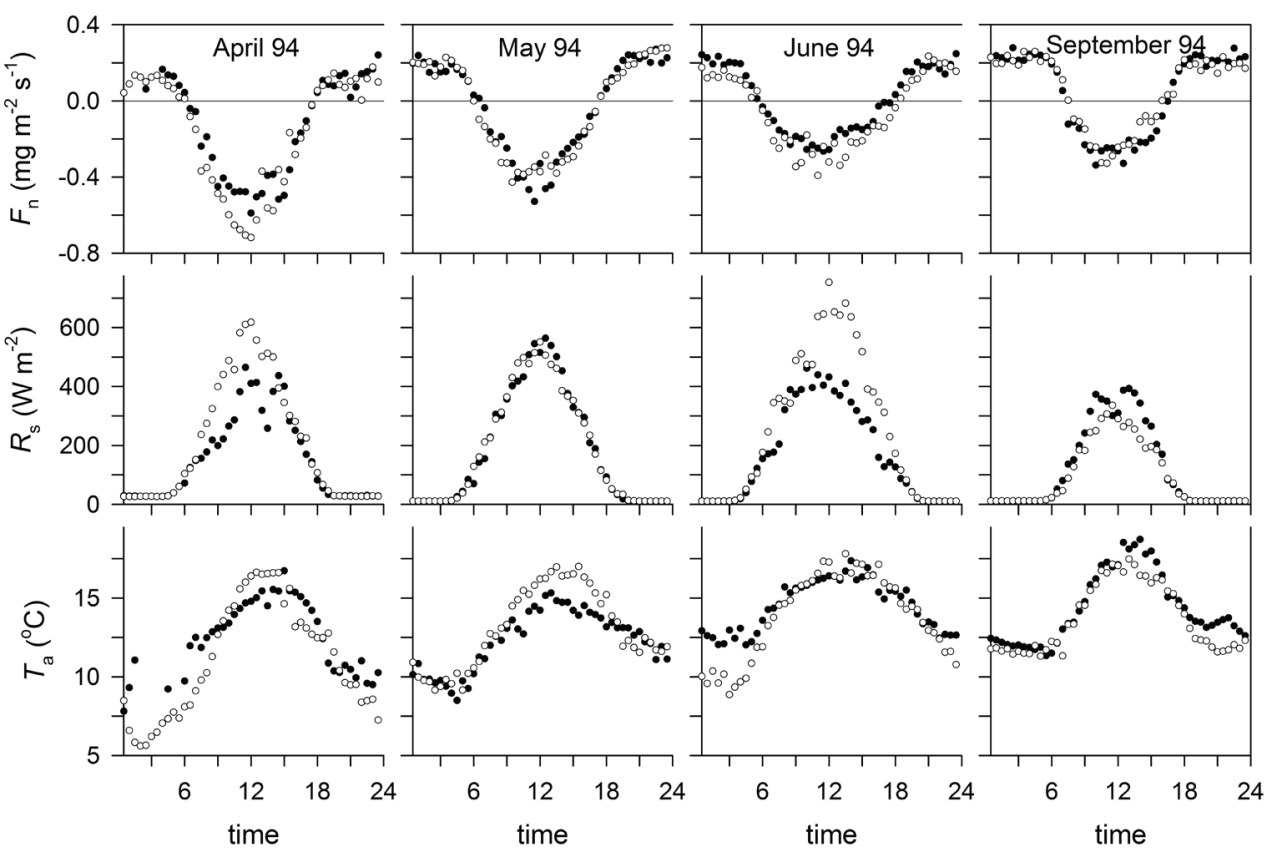

Figure 5.4. Monthly average diurnal patterns of measured net $\mathrm{CO}_{2}$ flux $\left(F_{\mathrm{n}}\right)$, shortwave irradiance $\left(R_{\mathrm{s}}\right)$ and air temperature $\left(T_{\mathrm{a}}\right)$, at high (closed symbols) and low groundwater tables (open symbols). For each 30 minute average $n \geq 3$.

exchange is calculated as the sum of the values in Figure 5.4 and listed in Table 5.3 under 'measured $F_{\mathrm{n}}$ '. At both drainage levels the pastureland acted as a $\mathrm{CO}_{2}$ sink from April up to June and subsequently changed into a $\mathrm{CO}_{2}$ source. The measurements at the low groundwater table were associated with the strongest $\mathrm{CO}_{2}$ sinks, with $F_{\mathrm{n}}$ ranging from +4.63 to $-13.04 \mathrm{~g} \mathrm{CO}_{2} \mathrm{~m}^{-2} \mathrm{~d}^{-1}$ as compared to +3.93 to $-9.17 \mathrm{~g} \mathrm{CO}_{2} \mathrm{~m}^{-2} \mathrm{~d}^{-1}$ at the high groundwater table. However, the patterns of the assimilatory $\mathrm{CO}_{2}$ flux $\left(F_{\mathrm{a}}\right)$ and the respiratory $\mathrm{CO}_{2}$ flux $(F)$ were indistinct. In April and June $F_{\mathrm{a}}$ was higher at the low groundwater table and $F_{\mathrm{r}}$ was moderately higher at the high groundwater table. In May high $F_{\mathrm{r}}$ coincided with high $F_{\mathrm{a}}$ at the low groundwater table, whereas in September $F_{\mathrm{a}}$ was moderately higher at the high groundwater table. A potential weather bias in the flux measurements is presented in the aggregated monthly diurnal courses of air temperature $\left(T_{\mathrm{a}}\right)$ and shortwave irradiance $(R)$ in Figure 5.4 and their aggregated monthly daily values in Table 5.3, which show substantial differences between the measurement conditions at both drainage levels. 


\subsection{DISCUSSION}

\subsubsection{Assimilatory $\mathrm{CO}_{2}$ flux}

The monthly asymptotic assimilatory $\mathrm{CO}_{2}$ flux $F_{\mathrm{a}(\max )}$ in the response of the gross assimilatory $\mathrm{CO}_{2}$ flux $F_{\mathrm{a}}$ to shortwave irradiance $R_{\mathrm{s}}$ ranged from 1.01 to $4.07 \mathrm{mg} \mathrm{CO}_{2} \mathrm{~m}^{-2}$ $\mathrm{s}^{-1}$. Figure 5.3 shows that $F_{\mathrm{a}(\max )}$ was never actually attained, suggesting that the assimilatory $\mathrm{CO}_{2}$ flux $(F)$ never exhibited light saturation. This is counter-intuitive as light-saturation in photosynthesis has been observed in countless experimental setups (Hall et al. 1993, Lawlor 1987). Lloyd and Taylor (1994) found that an Arrhenius relationship between respiratory rate and temperature - applied in this study to characterise the relationship between respiratory $\mathrm{CO}_{2}$ flux $(F)$ and air temperature $\left(T_{\mathrm{a}}\right)$ - could underestimate the rate at low temperature and overestimate the rate at high temperature. As the calculated respiratory $\mathrm{CO}_{2}$ flux $\left(F_{\mathrm{r}}\right)$ is subtracted from the measured net $\mathrm{CO}_{2}$ flux $\left(F_{\mathrm{n}}\right)$ to obtain the gross assimilatory $\mathrm{CO}_{2}$ flux $\left(F_{\mathrm{a}}\right)$, this could result in an underestimation of $F_{\mathrm{a}}$ at low temperature and low irradiance and an overestimation of $F_{\mathrm{a}}$ at high temperature and high irradiance. This could transform the response curve such that its asymptotic value is less likely to be reached. However, in an analysis of data from the similar experimental setup in Chapter 3, the application of a decreasing activation energy at increasing temperature as proposed by Lloyd and Taylor (1994) did not lead to a greatly different result. At a both constant and decreasing activation energy the asymptotic assimilatory $\mathrm{CO}_{2}$ flux was rarely ever attained, indicating that this does not explain the observed absence of light-saturation.

This same study also showed that low temperatures in the early part of the response of $F_{\mathrm{a}}$ to $R_{\mathrm{s}}$ can transform the response curve such that it simultaneously decreases the initial radiation use efficiency $\varepsilon$ and increases what is then an only apparent $F_{\text {a(max })}$. Most experiments measure the response of photosynthetic activity to radiation under conditions of constant temperature, whereas in this field study irradiance and temperature were correlated. Suboptimal temperatures at low irradiance thus result in an overestimation of $F_{\text {a(max) }}$, which can lead to the anomalous conclusion that the assimilatory $\mathrm{CO}_{2}$ flux does not reach light-saturation. Initial radiation use efficiency $\varepsilon$ for the gross assimilatory $\mathrm{CO}_{2}$ flux $F_{\mathrm{a}}$ and shortwave irradiance $R_{\mathrm{s}}$ ranged from 1.8 to $3.9 \mu \mathrm{g} \mathrm{J} \mathrm{J}^{-1}$, but $\varepsilon$ is expected to be higher after adjustment for low temperature. Ruimy et al. (1995) found that $\varepsilon$ is generally lower in grasslands than in forests and in crops, possibly because of the relatively erect canopy structure of grasslands; they list $\varepsilon$ values for the net $\mathrm{CO}_{2}$ flux of $0.9 \mu \mathrm{g} \mathrm{J}{ }^{-1}$ for $\mathrm{C}_{3}$ grasslands and $1.3 \mu \mathrm{g} \mathrm{J}^{-1}$ for grasslands in general. Adjustment for a respiratory $\mathrm{CO}_{2}$ flux would yield higher $\varepsilon$ values for the gross assimilatory $\mathrm{CO}_{2}$ flux, although still below the values found in this study. High initial radiation use efficiencies in grasslands in the Netherlands could be related to this pastureland sharing several productivity characteristics with cropland rather than with extensively managed grasslands. 
An effect of suboptimal temperatures on the assimilatory $\mathrm{CO}_{2}$ flux $\left(F_{\mathrm{a}}\right)$ in the periphery of the growing season was thus observed, which translates into lower $\varepsilon$ and $F_{\mathrm{a}}$ at low irradiance. The lowest temperatures for the measurements at the low and high groundwater tables were 2.3 and $8.6^{\circ} \mathrm{C}$ in April, respectively, and 8.5 and $10.4^{\circ} \mathrm{C}$ in October, respectively. In the remainder of the season $F_{\mathrm{a}}$ was generally higher at the low than at the high groundwater table. However, this analysis indicates that in this grassland the higher assimilatory $\mathrm{CO}_{2}$ fluxes at the low groundwater table could be largely attributed to higher levels of irradiance during the measurements. There was no distinct difference in instant productivity between both drainage regimes.

\subsubsection{Respiratory $\mathrm{CO}_{2}$ flux}

The activation energy $(E)$ in the Arrhenius equation for metabolic activity has been observed to decrease with increasing temperature (Criddle et al. 1994, Lloyd \& Taylor 1994). However, application of a decreasing activation energy at increasing temperature (Lloyd \& Taylor 1994) to the night-time $\mathrm{CO}_{2}$ flux data only marginally improved the explained variance. The Arrhenius equation with constant $E$ was therefore retained for reasons of simplicity. Fitted $E$ in this study indicates that the temperature response of the night-time $\mathrm{CO}_{2}$ flux $\left(F_{\mathrm{n}}\right)$ was slightly stronger at the low than at the high groundwater table at 78 and $67 \mathrm{~kJ} \mathrm{~mol}^{-1}$, respectively. An activation energy range of $67-78 \mathrm{~kJ} \mathrm{~mol}^{-1}$ agrees with values reported in literature, e.g. $81-124 \mathrm{~kJ} \mathrm{~mol}^{-1}$ (corresponding to a $Q_{10}$ value of 5) in Scottish peat soils by Chapman \& Thurlow (1996) and $53 \mathrm{~kJ} \mathrm{~mol}^{-1}$ (a $Q_{10}$ value of 2) in a variety of ecosystem soils by Lloyd \& Taylor (1994). Differences in $E$ may be associated with differences in physiological characteristics of the grass sward or in the soil microbial population. Whereas Silvola et al. (1996) found a weaker temperature response at lower groundwater tables for $\mathrm{CO}_{2}$ emissions from boreal mires at different groundwater tables, this study found that a lower groundwater table resulted in a stronger temperature response of the respiratory $\mathrm{CO}_{2}$ flux. A deeper aerobic soil profile at low groundwater tables will cause soil temperatures to follow air temperature more in phase and therefore result in a stronger response of the below-ground respiratory $\mathrm{CO}_{2}$ flux to air temperature.

Drainage levels in this study are unlikely to result into an aerobic soil profile of corresponding depth as a result of the soil's limited lateral conductivity to water (Schothorst 1982). A drainage level of $-0.6 \mathrm{~m}$ may result in aerobic soil profiles which are deeper in summer and remain more to the surface in the rest of the growing season. However, the agreement between soil subsidence levels -0.5 and $1.1 \mathrm{~cm} \mathrm{y}^{-1}-$ and drainage levels --0.3 and $-0.6 \mathrm{~m}-$ indicates that at least on a yearly basis the relative difference in drainage levels is reflected in the actual depth of the aerobic soil profiles. Whereas shrinkage and soil compaction can be a significant factor in explaining soil subsidence, part of the observed difference in soil subsidence is to result from a difference 
in the system's respiratory $\mathrm{CO}_{2}$ flux associated with the decomposition of peat in the aerobic soil profile. Silvola et al. (1996) measured $\mathrm{CO}_{2}$ emissions from boreal mires to increase by $0.002 \mathrm{mg} \mathrm{m}^{-2} \mathrm{~s}^{-1}$ for every additional $\mathrm{cm}$ of drainage, although only up to a drainage depth of 0.3-0.4 m. Glenn et al. (1993) found peatland $\mathrm{CO}_{2}$ emissions to increase from $0.04 \mathrm{mg} \mathrm{m}^{-2} \mathrm{~s}^{-1}$ to $0.10 \mathrm{mg} \mathrm{m}^{-2} \mathrm{~s}^{-1}$ upon increasing drainage depth from -0.1 to $-0.5 \mathrm{~m}$, which corresponds to $0.0015 \mathrm{mg} \mathrm{m}^{-2} \mathrm{~s}^{-1}$ for every $\mathrm{cm}$. In Canadian drained peat soils, Glenn et al. (1993) calculated that only $10 \%$ of the soil subsidence could be attributed to the oxidation of peat and that shrinkage was a major source of subsidence.

\subsubsection{Patterns of net $\mathrm{CO}_{2}$ exchange}

The differences in $\mathrm{CO}_{2}$ fluxes between both drainage levels were shown to be largely caused by differences in weather conditions during measurement at the particular incident wind angles corresponding to the drainage levels. After accounting for different levels of irradiance and temperature during measurement there appears to be little difference between both drainage levels. The pasture showed to be a net $\mathrm{CO}_{2}$ sink in April at approximately $11.1 \mathrm{~g} \mathrm{~m}^{-2} \mathrm{~d}^{-1}$ and in May at approximately $2.4 \mathrm{~g} \mathrm{~m}^{-2} \mathrm{~d}^{-1}$. It turned $\mathrm{CO}_{2}$ neutral around June and was a net $\mathrm{CO}_{2}$ source in September at approximately $4.3 \mathrm{~g} \mathrm{~m}^{-2}$ $\mathrm{d}^{-1}$. This gradual switch from $\mathrm{CO}_{2}$ sink to $\mathrm{CO}_{2}$ was caused by both a gradually increasing respiratory $\mathrm{CO}_{2}$ flux $\left(F_{\mathrm{r}}\right)$ and a gradually decreasing assimilatory $\mathrm{CO}_{2}$ flux $\left(F_{\mathrm{a}}\right)$ throughout the growing season. $F_{\mathrm{r}}$ increased because of increasing air and soil temperatures, increasing biomass and possibly an increasingly deep aerobic soil profile as a result of limited lateral conductivity. Decreasing $F_{a}$ was primarily caused by decreasing levels of irradiance. Temperature proved to have an outspoken effect on both $F_{\mathrm{a}}$ and $F_{\mathrm{r}}$. Low air temperatures decreased the response of the assimilatory $\mathrm{CO}_{2}$ flux to irradiance but appeared to decrease the respiratory $\mathrm{CO}_{2}$ flux even more. This shows how a combination of high irradiance and relatively low temperatures favoured a net $\mathrm{CO}_{2}$ sequestration. A strong short-term effect of temperature agrees with the observations made by Tenhunen et al. (1995). They measured $\mathrm{CO}_{2}$ exchange in a sloping and therefore differentially drained tussock tundra. The assimilatory $\mathrm{CO}_{2}$ flux was shown to follow leaf area and irradiance. The diurnal pattern of the respiratory $\mathrm{CO}_{2}$ flux followed temperature, whereas its seasonal pattern followed the aerated soil volume which closely aligned to water table depth. 



\section{Appendix A}

\section{Addenda to Chapters 3-5}

Written for this thesis 
Chapters 3 to 5 analyse and discuss instantaneous assimilatory and respiratory $\mathrm{CO}_{2}$ fluxes and fluxes of latent and sensible heat exchange. However, much less they show the interdependence of these fluxes, how they result in an instantaneous net $\mathrm{CO}_{2}$ flux and how the instantaneous $\mathrm{CO}_{2}$ fluxes relate to $\mathrm{CO}_{2}$ flux characteristics at larger time scales. The subsequent addenda develop the instantaneous fluxes in further detail and discuss how they translate into flux patterns at diurnal and seasonal scales. These addenda were not part of the original journal publications, but are considered relevant for the analysis and for the narrative of this thesis.

\section{A.1. TO CHAPTER 3: CO 2 FLUXES IN A DRAINED PEAT GRASSLAND}

\section{A.1.1. Characterisation of the respiratory $\mathrm{CO}_{2}$ flux}

The functional distinction between growth respiration (photorespiration) and maintenance respiration (dark respiration) has been the ecophysiological basis of many quantitative analyses of plant respiration (Gifford 2003, Goudriaan \& Van Laar 1994, Thornley 1998). Growth respiration is substrate dependent and maintenance respiration is structure dependent. Thornley (2011) has questioned this distinction and argued that the biochemical respiratory processes in growing organisms ('growth respiration') and organisms in a structural steady-state ('maintenance respiration') are the same. It is stated that plant respiration in an equilibrium situation - a conservative asymptotic $40 \%$ of gross photosynthetic rate - is the result of growth efficiency ('growth respiration'), senescence and recycling to the substrate pool, which can be described as maintenance respiration but from this point of view really isn't. This could be of relevance in view of the difficulties in establishing maintenance respiration under various experimental conditions (Thornley 2011).

However, even though the biochemical processes are the same, the emergent dynamics at plant level are still different. The explicit distinction between growth respiration and maintenance respiration is thus of relevance to this analysis. The separation of the measured net $\mathrm{CO}_{2}$ flux $\left(F_{\mathrm{n}}\right)$ into a respiratory $\left(F_{\mathrm{r}}\right)$ and gross assimilatory $\mathrm{CO}_{2}$ flux component $\left(F_{\mathrm{a}}\right)$ is based on the assumption that the relationship between temperature and night-time $\mathrm{CO}_{2}$ flux equates the general relationship between temperature and respiratory $\mathrm{CO}_{2}$ flux and can thus be extrapolated. Although substrate availability and growth may continue for some time after sunset, most of the night-time period could be characterised by the absence of growth and its associated growth respiration. It could be argued that the remaining growth respiration in the earlier (and warmer) part of the night-time period skews the response of night-time $F_{\mathrm{n}}$ to temperature such that calculated day-time $F_{\mathrm{r}}$ is higher than it would be entirely without growth respiration. But the omission from the 
analysis of $\mathrm{CO}_{2}$ flux measurements within 30 minutes from sunset or sunrise and the modest increase in $F_{\mathrm{r}}$ with $F_{\mathrm{a}}$ of $10-15 \%$ - or actually less when differentiating between the effects of $F_{\mathrm{a}}$ and temperature - indicate that the calculated respiratory $\mathrm{CO}_{2}$ flux is one predominantly without growth respiration. As the respiratory $\mathrm{CO}_{2}$ flux excludes most of the growth respiration, the calculated gross assimilatory $\mathrm{CO}_{2}$ flux would therefore largely include growth respiration.

Two alternative functions for the response of the night-time $\mathrm{CO}_{2}$ flux to temperature were tested. The variances explained by both a fitted exponential relationship $\left(Q_{10}=\right.$ 2.3) and a fitted Arrhenius relationship (activation energy $E=48 \mathrm{~kJ} \mathrm{~mol}^{-1}$ ) were similar to the explained variances for Equation 3.7. Both these functions respond stronger to temperature than the function of Lloyd and Taylor (1994) as the latter introduces a progressively decreasing activation energy. On fitting Equation 3.7 or one of the two other response functions to the night-time $\mathrm{CO}_{2}$ flux and temperature most of the variation in $F_{n}$ went unexplained. One source of variation may be a relatively low reliability of micrometeorological measurements at night, resulting in a higher relative variation. However, in absolute terms the variation in the night-time $\mathrm{CO}_{2}$ flux was comparable to the variation in the daytime $\mathrm{CO}_{2}$ flux, indicating that the absolute variations in the respiratory and assimilatory $\mathrm{CO}_{2}$ fluxes are similar. An important indicator for the data quality is the observation that the slopes of the fitted monthly responses increase with increasing temperature. Thereby emerges a response at the annual level which was enforced only at the monthly level through Equation 3.7. A progressively higher response of biological activity to temperature with increasing temperature is commensurate with literature.

Although the system's daytime respiratory $\mathrm{CO}_{2}$ flux cannot be directly measured and therefore tested for its plausibility, it is indirectly reflected in the gross assimilatory $\mathrm{CO}_{2}$ flux. An overestimation of the daytime respiratory $\mathrm{CO}_{2}$ flux results in an equivalent underestimation of the gross assimilatory $\mathrm{CO}_{2}$ flux. Unlike the system's respiratory $\mathrm{CO}_{2}$ flux the canopy's gross assimilatory $\mathrm{CO}_{2}$ flux can be tested against other measurement methodologies. It may thus be argued that the plausibility of the relationship between temperature and respiratory $\mathrm{CO}_{2}$ flux is reflected in the assimilatory $\mathrm{CO}_{2}$ flux.

\section{A.1.2. A seasonal pattern of assimilatory $\mathrm{CO}_{2}$ fluxes}

Monthly responses of the assimilatory $\mathrm{CO}_{2}$ flux to irradiance and temperature are in part characterised by its asymptotic value $F_{\text {a(max) }}$, whereas the monthly responses of the respiratory $\mathrm{CO}_{2}$ flux are partly characterised by its value at reference temperature $F_{\mathrm{r}(0)}$. Figure A.1A shows that $F_{\mathrm{a}(\max )}$ and $F_{\mathrm{r}(0)}$ were correlated $\left(r^{2}=0.81, n=18\right)$. With $F_{\mathrm{a}(\max )}$ being a measure for the leaf area's assimilatory capacity and $F_{\mathrm{r}(0)}$ a composite measure for the respiratory capacity of vegetation and soil microbial biomass, it illustrates how 

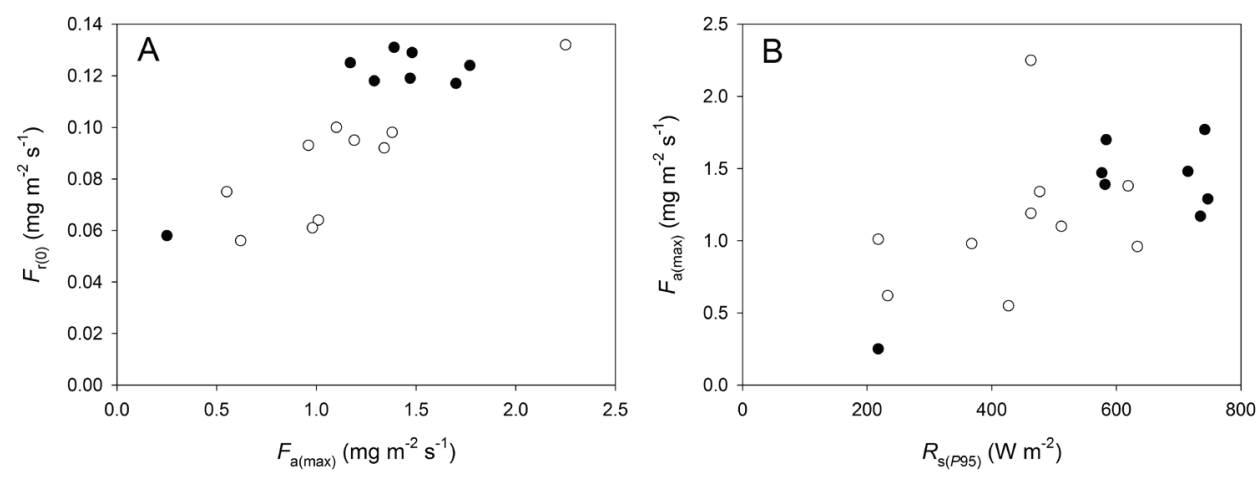

Figure A.l. (A) The monthly reference respiratory $\mathrm{CO}_{2}$ flux $\left(F_{\mathrm{r}(0)}\right)$ as a function of the monthly asymptotic assimilatory $\mathrm{CO}_{2}$ flux $\left(F_{\text {a(max })}\right)$; and $(B)$ the monthly asymptotic assimilatory $\mathrm{CO}_{2}$ flux $\left(F_{\mathrm{a}(\max )}\right)$ as a function of the monthly 95 percentile of shortwave irradiance $\left(R_{\mathrm{s}(P 95)}\right)$. In 1993 (closed symbols) and 1994 (open symbols).

a higher assimilatory activity relates to a higher system respiratory activity. Figure A.1B shows that $F_{\mathrm{a}(\max )}$ itself, after accounting for the effect of temperature on the assimilatory $\mathrm{CO}_{2}$ flux, was correlated with general levels of radiation. A higher upper level of shortwave irradiance was correlated with a higher asymptotic assimilatory $\mathrm{CO}_{2}$ flux. This indicates that higher levels of irradiance resulted in a higher leaf area or a higher assimilatory activity per unit of leaf area.

The asymptotic gross assimilatory $\mathrm{CO}_{2}$ flux thus is a measure for assimilatory capacity. After accounting for the effect of temperature, it decreased from approximately $1.70 \mathrm{mg}$ $\mathrm{CO}_{2} \mathrm{~m}^{-2} \mathrm{~s}^{-1}$ in spring, to $1.30 \mathrm{mg} \mathrm{CO} \mathrm{m}^{-2} \mathrm{~s}^{-1}$ in summer and to $0.50 \mathrm{mg} \mathrm{CO}_{2} \mathrm{~m}^{-2} \mathrm{~s}^{-1}$ in autumn and winter. The actual gross assimilatory $\mathrm{CO}_{2}$ flux at a shortwave irradiance of $500 \mathrm{~W} \mathrm{~m}^{-2}$ ranged from approximately $0.40 \mathrm{mg} \mathrm{CO}_{2} \mathrm{~m}^{-2} \mathrm{~s}^{-1}$ in late winter or early spring to $1.10 \mathrm{mg} \mathrm{CO}_{2} \mathrm{~m}^{-2} \mathrm{~s}^{-1}$ in late spring. The response range was much broader in 1994 than in 1993, which is indicative for the more variable weather conditions in 1994 including the driest months in the entire measurement period. After accounting for the effect of temperature, the initial radiation use efficiency for the gross assimilatory $\mathrm{CO}_{2}$ flux at non-limiting temperatures generally amounted to $4.0-4.5 \mu \mathrm{g} \mathrm{J}^{-1}$, occasionally reaching up to $6.0-6.5 \mu \mathrm{g} \mathrm{J}^{-1}$ in spring or summer.

The relationship between surface conductance and assimilatory $\mathrm{CO}_{2}$ flux is ambiguous. At increasing irradiance, surface conductance tends to follow the assimilatory $\mathrm{CO}_{2}$ flux (Collatz et al. 1991), whereas low soil moisture or high vapour pressure deficit at higher irradiance causes surface conductance to limit the assimilatory $\mathrm{CO}_{2}$ flux (Jarvis 1995, Verma et al. 1986, Woledge et al. 1989). Low surface conductance thus occurs at both ends of the response curve, complicating the model proposed in Figure 3.1C. Hysteresis in the monthly average diurnal response of $F_{\mathrm{a}}$ to $R_{\mathrm{s}}$ in August 1994 (Figure 3.8) also 
indicates that even at high irradiance the role of $g_{\mathrm{s}}$ on $F_{\mathrm{a}}$ is not unequivocal. Lower $g_{\mathrm{s}}$ after noon concurred with higher levels of $F$, which suggests that a stronger gradient between ambient and intercellular $\mathrm{CO}_{2}$ concentrations may be able to compensate for lower surface conductance. This adds to the complexity of the effect of $g_{s}$ on $F_{\mathrm{a}}$.

\section{A.1.3. Instant patterns of net $\mathrm{CO}_{2}$ exchange}

Monthly asymptotic assimilatory $\mathrm{CO}_{2}$ flux $F_{\text {a(max })}$ and monthly reference respiratory $\mathrm{CO}_{2}$ flux $F_{\mathrm{r}(0)}$ can be compared in relative terms, but not in absolute terms as the former equates $F_{\mathrm{a}}$ under saturating irradiance and the latter $F_{\mathrm{r}}$ at a set air temperature of 0 ${ }^{\circ} \mathrm{C} . F_{\mathrm{a}(\max )}$ and $F_{\mathrm{r}(0)}$ cast light on the $\mathrm{CO}_{2}$ exchange components only and not on the system's net $\mathrm{CO}_{2}$ exchange itself. Figures A.2A and A.2B instead show the instantaneous respiratory $\mathrm{CO}_{2}$ flux $\left(F_{\mathrm{r}}\right)$ as a function of the instantaneous gross assimilatory $\mathrm{CO}_{2}$ flux $\left(F_{\mathrm{a}}\right)$. A linear relationship between $F_{\mathrm{a}}$ and $F_{\mathrm{r}}$ can be observed, but it is far from an instant balance between both flux components. Although $F_{\mathrm{r}}$ increased with $F_{\mathrm{a}}$ linearly, it did so only modestly. Whereas at low levels of $F_{\mathrm{a}}$ a consistent instantaneous net $\mathrm{CO}_{2}$ release was observed, higher levels of $F_{\mathrm{a}}$ were consistently associated with an instantaneous net $\mathrm{CO}_{2}$ sequestration. An instantaneous net $\mathrm{CO}_{2}$ release was only observed at low or zero irradiance, whereas the remainder of the $F_{\text {a }}$ range was associated with a consistently increasing instantaneous net $\mathrm{CO}_{2}$ sequestration.

Figures A.2A and A.2B show how the response of the respiratory $\mathrm{CO}_{2}$ flux $(F)$ to the gross assimilatory $\mathrm{CO}_{2}$ flux $\left(F_{\mathrm{a}}\right)$ exhibited two distinct response ranges. Higher $F_{\mathrm{r}}$ values were observed from April to September than from October to March. Figures A.2C and A.2D show the matching temperature profiles to the course of $F_{\mathrm{a}}$ and indicate that low temperatures clearly contributed to the lower $F_{\mathrm{r}}$ values in the winter half of the year. Closer inspection of the data shows that the temperature effect was continuous and also explains part of the width of the two seasonal response ranges. The upper part of the summer response range corresponded to higher temperatures, although these higher temperatures were also correlated with higher metabolically active biomass (as reflected in the reference respiratory $\mathrm{CO}_{2}$ flux $F_{\mathrm{r}(0)}$ ). The gap between both seasonal response ranges was related to the availability of fewer data from the intermediate autumn season, particularly so in 1993 (see Table 3.1). A discrete effect of water management can be excluded, as its practice actually aims to mitigate that which was observed. Active water management is thus unlikely to have caused such a discontinuity but rather to have resulted in a convergence of ranges.

Whereas the vertical profile of the response range switch is a largely seasonal response to (discrete) monthly differences in temperature and metabolically active biomass $\left(-F_{\mathrm{r}(0)}\right)$, its horizontal profile represents a mostly instant response to temperature and assimilatory activity $F_{\mathrm{a}}$. The summer response ranges for 1993 and 1994 show that the respiratory 


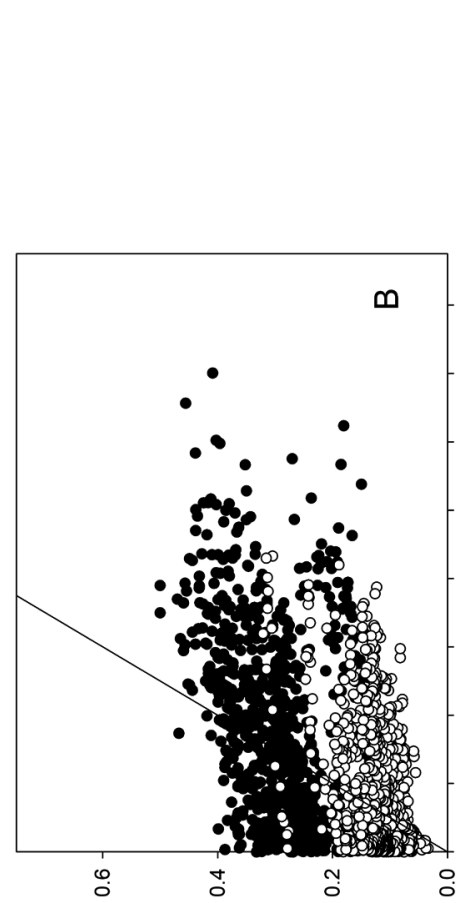

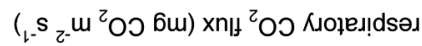

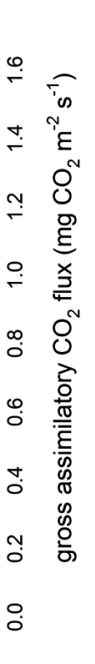

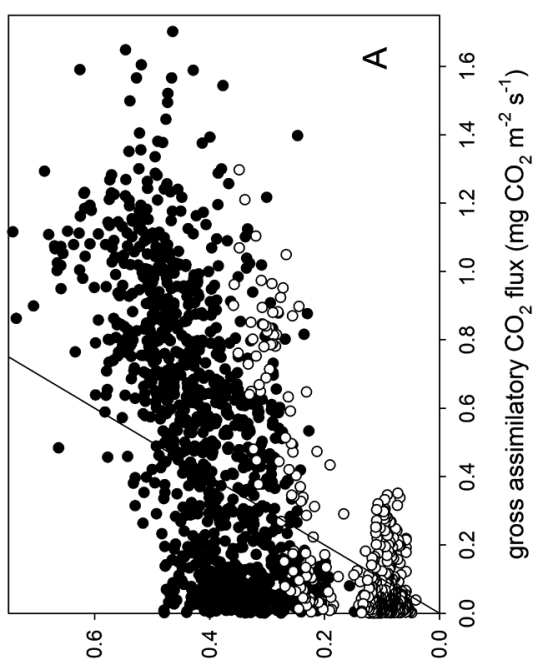

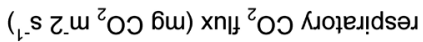

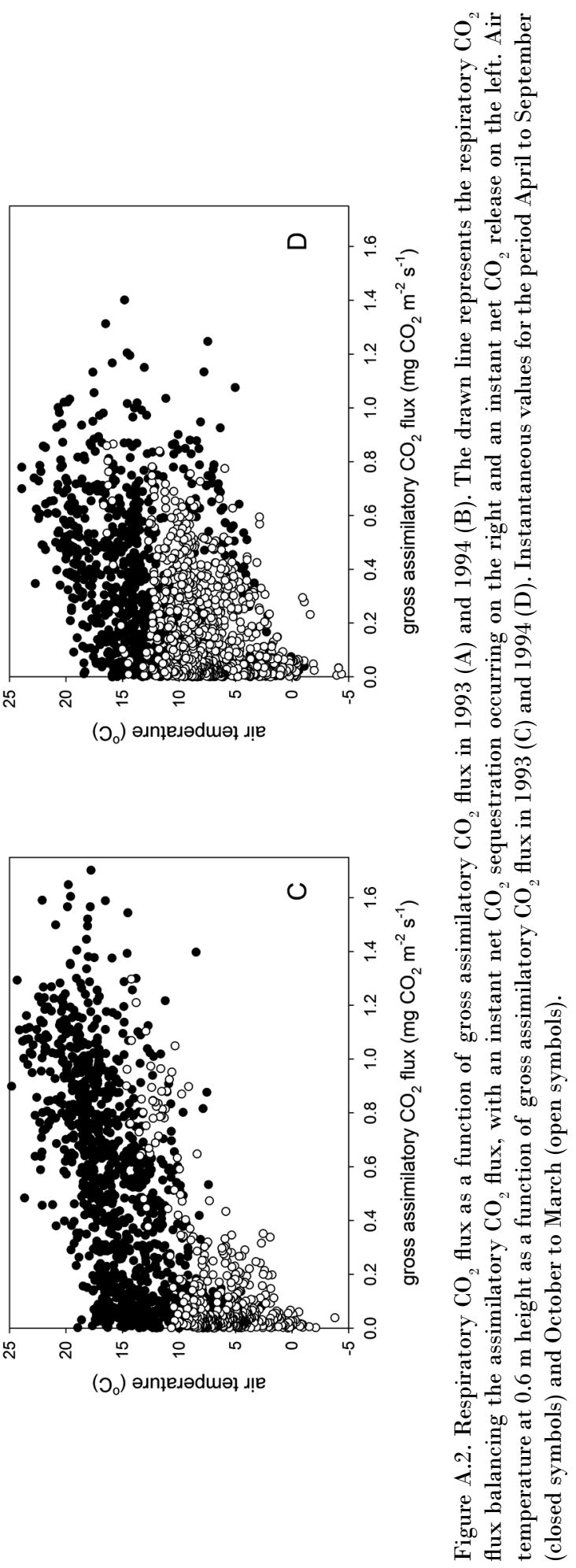




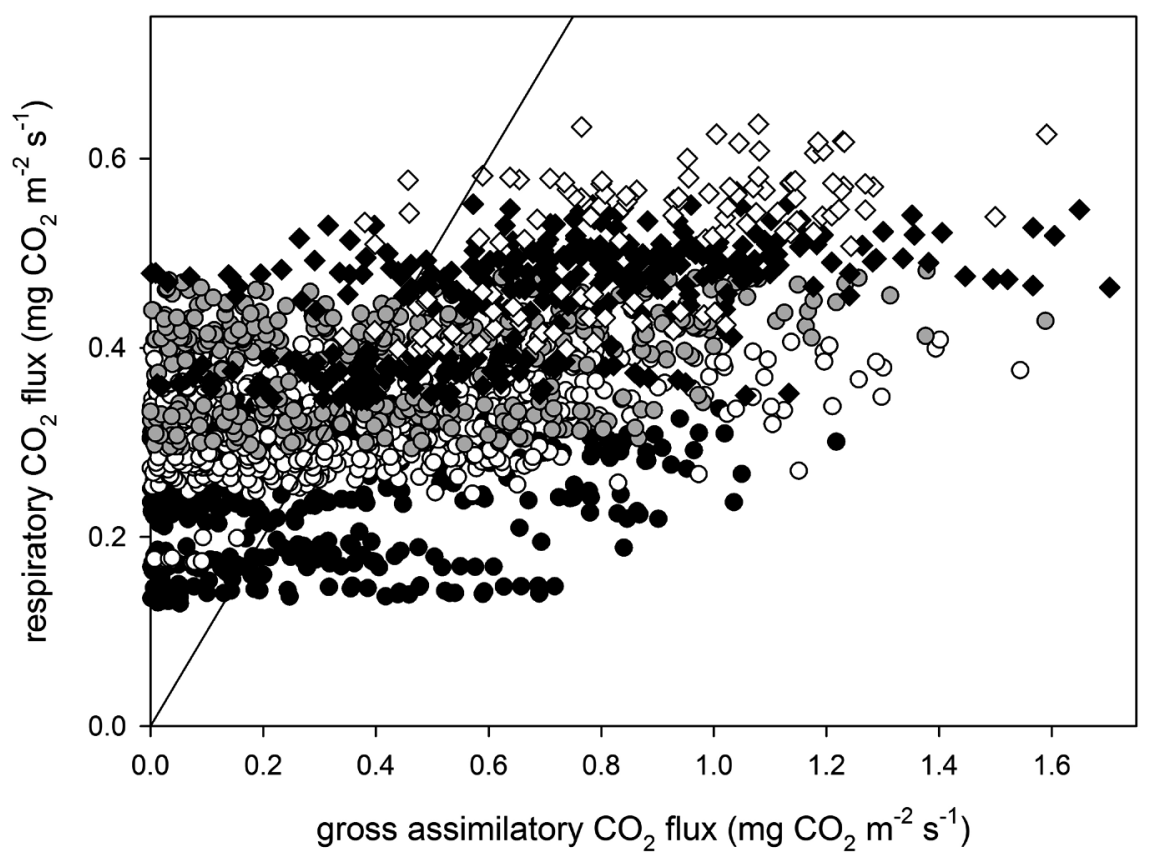

Figure A.3. Respiratory $\mathrm{CO}_{2}$ flux as a function of gross assimilatory $\mathrm{CO}_{2}$ flux in 1993 and 1994 for temperature classes 10.0-12.5 ${ }^{\circ} \mathrm{C}$ (black circle), $12.5-15.0^{\circ} \mathrm{C}$ (white circle), $15.0-17.5{ }^{\circ} \mathrm{C}$ (gray circle), $17.5-20.0^{\circ} \mathrm{C}$ (black diamond) and $20.0-22.5{ }^{\circ} \mathrm{C}$ (white diamond). The drawn line represents the respiratory $\mathrm{CO}_{2}$ flux balancing the assimilatory $\mathrm{CO}_{2}$ flux, with an instant net $\mathrm{CO}_{2}$ sequestration occurring on the right and an instant net $\mathrm{CO}_{2}$ release on the left.

$\mathrm{CO}_{2}$ flux $F_{\mathrm{r}}$ increased with the gross assimilatory $\mathrm{CO}_{2}$ flux $F_{\mathrm{a}}$ at approximately $0.10-0.15$ $\mathrm{mg} \mathrm{mg}$. Multiple linear regression analysis on the response of the respiratory $\mathrm{CO}_{2}$ flux $\left(F_{\mathrm{r}}\right)$ to both the assimilatory $\mathrm{CO}_{2}$ flux $\left(F_{\mathrm{a}}\right)$ and ambient temperature $\left(T_{\mathrm{a}}\right)$ for the period of April up to September found no collinearity between both independent variables $(P<0.001)$ and indicates that most of the response to $F_{\mathrm{a}}$ was in fact a response to a concomitant increase in temperature in both $1993\left(r^{2}=0.96, n=812\right)$ and $1994\left(r^{2}=\right.$ $0.90, n=614) . F_{\mathrm{r}}$ increased with temperature at 0.026 and $0.016 \mathrm{mg} \mathrm{CO}_{2} \mathrm{~m}^{-2} \mathrm{~s}^{-1}$ for every ${ }^{\circ} \mathrm{C}$, whereas it increased with $F_{\mathrm{a}}$ at 0.013 and $0.032 \mathrm{mg} \mathrm{mg}^{-1}$, respectively. Temperature thus appears to be the dominant factor in the instantaneous response of the respiratory $\mathrm{CO}_{2}$ flux to the assimilatory $\mathrm{CO}_{2}$ flux, whereas the assimilatory $\mathrm{CO}_{2}$ flux itself accounted for approximately $10-20 \%$ of the response. Figure A.3 illustrates the combined effect of temperature on the vertical (monthly) and horizontal profile (instantaneous) of the response range after stratification into $2.5^{\circ} \mathrm{C}$ temperature classes. This shows how $F_{\mathrm{r}}$ increases relative to $F_{\mathrm{a}}$ with increasing temperatures, even though $F_{\mathrm{a}}$ itself also increases over much of the range of ambient temperature. 


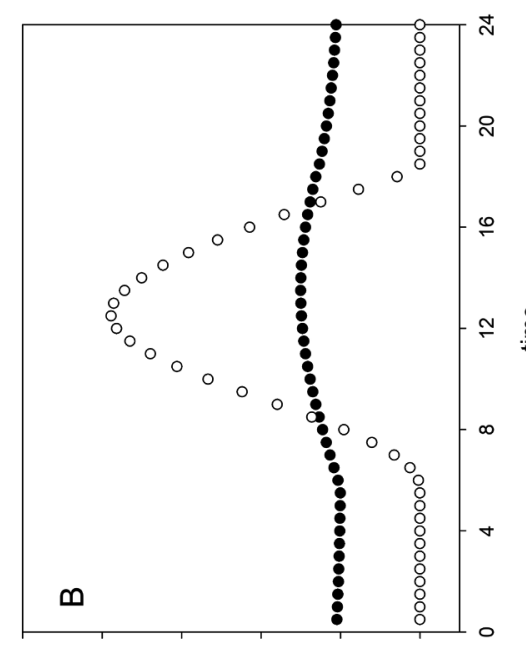

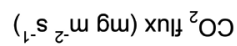

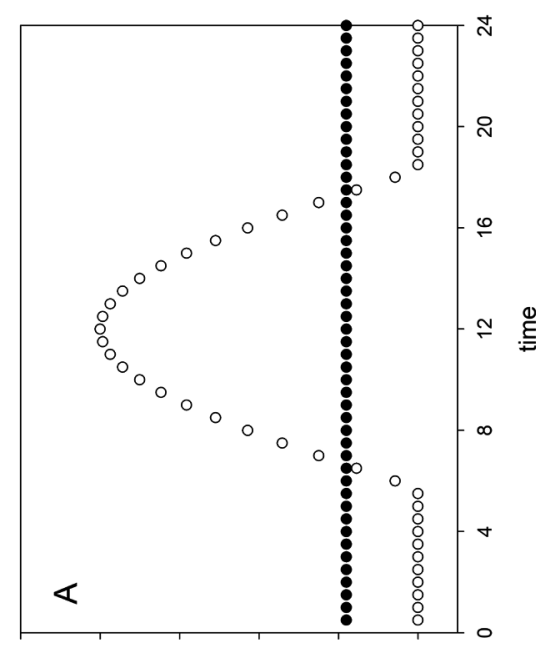

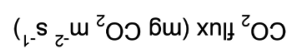
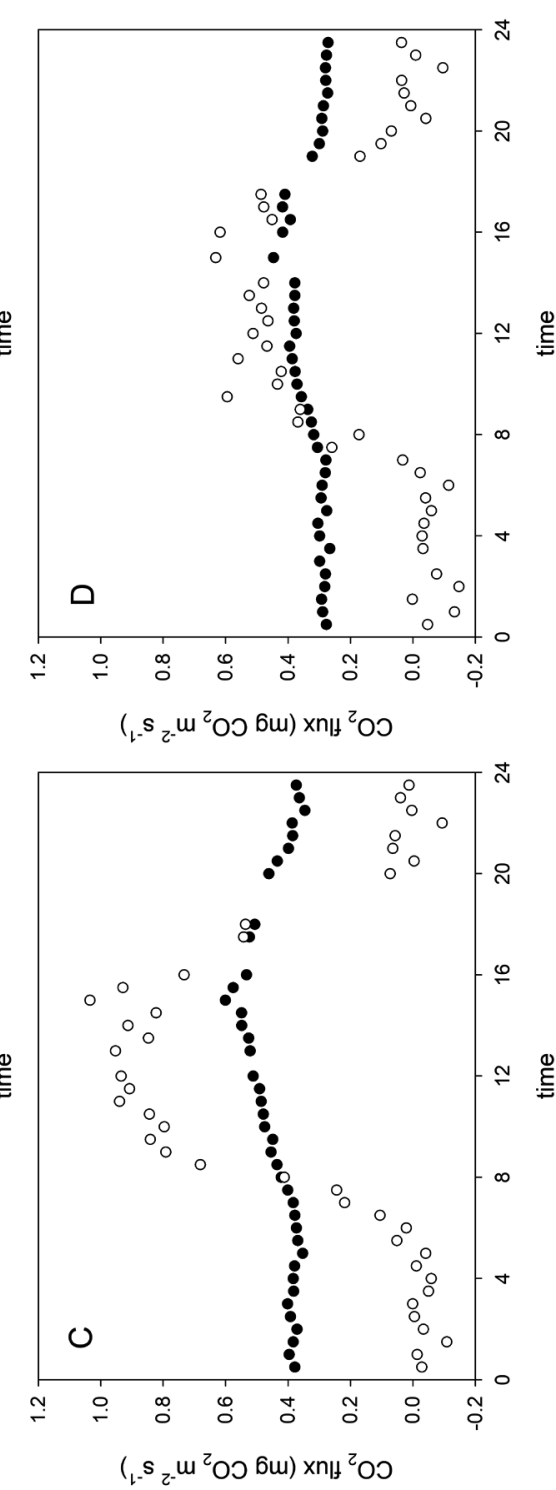

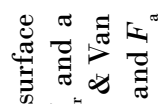

圷政"

है पै

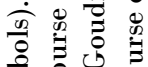

है

家苛

政寻

능

E.

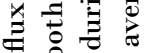

$\vartheta^{\circ} \mathcal{O}^{\circ}$

य递

娄䒼

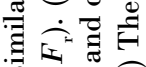

要 $\wedge$ 㲾

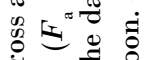

on $\approx \equiv$

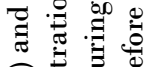

T)

节总总

की

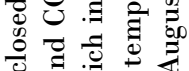

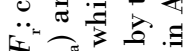

$\underbrace{}_{x} x^{\circ}=1$

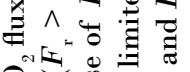

ᄋㅝㅔ

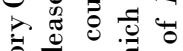

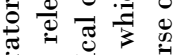

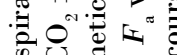

की

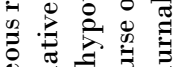

递方

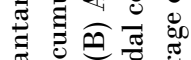

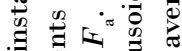

원

पै

ن

苛范

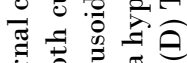

를

ดี क

मं

$\triangle \stackrel{\circ}{\circ}$

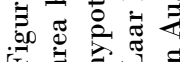




\section{A.1.4. Seasonal patterns of net $\mathrm{CO}_{2}$ exchange}

The gross assimilatory flux $F_{\mathrm{a}}$ (representing the grassland system's $\mathrm{CO}_{2}$ sequestration) is primarily characterised by an initial radiation use efficiency $\varepsilon$ and an asymptotic assimilatory $\mathrm{CO}_{2}$ flux $F_{\mathrm{a}(\max )}$. Particularly $\varepsilon$ was shown to be sensitive to suboptimal temperatures over much of the occurring temperature range. Neither vapour pressure deficit nor surface conductance appeared to have a distinct effect on instant assimilatory activity, which was probably caused by the ambiguous role of surface conductance in assimilatory activity, although a statistical effect resulting from a limited variation in the data cannot be ruled out. $F_{\mathrm{a}(\max )}$ is a composite measure for the grassland system's assimilatory capacity - combining leaf area and photosynthetic activity per unit of leaf area - and was shown to respond positively to longer-term levels of irradiance.

The respiratory $\mathrm{CO}_{2}$ flux $F_{\mathrm{r}}$ (representing the grassland system's $\mathrm{CO}_{2}$ release) responded strongly to temperature in several $Q_{10}$ type of relationships. $F_{\mathrm{r}}$ at a reference temperature is a composite measure for the grassland system's metabolically active biomass (both plant and soil microbial biomass) and was strongly dependent on $F_{\mathrm{a}(\max )}$. This indicates that most of $F_{\mathrm{r}}$ originates from the vegetation's maintenance respiration and decomposition of newly senesced biomass rather than from microbial activity in the aerobic soil profile. The decomposition of peat in the aerobic soil profile can thus only constitute a relatively small part in the system's respiratory $\mathrm{CO}_{2}$ flux.

Both $F_{\mathrm{a}}$ and $F_{\mathrm{r}}$ responded to temperature, but multiple linear regression on the response of $F_{\mathrm{r}}$ to both $F_{\mathrm{a}}$ and ambient temperature indicates that $F_{\mathrm{r}}$ increased more with temperature than $F_{\mathrm{a}}$. Higher temperatures thus result in higher ratios of $F_{\mathrm{r}}$ over $F_{\mathrm{a}}$ and therefore less $\mathrm{CO}_{2}$ sequestration or more $\mathrm{CO}_{2}$ release. The balance of the instant gross assimilatory $\left(F_{\mathrm{a}}\right)$ and respiratory $\mathrm{CO}_{2}$ fluxes $(F)$ in Figure A.2 shows that $F_{\mathrm{r}}$ increased only moderately with $F_{\mathrm{a}}$. At assimilatory $\mathrm{CO}_{2}$ fluxes higher than a particular value, $F_{\mathrm{a}}$ consistently exceeded $F_{\mathrm{r}}$ and the grassland ecosystem exhibited instant $\mathrm{CO}_{2}$ sequestration. $\mathrm{CO}_{2}$ was released only at assimilatory $\mathrm{CO}_{2}$ fluxes lower than this threshold value. The inflection point (where $F_{a}$ equates $F_{\mathrm{r}}$ ) appears to much depend on air temperature. The lower ambient temperature, the lower was $F_{\mathrm{a}}$ where it starts exceeding $F_{\mathrm{r}}$. As $F_{\mathrm{a}}$ increased with temperature through an effect particularly on $\varepsilon$, the inflection point more or less moves with temperature and a concomitantly expanding $F_{\mathrm{a}}$ range to such an extent that the inflection point seemed to be approximately situated at $1 / 3$ into the range of $F_{\mathrm{a}}$ values. The inflection point ranged from approximately $0.1 \mathrm{mg} \mathrm{CO}_{2} \mathrm{~m}^{-2} \mathrm{~s}^{-1}$ in winter to $0.4 \mathrm{mg} \mathrm{CO}_{2} \mathrm{~m}^{-2} \mathrm{~s}^{-1}$ in summer. This implies that once instant $F_{\mathrm{a}}$ exceeded 0.1 or $0.4 \mathrm{mg} \mathrm{CO}_{2} \mathrm{~m}^{-2} \mathrm{~s}^{-1}$, respectively, the grassland ecosystem started to sequester $\mathrm{CO}_{2}$ and as soon as it fell below the inflection point it started to release $\mathrm{CO}_{2}$. A schematic representation of the dynamic diurnal balance between $\mathrm{CO}_{2}$ sequestration and release is proposed in Figures A.4A and A.4B, where $\mathrm{CO}_{2}$ is sequestered during that time of the day where the assimilatory $\mathrm{CO}_{2}$ flux exceeds 
$1 / 3$ of its maximum value. The amount of $\mathrm{CO}_{2}$ sequestered or released is represented by the surface area between the courses of the respiratory and assimilatory $\mathrm{CO}_{2}$ flux. This inflection point depends on temperature as does the amount of sequestered $\mathrm{CO}_{2} \cdot \mathrm{CO}_{2}$ is being released during the remainder of the day, the amount of which also depends on temperature. Daily net $\mathrm{CO}_{2}$ exchange is the sum of the $\mathrm{CO}_{2}$ exchanged during both periods and consequentially tends towards sequestration at higher productivity and lower temperatures. Lower temperatures reduce both the respiratory and assimilatory $\mathrm{CO}_{2}$ flux, but more so the former than the latter. Higher productivity increases the difference between the day-time assimilatory and respiratory $\mathrm{CO}_{2}$ fluxes. Figures A.4C and A.4D illustrate the case for August 1993 and August 1994. It shows how for both months the net $\mathrm{CO}_{2}$ exchange is determined by on the one hand comparable respiratory $\mathrm{CO}_{2}$ fluxes which respond to the diurnal course of temperature and on the other hand different courses of the assimilatory $\mathrm{CO}_{2}$ flux reflecting conditions less conducive to assimilatory activity in August 1994. Figure A.4 visualises how in a particular ecosystem the course of daylength (determining the period where $F_{\mathrm{a}}$ exceeds $F_{\mathrm{r}}$ as well as the difference between the day-time assimilatory and respiratory $\mathrm{CO}_{2}$ fluxes) and temperature (setting both absolute and relative $F_{\mathrm{r}}$ ) can much determine the development of the balance between $\mathrm{CO}_{2}$ sequestration and $\mathrm{CO}_{2}$ release and how this balance only follows from aggregation in time. This indicates that conditions in the boreal zone with high daily irradiance and moderate temperatures during the growing season (enhancing net productivity) and low temperatures outside the growing season (reducing $\mathrm{CO}_{2}$ release) are particularly associated with a high net $\mathrm{CO}_{2}$ sequestration. Both boreal forests and grasslands are the characteristic vegetation types of the boreal zone and could thus constitute globally significant $\mathrm{CO}_{2}$ sinks. Moreover, both tundra and taiga - a transition zone between forest and tundra - have large areas of wetlands with organic soils as a result of their often flat geography, large fluvial systems and relatively low evapotranspiration. These largely anaerobic organic soils enhance $\mathrm{CO}_{2}$ sequestration through a decreased decomposition in the root zone. The combination of a relatively high productivity and low respiratory activity as a result of climatic conditions and anaerobic organic soils which further reduce respiratory activity in the root zone would predict boreal grasslands and forests to be important $\mathrm{CO}_{2}$ sinks in the terrestrial biosphere. 


\section{A.2. TO CHAPTER 4: ENERGY FLUXES IN A DRAINED PEAT GRASSLAND}

\section{A.2.1. Coupling of mass and energy exchange}

The energy exchange $(H$ and $\lambda E)$ and mass exchange $\left(\mathrm{CO}_{2}\right)$ meet in the aerodynamic conductance $\left(g_{\mathrm{a}}\right)$ and the surface conductance $\left(g_{\mathrm{s}}\right)$. If reduced $g_{\mathrm{a}}$ or $g_{\mathrm{s}}$ impairs the latent heat flux, it also impairs $\mathrm{CO}_{2}$ exchange. A reduced diffusion of $\mathrm{CO}_{2}$ from the boundary layer towards the plant canopy $\left(g_{\mathrm{a}}\right)$ or through the plant's stomata to the leaves' intercellular space $(g)$ limits the assimilatory $\mathrm{CO}_{2}$ flux and therefore plant productivity. Buchmann and Schulze (1999) noted that the exchange of $\mathrm{CO}_{2}$ and latent heat between terrestrial ecosystems and the atmosphere are strongly coupled. Moreover, if an impaired latent heat flux (canopy transpiration) results in a higher canopy temperature (reflected in a higher sensible heat flux), this may cause the leaf temperature to exceed a temperature optimum for photosynthetic activity and thus also reduce the assimilatory $\mathrm{CO}_{2}$ flux.

Chapter 3 showed that it proved to be difficult to observe an instantaneous effect of $g_{\mathrm{s}}$ on the grassland ecosystem's assimilatory $\mathrm{CO}_{2}$ flux, primarily because it is reflected in an effect on the instantaneous response of the assimilatory $\mathrm{CO}_{2}$ flux to irradiance. The monthly variation in $g_{s}$ was too limited to statistically identify an effect within monthly stratifications of flux measurements, although on several occasions low $g_{\mathrm{s}}$ did coincide with a moderated response of the assimilatory $\mathrm{CO}_{2}$ flux to low irradiance and a lower assimilatory $\mathrm{CO}_{2}$ flux at saturating irradiance. However, a shift in the dissipation of net energy from $\lambda E$ to $H$ translates into a robust pattern of monthly Bowen ratio values $\beta$ indicative of limiting levels of $g_{\mathrm{s}} \cdot g_{\mathrm{s}}$ will limit the grassland ecosystem's assimilatory $\mathrm{CO}_{2}$ flux but much less so its respiratory $\mathrm{CO}_{2}$ flux. Months with high levels of $\beta$ will thus be characterised by a tendency to a lower $\mathrm{CO}_{2}$ sequestration or a higher $\mathrm{CO}_{2}$ release. Increased levels of $g_{s}$ as a result of lower vapour pressure deficit or higher soil moisture could thus increase the assimilatory $\mathrm{CO}_{2}$ relative to the respiratory $\mathrm{CO}_{2}$ flux and thereby increase the grassland ecosystem's $\mathrm{CO}_{2}$ sequestration.

\section{A.2.2. The seasonal course of the Bowen ration}

The observed effect of $g_{\mathrm{s}}$ on $\lambda E$ in this study is reflected in the respective Bowen ratio values $\beta$ which can be derived from Table 4.3. $\beta$ ranged from 0.37 to 0.75 . Autumn and winter were characterised by high $\beta$ values of $0.69-0.70$, when both $\lambda E$ and $H$ were small and low $g_{s}$ and $\lambda E$ may have been related to a limited leaf surface. In both April months $\beta$ was also relatively high at $0.50-0.60$, which may also be related to limited leaf surface and low $\lambda E$. The highest values could be observed for those months which were characterised before as having high $D$, a consequentially low $g_{\mathrm{s}}$ and impaired $\lambda E$ : June $1993(\beta=0.65)$, July $1993(\beta=0.58)$ and August $1994(\beta=0.75)$. A progressively lower vapour pressure deficit from June to August 1993 also emerges from $\beta$ values of $0.65,0.58$ and 0.39, 
respectively. August 1993 was a month with $g_{\mathrm{s}}$ being little affected by $D$, which shows in a low $\beta$ value of 0.39 . The lowest $\beta$ value (0.37) was observed for May 1994, which indicates conditions particularly favourable to transpiration and $\mathrm{CO}_{2}$ assimilation.

Reduced surface conductance $\left(g_{s}\right)$ is a potentially important factor in the assimilatory $\mathrm{CO}_{2}$ flux, but its occurrence can be difficult to identify as it is mediated by the effects of radiation and temperature. Its identification through regression analysis also requires a sufficiently broad spectrum of $g_{s}$ values at high irradiance. Predominantly low $g_{s}$ values at high irradiance may result in its effect being part of the normal irradiance-response and therefore not being detected. The energy balance could provide a more robust way of identifying a limiting effect by $g_{s}$ as it strongly affects the distribution of the upwardly dissipated energy into the sensible $(H)$ and latent heat fluxes $(\lambda E) . \lambda E$ impaired by limited $g_{s}$ results in a higher $H$. This analysis shows that the Bowen ratio served as a reasonable measure for the extent to which the system's latent heat flux is limited by surface conductance. It identified several months in which $g_{s}$ clearly limited $\lambda E$ and thus may also have limited the assimilatory $\mathrm{CO}_{2}$ flux and the system's gross $\mathrm{CO}_{2}$ sequestration. It was demonstrated how surface conductance is strongly affected by aerial vapour pressure deficit. The latent heat flux is primarily driven by vapour pressure deficit, but the negative effect of vapour pressure deficit on surface conductance partly negates the effect of vapour pressure deficit on the latent heat flux. The effect of $g_{s}$ on the dissipation of energy into $H$ and $\lambda E$ and therefore probably also on the assimilatory $\mathrm{CO}_{2}$ flux could be observed on a monthly basis and it thus appears to be a factor which affects the grassland ecosystem's mass and energy exchange on longer time scales. 


\section{A.3. TO CHAPTER 5: THE EFFECT OF DIFFERENTIAL DRAINAGE IN A PEAT GRASSLAND}

\section{A.3.1. Confounding effect of weather conditions in $\mathrm{CO}_{2}$ flux components}

To assess the extent to which differences in weather conditions during the measurements contributed to the observed differences in respiratory $\left(F_{\mathrm{r}}\right)$ and assimilatory $\mathrm{CO}_{2}$ flux $\left(F_{\mathrm{a}}\right)$, Figure A.5 takes the data from the diurnal courses in Figure 5.4 to display the response of night-time $F_{\mathrm{r}}$ to $T_{\mathrm{a}}$ and of $F_{\mathrm{a}}$ to $R_{\mathrm{s}}$. In the months of April and June, $\mathrm{CO}_{2}$ fluxes at the low groundwater table were measured at higher irradiance $\left(R_{s}\right)$ and lower air temperature $\left(T_{\mathrm{a}}\right)$ than the fluxes at the high groundwater table. Measurements at higher $R_{\mathrm{s}}$ resulted in a $F_{\mathrm{a}}$ which was $2.3-3.7 \mathrm{~g} \mathrm{~m}^{-2} \mathrm{~d}^{-1}$ higher at the low groundwater table. But the radiation use, shown in Table 5.3 to be lower at the low groundwater table by 0.30 $\mathrm{g} \mathrm{MJ}^{-1}$, indicates an assimilatory $\mathrm{CO}_{2}$ flux which was actually limited by temperature, particularly before noon. Low $T_{\mathrm{a}}$ during the measurements at the low groundwater table contributed to $F_{\mathrm{r}}$ being $1.4 \mathrm{~g} \mathrm{~m}^{-2} \mathrm{~d}^{-1}$ lower than at the high groundwater table. In May levels of $R_{\mathrm{s}}$ were comparable but $T_{\mathrm{a}}$ was substantially higher for the measurements at the low groundwater table. Higher $T_{\mathrm{a}}$ could thus have contributed to higher $\varepsilon, F_{\mathrm{a}}$ and $F_{\mathrm{r}}$ at the low groundwater table, the latter as a result of more biomass and higher metabolic activity. Net $\mathrm{CO}_{2}$ exchange was similar for the measurements at both drainage levels, as higher $F_{\mathrm{a}}$ at the low groundwater table was compensated for by higher $F_{\mathrm{r}}$. September was characterised by generally high levels of $T_{\mathrm{a}}$ and $R_{\mathrm{s}}$, which was reflected in high radiation uses at all incident wind angles. Slightly higher values at the high groundwater table resulted in correspondingly higher $F_{\mathrm{a}}$ and $F_{\mathrm{r}}$ values, with little difference in the net $\mathrm{CO}_{2}$ exchange between both drainage levels. The process analysis thus shows that differential weather conditions during the measurements can explain much of the differences in the seasonal pattern of assimilatory $\left(F_{\mathrm{a}}\right)$ and respiratory $\mathrm{CO}_{2}$ fluxes $\left(F_{\mathrm{r}}\right)$ between both drainage levels. Both $\mathrm{CO}_{2}$ flux profiles would converge rather than diverge if the entire weather spectrum were taken into account.

Whereas the seasonal course of the ecosystem's net $\mathrm{CO}_{2}$ flux $\left(F_{n}\right)$ is a result of its constituent assimilatory $\left(F_{\mathrm{a}}\right)$ and respiratory $\mathrm{CO}_{2}$ fluxes $(F)$, it also shows that after taking into account differential weather conditions during measurement no distinct differences in the $\mathrm{CO}_{2}$ flux components between both drainage regimes were apparent. A subsequent more detailed analysis of the difference in the net $\mathrm{CO}_{2}$ flux between both drainage levels is based on a normalised ratio of $F_{\mathrm{r}}$ to $F_{\mathrm{a}}$ as well as on $F_{\mathrm{n}}$ as a process in its own right.

\section{A.3.2. Decomposition of peat by reference respiratory $\mathrm{CO}_{2}$ flux}

The reference respiratory $\mathrm{CO}_{2}$ flux at $20{ }^{\circ} \mathrm{C}\left(F_{\mathrm{r}(20)}\right)$ was consistently higher at the low groundwater table by $0.03-0.12 \mathrm{mg} \mathrm{CO} \mathrm{m}^{-2} \mathrm{~s}^{-1}$. Whereas this could be attributed to an enhanced decomposition of organic matter in the aerobic soil profile, $F_{\mathrm{r}(20)}$ also 


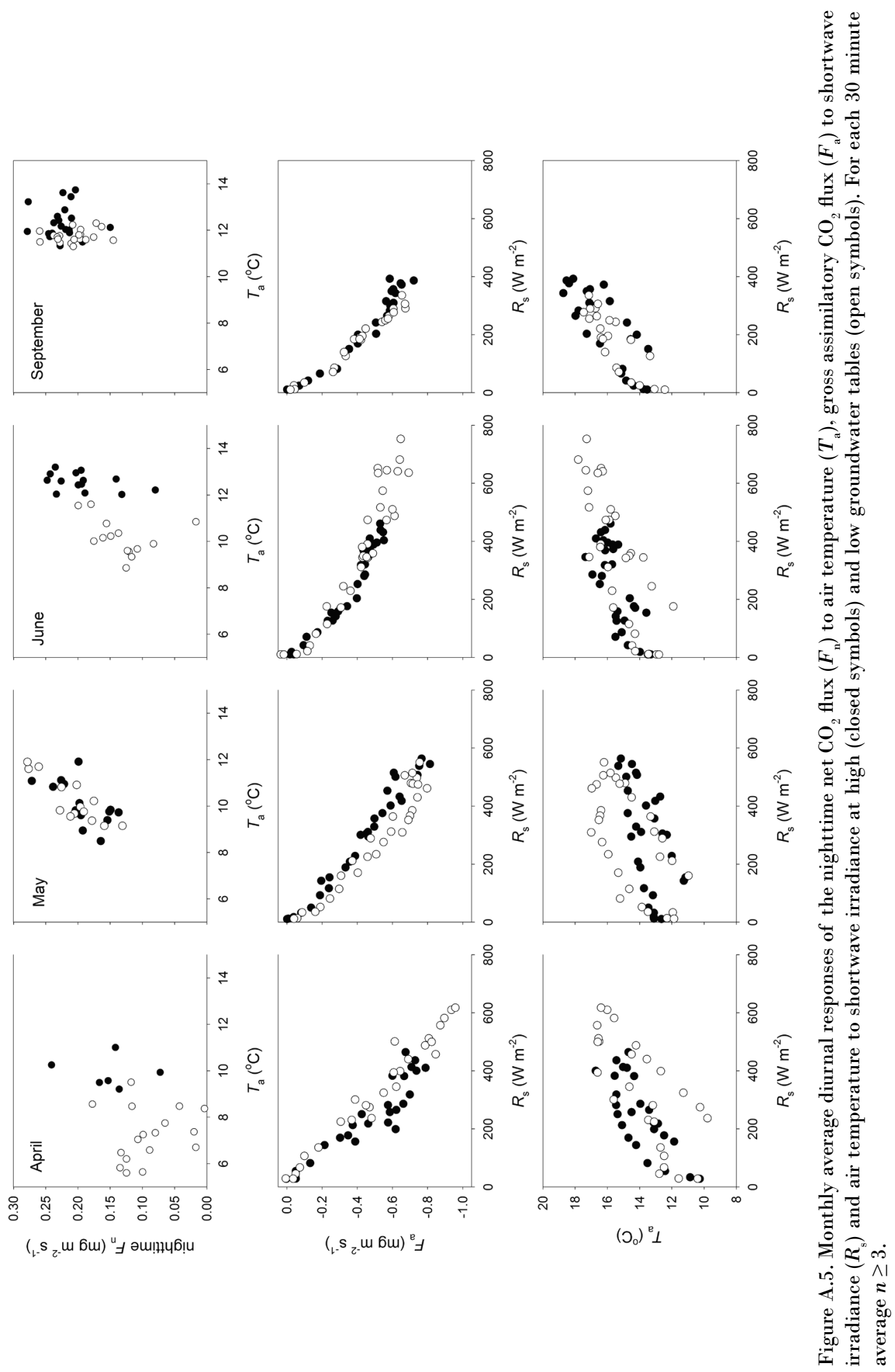


includes the effect of a higher assimilatory $\mathrm{CO}_{2}$ flux. A higher assimilatory $\mathrm{CO}_{2}$ flux is associated with a higher maintenance respiration and a higher respiratory $\mathrm{CO}_{2}$ flux from the decomposition of litter. It can thus not be determined by direct observation what caused a higher respiratory $\mathrm{CO}_{2}$ flux at the low groundwater table. Table A.1 now calculates from Equations 5.1 and 5.2 and the fitted parameters in Table 5.2 the respiratory $(F)$ and assimilatory $\mathrm{CO}_{2}$ fluxes $\left(F_{2}\right)$ at the highest levels of temperature $\left(T_{\mathrm{a}}\right)$ and irradiance $\left(R_{\mathrm{s}}\right)$ recorded for the particular month. It shows that the ratio of $F_{\mathrm{r}}$ to $F$ tended to be higher at the low groundwater table (at 0.35-0.85) than at the high groundwater table (at $0.26-0.59) . F_{\mathrm{r}}$ was thus relatively higher at the low groundwater table. If the ratio of $F_{\mathrm{r}}$ to $F_{\mathrm{a}}$ at the high groundwater table is taken as a reference, the increases in $F_{\mathrm{r}}$ disproportionate to $F_{\mathrm{a}}$ at the low groundwater table amounted to 0.094, $0.021,0.039$ and $0.225 \mathrm{mg} \mathrm{CO}_{2} \mathrm{~m}^{-2} \mathrm{~s}^{-1}$ in April, June, August and October, respectively. In May the ratios of $F_{\mathrm{r}}$ to $F_{\mathrm{a}}$ did not differ, whereas in September $F_{\mathrm{r}} / F_{\mathrm{a}}$ was lower at the low groundwater table. The disproportionate increase in $F_{\mathrm{r}}$ is the amount exceeding the increase which could be expected solely on basis of the increase in $F_{a}$. It is a better estimate for the additional decomposition of organic matter in the aerobic soil profile at the low groundwater table than $F_{\mathrm{r}}$ as such as it seeks to exclude maintenance respiration and the decomposition of litter.

The reference respiratory $\mathrm{CO}_{2}$ flux $F_{\mathrm{r}(20)}$ at the low groundwater tables was thus found to be higher by $0.03-0.12 \mathrm{mg} \mathrm{CO}_{2} \mathrm{~m}^{-2} \mathrm{~s}^{-1}$. After accounting for differences in productivity between both drainage regimes and its effect on respiratory activity, a disproportionate increase in $F_{\mathrm{r}}$ at the low groundwater table relative to the high groundwater table was calculated of $0.021-0.225 \mathrm{mg} \mathrm{CO}_{2} \mathrm{~m}^{-2} \mathrm{~s}^{-1}$. This respiratory $\mathrm{CO}_{2}$ flux could be interpreted as an upper boundary to the decomposition of organic matter associated with an

Table A.l. Calculated instantaneous respiratory $\mathrm{CO}_{2}$ flux $\left(F_{\mathrm{r}}\right)$ and gross assimilatory $\mathrm{CO}_{2}$ flux $\left(F_{\mathrm{a}}\right)$ at close to highest occurring air temperature $\left(T_{\mathrm{a}}\right)$ and shortwave irradiance $\left(R_{\mathrm{s}}\right)$ for the particular months at high (H) and low (L) groundwater tables while applying Equations 5.1 and 5.2 and the fitted parameters from Table 5.2. Ratio between $F_{\mathrm{r}}$ and $F_{\mathrm{a}}\left(F_{\mathrm{r}} / F_{\mathrm{a}}\right)$ and the disproportionate increase in respiratory $\mathrm{CO}_{2}$ flux at the low groundwater table $\left(\Delta F_{\mathrm{r}(\mathrm{dis})}\right)$.

\begin{tabular}{|c|c|c|c|c|c|c|c|c|c|}
\hline \multirow[t]{2}{*}{ month } & \multirow[t]{2}{*}{$\underset{\left({ }^{\circ} \mathrm{C}\right)}{T}$} & \multirow[t]{2}{*}{$\begin{array}{c}R_{s} \\
\left(\mathbf{W ~ m}^{-2}\right)\end{array}$} & \multicolumn{2}{|c|}{$\begin{array}{c}F_{\mathrm{r}} \\
\left(\mathrm{mg} \mathrm{m}^{-2} \mathbf{s}^{-1}\right) \\
\end{array}$} & \multicolumn{2}{|c|}{$\begin{array}{c}F_{\mathrm{a}} \\
\left(\mathbf{m g ~ m}^{-2} \mathbf{s}^{-1}\right) \\
\end{array}$} & \multicolumn{2}{|c|}{$F_{\mathrm{r}} / F_{\mathrm{a}}$} & \multirow{2}{*}{$\frac{\begin{array}{c}\Delta F_{\mathrm{r}(\mathrm{dis})} \\
\left(\mathrm{mg} \mathrm{m}^{-2} \mathrm{~s}^{-1}\right)\end{array}}{\mathrm{L}}$} \\
\hline & & & $\mathbf{H}$ & $\mathbf{L}$ & $\mathbf{H}$ & $\mathbf{L}$ & $\mathbf{H}$ & $\mathbf{L}$ & \\
\hline April & 19.5 & 750 & 0.328 & 0.360 & 1.284 & 1.041 & 0.26 & 0.35 & 0.094 \\
\hline May & 19.5 & 800 & 0.484 & 0.585 & 0.884 & 1.067 & 0.55 & 0.55 & 0.000 \\
\hline June & 19.5 & 800 & 0.409 & 0.441 & 0.696 & 0.711 & 0.59 & 0.62 & 0.021 \\
\hline August & 23.5 & 700 & 0.284 & 0.399 & 0.620 & 0.788 & 0.46 & 0.51 & 0.039 \\
\hline September & 20.0 & 600 & 0.452 & 0.502 & 0.832 & 1.010 & 0.54 & 0.50 & -0.040 \\
\hline October & 20.0 & 450 & 0.484 & 0.602 & 0.908 & 0.704 & 0.53 & 0.85 & 0.225 \\
\hline
\end{tabular}


additional $0.3 \mathrm{~m}$ of peat soil exposed to aerobic conditions. It compares to values reported in literature of $0.0015-0.0020 \mathrm{mg} \mathrm{m}^{-2} \mathrm{~s}^{-1}$ for each $\mathrm{cm}$ of peat soil exposed to aerobic conditions (Glenn et al. 1993, Silvola et al. 1996), although the added complexity of the time axis in the decomposition of soil organic matter complicates comparison of the values. According to the $\mathrm{Q}$ model for the decomposability of soil organic matter (e.g. Ågren \& Bosatta 1996, Feng 2009) the decomposition rate of any volume of organic matter decreases in time as the easily decomposable fractions decompose first, which gradually shifts the organic matter's composition to fractions which are increasingly resistant to decomposition. This equally applies to peat soil fractions exposed to aerobic conditions after drainage. It can thus be seen that the time elapsed since drainage matters and that the respiratory $\mathrm{CO}_{2}$ flux emanating from a particular volume of peat should decrease in time. Drainage events should thus result in spikes in the respiratory $\mathrm{CO}_{2}$ flux, which gradually level off (Van Huissteden et al. 2006). The drainage levels at the experimental site in this study date back to 1969 . This implies that the respiratory $\mathrm{CO}_{2}$ fluxes associated with that particular event and that particular volume of peat - lowering the water table with up to $30 \mathrm{~cm}$ - was high at the start but gradually decreased over time. The volume of peat newly exposed to aerobic conditions equates the annual downward adjustment of water levels necessary to compensate for the annual soil subsidence, i.e. 0.5 and $1.1 \mathrm{~cm} \mathrm{y}^{-1}$. The total respiratory $\mathrm{CO}_{2}$ flux from the decomposition of peat is thus the composite flux from fractions associated with major drainage events and from multiple annual fractions to compensate for soil subsidence.

\section{A.3.3. Decomposition of peat by assimilatory $\mathrm{CO}_{2}$ flux and temperature}

An alternative approach to the calculation of the decomposition of organic matter in the aerobic soil profile uses the instantaneous net $\mathrm{CO}_{2}$ exchange as a process as such, in which it is attempted to eliminate the effect of both assimilatory activity and temperature. This approach applies the data from the average diurnal patterns shown in figures 5.4 and A.5. Figure A.6A shows how the instantaneous net $\mathrm{CO}_{2}$ sequestration $\left(F_{\mathrm{n}}\right)$ responds positively to the instantaneous assimilatory $\mathrm{CO}_{2}$ flux $\left(F_{\mathrm{a}}\right)$, i.e. the higher the assimilatory $\mathrm{CO}_{2}$ flux the higher the net $\mathrm{CO}_{2}$ sequestration. Figure A.6B shows how the instantaneous respiratory $\mathrm{CO}_{2}$ flux $(F)$ increased only modestly with the instantaneous assimilatory $\mathrm{CO}_{2}$ flux $\left(F_{\mathrm{a}}\right)$, which indicates that $F_{\mathrm{a}}$ was a dominating factor in changes in the net $\mathrm{CO}_{2}$ exchange. There was no apparent difference between both drainage levels, implying that the net $\mathrm{CO}_{2}$ sequestration in response to assimilatory activity seems to be largely independent of the depth of the aerobic soil profile. The fitted linear responses of $F_{\mathrm{n}}$ to $F_{\text {a }}$ given in Table A.2 show a slightly higher intercept $\left(\mathrm{CO}_{2}\right.$ emission at zero assimilatory activity) and a slightly sleeper slope $\left(\mathrm{CO}_{2}\right.$ sequestration at increasing assimilatory activity) at the higher groundwater table, but it shows that neither intercept nor slope were significantly different between both drainage levels $(P>0.10)$. The average response translates into a net $\mathrm{CO}_{2}$ release of $0.18 \mathrm{mg} \mathrm{CO}_{2} \mathrm{~m}^{-2} \mathrm{~s}^{-1}$ at zero assimilatory activity and 

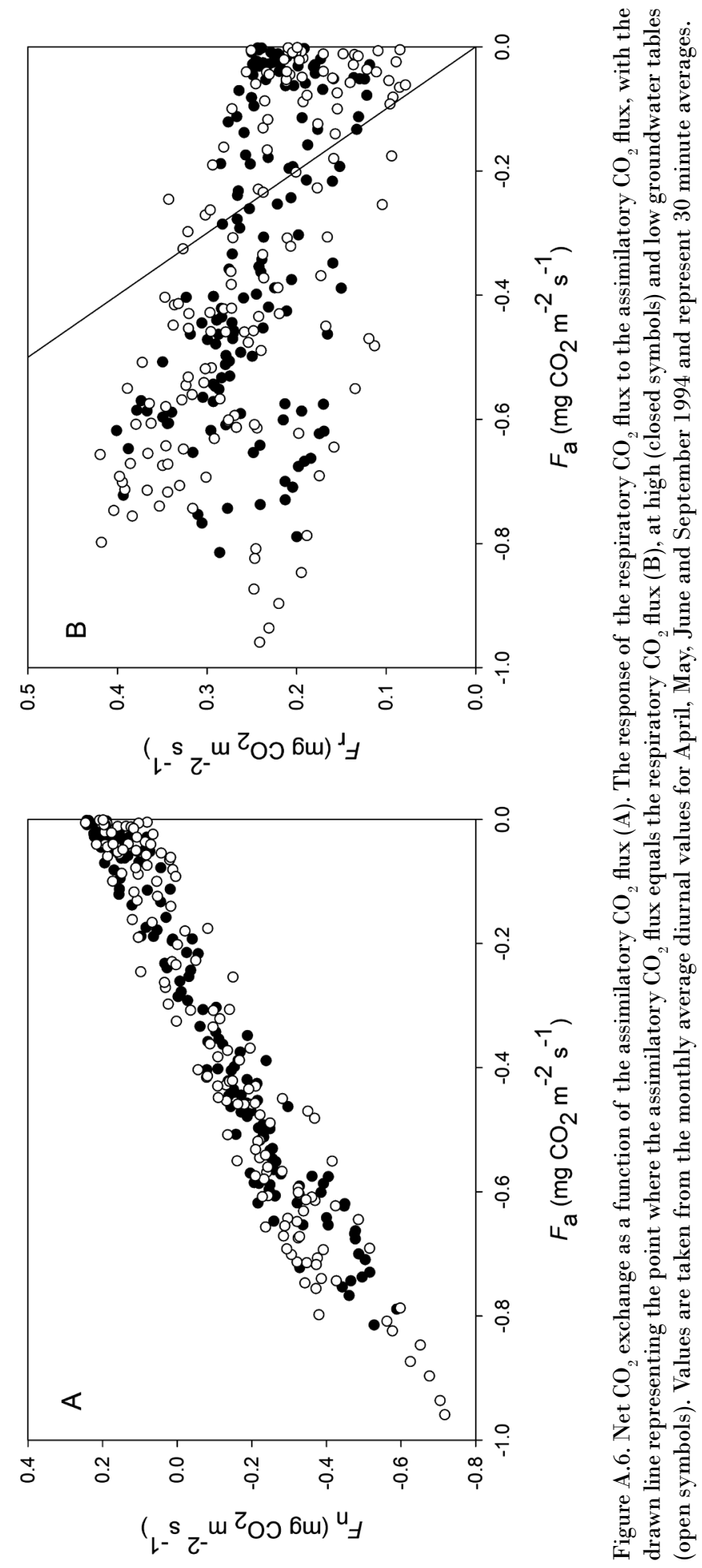
a net sequestration of $0.83 \mathrm{~g} \mathrm{CO}_{2}$ for every $\mathrm{g} \mathrm{CO}_{2}$ assimilated. This high instant relative net $\mathrm{CO}_{2}$ sequestration should be seen in the context of the diurnal course, where much of the day has little assimilatory activity.

An increase in respiratory activity with temperature reduces net $\mathrm{CO}_{2}$ sequestration. At least part of the variation in the response of net $\mathrm{CO}_{2}$ exchange $F_{\mathrm{n}}$ to gross assimilatory $\mathrm{CO}_{2}$ flux $F_{\mathrm{a}}$ could thus be related to a variation in air temperature $T_{\mathrm{a}}$, which is explored by fitting a linear dependency of $F_{\mathrm{n}}$ on both $F_{\mathrm{a}}$ and $T_{\mathrm{a}}$. A high degree of collinearity between assimilatory $\mathrm{CO}_{2}$ flux and temperature is not expected, as a positive effect of temperature on assimilatory activity is already implicit in the assimilatory $\mathrm{CO}_{2}$ flux itself. The relationship is evaluated on basis of the aggregated values from the average diurnal flux patterns shown in Figure 5.4. This evaluation applies the following linear equation:

$F_{\mathrm{n}}=a_{0}+a_{1} \times G+a_{2} \times F_{\mathrm{a}}+a_{3} \times G \times F_{\mathrm{a}}+a_{4} \times T_{\mathrm{a}}+a_{5} \times G \times T_{\mathrm{a}}$

where $F_{\mathrm{n}}$ is the aggregated net $\mathrm{CO}_{2}$ flux $\left(\mathrm{mg} \mathrm{CO}_{2} \mathrm{~m}^{-2} \mathrm{~s}^{-1}\right), F_{\mathrm{a}}$ is the aggregated assimilatory $\mathrm{CO}_{2}$ flux ( $\left.\mathrm{mg} \mathrm{CO}_{2} \mathrm{~m}^{-2} \mathrm{~s}^{-1}\right), T_{\mathrm{a}}$ is the aggregated air temperature $\left({ }^{\circ} \mathrm{C}\right)$ and $G$ is a categorical variable representing the drainage level (i.e. 0 for a high groundwater table and 1 for a low groundwater table). $a_{0}$ to $a_{5}$ are the regression coefficients, in which coefficients $a_{3}$ and $a_{5}$ test for the null hypothesis stating that the linear relations between $F_{\mathrm{a}}$ and $T_{\mathrm{a}}$ on the one hand and $F_{\mathrm{n}}$ on the other are the same at both drainage levels.

Table A.2 lists the respective regression parameters. The analysis confirms the absence of collinearity and shows that inclusion of temperature increased explained variance. Instant net $\mathrm{CO}_{2}$ sequestration increases with assimilatory activity and decreases with temperature. The response of $F_{\mathrm{n}}$ to both $F_{\mathrm{a}}$ and $T_{\mathrm{a}}$ allows for the calculation of the net $\mathrm{CO}_{2}$ flux at zero irradiance and a set temperature of $15^{\circ} \mathrm{C}$. This results in an instantaneous net

Table A.2. Fitted linear course $(P<0.001)$ of the instantaneous net $\mathrm{CO}_{2}$ exchange $\left(F_{\mathrm{n}}\right)$ at high $(\mathrm{H})$ and low groundwater levels $(\mathrm{L})$. In response $(1)$ to only the assimilatory $\mathrm{CO}_{2}$ flux $\left(F_{\mathrm{a}}\right)$ and $(2)$ to both the assimilatory $\mathrm{CO}_{2}$ flux $\left(F_{\mathrm{a}}\right)$ and aerial temperature $\left(T_{\mathrm{a}}\right)$. Data taken from the monthly average diurnal patterns in April, May, June and September 1994 at 30 minute intervals. Downward $\mathrm{CO}_{2}$ fluxes (towards sequestration) are indicated as negative values, i.e. a positive response to $F_{\text {a }}$ leans towards $\mathrm{CO}_{2}$ sequestration and a positive response to $T_{\mathrm{a}}$ leans towards $\mathrm{CO}_{2}$ release.

\begin{tabular}{lllllll}
\hline response & $\begin{array}{l}\text { groundwater } \\
\text { level }\end{array}$ & $\begin{array}{l}\text { intercept } \\
\left(\mathbf{m g ~ C O} \mathbf{~ m}^{-2} \mathbf{s}^{-1}\right)\end{array}$ & $\begin{array}{l}\boldsymbol{F}_{\mathrm{a}} \\
(-)\end{array}$ & $\begin{array}{l}\boldsymbol{T}_{\mathrm{a}} \\
\left(\mathbf{m g ~ C O} \mathbf{C O}_{\mathbf{2}} \mathbf{m}^{-2} \mathbf{~ s}^{-\mathbf{1}} \mathbf{o C}^{-1}\right)\end{array}$ & $\boldsymbol{n}$ & $\boldsymbol{r}^{2}$ \\
\hline$F_{\mathrm{n}}=f\left(F_{\mathrm{a}}\right)$ & $\mathrm{H}$ & 0.189 & 0.854 & - & 191 & 0.95 \\
$F_{\mathrm{n}}=f\left(F_{\mathrm{a}}\right)$ & $\mathrm{L}$ & 0.172 & 0.804 & - & 192 & 0.93 \\
$F_{\mathrm{n}}=f\left(F_{\mathrm{a}}, T_{\mathrm{a}}\right)$ & $\mathrm{H}$ & -0.108 & 1.023 & 0.0255 & 191 & 0.98 \\
$F_{\mathrm{n}}=f\left(F_{\mathrm{a}}, T_{\mathrm{a}}\right)$ & $\mathrm{L}$ & -0.114 & 1.016 & 0.0267 & 192 & 0.98 \\
\hline
\end{tabular}


$\mathrm{CO}_{2}$ release of $0.275 \mathrm{mg} \mathrm{CO}_{2} \mathrm{~m}^{-2} \mathrm{~s}^{-1}$ at high groundwater level and $0.287 \mathrm{mg} \mathrm{CO}_{2}$ $\mathrm{m}^{-2} \mathrm{~s}^{-1}$ at low groundwater level. The difference of $0.012 \mathrm{mg} \mathrm{CO}_{2} \mathrm{~m}^{-2} \mathrm{~s}^{-1}$ between both drainage levels could then be attributed to the different depths of the aerobic soil profile and therefore difference in the decomposition of peat between both drainage levels. However, application of Equation A.1 indicates that the differences in net $\mathrm{CO}_{2}$ exchange characteristics between both drainage levels were not significant, reflected in regression coefficients $a_{3}$ and $a_{5}(P>0.10)$. Despite the difference not being significant, the data do suggest that an additional $30 \mathrm{~cm}$ of aerobic soil profile depth is associated with an instant respiratory $\mathrm{CO}_{2}$ flux of $0.0120 \mathrm{mg} \mathrm{CO}_{2} \mathrm{~m}^{-2} \mathrm{~s}^{-1}$, which represents approximately $4 \%$ of the total respiratory $\mathrm{CO}_{2}$ flux. A percentage this low explains how any effect of drainage level on the ecosystem respiratory $\mathrm{CO}_{2}$ flux could go largely undetected.

This thus suggests that, at a temperature of $15^{\circ} \mathrm{C}$, the respiratory $\mathrm{CO}_{2}$ flux associated with a drainage level of $-60 \mathrm{~cm}$ was $0.012 \mathrm{mg} \mathrm{CO}_{2} \mathrm{~m}^{-2} \mathrm{~s}^{-1}$ higher than the $\mathrm{CO}_{2}$ flux associated with a drainage level of $-30 \mathrm{~cm}$. Although a decrease in the ecosystem's $\mathrm{CO}_{2}$ release with increasing assimilatory activity and an increase in the $\mathrm{CO}_{2}$ release with increasing temperature were both statistically significant, the difference between both drainage levels proved not to be. This may in part be caused by a dependence of $\mathrm{CO}_{2}$ fluxes on fluxes in preceding time intervals. Although not statistically significant, this difference could still be attributed to an additional $30 \mathrm{~cm}$ depth in the aerobic soil profile and a concomitant increase in the decomposition of peat. It is lower than other estimates and values reported in literature (Glenn et al. 1993, Silvola et al. 1996), but in view of the time lapsed since these grasslands' major drainage events probably more realistic. The difference constitutes a mere $4 \%$ of the total respiratory $\mathrm{CO}_{2}$ flux, which explains why differences between both drainage levels are not easily discernible in measurements. This respiratory $\mathrm{CO}_{2}$ flux associated with an additional drainage of $30 \mathrm{~cm}$ is nevertheless not negligible, which could be inferred from its daily value of approximately $1.04 \mathrm{~g} \mathrm{CO}_{2} \mathrm{~m}^{-2}$ $\mathrm{d}^{-1}$. When simply ignoring the fact that temperature is not a constant $15^{\circ} \mathrm{C}$, it can be seen that the annual respiratory $\mathrm{CO}_{2}$ flux associated with such a difference in drainage level would be in the order of magnitude of $375 \mathrm{~g} \mathrm{CO}_{2} \mathrm{~m}^{-2} \mathrm{y}^{-1}$. As a proportionality between drainage level and soil subsidence was observed this respiratory $\mathrm{CO}_{2}$ flux could even be extrapolated to the entire aerobic soil profile at a drainage level of $-60 \mathrm{~cm}$, resulting in an annual respiratory $\mathrm{CO}_{2}$ flux from the decomposition of peat of approximately 750 $\mathrm{g} \mathrm{CO}_{2} \mathrm{~m}^{-2} \mathrm{y}^{-1}$. Leiber-Sauheitl et al. (2014) found the ecosystem respiratory $\mathrm{CO}_{2}$ flux in grasslands on histic Gleysols to increase across gradients of both soil $\mathrm{C}$ and drainage depth. In a drained and extensively used Alpine peat grassland, Rogiers et al. (2008) measured an unusually high net $\mathrm{CO}_{2}$ emission of 1700-2200 $\mathrm{g} \mathrm{CO}_{2} \mathrm{~m}^{-2} \mathrm{y}^{-1}$ over 3 successive years. Campbell et al. (2015) measured a net $\mathrm{CO}_{2}$ emission of $1078 \mathrm{~g} \mathrm{CO}_{2}$ $\mathrm{m}^{-2} \mathrm{y}^{-1}$ in a drained peat grassland used for intensive dairy farming, at a drainage depth approaching $-50 \mathrm{~cm}$. 


\section{A.3.4. Net $\mathrm{CO}_{2}$ emissions on drainage}

It is shown that the peat grassland ecosystem's net $\mathrm{CO}_{2}$ exchange is largely determined by the balance between the gross assimilatory $\mathrm{CO}_{2}$ flux and the effect of temperature on the respiratory $\mathrm{CO}_{2}$ flux. The respiratory $\mathrm{CO}_{2}$ flux exceeded the assimilatory $\mathrm{CO}_{2}$ flux in the periphery of the daytime period and at night. The balance between these two periods determined whether for a particular day the ecosystem sequestered or released $\mathrm{CO}_{2} \cdot \mathrm{CO}_{2}$ sequestration is therefore enhanced by high levels of irradiance (e.g. long daylength), daytime temperatures which do not limit assimilatory activity, cool nights during the growing season and low temperatures minimising respiratory activity during the remainder of the year. Only in early spring (at high irradiance and moderate temperature) does the assimilatory $\mathrm{CO}_{2}$ flux exceed the respiratory $\mathrm{CO}_{2}$ flux to a substantial extent.

Deeper drainage is applied to improve conditions for growth and increase the peat pastures' physical carrying capacity earlier in the growing season (Pleijter \& Van den Akker 2007). Of primary interest to this study is the question whether this deeper drainage and therefore elevated exposure of the organic soil profile to aerobic conditions results in a higher decomposition of peat and therefore higher respiratory $\mathrm{CO}_{2}$ flux. Veenendaal et al. (2007) found annual relative respiratory $\mathrm{CO}_{2}$ fluxes of 1.00 and 1.09 $\mathrm{g} \mathrm{g}^{-1}$ in an extensively and an intensively managed peat grassland, respectively. Jacobs et al. (2007) observed annual relative respiratory $\mathrm{CO}_{2}$ fluxes ranging from 0.90 to $1.11 \mathrm{~g}$ $\mathrm{g}^{-1}$ in an intensively managed peat pasture. This aligns with the observation in this study that the $5-10 \%$ difference in the respiratory $\mathrm{CO}_{2}$ flux as a result of the decomposition of peat is of the order of magnitude which determines whether a peat pasture is an annual $\mathrm{CO}_{2}$ sink or source. Weideveld et al. (2020) measured the effect of sub-soil irrigation pipes at a depth of $-70 \mathrm{~cm}$ in drained peat pasture, mainly reducing the depth of the groundwater table in summer relative to pasture without such irrigation. Both drainage levels were characterised by a net $\mathrm{CO}_{2}$ release. A reduction in the instantaneous ecosystem respiratory $\mathrm{CO}_{2}$ flux of $5-10 \%$ was observed when the difference in the depth of the groundwater table exceeded $20 \mathrm{~cm}$, which corresponds with the observations made in the studies mentioned before. The authors also calculated the ecosystems' annual respiratory and net release fluxes but found the difference between both drainage levels to be not significant either. A much larger difference in net $\mathrm{CO}_{2}$ release between drainage levels in drained peat pasture was found by Campbell et al. (2020), comparing pasture with drainage pipes and a water table depth of $-65 \mathrm{~cm}$ and without such drainage and a water table depth of $-85 \mathrm{~cm}$. The net $\mathrm{CO}_{2}$ release amounted to $818 \mathrm{~g} \mathrm{CO}_{2} \mathrm{~m}^{-2} \mathrm{y}^{-1}$ at a water table depth of $-65 \mathrm{~cm}$ and $3105 \mathrm{~g} \mathrm{CO}_{2} \mathrm{~m}^{-2} \mathrm{y}^{-1}$ at $-85 \mathrm{~cm}$. The difference was largely caused by a much enhanced respiratory $\mathrm{CO}_{2}$ flux at the low groundwater table during an unusually dry part of the growing season, possibly related to a vertical distribution of soil moisture sustaining such levels of respiration. 
Whereas the magnitude of the respiratory $\mathrm{CO}_{2}$ fluxes appears to vary strongly and to depend on soil characteristics and drainage history, drained peat grassland ecosystems appear to be consistently characterised by a net $\mathrm{CO}_{2}$ release. Observation of the data also supports the hypothesis that deeper drainage generally results in a higher net $\mathrm{CO}_{2}$ release because of an enhanced decomposition of organic matter in the aerobic soil profile. A difference in net $\mathrm{CO}_{2}$ release may not always be recognised as such because it is often hidden in the variation of a much larger total ecosystem respiratory $\mathrm{CO}_{2}$ flux, which then evades statistical significance. But despite its minute size relative to the total respiratory $\mathrm{CO}_{2}$ flux, the net $\mathrm{CO}_{2}$ release as such is substantial. A different management of drainage levels offers the possibility of lower $\mathrm{CO}_{2}$ emissions from peat grasslands and even the restoration of a net $\mathrm{CO}_{2}$ sequestration which originally characterised peat grasslands.

In Section A.3.3, it was found that the differences in assimilatory and respiratory $\mathrm{CO}_{2}$ flux between peat grassland drainage levels -30 and $-60 \mathrm{~cm}$ were of a relatively small magnitude such that they are difficult to discern in the flux components proper. By accounting for an effect of assimilatory activity and temperature on the net $\mathrm{CO}_{2}$ flux it was shown that the deeper level of drainage could have resulted in an added instantaneous respiratory $\mathrm{CO}_{2}$ flux of approximately $0.012 \mathrm{mg} \mathrm{CO}_{2} \mathrm{~m}^{-2} \mathrm{~s}^{-1}$ at a reference temperature of $15^{\circ} \mathrm{C}$. A simple extrapolation at the same constant temperature puts this difference in a temporal perspective, equating a differential decomposition of organic matter in the aerobic soil profile between both drainage levels of $375 \mathrm{~g} \mathrm{CO}_{2} \mathrm{~m}^{-2} \mathrm{y}^{-1}$ or 3.75 ton $\mathrm{CO}_{2}$ $h^{-1} y^{-1}$. 


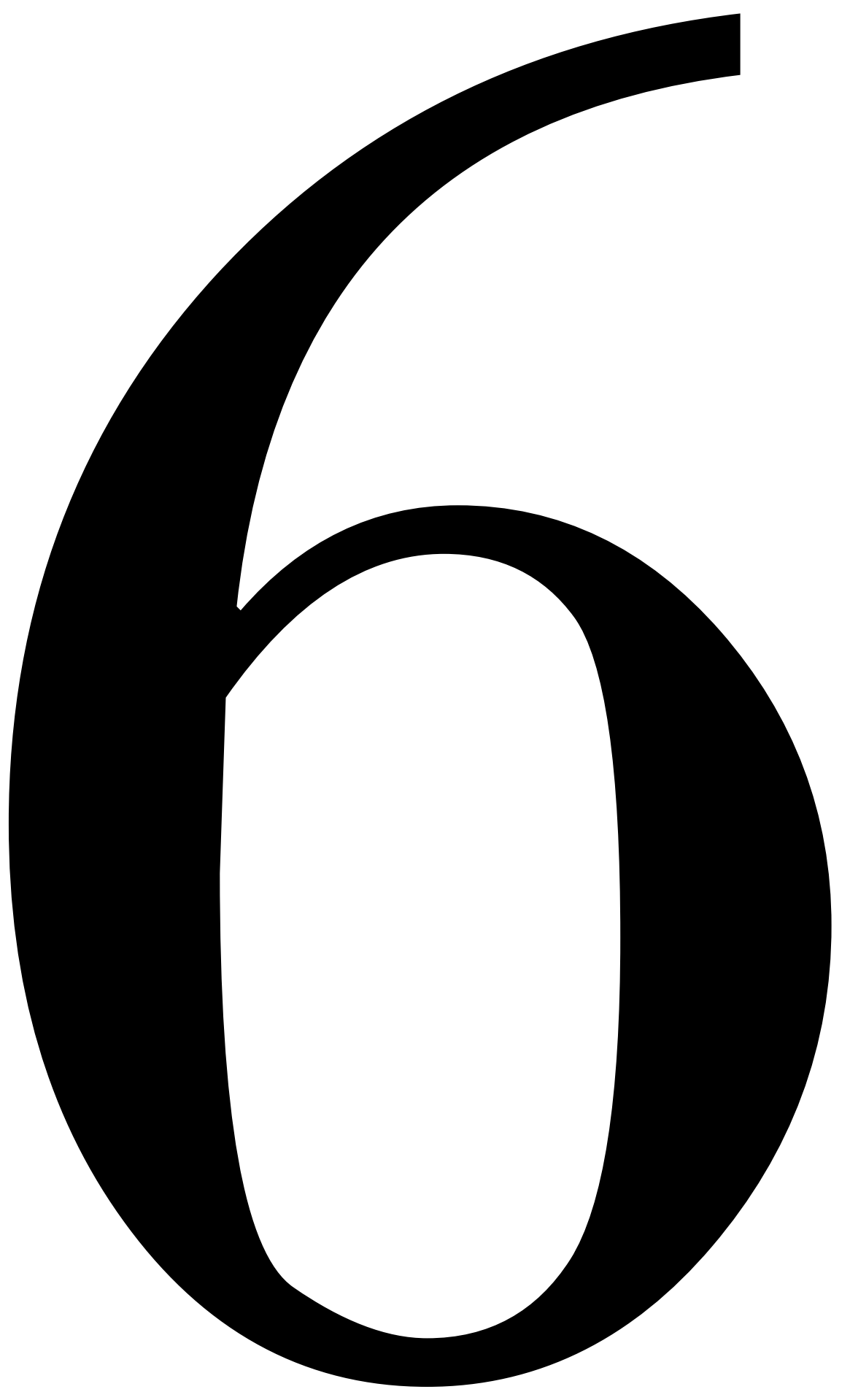




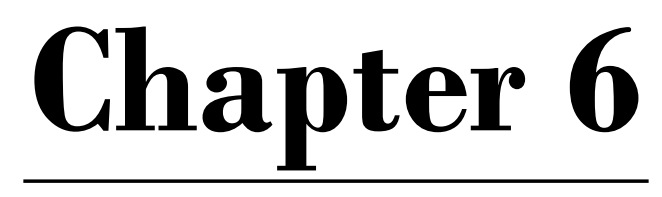

Patterns of monthly and annual $\mathrm{CO}_{2}$ exchange in a drained peat grassland 


\section{SUMMARY}

Aerodynamic gradient measurements of instantaneous net $\mathrm{CO}_{2}$ exchange in a drained and grazed peat grassland ecosystem in the Netherlands during 2 consecutive years were separated into respiratory and gross assimilatory $\mathrm{CO}_{2}$ flux components. The instantaneous flux components were aggregated to monthly values and related to levels of irradiance, air temperature and air humidity. It is shown that the monthly assimilatory $\mathrm{CO}_{2}$ flux responded linearly to monthly shortwave irradiance, becoming limited at monthly average air temperatures $<10^{\circ} \mathrm{C}$ and monthly average vapour pressure deficits $>350 \mathrm{~Pa}$. The monthly respiratory $\mathrm{CO}_{2}$ flux responded linearly to monthly average air temperature if $>5{ }^{\circ} \mathrm{C}$. It is also shown that the monthly respiratory $\mathrm{CO}_{2}$ flux responded both positively and with some delay to the monthly assimilatory $\mathrm{CO}_{2}$ flux. The relationship between assimilatory and respiratory $\mathrm{CO}_{2}$ fluxes exhibited a clear case of hysteresis, where the assimilatory $\mathrm{CO}_{2}$ flux exceeded the respiratory $\mathrm{CO}_{2}$ flux in spring and early summer whereas the respiratory $\mathrm{CO}_{2}$ flux exceeded the assimilatory $\mathrm{CO}_{2}$ flux during the remainder of the year. The drained peat grassland proved to be an annual $\mathrm{CO}_{2}$ source at $623-920$ $\mathrm{g} \mathrm{CO}_{2} \mathrm{~m}^{-2}$ and a ratio between annual respiratory and assimilatory $\mathrm{CO}_{2}$ flux of 1.121.14. The annual net $\mathrm{CO}_{2}$ release was related to the decomposition of organic matter in the aerobic soil profile and accounted for a minimum of $22-32 \%$ of the observed soil subsidence. The monthly net $\mathrm{CO}_{2}$ exchange in itself could be largely explained by primary productivity and temperature: higher assimilatory $\mathrm{CO}_{2}$ fluxes tended towards a net $\mathrm{CO}_{2}$ sequestration and higher temperatures tended towards a net $\mathrm{CO}_{2}$ release.

\subsection{INTRODUCTION}

Atmospheric $\mathrm{CO}_{2}$ is a small but significant part in the biogeochemical cycle of C. It is an important resource in biospheric productivity and constitutes the basis of much of the global food chain. The gradual increase in the atmospheric $\mathrm{CO}_{2}$ concentration observed since the onset of the Industrial Revolution is largely related to anthropogenic activities such as the burning of fossil fuels (Ciais et al. 2013). It has received much attention in view of its role as an agent in climate change (Proctor et al. 2018). Neither well understood nor appreciated is the observation that this increase only accounts for on average $50 \%$ of anthropogenic $\mathrm{CO}_{2}$ emissions (Eldering et al. 2017, Le Quéré et al. 2018). The difference between $\mathrm{CO}_{2}$ emissions and the increase in atmospheric $\mathrm{CO}_{2}$ concentration is thought to be sequestered by the biosphere and the oceans (Keeling et al. 2001, Janssens et al. 2003). The net $\mathrm{CO}_{2}$ sequestration reduces the amount of atmospheric $\mathrm{CO}_{2}$ and moderates the anthropogenic $\mathrm{CO}_{2}$ emissions by on average 50\% (Levin 2012). However, it remains unclear which parts of the biosphere and oceans sequester this $\mathrm{CO}_{2}$. It could be partly driven by the increasing atmospheric $\mathrm{CO}_{2}$ concentration itself and may also involve 
processes on longer time scales. It is not clear how this net $\mathrm{CO}_{2}$ sequestration and its proportion to anthropogenic $\mathrm{CO}_{2}$ emissions will develop in time. The $\mathrm{CO}_{2}$ exchange processes between atmosphere and biospheric and oceanic systems are of significance because of their effect on the course of the atmospheric $\mathrm{CO}_{2}$ concentration.

Grasslands constitute an important biome in the global C cycle, because of their large surface cover, relatively low physiological maintenance requirements and high root proportion. They accumulate large amounts of $\mathrm{C}$ in the soil profile, albeit at highly varying levels of productivity (Jones \& Donnelly 2004, Scurlock et al. 2002). Conant et al. (2001) found a clear increase in soil C upon both grassland improvement and conversion of agricultural land into grassland. Grasslands on organic soils contain much larger amounts of $\mathrm{C}$ - largely immobilised in the anaerobic soil profile - and share many similarities with wetlands in general (Tenhunen et al. 1995). Many of these grasslands have been drained to some extent and converted into improved pastureland or cropland. Drainage thus leads to the creation of an aerobic and an anaerobic section of the soil profile. Whereas a net $\mathrm{CO}_{2}$ sequestration may be observed for undrained wetlands, the net $\mathrm{CO}_{2}$ balance becomes more ambiguous after drainage as the decomposition of the organic soil in the aerobic soil profile constitutes an additional $\mathrm{CO}_{2}$ source (Beetz et al. 2013, Lohila et al. 2004). The topology of the Netherlands at the mouth of a vast flat river delta is conducive to the formation of wetlands (Van Dinter 2013). As a result of different degrees of drainage a broad spectrum of grasslands on organic soil has arisen, varying from undrained grasslands now used for nature conservation to highly productive drained peat pastures used for dairy farming (Jacobs et al. 2007, Veenendaal et al. 2007).

Satellite measurements of patterns in the atmospheric $\mathrm{CO}_{2}$ concentration are able to identify $\mathrm{CO}_{2}$ sinks and sources on a regional scale (Crisp et al. 2004, Eldering et al. 2017). These measurements constitute the highest aggregation level in the global $\mathrm{CO}_{2}$ exchange processes, but their spatial resolution is generally too low to distinguish between different biomes. Only at the level of the biome it is possible to analyse the $\mathrm{CO}_{2}$ fluxes and their components in detail. Micrometeorological measurement constitutes an established methodology to measure the instantaneous atmospheric-biospheric $\mathrm{CO}_{2}$ exchange at a smaller spatial scale in homogeneous ecosystems. The sum of the instantaneous fluxes over an entire year yields the ecosystem's annual net $\mathrm{CO}_{2}$ exchange. This technique has also been applied in a range of Dutch peat pastures (e.g. Jacobs et al. 2007, Veenendaal et al. 2007) with equivocal results for the ecosystems' annual net $\mathrm{CO}_{2}$ exchange values. The annual net $\mathrm{CO}_{2}$ exchange is the dynamic result of its assimilatory and respiratory $\mathrm{CO}_{2}$ fluxes, but the high temporal resolution of the flux measurements is less suitable for an analysis of how the assimilatory and respiratory $\mathrm{CO}_{2}$ flux components lead to an annual net $\mathrm{CO}_{2}$ exchange. The instantaneous $\mathrm{CO}_{2}$ flux components are related to environmental factors such as radiation and temperature (Albergel et al. 2010, Ammann et al. 2007, 
Imer et al. 2013, Jacobs et al. 2003). Whereas these analyses increase the understanding of the underlying processes of the instantaneous $\mathrm{CO}_{2}$ flux, the discrepancy in temporal resolution is too large for these instantaneous dependencies to explain the dynamics of the ecosystem's annual net $\mathrm{CO}_{2}$ flux.

In a re-appreciation of various studies on $\mathrm{CO}_{2}$ exchange in European grasslands, Gilmanov et al. (2007) found a strong coherence between irradiance and the assimilatory $\mathrm{CO}_{2}$ flux. The effect of irradiance on primary productivity is primarily mediated by soil fertility, soil moisture, air humidity and temperature. Whereas the level of soil fertility is a characteristic of any grassland ecosystem, temperature, soil moisture and air humidity vary within and among growing seasons. Once precipitation is limiting growth, the dependence of the productivity on radiation may disappear altogether (e.g. Sala et al. 1988). Data in a study of the annual ecosystem assimilatory $\mathrm{CO}_{2}$ flux in a drained peat grassland by Jacobs et al. (2007) suggest a strong dependence on air humidity. On the other hand, the respiratory $\mathrm{CO}_{2}$ flux in this ecosystem appears to depend on temperature and metabolically active biomass (Veenendaal et al. 2007). This study seeks to establish the annual net $\mathrm{CO}_{2}$ flux in a drained peat grassland by re-evaluating previously instantaneous $\mathrm{CO}_{2}$ flux measurements (Chapters 3 and 4, and to some extent Chapter 5) and clustering the assimilatory and respiratory $\mathrm{CO}_{2}$ flux components to monthly values. The drained peat grassland's annual net $\mathrm{CO}_{2}$ exchange is calculated. Inter-annual differences between the annual net $\mathrm{CO}_{2}$ fluxes are analysed by considering the monthly assimilatory and respiratory $\mathrm{CO}_{2}$ fluxes and their dependencies on monthly irradiance, temperature and air humidity.

\subsection{MATERIALS AND METHODS}

\subsubsection{Micrometeorological $\mathrm{CO}_{2}$ flux measurements}

This analysis covers two grassland sites in the Netherlands. The primary site is a drained grazed peat grassland ecosystem near Cabauw ( $\left.51^{\circ} 58^{\prime} \mathrm{N}, 4^{\circ} 54^{\prime} \mathrm{E}\right)$. The aerodynamic gradient $\mathrm{CO}_{2}$ flux measurements done from March 1993 to February 1995 (Chapter 3) are grouped into two years: (1) from March 1993 to February 1994 (referred to as 1993) and (2) from March 1994 to February 1995 (referred to as 1994). Incident wind angles $195-250^{\circ}$ correspond to an unobstructed flux footprint or fetch of grassland of approximately $2 \mathrm{~km}$, whereas the remaining wind angles included orchards and minor roads. The secondary site is located near Zegveld (52。 $7^{\prime} \mathrm{N}, 4^{\circ} 50^{\prime} \mathrm{E}$ ), $15 \mathrm{~km}$ north of primary site Cabauw. Eddy covariance $\mathrm{CO}_{2}$ flux measurements were made in a grazed peat grassland ecosystem from April to October 1994 (Chapter 5). Incident wind angles 7-74 ${ }^{\circ}$ and $187-272^{\circ}$ corresponded to a high groundwater table of $30 \mathrm{~cm}$ below ground level, whereas incident wind angles $75-186^{\circ}$ and $273-334^{\circ}$ corresponded to a low groundwater 
table of $60 \mathrm{~cm}$ below ground level. The latter drainage level paralleled the conditions at site Cabauw. All $\mathrm{CO}_{2}$ flux measurements (as averaged over 30 minute time intervals) were re-evaluated in this study to calculate the monthly and annual $\mathrm{CO}_{2}$ fluxes and their dependencies on environmental factors.

The ecosystem annual net $\mathrm{CO}_{2}$ flux can be calculated by adding the measured $\mathrm{CO}_{2}$ fluxes, although this cannot explain inter-annual variations. By separating the net flux into its constituent respiratory and assimilatory $\mathrm{CO}_{2}$ fluxes it is possible to identify causes for inter-annual variations in the net flux and arrive at more generic assertions about its course. An established methodology to characterise the respiratory $\mathrm{CO}_{2}$ flux is to define the relationship between temperature and the night-time $\mathrm{CO}_{2}$ flux (which is assumed to exclude the assimilatory component) and extrapolate its validity to the day-time period (e.g. Baldocchi 2003, Gilmanov et al. 2007). This important assumption remains subject of further investigation and improvement (e.g. Reichstein et al. 2005). Subtraction of the calculated respiratory $\mathrm{CO}_{2}$ flux from the measured net $\mathrm{CO}_{2}$ flux yields the gross assimilatory $\mathrm{CO}_{2}$ flux.

\subsection{2. $\mathrm{CO}_{2}$ flux components}

The peat grassland ecosystem's respiratory $\mathrm{CO}_{2}$ flux is a composite flux and consists of (1) microbial respiration in the drained organic soil, (2) microbial respiration in the soil organic matter, (3) maintenance respiration of the vegetation, (4) growth respiration of the vegetation and (5) respiratory activity of the cattle. These respiratory flux components are not necessarily evenly distributed in time.

The measured night-time $\mathrm{CO}_{2}$ flux - in absence of irradiance and therefore assimilatory activity - is assumed to represent the system's respiratory $\mathrm{CO}_{2}$ flux (Ruimy et al. 1995) and its dependence on air temperature is used to calculate the respiratory $\mathrm{CO}_{2}$ flux throughout the day. Various $Q_{10}$ type of relationships between temperature and respiratory $\mathrm{CO}_{2}$ flux have been proposed (Kruse et al. 2011). However, the characterisation of a progressively stronger response as temperature increases is not undisputed. Robson et al. (1988) suggested that dark respiration in grass may be partly suppressed under illumination. Whereas previous studies (Chapters 3 and 5; Jacobs et al. 2007) applied the relationship established by Lloyd and Taylor (1994) to characterise the response of the respiratory $\mathrm{CO}_{2}$ flux to temperature, a linear relationship between air temperature and night-time $\mathrm{CO}_{2}$ flux is used in this study to calculate the respiratory $\mathrm{CO}_{2}$ flux throughout the night-time and day-time periods.

The assimilatory $\mathrm{CO}_{2}$ flux equates the gross $\mathrm{CO}_{2}$ assimilation of the vegetation and is calculated as the difference between the measured (net) $\mathrm{CO}_{2}$ flux and the calculated respiratory $\mathrm{CO}_{2}$ flux. 


\subsubsection{Meteorological measurements}

Assimilatory and respiratory $\mathrm{CO}_{2}$ fluxes are related to shortwave irradiance, air temperature and aerial vapour pressure deficit. The measurement set-ups at both sites were slightly different as were the heights at which the various measurements were done. Shortwave irradiance $\left(R_{\mathrm{s}}\right)$ was measured at $0.6 \mathrm{~m}$ height at site Cabauw and at $1.5 \mathrm{~m}$ height at site Zegveld. Air temperature $(T)$ was measured at $0.6 \mathrm{~m}$ and $2.5 \mathrm{~m}$ height, respectively. Aerial vapour pressure deficit $(D)$ was calculated from air temperature $\left(T_{\mathrm{a}}\right)$ and specific air humidity $(q)$ at $0.6 \mathrm{~m}$ height at site Cabauw and $4 \mathrm{~m}$ height at site Zegveld. $D$ is the difference between saturation vapour pressure $(e)$ and actual vapour pressure $(e)$ and follows from the (dimensionless) mixing ratio $w$ (Monteith \& Unsworth 1990):

$w=q /(1-q)$

where $q$ is the specific air humidity $\left(\mathrm{kg} \mathrm{kg}^{-1}\right)$. The actual vapour pressure is calculated:

$e=w \times R_{\mathrm{v}} \times p /\left(R_{\mathrm{d}}+w \times R_{\mathrm{v}}\right)$

where $e$ is the actual vapour pressure $(\mathrm{Pa}), w$ the mixing ratio $\left(\mathrm{kg} \mathrm{kg}^{-1}\right), p$ the air pressure (set at a constant $101.325 \mathrm{kPa}), R_{\mathrm{v}}$ the specific gas constant for water vapour $(461.5 \mathrm{~J}$ $\left.\mathrm{kg}^{-1} \mathrm{~K}^{-1}\right)$ and $R_{\mathrm{d}}$ the specific gas constant for dry air $\left(287.1 \mathrm{~J} \mathrm{~kg}^{-1} \mathrm{~K}^{-1}\right)$. The saturation vapour pressure follows from:

$e_{\mathrm{s}}=611 \times \exp \left(17.67 \times\left(T_{\mathrm{a}}-T_{0}\right) /\left(T_{\mathrm{a}}-29.65\right)\right)$

where $e_{\mathrm{s}}$ is the saturation vapour pressure $(\mathrm{Pa}), T_{\mathrm{a}}$ the air temperature $(\mathrm{K})$ and $T_{0}$ the reference temperature (273 K).
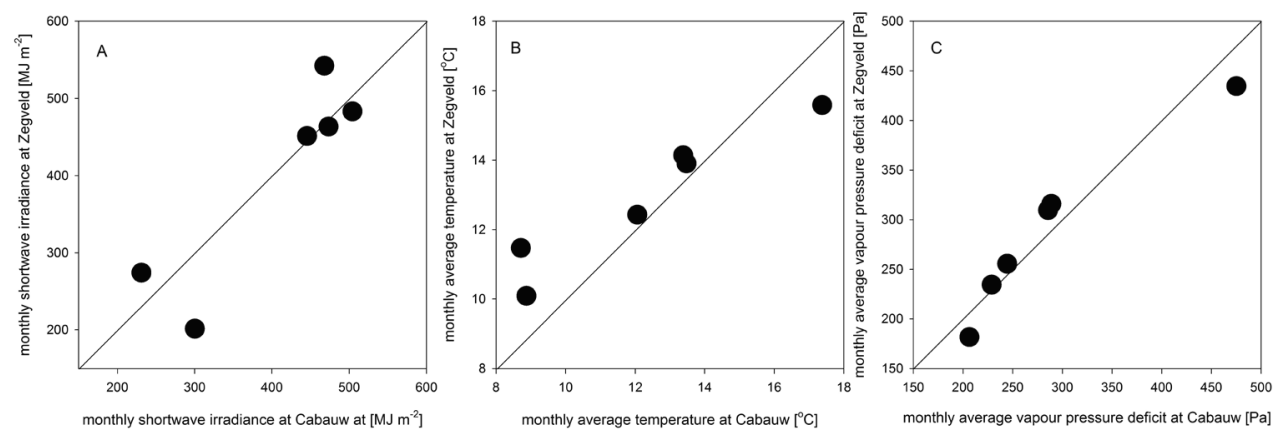

Figure 6.1. Comparison of the monthly shortwave irradiance, average air temperature and average vapour pressure deficit at all incident wind angles for sites Cabauw and Zegveld in April, May, June, August, September and October 1994. 
For a comparison of the measurements at sites Cabauw and Zegveld for the period of April to October 1994, the instantaneous measurements were averaged over 30 minute intervals and subsequently aggregated to monthly values by extrapolation. This aggregation for both sites is inevitably done on basis of values at different points in time and at different incident wind angles. As a consequence, the monthly values do not always compare well, which is demonstrated in Figure 6.1. Whereas in most months the aggregated meteorological parameters for Cabauw and Zegveld compare reasonably well, some months show appreciable differences. The differences in monthly vapour pressure deficit between both sites are smaller than for irradiance and temperature, indicating that air humidity is a more robust entity.

\subsubsection{Distribution and aggregation of measurements}

At Cabauw an unobstructed fetch of grassland of $2 \mathrm{~km}$ was attained at incident wind angles $195-250^{\circ}$, whereas measurements at the remainder of the wind angles were disturbed by a few roads, barns and occasional orchards. As a wind angle range of 195$250^{\circ}$ corresponds to weather conditions at maritime westerly to southwesterly winds, restriction of the measurements to this range introduces a weather bias. It precludes $\mathrm{CO}_{2}$ fluxes at the warmer and colder ends of the temperature spectrum and at generally drier conditions. Figure 6.2 plots the distribution of the air temperatures over the different wind angles for both years. It illustrates the exposure of the site to predominantly westerly and southwesterly winds, whereas most of the lowest and highest temperatures are clustered in a broad range of eastern winds. Figure 6.3 plots the distribution of the measured $\mathrm{CO}_{2}$ fluxes. It shows that fluxes with the highest assimilatory value occurred at southerly winds,
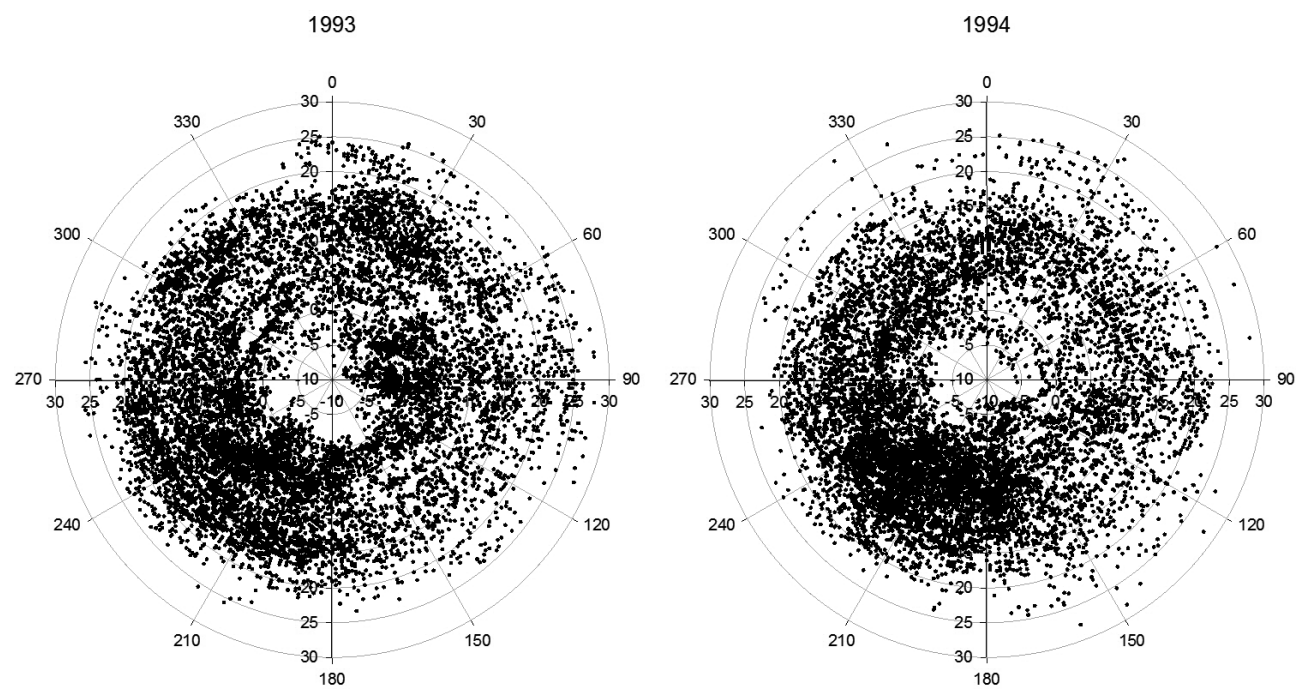

Figure 6.2. Angular distribution of measured air temperatures (minus 10 to $30^{\circ} \mathrm{C}$ ) at all incident wind angles $\left(1-360^{\circ}\right)$ at site Cabauw in 1993 and 1994. 

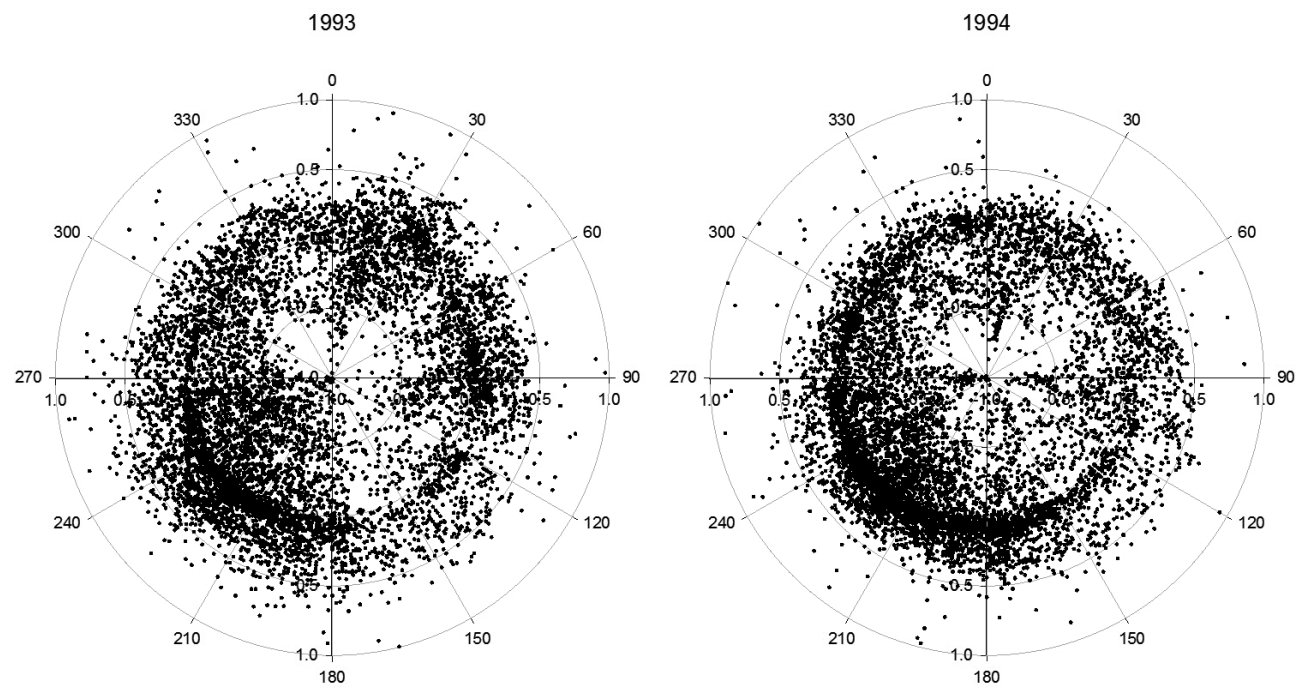

Figure 6.3. Angular distribution of measured $\mathrm{CO}_{2}$ fluxes (minus 1 to $1 \mathrm{mg} \mathrm{CO}_{2} \mathrm{~m}^{-2} \mathrm{~s}^{-1}$ ) at all incident wind angles $\left(1-360^{\circ}\right)$ at site Cabauw in 1993 and 1994.

which potentially causes the distribution to be skewed towards net assimilatory fluxes. The analysis of the monthly and annual $\mathrm{CO}_{2}$ fluxes at Cabauw compares the results for wind angle ranges $195-250^{\circ}$ (unobstructed fetch) and 1-360 (minor disturbances). Figure 6.4 shows the measurement time series stretching across two years.

Tables 6.1 and 6.2 list the aggregated monthly values of the $\mathrm{CO}_{2}$ flux components, shortwave irradiance, air temperature and vapour pressure deficit at both sites. Excluded from analysis are the aggregated values of the $\mathrm{CO}_{2}$ fluxes in September 1993 at incident wind angles $195-250^{\circ}$, which are considered evident outliers.

\subsubsection{External C sinks and sources}

In $\mathrm{C}$ balance calculations $\mathrm{C}$ harvested or removed as dairy produce is generally subtracted and the $\mathrm{C}$ supplied as manure is added. For intensively managed grassland ecosystems across Japan Hirata et al. (2013) concluded that mowed grasslands without application of manure were net $\mathrm{CO}_{2}$ sources and mowed grasslands with application of manure were net $\mathrm{CO}_{2}$ sinks, but the difference really was the manure from external sources. Although numerically correct, this approach forgoes the nature of $\mathrm{C}$ flows across system boundaries and the question of how system boundaries for the grassland's $\mathrm{C}$ balance are to be drawn. Harvested biomass remains relevant to a grassland's $\mathrm{C}$ balance, even beyond its immediate boundaries. To properly characterise the $\mathrm{C}$ balance, harvested biomass remains part of the grassland ecosystem, decomposing as senesced or grazed organic matter, if displaced in space and time. The removal of $\mathrm{C}$ from the system through harvesting or dairy produce could be seen as an underestimation of the respiratory $\mathrm{CO}_{2}$ flux (and 


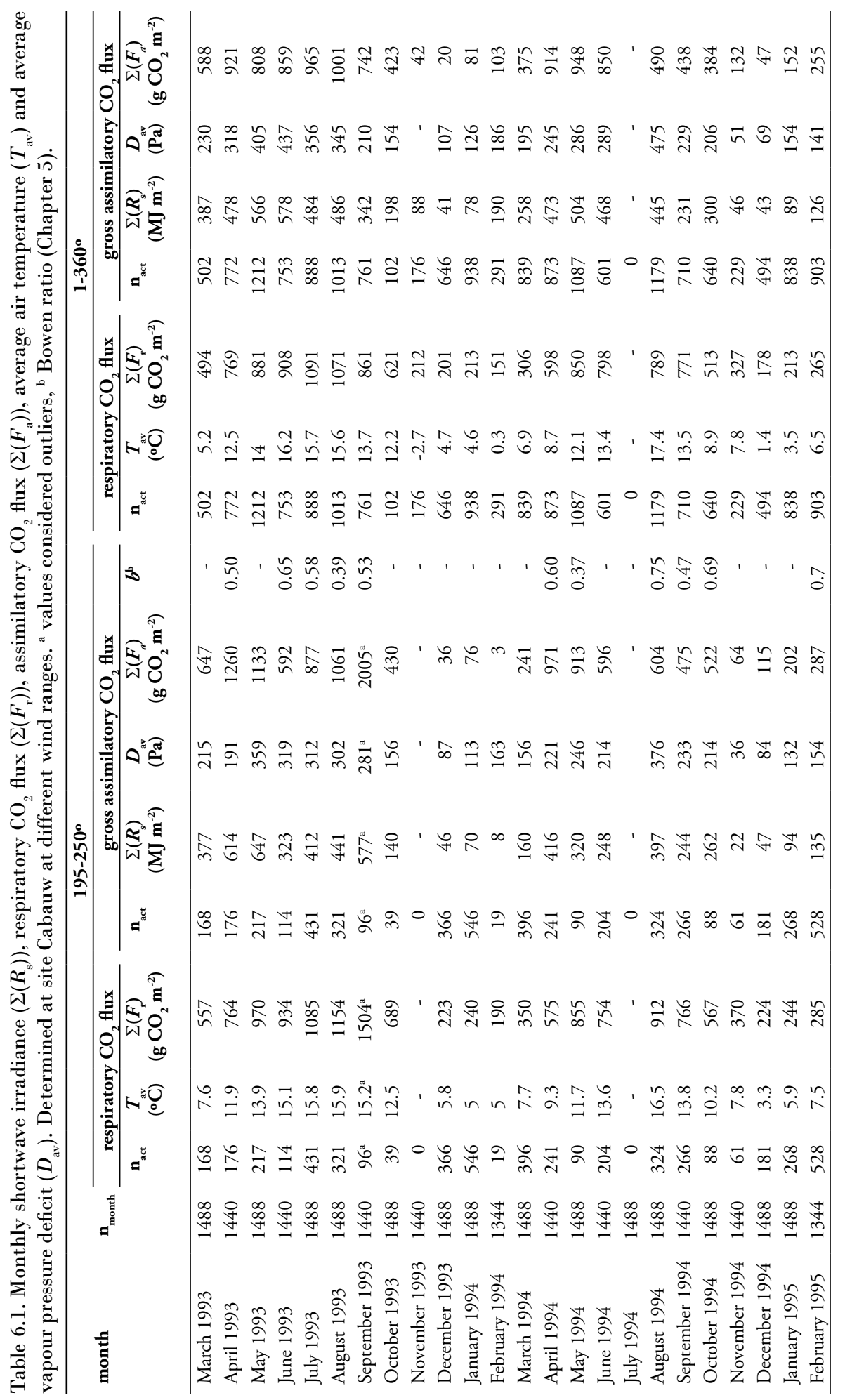




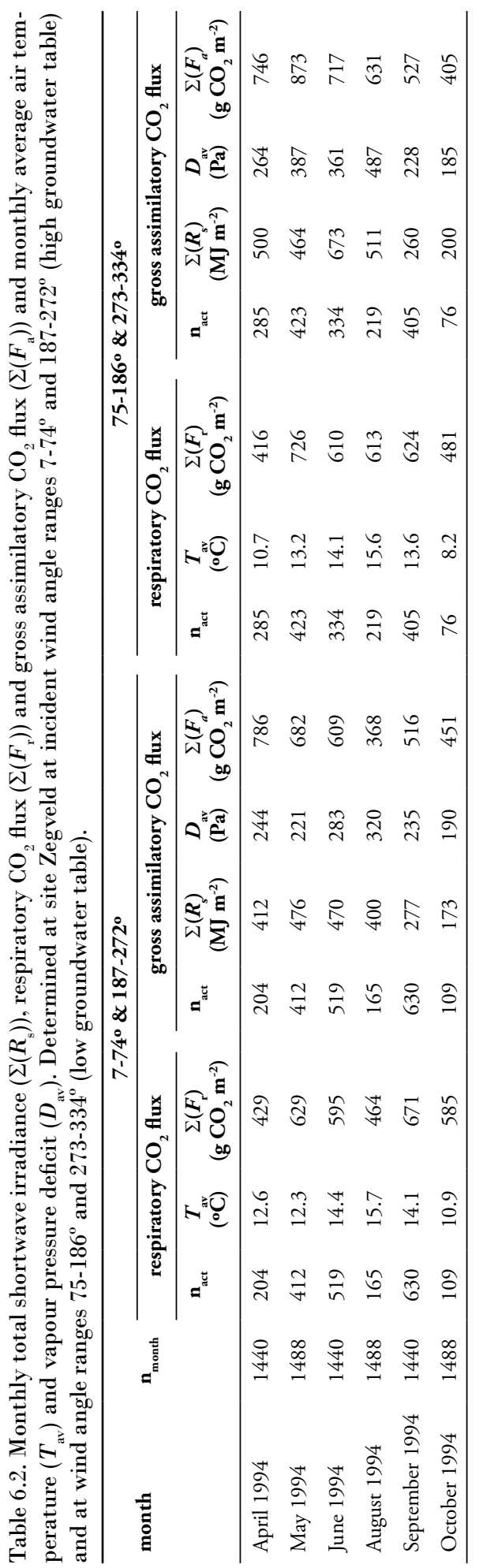



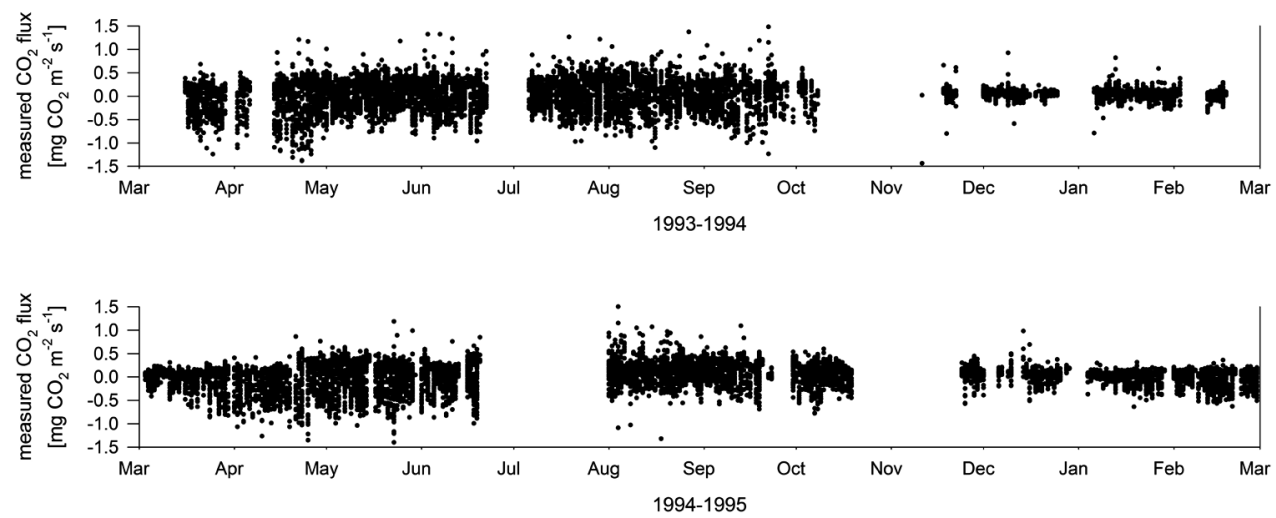

Figure 6.4. Temporal distribution of measured $\mathrm{CO}_{2}$ fluxes at site Cabauw in 1993 and 1994.

therefore overestimation of a net $\mathrm{CO}_{2}$ sequestration) as these $\mathrm{C}$ compounds are being degraded elsewhere. However, its extent depends on the degree of degradation as the organic matter removed is being decomposed neither instantly nor entirely, such as is the case for the conversion of harvested biomass to manure. In turn, supply of $\mathrm{C}$ to the system through manure from external sources results in an overestimation of the respiratory $\mathrm{CO}_{2}$ flux (and therefore underestimation of a net $\mathrm{CO}_{2}$ sequestration). However, this added respiratory activity is a continuation of the decomposition of biomass harvested elsewhere. This illustrates how grassland ecosystems are intertwined and their $\mathrm{C}$ balances can be indistinct. Moreover, the decomposition of the added manure takes place gradually in time. As a result, the consequences to the $\mathrm{C}$ balance of $\mathrm{C}$ harvested and $\mathrm{C}$ applied cannot be compared instantly, as the respective types of organic matter exist in different phases of decomposition.

The $\mathrm{C}$ flow comes full circle only if manure applied from external sources originates from the same amount of biomass as is the biomass harvested. It could be argued that, at least on average, most of these reciprocal C flows across grassland ecosystem boundaries even each other out. For a typical cattle density at site Cabauw, Langeveld et al. (1997) calculated a gross daily $\mathrm{C}$ uptake of $11.97 \mathrm{~kg} \mathrm{C} \mathrm{ha}^{-1} \mathrm{~d}^{-1}$. The cattle loses $\mathrm{C}$ through excretion as manure of $3 \mathrm{~kg} \mathrm{Cha}^{-1} \mathrm{~d}^{-1}$, dairy production of $1.48 \mathrm{~kg} \mathrm{C} \mathrm{ha}^{-1} \mathrm{~d}^{-1}$ and a respiratory activity of 7.49 $\mathrm{kg} \mathrm{C} \mathrm{ha-1} \mathrm{d}^{-1}$. Gross $\mathrm{C}$ uptake and the excretion through manure and respiratory activity are captured in the measured $\mathrm{CO}_{2}$ fluxes. Barns housing the cattle during the nighttime period were within the entire wind angle range measurements, which means that most of the cattle's night-time respiratory activity is included in the flux measurements. Dairy production escapes measurement entirely and its $\mathrm{C}$ can be added to the calculated respiratory $\mathrm{CO}_{2}$ flux (or subtracted from the measured net $\mathrm{CO}_{2}$ flux) at approximately $200 \mathrm{~g} \mathrm{CO}_{2} \mathrm{~m}^{-2} \mathrm{y}^{-1}\left(-1.48 \mathrm{~kg} \mathrm{Cha}^{-1} \mathrm{~d}^{-1}\right)$, whereas it does not affect the calculated gross assimilatory $\mathrm{CO}_{2}$ flux. 


\subsection{RESULTS}

\subsubsection{Assimilatory $\mathrm{CO}_{2}$ exchange}

\subsubsection{Monthly assimilatory $\mathrm{CO}_{2}$ flux and its processes}

$\mathrm{CO}_{2}$ assimilation and dry matter accumulation depend on absorbed radiation at multiple levels of aggregation (Goudriaan 1997, Harley et al. 1985, Lawlor 1987). Figure 6.5 shows the response of the grassland ecosystem's monthly gross assimilatory $\mathrm{CO}_{2}$ flux $\left(F_{\mathrm{a}}\right)$ to the monthly shortwave irradiance $(R)$ - the incident radiation use efficiency - at site Cabauw for both incident wind angle ranges. It illustrates how the $360^{\circ}$ wind angle range and its weather conditions produced a broad response of $F_{\mathrm{a}}$ to $R_{\mathrm{s}}$. The response at wind directions $195-250^{\circ}$ was more distinct and constituted the $360^{\circ}$ response range's upper limit. This implies that the weather conditions at the maritime westerly to southwesterly winds were most conducive to assimilatory activity. An $F_{\mathrm{a}}$ value of $1300 \mathrm{~g} \mathrm{CO}_{2} \mathrm{~m}^{-2}$ was attained at an $R_{\mathrm{s}}$ level of $600 \mathrm{MJ} \mathrm{m}^{-2}$.

Low temperatures are known to limit plant assimilatory activity (Wilson \& Cooper 1969, Woledge \& Dennis 1982, Woledge \& Parsons 1986). However, an effect of suboptimal temperature can also be observed at ecosystem level. Figure 6.6 distinguishes between the responses of the gross assimilatory $\mathrm{CO}_{2}$ flux $\left(F_{\mathrm{a}}\right)$ to shortwave irradiance $\left(R_{\mathrm{s}}\right)$ at monthly average air temperatures $\left(T_{\mathrm{a}}\right)$ below and above $10^{\circ} \mathrm{C}$. In the periphery of the growing

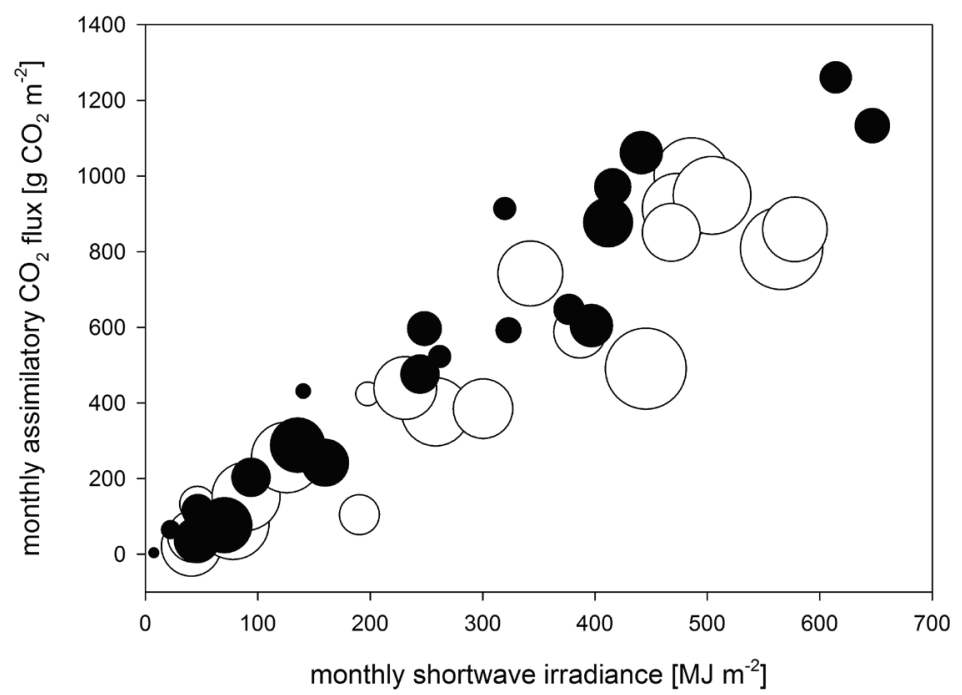

Figure 6.5. Response of monthly gross assimilatory $\mathrm{CO}_{2}$ flux to monthly shortwave irradiance at incident wind angle ranges $1-360^{\circ}$ (open symbols) and $195-250^{\circ}$ (closed symbols) at site Cabauw during 1993 and 1994. The radius of the symbols is proportional to the actual number of flux measurements in the particular month. 


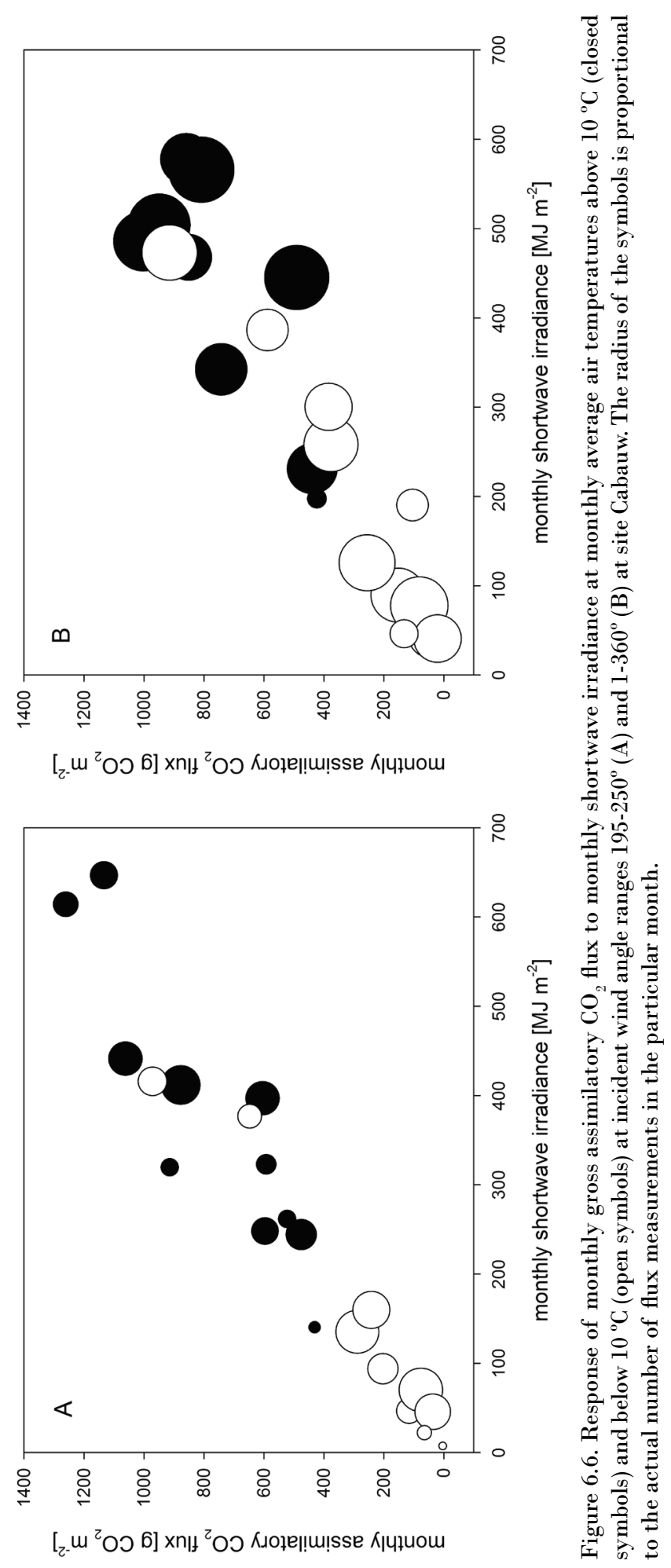




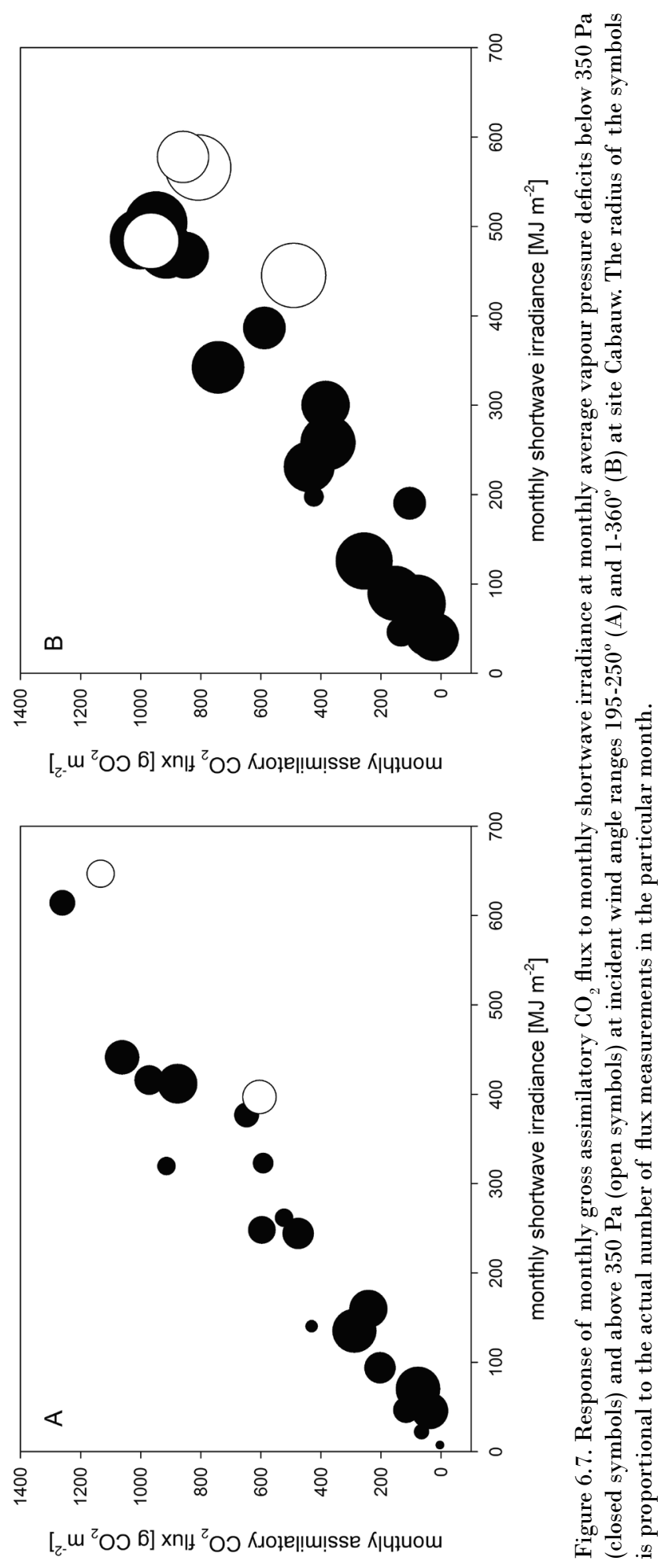


season low $R_{\mathrm{s}}$ levels of up to $150 \mathrm{MJ} \mathrm{m}^{-2}$ concurred with $T_{\mathrm{a}}$ below $10^{\circ} \mathrm{C}$. However, also at levels of $R_{\mathrm{s}}$ exceeding $150 \mathrm{MJ} \mathrm{m}^{-2}$ the response of $F_{\mathrm{a}}$ appeared to be limited by low temperature during several months. This was particularly evident at all incident wind angles because of a wider range of temperatures. It shows how $F_{a}$ repeatedly fell below its maximum response to $R_{\mathrm{s}}$ at $T_{\mathrm{a}}$ below $10^{\circ} \mathrm{C}$. The high radiation use efficiency observed at an $R_{\mathrm{s}}$ value of $415 \mathrm{MJ} \mathrm{m}^{-2}$ was associated with a $T_{\mathrm{a}}$ of $9.3^{\circ} \mathrm{C}$, which was on the 10 ${ }^{\circ} \mathrm{C}$ threshold.

Whereas low air temperature limits assimilatory activity, high aerial vapour pressure deficit at the other end of the temperature spectrum may also limit assimilatory activity (Woledge et al. 1989). High aerial vapour pressure deficits (either through a direct effect on stomatal behaviour or as a measure for low soil moisture) can lead to lower stomatal conductance, reducing both transpiration and $\mathrm{CO}_{2}$ assimilation. Figure 6.7 shows that limiting vapour pressure deficits can also be observed at ecosystem level. It shows the responses of the monthly assimilatory $\mathrm{CO}_{2}$ flux $\left(F_{\mathrm{a}}\right)$ to monthly irradiance $(R)$ at site Cabauw, while distinguishing between monthly average aerial vapour pressure deficits $(D)$ below and above $350 \mathrm{~Pa}$. In both wind angle ranges levels of $D$ exceeding $350 \mathrm{~Pa}$ coincided with a reduced response of $F_{\mathrm{a}}$ to $R_{\mathrm{s}}$. A high radiation use efficiency at an $R_{\mathrm{s}}$ value of $485 \mathrm{MJ} \mathrm{m}^{-2}$ concurred with a $D$ value of $356 \mathrm{~Pa}$, which was on the $350 \mathrm{~Pa}$ threshold. The effect of vapour pressure deficit on the assimilatory $\mathrm{CO}_{2}$ flux is illustrated in more detail in figure 6.8. $F_{\text {a }}$ increased with $D$ up to a threshold value of approximately 300 $\mathrm{Pa}$, which reflects the effect of irradiance. Beyond levels of $D$ of approximately $350 \mathrm{~Pa}$ the negative effect of $D$ on $F_{\text {a }}$ predominated. The effect of $D$ was less evident in the 195$250^{\circ}$ wind angle range, as $D$ values higher than 350 Pa were less frequent at westerly to southwesterly winds. It could be argued that the negative effect of vapour pressure deficit on the assimilatory $\mathrm{CO}_{2}$ flux was in fact an effect of temperature, but high temperatures as such were less able to discriminate between maximum and limited assimilatory $\mathrm{CO}_{2}$ fluxes (not shown). Moreover, table 6.1 demonstrates a clear correlation between the monthly average vapour pressure deficit and the monthly Bowen ratio (as determined in Chapter 4). It shows that for the period May to September with increasing levels of $D$ the dissipation of incident net energy shifted from the latent heat flux to the sensible heat flux, which signifies progressively impaired levels of surface conductance.

The radiation use efficiencies in figure 6.5 were $1.98 \mathrm{~g} \mathrm{CO}_{2} \mathrm{MJ}^{-1}$ for wind angles $195-250^{\circ}$ $\left(r^{2}=0.92, n=20\right)$ and $1.78 \mathrm{~g} \mathrm{CO}_{2} \mathrm{MJ}^{-1}$ for the entire wind angle range $\left(r^{2}=0.88, n=\right.$ 22). Figure 6.9 integrates the limiting effects of both low temperature and high vapour pressure deficit. It distinguishes between the responses of $F_{\mathrm{a}}$ to $R_{\mathrm{s}}$ at (1) monthly average temperatures $<10^{\circ} \mathrm{C}$ and monthly irradiances $>150 \mathrm{MJ} \mathrm{m}^{-2}$, (2) monthly average vapour pressure deficits $>350 \mathrm{~Pa}$ and (3) the remaining (non-limiting) conditions. It demonstrates that in both wind angle ranges the lower radiation use efficiencies could be 


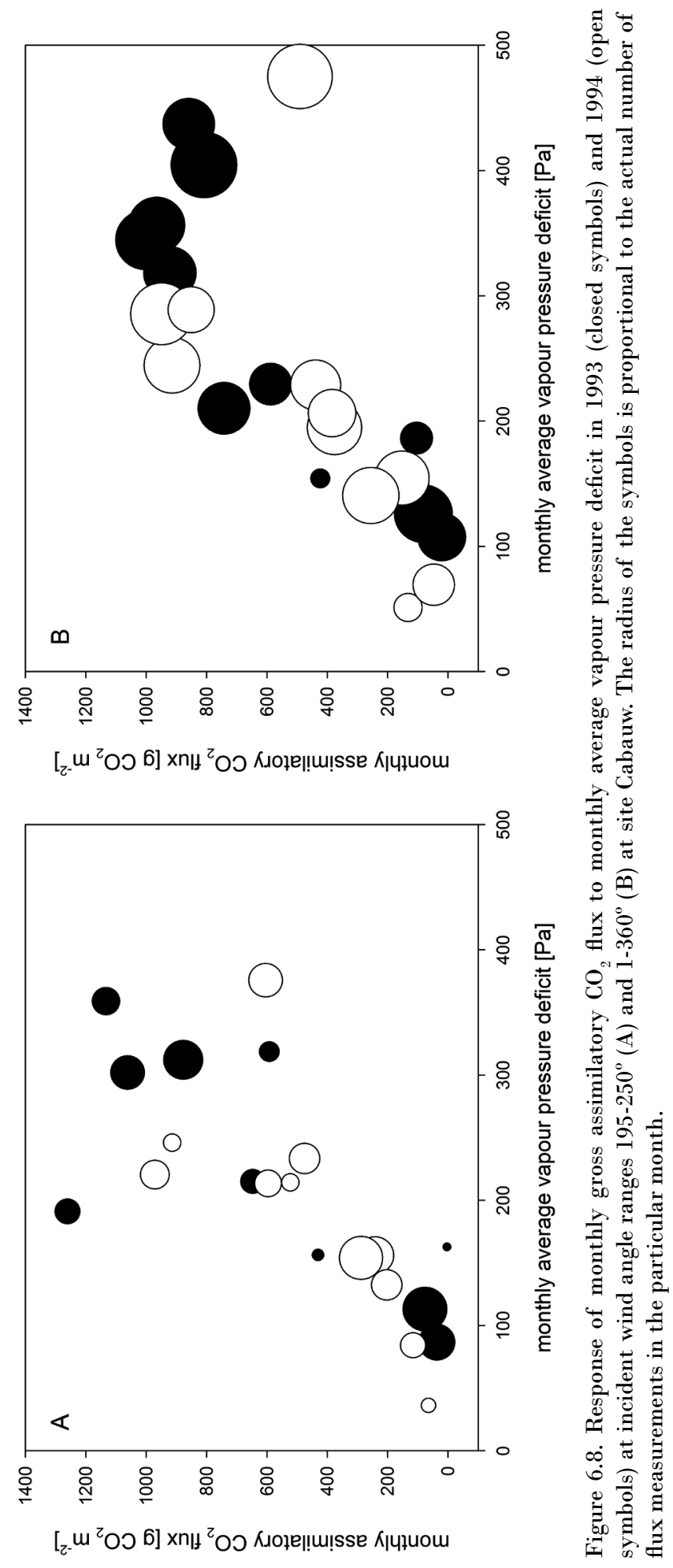




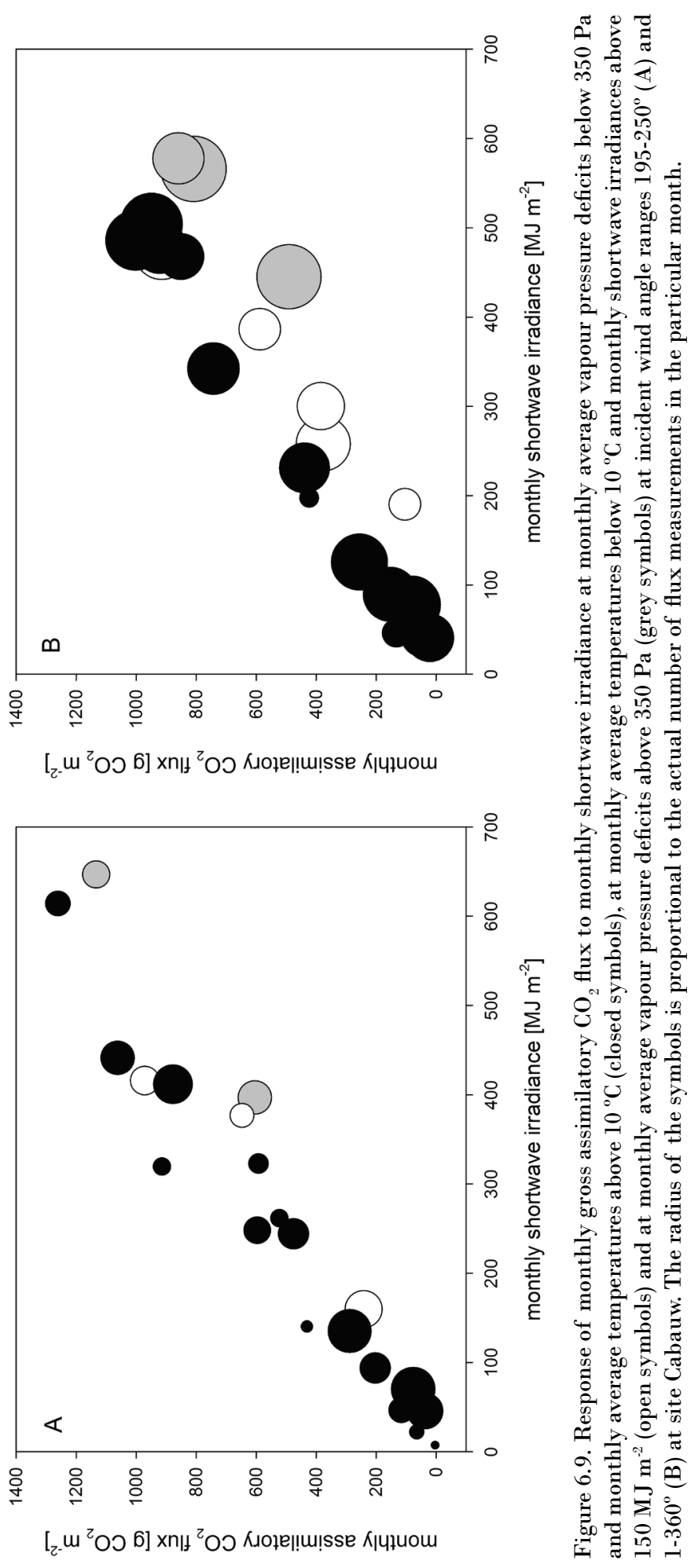



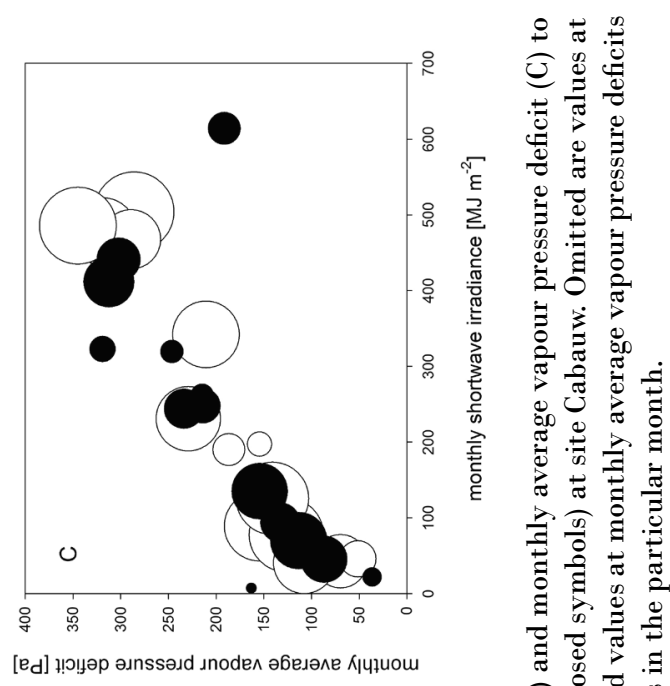

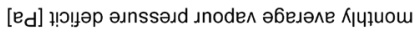

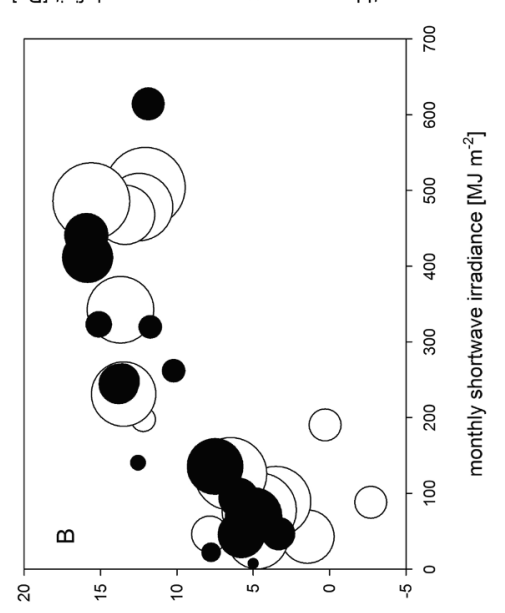

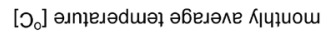

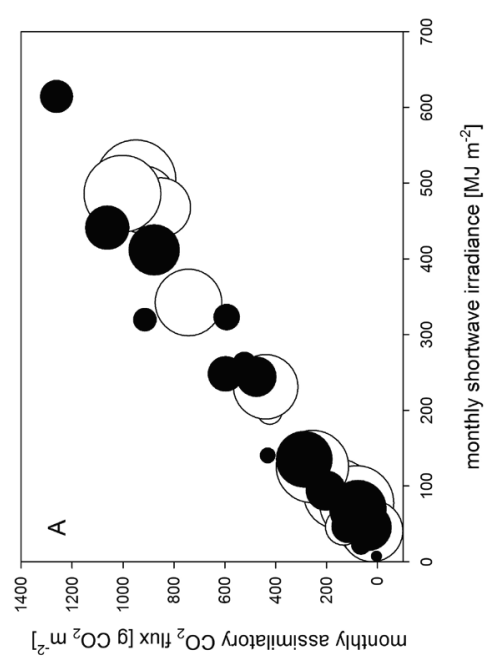
กิ : ㄴํㄱ 낭ㄹำ 공 ๘

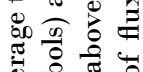
एै क ह है

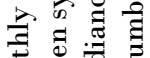
हैं $\because: 0$ दे

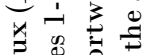

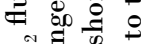
ᄋำ 원 형 䒕苛苛 局看娄 का a $\overrightarrow{0} 0 \frac{\pi}{0}$ 量 웡 의

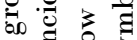
공 吾要曹 ఏ छ ช 䜦 过 के

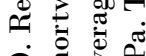
$\dot{0} \frac{1}{n}$
0
0
0

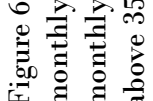


explained by low temperature and high vapour pressure deficit. This results in a baseline radiation use efficiency under conditions most conducive to assimilatory activity. The radiation use efficiencies at both wind angle ranges thus converge, which is illustrated in figure $6.10 \mathrm{~A}$ where $F_{\text {a }}$ values at low temperature and high vapour pressure deficit were omitted. The baseline radiation use efficiencies amounted to $2.19 \mathrm{~g} \mathrm{CO}_{2} \mathrm{MJ}^{-1}$ for wind angles $195-250^{\circ}\left(r^{2}=0.95, n=15\right)$ and $2.03 \mathrm{~g} \mathrm{CO}_{2} \mathrm{MJ}^{-1}$ for the entire wind angle range $\left(r^{2}=0.98, n=13\right)$. The remaining difference was caused by a slightly lower radiation use efficiency at high irradiance in the $360^{\circ}$ wind angle range. The concurrent courses of average temperature and vapour pressure deficit in figures $6.10 \mathrm{~B}$ and $6.10 \mathrm{C}$ indicate that this slightly lower radiation use efficiency could be related to relatively low temperatures of approximately $13{ }^{\circ} \mathrm{C}$ as opposed to $15^{\circ} \mathrm{C}$ in the $195-250^{\circ}$ range. It could thus be concluded that not only monthly average temperatures below $10^{\circ} \mathrm{C}$ had a limiting effect on the monthly assimilatory $\mathrm{CO}_{2}$ flux, but that a moderately limiting effect persisted at higher irradiance and higher temperature. After omitting these particular $F_{\mathrm{a}}$ values, the radiation use efficiency at the entire wind angle range increased to $2.22 \mathrm{~g} \mathrm{CO}_{2} \mathrm{MJ}^{-1}\left(r^{2}\right.$ $=0.98, n=10)$. The baseline incident radiation use efficiencies for the gross assimilatory $\mathrm{CO}_{2}$ flux thus converged to 2.19-2.22 $\mathrm{g} \mathrm{CO}_{2} \mathrm{MJ}^{-1}$. The response of the gross assimilatory $\mathrm{CO}_{2}$ flux to irradiance appears to be linear to an extent that it justifies extrapolation.

Figure 6.11 shows the incident radiation use efficiencies at site Zegveld in combination with a theoretical baseline incident radiation use efficiency of $2.20 \mathrm{~g} \mathrm{CO}_{2} \mathrm{MJ}^{-1}$. Despite the limited number of observations, it demonstrates that an average aerial vapour pressure deficit $(D)$ higher than $300 \mathrm{~Pa}$ reduced the response of the assimilatory $\mathrm{CO}_{2}$ flux $(F)$ to irradiance. At levels of $D$ exceeding $300 \mathrm{~Pa}$ the incident radiation use efficiency was well below the baseline value of $2.20 \mathrm{~g} \mathrm{CO}_{2} \mathrm{MJ}^{-1}$. Several radiation use efficiencies at $250 \mathrm{~Pa}$ also fell below this baseline value, which for site Zegveld suggests either a higher sensitivity to aerial vapour pressure deficit or a lower baseline incident radiation efficiency.

\subsubsection{Annual assimilatory $\mathrm{CO}_{2}$ flux}

Annual $\mathrm{CO}_{2}$ exchange is the sum of the fluxes at all wind directions. Monthly gross assimilatory $\mathrm{CO}_{2}$ fluxes add up to $6553 \mathrm{~g} \mathrm{CO}_{2} \mathrm{~m}^{-2}$ at an incident shortwave irradiance of $3916 \mathrm{MJ} \mathrm{m}^{-2}$ in 1993 (12 months) and $4985 \mathrm{~g} \mathrm{CO}_{2} \mathrm{~m}^{-2}$ at $2983 \mathrm{MJ} \mathrm{m}^{-2}$ in 1994 (11 months). At a dry matter C content of $45 \%$ (Goudriaan \& Van Laar 1994) this corresponds to an annual gross dry matter production of $39715 \mathrm{~kg} \mathrm{dm} \mathrm{ha}^{-1}$ (12 months) and $30212 \mathrm{~kg} \mathrm{dm} \mathrm{ha}^{-1}$ (11 months), respectively. This translates into an annual radiation use efficiency of $1.67 \mathrm{~g} \mathrm{CO}_{2} \mathrm{MJ}^{-1}$ for both years, which is well below a potential value of $2.20 \mathrm{~g} \mathrm{CO}_{2} \mathrm{MJ}^{-1}$ and shows that at least throughout part of the year primary productivity was limited by temperature or air humidity. 


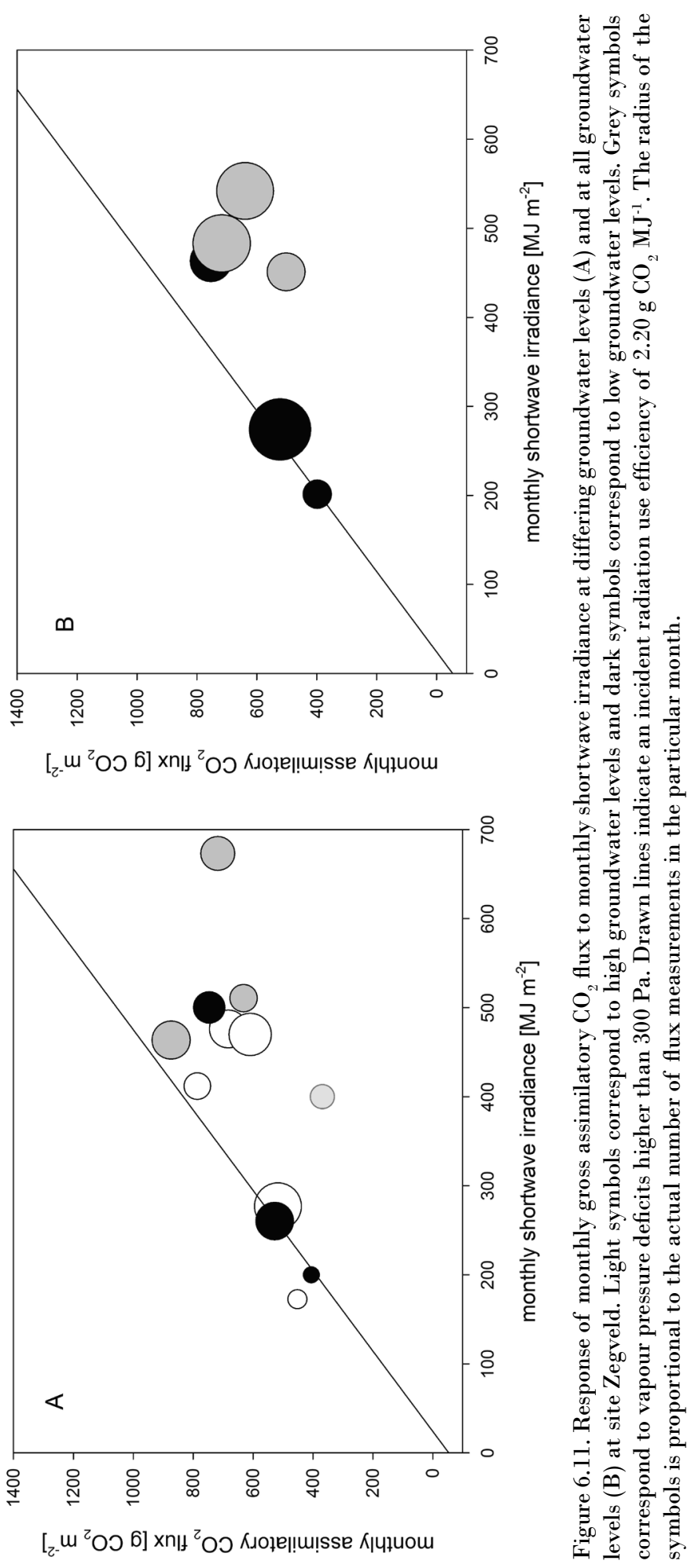




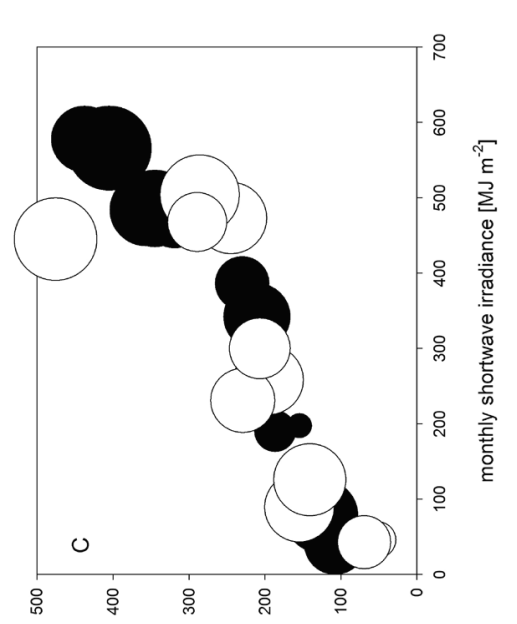

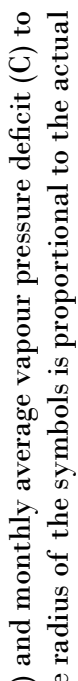

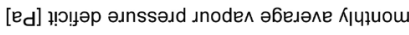

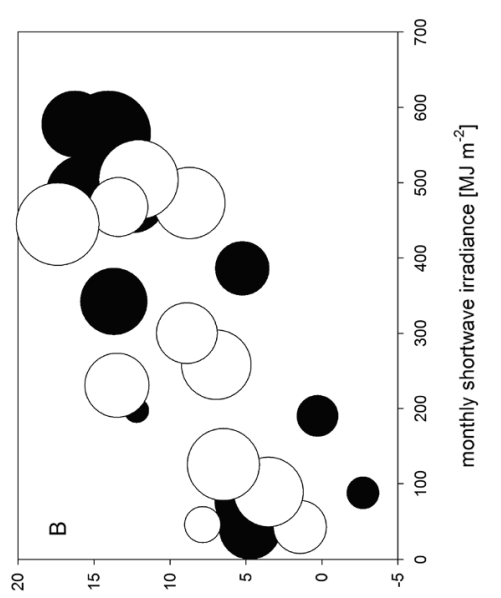

(ิ)

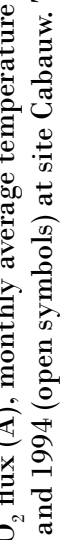

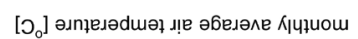

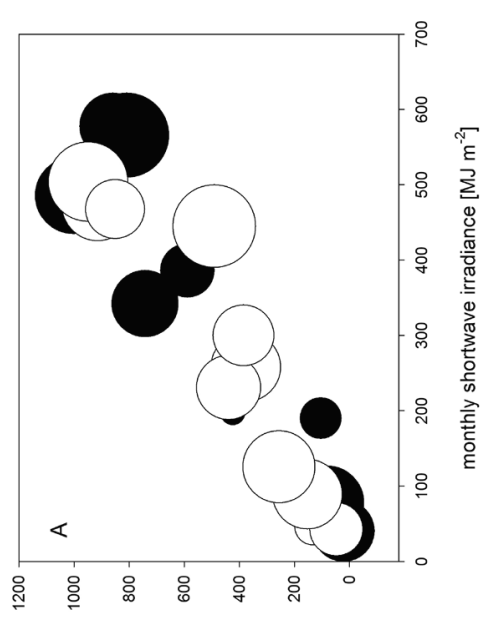

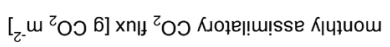




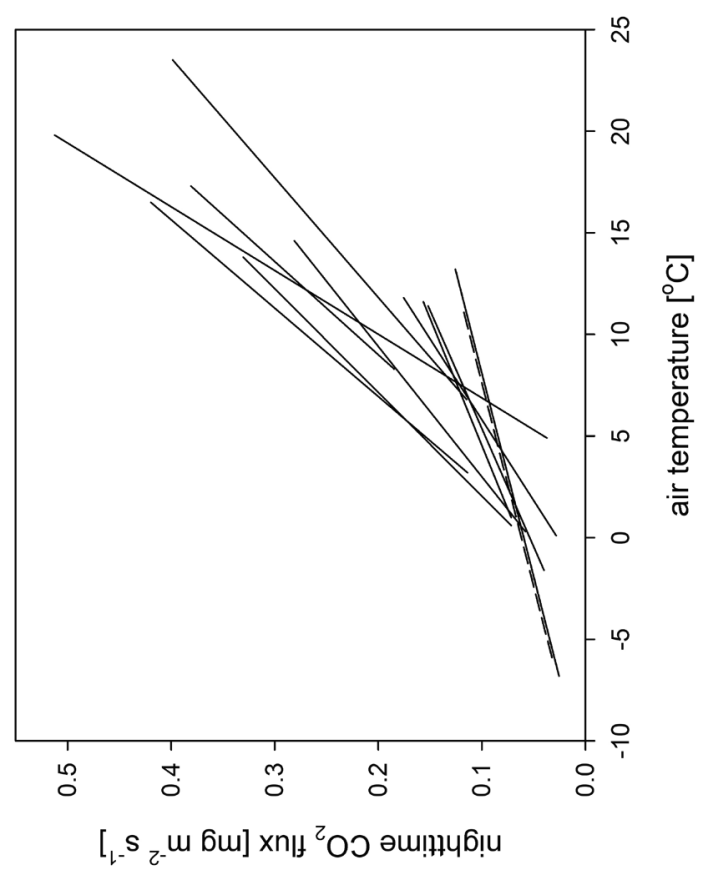

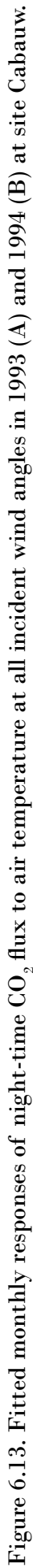


Figure 6.12 compares the annual responses of the assimilatory $\mathrm{CO}_{2}$ flux to irradiance in more detail and shows that both years include months with a limited response particularly at higher irradiance. It shows that annual radiation use efficiencies below their potential value were primarily caused by high aerial vapour pressure deficit ( $>400 \mathrm{~Pa}$ ) in May and June 1993 and in August 1994. Low air temperature $\left(-5^{\circ} \mathrm{C}\right)$ at intermediate levels of irradiance had a limiting effect in March 1993.

\subsubsection{Respiratory $\mathrm{CO}_{2}$ exchange}

\subsubsection{Monthly respiratory $\mathrm{CO}_{2}$ flux and its processes}

Table 6.3 and figure 6.13 show the fitted monthly linear responses of the measured nighttime $\mathrm{CO}_{2}$ flux $\left(F_{\mathrm{n}}\right)$ to air temperature $\left(T_{\mathrm{a}}\right)$ at the entire wind angle range at site Cabauw, which constitute the basis for the calculated respiratory $\mathrm{CO}_{2}$ flux $\left(F_{\mathrm{r}}\right.$ ). It shows that $F_{\mathrm{n}}$ increased with $T_{\mathrm{a}}$ consistently, but also that the rate of increase increased at progressively higher levels of $T_{\mathrm{a}}^{\mathrm{a}}$. Both composite response curves exhibit clear $Q_{10}$ type characteristics. The fitted $Q_{10}$ values amount to 2.1 for $1993\left(r^{2}=0.82\right)$ and 2.3 for $1994\left(r^{2}=0.80\right)$, and 2.2 for both years combined $\left(r^{2}=0.80\right)$.

Figure 6.14 shows the response of the grassland ecosystem's monthly respiratory $\mathrm{CO}_{2}$ flux $\left(F_{\mathrm{r}}\right)$ to the monthly average temperature $\left(T_{\mathrm{a}}\right)$ at site Cabauw at both incident wind angle ranges. $F_{\mathrm{r}}$ was constant at approximately $200 \mathrm{~g} \mathrm{CO}_{2} \mathrm{~m}^{-2}$ up to $T_{\mathrm{a}}$ values of $5^{\circ} \mathrm{C} . F_{\mathrm{r}}$ increased linearly with temperature once exceeding $5^{\circ} \mathrm{C}$. The response was more distinct

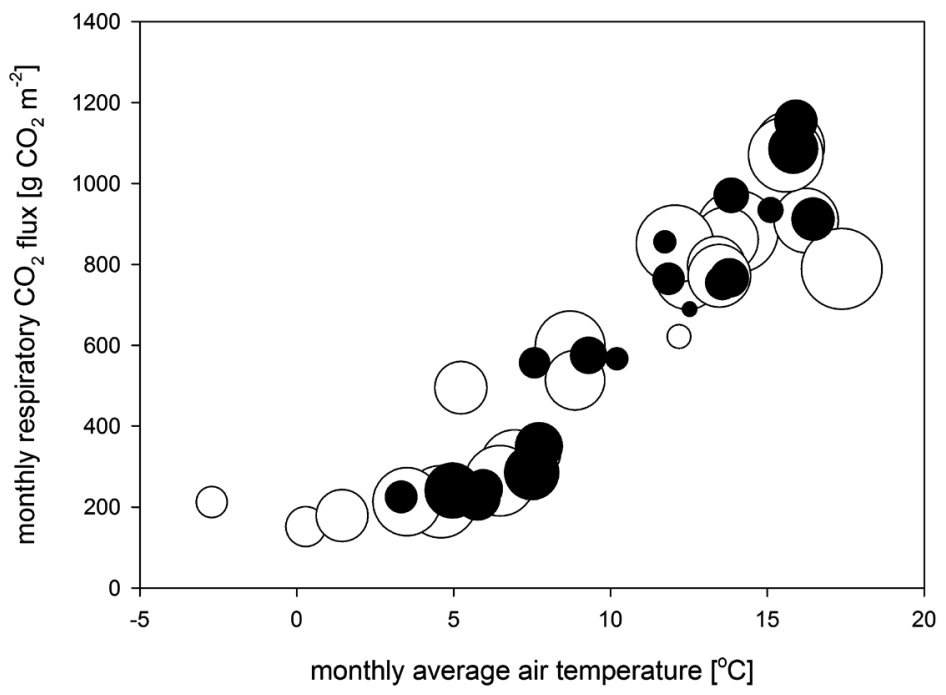

Figure 6.14. Response of monthly respiratory $\mathrm{CO}_{2}$ flux to monthly average air temperature at incident wind angle ranges $1-360^{\circ}$ (open symbols) and 195-250 (closed symbols) at site Cabauw. The radius of the symbols is proportional to the actual number of flux measurements in the particular month 
Table 6.3. Fitted monthly linear responses of the night-time net $\mathrm{CO}_{2}$ flux $\left(F_{n}\right)$ to air temperature $\left(T_{\mathrm{a}}\right)$ at incident wind angles $195-250^{\circ}$ and $1-360^{\circ}$.

\begin{tabular}{|c|c|c|c|c|c|c|c|c|}
\hline \multirow[t]{2}{*}{ month } & \multicolumn{4}{|c|}{ wind angles $195-250^{\circ}$} & \multicolumn{4}{|c|}{ wind angles $1-360^{\circ}$} \\
\hline & $n$ & $\begin{array}{c}y_{0} \\
\left(\mathrm{mg} \mathrm{m}^{-2} \mathrm{~s}^{-1}\right)\end{array}$ & $\begin{array}{c}a \\
\left(\mathrm{mg} \mathrm{m}^{-2} \mathrm{~s}^{-1} o^{\circ} \mathrm{C}^{-1}\right)\end{array}$ & $r^{2}$ & $n$ & $\begin{array}{c}y_{0} \\
\left(\mathrm{mg} \mathrm{m}^{-2} \mathrm{~s}^{-1}\right)\end{array}$ & $\begin{array}{c}a \\
\left(\mathrm{mg} \mathrm{m}^{-2} \mathrm{~s}^{-1} \circ \mathrm{o}^{-1}\right)\end{array}$ & $r^{2}$ \\
\hline March 1993 & 82 & 0.1608 & 0.0062 & 0.04 & 260 & 0.1375 & 0.0090 & 0,14 \\
\hline April 1993 & 65 & 0.1217 & 0.0146 & 0.22 & 315 & 0.2084 & 0.0071 & 0.07 \\
\hline May 1993 & 57 & 0.0145 & 0.0251 & 0.26 & 418 & 0.1308 & 0.0141 & 0.20 \\
\hline June 1993 & 46 & 0.2923 & 0.0045 & 0.00 & 219 & 0.0986 & 0.0155 & 0.10 \\
\hline July 1993 & 152 & -0.0396 & 0.0281 & 0.30 & 284 & -0.0545 & 0.0294 & 0.24 \\
\hline August 1993 & 122 & 0.0359 & 0.0248 & 0.20 & 333 & -0.0493 & 0.0288 & 0.20 \\
\hline September 1993 & 17 & -0.6494 & 0.0809 & 0.36 & 327 & -0.0045 & 0.0246 & 0.12 \\
\hline October 1993 & 25 & 0.0418 & 0.0172 & 0.08 & 55 & 0.2064 & 0.0021 & 0.00 \\
\hline November 1993 & - & - & - & - & 113 & 0.0972 & 0.0057 & 0.04 \\
\hline December 1993 & 181 & 0.0580 & 0.0044 & 0.07 & 337 & 0.0615 & 0.0029 & 0.03 \\
\hline January 1994 & 265 & 0.0703 & 0.0039 & 0.09 & 446 & 0.0560 & 0.0051 & 0.12 \\
\hline February 1994 & 14 & -0.0597 & 0.0277 & 0.20 & 146 & 0.0613 & 0.0041 & 0.08 \\
\hline March 1994 & 72 & 0.0250 & 0.0137 & 0.41 & 147 & 0.0269 & 0.0126 & 0.41 \\
\hline April 1994 & 30 & 0.0599 & 0.0174 & 0.53 & 143 & 0.0600 & 0.0196 & 0.31 \\
\hline May 1994 & 35 & 0.0928 & 0.0193 & 0.13 & 379 & 0.0401 & 0.0230 & 0.34 \\
\hline June 1994 & 81 & -0.0795 & 0.0273 & 0.30 & 190 & -0.1192 & 0.0319 & 0.54 \\
\hline August 1994 & 130 & -0.1058 & 0.0271 & 0.16 & 478 & -0.0009 & 0.0170 & 0.11 \\
\hline September 1994 & 133 & -0.0216 & 0.0230 & 0.18 & 367 & 0.0038 & 0.0218 & 0.11 \\
\hline October 1994 & 44 & 0.0401 & 0.0168 & 0.30 & 282 & 0.0532 & 0.0156 & 0.23 \\
\hline November 1994 & 51 & 0.1094 & 0.0043 & 0.02 & 155 & 0.0636 & 0.0080 & 0.10 \\
\hline December 1994 & 138 & 0.0628 & 0.0063 & 0.11 & 352 & 0.0594 & 0.0050 & 0.06 \\
\hline January 1995 & 155 & 0.0413 & 0.0084 & 0.25 & 504 & 0.0618 & 0.0050 & 0.22 \\
\hline February 1995 & 304 & 0.0533 & 0.0086 & 0.26 & 532 & 0.0537 & 0.0086 & 0.31 \\
\hline
\end{tabular}

at incident wind angles $195-250^{\circ}$ than at the entire wind angle range, but the effect was less outspoken than for the relationship between irradiance and assimilatory $\mathrm{CO}_{2}$ flux. The relatively low sensitivity of the relationship between $T_{\mathrm{a}}$ and $F_{\mathrm{r}}$ to the incident wind angle can be thought of as the effect of the wind angle already being incorporated in $T_{\mathrm{a}}$ itself, as the effects of wind angle and $T_{\mathrm{a}}$ concur. The established responses diverged only at higher levels of $T_{\mathrm{a}}$. Figure 6.15 highlights the respiratory $\mathrm{CO}_{2}$ fluxes which were determined at high vapour pressure deficit $>425 \mathrm{~Pa}$ at all wind angles and $-375 \mathrm{~Pa}$ at westerly to southwesterly winds). It shows that high aerial vapour pressure deficit was associated with lower respiratory $\mathrm{CO}_{2}$ fluxes, either indirectly as a result of limited assimilatory activity or directly as a result of impaired respiratory processes by drought. The fitted linear response of $F_{\mathrm{r}}$ to $T_{\mathrm{a}}$ higher than $5^{\circ} \mathrm{C}$ was $76 \mathrm{~g} \mathrm{CO}_{2} \mathrm{~m}^{-2}{ }^{\circ} \mathrm{C}^{-1}\left(r^{2}=0.90\right.$, 


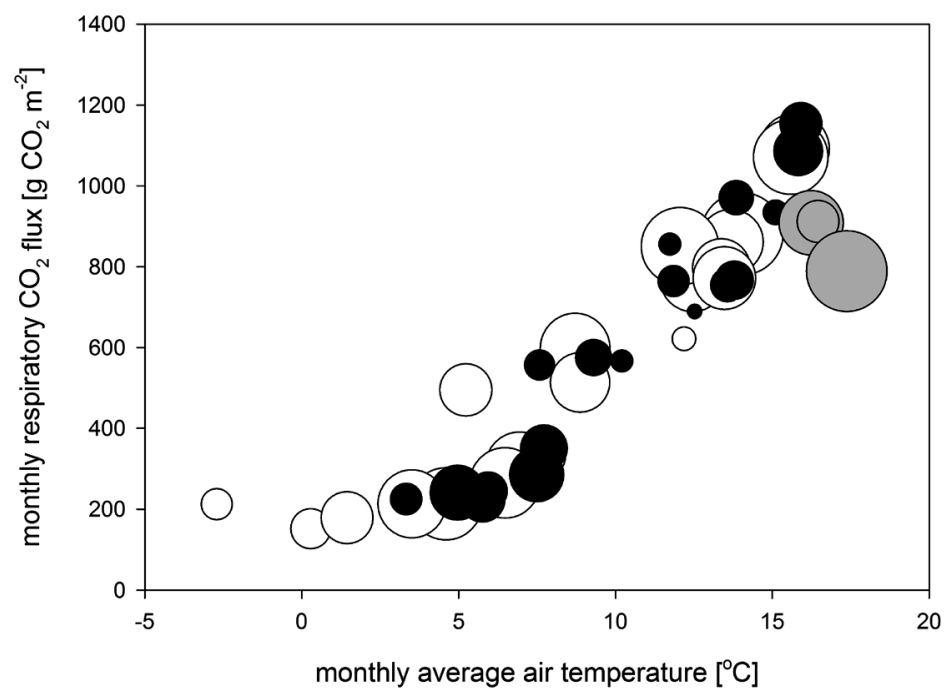

Figure 6.15. Response of monthly respiratory $\mathrm{CO}_{2}$ flux to monthly average temperature at incident wind angle range $1-360^{\circ}$ (open symbols), incident wind angle range $195-250^{\circ}$ (closed symbols) and average vapour pressure deficits above $350 \mathrm{~Pa}$ (grey symbols) at site Cabauw. The radius of the symbols is proportional to the actual number of flux measurements in the particular month.

$n=18)$ at incident wind angles $195-250^{\circ}$ and $59 \mathrm{~g} \mathrm{CO}_{2} \mathrm{~m}^{-2} \mathrm{o}^{-1}\left(r^{2}=0.78, n=17\right)$ at all wind angles. After omitting the lower respiratory $\mathrm{CO}_{2}$ fluxes at high vapour pressure deficit, the response of $F_{\mathrm{r}}$ to $T_{\mathrm{a}}$ increased to $81 \mathrm{~g} \mathrm{CO}_{2} \mathrm{~m}^{-2}{ }^{\circ} \mathrm{C}^{-1}\left(r^{2}=0.91, n=17\right)$ and $70 \mathrm{~g} \mathrm{CO}_{2} \mathrm{~m}^{-2}{ }^{\circ} \mathrm{C}^{-1}\left(r^{2}=0.86, n=15\right)$, respectively.

Respiratory activity also increases with biomass, which is composed of different components and corresponding respiratory processes. A measure for the composite biomass is the assimilatory $\mathrm{CO}_{2}$ flux itself, which correlates strongly with leaf area and the vegetation's biomass, although less with the microbial biomasses. Figure 6.16 explores the response of the monthly respiratory $\mathrm{CO}_{2}$ flux $(F)$ to the monthly assimilatory $\mathrm{CO}_{2}$ flux $\left(F_{\mathrm{a}}\right)$ at both incident wind angle ranges. The response of both $F_{\mathrm{a}}$ and $F_{\mathrm{r}}$ to environmental factors was more distinct at incident wind angles $195-250^{\circ}$ as they concurred with a narrower band of weather conditions. However, for the response of $F_{\mathrm{r}}$ to $F_{\mathrm{a}}$ the opposite could be observed such that measurements at the entire wind angle range resulted in the most distinct response. This observation may appear counter-intuitive, but is a consequence of the different time coefficients of $F_{\mathrm{r}}$ and $F_{\mathrm{a}}$. Whereas $F_{\mathrm{a}}$ responds primarily and instantaneously to environmental factors, $F_{\mathrm{r}}$ is in part the result of the accumulation of organic matter over longer periods of time. At incident wind angles $195-250^{\circ} F_{\text {a }}$ was the exclusive result of assimilatory activity at westerly to southwesterly winds, whereas $F_{\mathrm{r}}$ was the result of the accumulation of dry matter (i.e. $F_{\mathrm{a}}$ ) at all incident wind angles. This discrepancy in time coefficient at incident wind angles $195-250^{\circ}$ therefore weakens the 


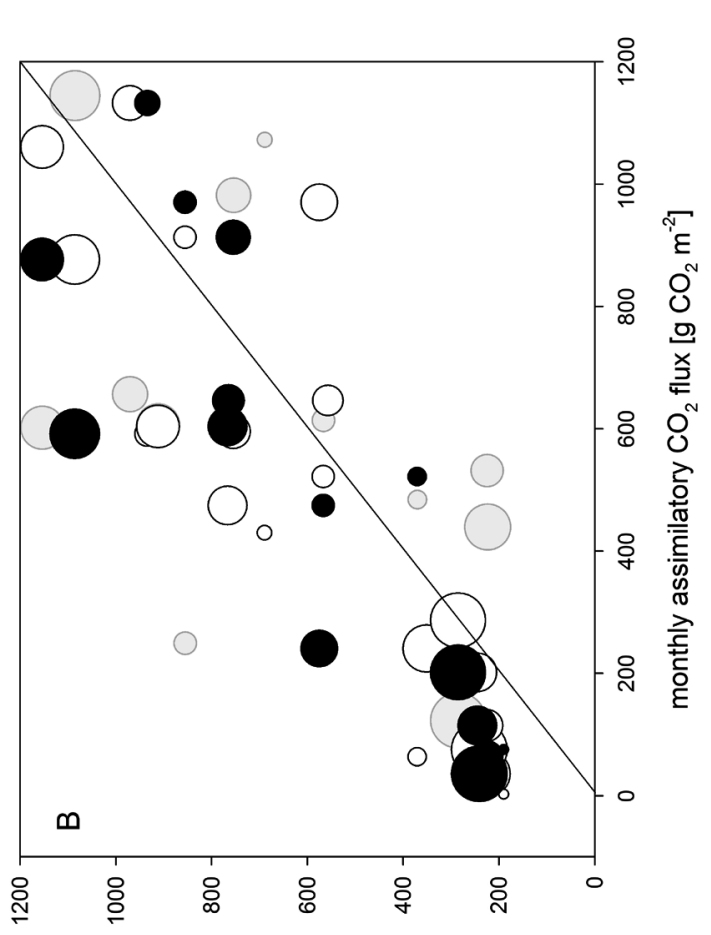

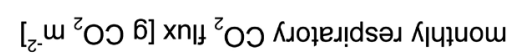

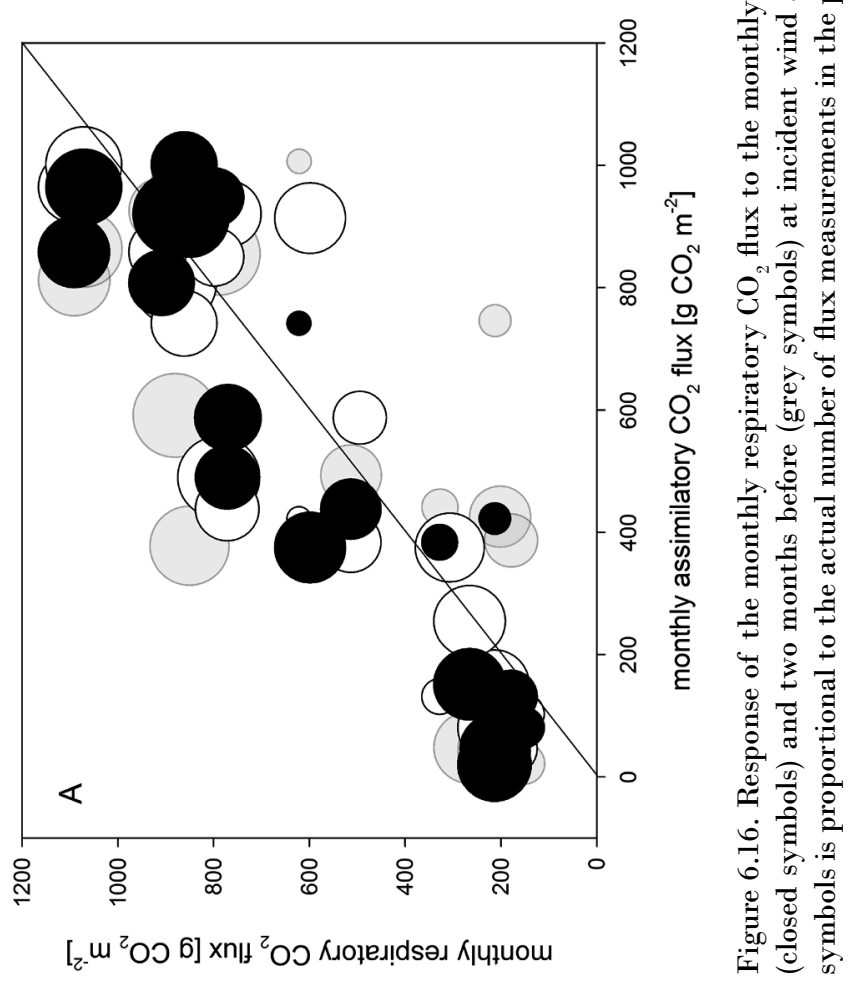


relationship between $F_{\mathrm{r}}$ and $F_{\mathrm{a}}$. At all incident wind angles the relationship is tightened as $F_{\mathrm{a}}$ is a better measure for the assimilated organic matter being respired as $F_{\mathrm{r}}$.

Figure 6.16 plots the response of the monthly respiratory $\mathrm{CO}_{2}$ flux $\left(F_{\mathrm{r}}\right)$ to the monthly assimilatory $\mathrm{CO}_{2}$ flux $\left(F_{\mathrm{a}}\right)$ in the same month, $F_{\mathrm{a}}$ one month before and $F_{\mathrm{a}}$ two months before. $F_{\mathrm{r}}$ responded approximately linearly to $F_{\mathrm{a}}$ in the same month and to $F_{\mathrm{a}}$ in the month before, whereas beyond one month the relationship started to disappear. This implies that the assimilatory activity in primarily the current and the previous month contributed to the respiratory activity, emanating from the vegetation's maintenance respiration and degradation of litter. Figure 6.16 also shows that $F_{\mathrm{r}}$ generally exceeded $F_{\mathrm{a}}$, with the exception of spring where at high irradiance $F_{\mathrm{a}}$ invariably exceeded $F_{\mathrm{r}}$. The relatively low respiratory $\mathrm{CO}_{2}$ fluxes in the early part of the growing season were less related to temperature as they occurred at both low $\left(<9^{\circ} \mathrm{C}\right)$ and high air temperature $\left(>12{ }^{\circ} \mathrm{C}\right)$, although low soil temperature lagging behind increasing air temperature could have resulted in a low effective temperature. The relatively low respiratory $\mathrm{CO}_{2}$ flux may also have been related to smaller amounts of new organic matter early in the growing season and a consequentially lower respiratory activity in the microbial biomass. Alternatively, limited lateral diffusivity to water may have resulted in relatively high groundwater tables in the early part of the growing season, reducing respiratory activity in the aerobic part of the soil profile.

The delayed response of $F_{\mathrm{r}}$ to $F_{\mathrm{a}}$ in the earlier part of the growing season thus translates into a pattern of hysteresis. From early spring to early summer $F_{\mathrm{a}}$ increased while $F_{\mathrm{r}}$ lagged behind, whereas from summer into winter $F_{\mathrm{a}}$ decreased and was now exceeded by $F_{\mathrm{r}}$. Hysteresis in the ratio between $F_{\mathrm{r}}$ and $F_{\mathrm{a}}$ was the result of a direct relationship between irradiance and $F_{a}$ on the one hand and an accumulation of new organic matter subject to decomposition and increasing composite temperatures as the season progresses on the other hand. Despite the limited number of observations, figure 6.17 demonstrates that a similar pattern of hysteresis could be observed at site Zegveld. In April $F_{\mathrm{a}}$ clearly exceeded $F_{\mathrm{r}}$, whereas in May and June $F_{\mathrm{a}}$ exceeded $F_{\mathrm{r}}$ only marginally. From August onwards $F_{\mathrm{r}}$ exceeded $F_{\mathrm{a}}$.

\subsubsection{Annual respiratory $\mathrm{CO}_{2}$ flux}

The sum of the monthly respiratory $\mathrm{CO}_{2}$ fluxes at all incident wind directions amounted to $7473 \mathrm{~g} \mathrm{CO}_{2} \mathrm{~m}^{-2}$ at an average air temperature of $9.3^{\circ} \mathrm{C}$ in 1993 (12 months) and 5608 $\mathrm{g} \mathrm{CO}_{2} \mathrm{~m}^{-2}$ at an average temperature of $9.1^{\circ} \mathrm{C}$ in 1994 (11 months). When related to the annual assimilatory $\mathrm{CO}_{2}$ flux this results in an annual relative respiratory $\mathrm{CO}_{2}$ flux of $1.14 \mathrm{~g} \mathrm{CO}_{2} \mathrm{~g}^{-1} \mathrm{CO}_{2}$ in 1993 and $1.12 \mathrm{~g} \mathrm{CO}_{2} \mathrm{~g}^{-1} \mathrm{CO}_{2}$ in 1994 , demonstrating that the drained peat grassland ecosystem at site Cabauw exhibited an annual net $\mathrm{CO}_{2}$ release in both years amounting to $12-14 \%$ of the gross assimilatory $\mathrm{CO}_{2}$ flux. 

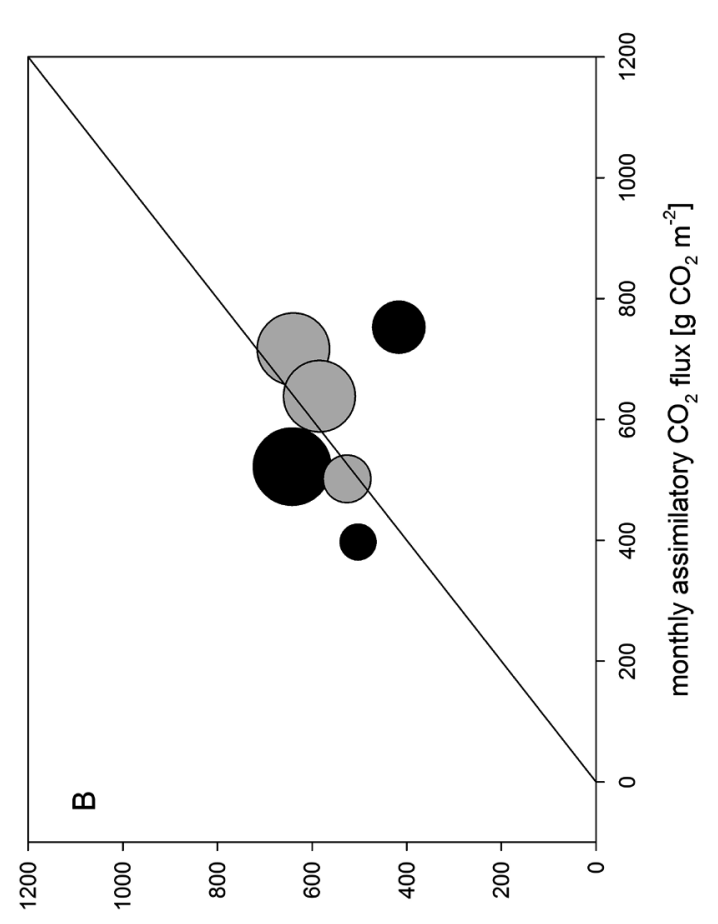

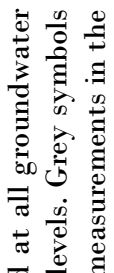

Oั

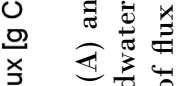

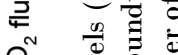

U

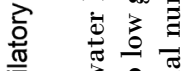

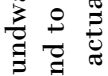

范

so

$\because \frac{8}{0}$

$\stackrel{0}{=} \frac{0}{0}: \frac{0}{0}$

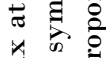

$\stackrel{4}{*} \div$

$0^{\prime \prime} \frac{\pi}{2} \cdot \frac{\pi}{4}$

$\Theta 2 \frac{0}{8}$

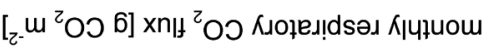

萡

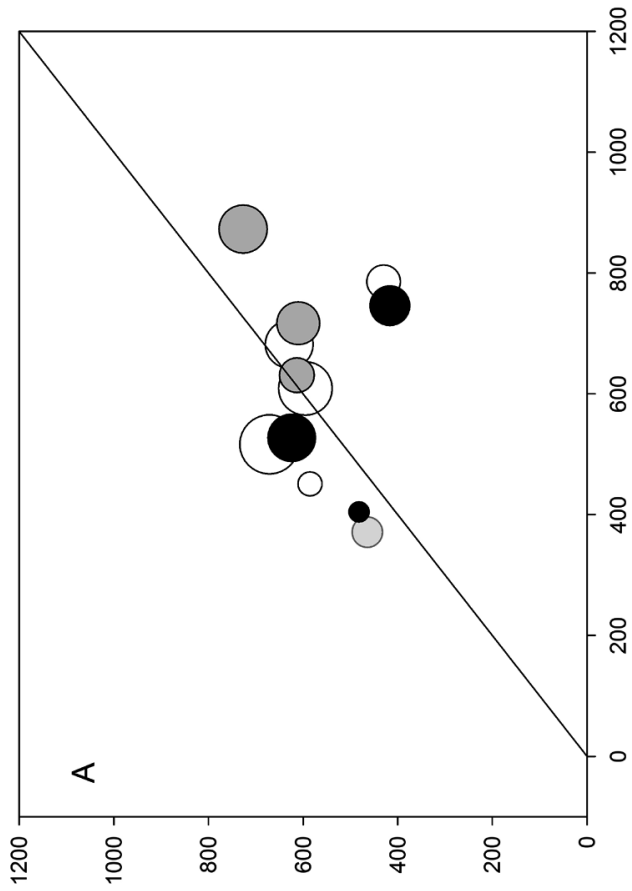

灵

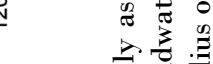

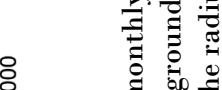

त 2.00

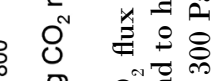

밍

希

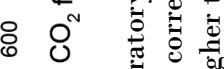

ते

党

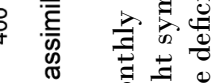

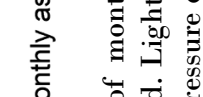

पे

范

䑻 需

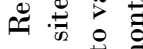

든

ๆ. $\overparen{9}$

min

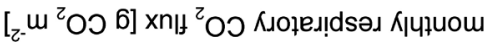



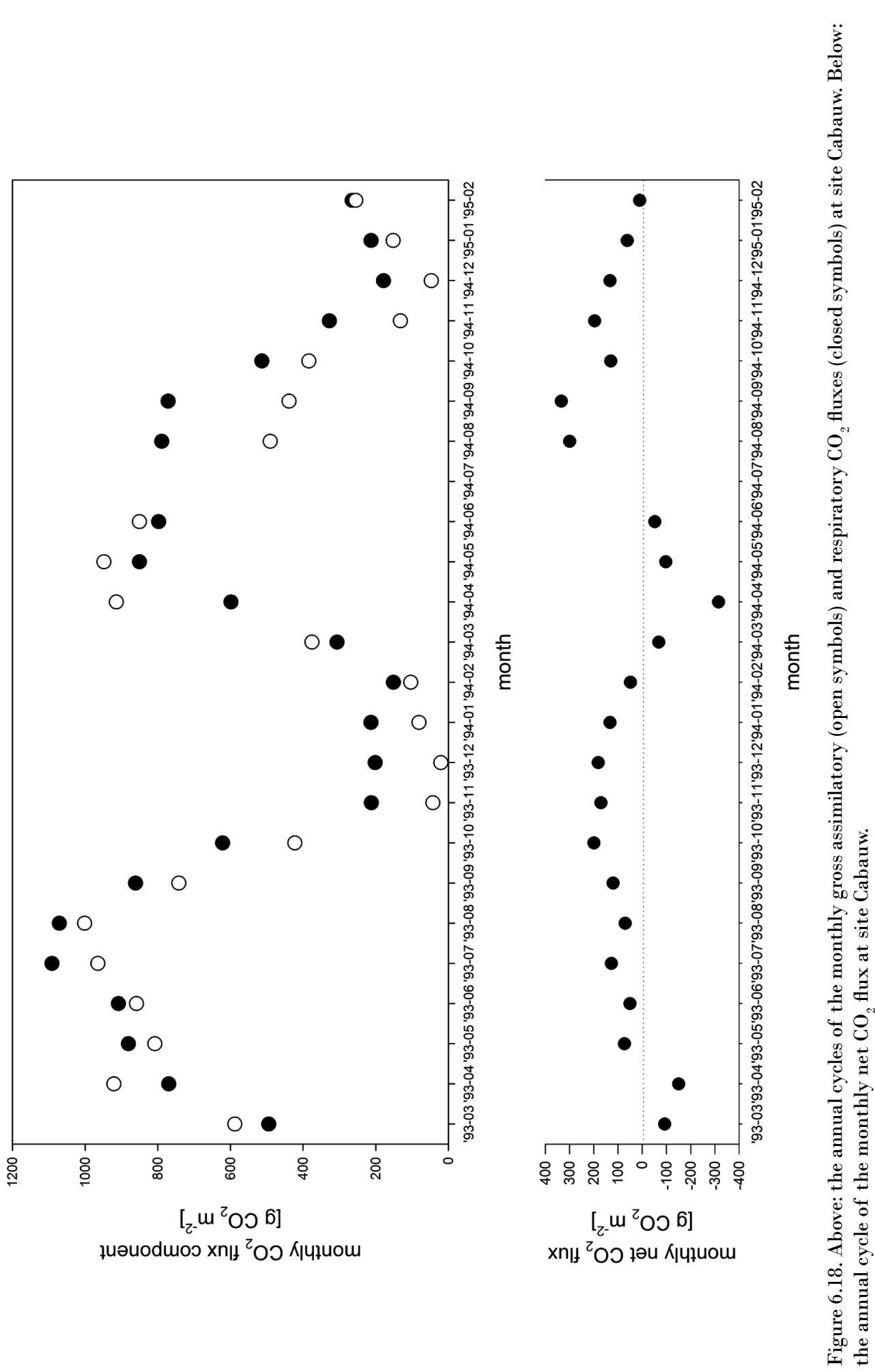


\subsubsection{Net $\mathrm{CO}_{2}$ exchange and its annual cycle}

\subsubsection{Annual cycle of $\mathrm{CO}_{2}$ exchange}

Figure 6.18 plots the two annual cycles of monthly assimilatory and respiratory $\mathrm{CO}_{2}$ exchange and demonstrates the observed hysteresis in the ratio of $F_{\mathrm{r}}$ and $F_{\mathrm{a}}$ on a time axis. The assimilatory $\mathrm{CO}_{2}$ flux $\left(F_{\mathrm{a}}\right)$ exceeded the respiratory $\mathrm{CO}_{2}$ flux $\left(F_{\mathrm{r}}\right)$ in spring, when $F_{\mathrm{a}}$ increased faster than $F_{\mathrm{r}}$. During the remainder of the year $F_{\mathrm{r}}$ exceeded $F_{\mathrm{a}}$. Consequentially, net $\mathrm{CO}_{2}$ sequestration in this drained peat grassland ecosystem occurred in spring only. Monthly net $\mathrm{CO}_{2}$ exchange ranged from a release of $400 \mathrm{~g} \mathrm{CO}_{2} \mathrm{~m}^{-2}$ to a sequestration of $300 \mathrm{~g} \mathrm{CO}_{2} \mathrm{~m}^{-2}$. Figure 6.19 compares the annual cycles in more detail, showing their monthly assimilatory $\left(F_{\mathrm{a}}\right)$ and respiratory $\mathrm{CO}_{2}$ fluxes $\left(F_{\mathrm{r}}\right)$, monthly shortwave irradiance $(R)$, monthly average air temperature $\left(T_{\mathrm{a}}\right)$ and monthly average aerial vapour pressure deficit $(D)$. In the growing season $F_{\text {a }}$ was higher in 1993 than in 1994. Levels of $R_{\mathrm{s}}$ were higher in 1993 than in 1994, being the dominant factor in productivity. $D$ frequently imposed a limiting effect on the assimilatory activity, particularly observed in late spring and summer. In March and April, $F_{\mathrm{a}}$ closely followed $R_{\mathrm{s}}$ at non-limiting levels of $D$ at 200-325 Pa. Levels of $R_{\mathrm{s}}$ in May and June were higher in 1993 than in 1994, but $F_{\mathrm{a}}$ was similar or even lower. This was caused by high levels of $D$ in 1993 at 400-450 Pa. The clearest effect of limiting $D$ was observed in August 1994. Moderately lower levels of $R_{s}$ in 1994 resulted in a much lower $F_{\mathrm{a}}$ at the highest level of $D$ in the two measurement years (> $450 \mathrm{~Pa}$ ). $D$ fell below $250 \mathrm{~Pa}$ in September, which restored the relationship between $R_{\mathrm{s}}$ and $F_{\mathrm{a}} . F_{\mathrm{r}}$ followed $F_{\mathrm{a}}$ closely, with notable exceptions of August and September 1994 when $F_{\mathrm{r}}$ exceeded $F_{\mathrm{a}}$ by approximately $300 \mathrm{~g} \mathrm{CO}_{2} \mathrm{~m}^{-2}$. August was characterised by a strongly impaired $F_{a}$ as a consequence of warm and dry conditions, as reflected in $T_{a}$ and $D$. A low groundwater table in the drained peat soil as a consequence of a limited lateral water flow may thus have increased $F_{\mathrm{r}}$ associated with the decomposition of the organic soil. The effect of a deep aerobic soil profile could have lasted into September. $F_{\mathrm{a}}$ exceeded $F_{\mathrm{r}}$ in the earlier part of the growing season, even though $F_{\mathrm{a}}$ itself was partly limited by high $D$. The amount of litter subject to rapid decomposition is still low early in the growing season.

The system's gross assimilatory $\mathrm{CO}_{2}$ flux increased linearly with irradiance, but was limited by high vapour pressure deficit and, to a lesser extent, by low temperature. The system's respiratory $\mathrm{CO}_{2}$ flux increased seasonally with biomass and temperature, but their effects cannot be clearly separated. Whereas the monthly assimilatory and respiratory $\mathrm{CO}_{2}$ fluxes were correlated, the system's monthly net $\mathrm{CO}_{2}$ exchange varied. It ranged from a net $\mathrm{CO}_{2}$ sequestration in spring and early summer to a net release during the remainder of the year. A simple multiple linear regression for the dependence of the system's monthly net $\mathrm{CO}_{2}$ exchange $\left(F_{\mathrm{n}}\right)$ on monthly shortwave irradiance $\left(R_{\mathrm{s}}\right)$, average vapour pressure deficit $(D)$ and average temperature $\left(T_{\mathrm{a}}\right)$ shows that all independent variables $R_{\mathrm{s}}, D$ 

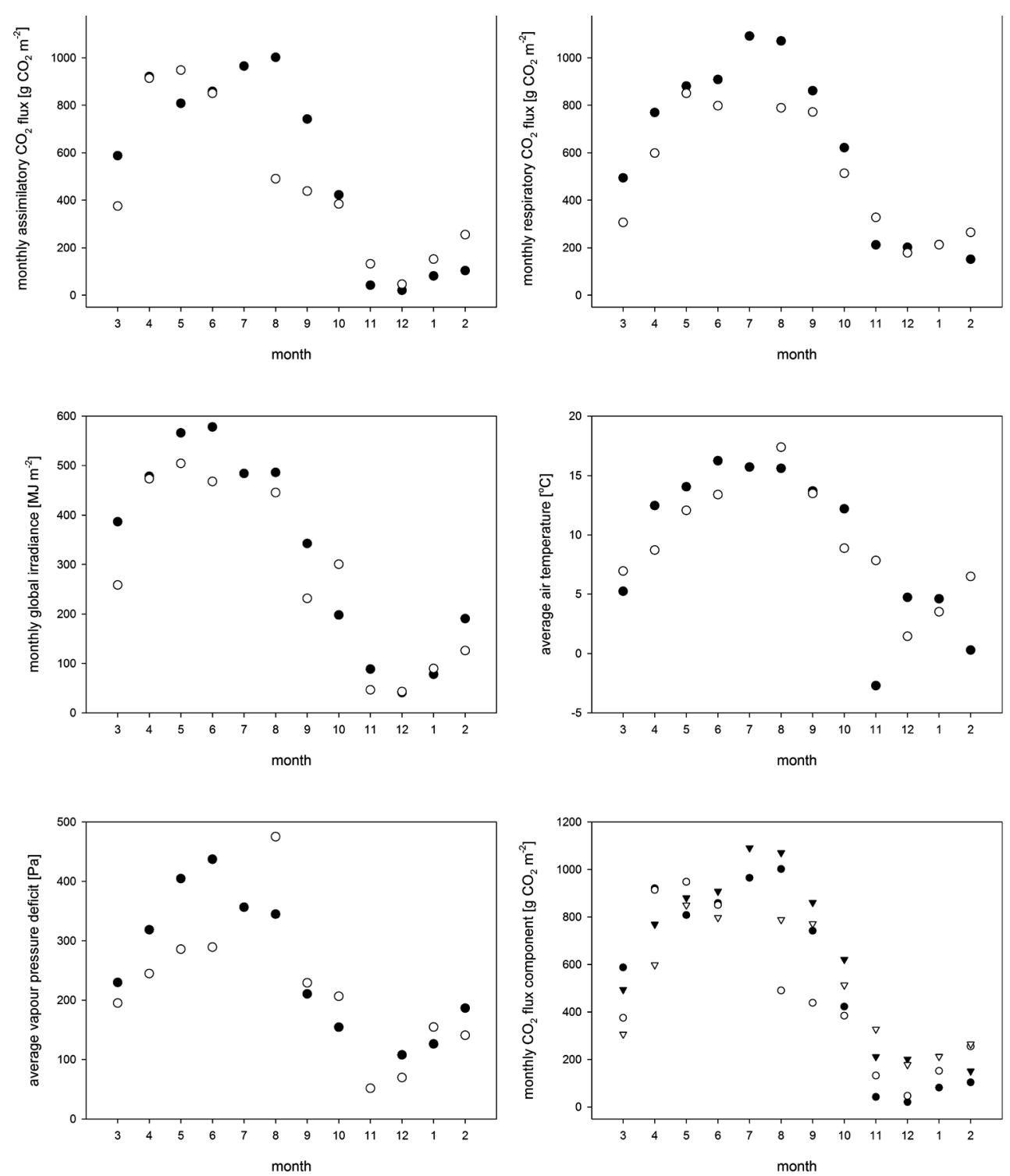

Figure 6.19. The annual cycles of the monthly assimilatory and respiratory $\mathrm{CO}_{2}$ fluxes, monthly shortwave irradiance, average air temperature and average vapour pressure deficit at site Cabauw in 1993 (closed symbols) and 1994 (open symbols).

and $T_{\mathrm{a}}$ contributed significantly to predicting $F_{\mathrm{n}}\left(n=23, r^{2}=0.76, P<0.05\right) . R_{\mathrm{s}}$ was correlated with a net $\mathrm{CO}_{2}$ sequestration and both $D$ and $T_{\mathrm{a}}$ were correlated with a net $\mathrm{CO}_{2}$ release. The direct effect of $R_{\mathrm{s}}$ on primary productivity thus exceeded its indirect effect on respiratory activity, whereas the effect of $T_{\mathrm{a}}$ on a higher respiratory exceeded its effect on a higher primary productivity. This is also shown in the linear dependence of 
the monthly net $\mathrm{CO}_{2}$ exchange $\left(F_{\mathrm{n}}\right)$ on the monthly gross assimilatory $\mathrm{CO}_{2}$ flux $\left(F_{\mathrm{a}}\right)$ and monthly average temperature $\left(T_{\mathrm{a}}\right)$, where $F_{\mathrm{a}}$ was correlated with a net $\mathrm{CO}_{2}$ sequestration and $T_{\mathrm{a}}$ was correlated with a net $\mathrm{CO}_{2}$ release $\left(n=23, r^{2}=0.70, P<0.05\right)$.

\subsubsection{Annual net $\mathrm{CO}_{2}$ exchange}

The annual relative respiratory $\mathrm{CO}_{2}$ flux of 1.12-1.14 $\mathrm{g} \mathrm{CO}_{2} \mathrm{~g}^{-1} \mathrm{CO}_{2}$ shows that in both years the drained peat grassland ecosystem at Cabauw was a net $\mathrm{CO}_{2}$ source, with a net release of $920 \mathrm{~g} \mathrm{CO}_{2} \mathrm{~m}^{-2}$ in 1993 and $623 \mathrm{~g} \mathrm{CO}_{2} \mathrm{~m}^{-2}$ in 1994 (with July 1994 missing). Whereas the characteristics of the annual respiratory activity are similar, the annual cycles for both years illustrate that the constituent monthly characteristics are different. In 1993 the assimilatory $\mathrm{CO}_{2}$ flux $(F)$ exceeded the respiratory $\mathrm{CO}_{2}$ flux $\left(F_{\mathrm{r}}\right)$ up to April after which $F_{\mathrm{r}}$ evenly exceeded $F_{\mathrm{a}}$. In $1994 F_{\mathrm{a}}$ exceeded $F_{\mathrm{r}}$ up to June, but this higher net $\mathrm{CO}_{2}$ sequestration was compensated for in late summer when $F_{\mathrm{r}}$ exceeded $F_{\mathrm{a}}$ by a wide margin.

The calculated annual net $\mathrm{CO}_{2}$ emission of $623-920 \mathrm{~g} \mathrm{CO}_{2} \mathrm{~m}^{-2}$ is associated with the decomposition of peat. As an ecosystem on an undisturbed soil is generally characterised by a net $\mathrm{CO}_{2}$ sequestration, this peat grassland's net $\mathrm{CO}_{2}$ emission can be considered to be the lower boundary of the decomposition of the drained peat soil. A peat soil bulk density of $140 \mathrm{~kg} \mathrm{~m}^{-3}$, an organic soil content of $80 \%$ and an organic soil C content of 55\% (Kuikman et al. 2005) result in a conversion factor of $0.44310^{-2} \mathrm{~mm}$ of peat soil profile depth decomposed for every g $\mathrm{CO}_{2}$ emitted. The annual $\mathrm{CO}_{2}$ emission at site Cabauw thus corresponds to the decomposition of 2.8-4.1 mm of peat soil. At an annual soil subsidence of $13 \mathrm{~mm}$ for well-drained peat soils with a clay layer (Kuikman et al. 2005) this equals $22-32 \%$ of the total soil subsidence. The net $\mathrm{CO}_{2}$ emission at site Cabauw constituted only $11-12 \%$ of the total respiratory $\mathrm{CO}_{2}$ flux, which explains why differences in $\mathrm{CO}_{2}$ flux between both drainage levels at site Zegveld are not apparent in the instantaneous respiratory $\mathrm{CO}_{2}$ fluxes.

\subsection{DISCUSSION}

\subsubsection{Aggregation in space and time}

At site Cabauw, the measurement flux footprint or fetch at incident wind angles 195-250 consisted of a homogeneously drained and grazed peat grassland over approximately 2 $\mathrm{km}$, whereas measurements at the remaining wind angles included disturbances by minor roads and orchards. Restriction of the analysis to measurements made at wind angles $195-250^{\circ}$ excludes noise from $\mathrm{CO}_{2}$ sinks and sources other than grassland. However, as westerly and southwesterly winds are correlated with maritime weather conditions and this temperate weather type precludes low air temperatures and high vapour pressure deficits, this restriction results in a bias towards larger $\mathrm{CO}_{2}$ fluxes. Calculation of the 
annual $\mathrm{CO}_{2}$ flux on basis of these measurements would emulate an environment with only westerly to southwesterly winds. The annual flux can therefore only be calculated on basis of measurements made at all wind angles even if they include noise from other sinks and sources. The analysis shows that $\mathrm{CO}_{2}$ sinks and sources unrelated to the grassland system hardly affected the exchange patterns. $\mathrm{CO}_{2}$ emitted by occasional traffic disappears in the 30 minute flux averages. With respect to the orchards east of the site, the response of the $\mathrm{CO}_{2}$ flux components to environmental factors proved to be the same at both incident wind angle ranges. After accounting for limiting factors in the responses of the assimilatory $\mathrm{CO}_{2}$ flux $\left(F_{\mathrm{a}}\right)$ to irradiance $\left(R_{\mathrm{s}}\right)$ and of the respiratory $\mathrm{CO}_{2}$ flux $\left(F_{\mathrm{r}}\right)$ to temperature $\left(T_{\mathrm{a}}\right)$ the baseline responses at both wind angle ranges were similar. It is concluded that there was little difference in the $\mathrm{CO}_{2}$ exchange patterns between peat grasslands and orchards on the same peat soil at the same level of drainage. Under conditions conducive to high primary productivity canopies in different types of vegetations behave similarly.

Measurements at a narrower range of environmental conditions can characterise the $\mathrm{CO}_{2}$ exchange processes (Albergel et al. 2010, Gilmanov et al. 2007, Imer et al. 2013, Veenendaal et al. 2007). They set the baseline responses of the $\mathrm{CO}_{2}$ flux components to environmental factors against which the measurements made at the entire wind angle range are being analysed. $\mathrm{CO}_{2}$ exchange processes allow the assessment of the flux measurements, as processes can be compared more meaningfully than sums of fluxes. After aggregation of the 30 minute $\mathrm{CO}_{2}$ flux components to monthly values baseline responses were set of the assimilatory and respiratory $\mathrm{CO}_{2}$ fluxes across both years and limiting factors were identified at a degree of detail which is reminiscent of much lower levels of aggregation and smaller time scales.

The time series of measurements at Cabauw includes several gaps, which are unevenly distributed in time. In similar studies (e.g. Jacobs et al. 2007) missing $\mathrm{CO}_{2}$ flux data are often accounted for by calculation. The $\mathrm{CO}_{2}$ flux measurements are used to define the responses of the flux components to temperature and irradiance, which are then applied to calculate the respiratory and assimilatory $\mathrm{CO}_{2}$ fluxes over the periods in which flux data are missing. Although this approach is process-based, it introduces its own uncertainty because of the extrapolation of the validity of the calculated relationships. It also requires the availability of meteorological data for the entire period of measurement. In this study missing $\mathrm{CO}_{2}$ flux data are accounted for by extrapolating the $\mathrm{CO}_{2}$ flux components on a monthly basis. This extrapolation shifts the uncertainty from the response curves to the ambient environmental conditions. To inter-annual differences in the $\mathrm{CO}_{2}$ flux this uncertainty weighs in less as $\mathrm{CO}_{2}$ fluxes and environmental characteristics apply to the same periods of time. 


\subsubsection{Assimilatory $\mathrm{CO}_{2}$ flux}

The gross assimilatory $\mathrm{CO}_{2}$ flux constitutes the ecosystem's gross $\mathrm{CO}_{2}$ capture. Radiation is the most important factor in the variation of primary productivity in time (Gilmanov et al. 2007, Monteith 1994) and may also explain part of its variation in space. Radiation use efficiency normalises primary productivity for irradiance levels. The response of the gross assimilatory $\mathrm{CO}_{2}$ flux $\left(F_{\mathrm{a}}\right)$ to incident shortwave irradiance $\left(R_{\mathrm{s}}\right)$ at site Cabauw under conditions non-limiting to growth was a distinct $2.20 \mathrm{~g} \mathrm{CO}_{2} \mathrm{MJ}^{-1}$ across both measurement years and at both incident wind angle ranges. Gross primary productivity is often related to absorbed radiation rather than irradiance, although absorbed radiation in a grass sward is difficult to determine. Turner et al. (2003) combined measured leaf area index and a simple extinction function. They found a linear response of $6.3 \mathrm{~g} \mathrm{CO}_{2}$ $\mathrm{MJ}^{-1}$ absorbed photosynthetically active radiation (PAR) in a tallgrass prairie during the growing season, whereas the response was hyperbolic in corn and forests. Yuan et al. (2007) used the normalised difference vegetation index (NDVI) to calculate absorbed radiation and found a uniform radiation use efficiency of $7.8 \mathrm{~g} \mathrm{CO}_{2} \mathrm{MJ}^{-1}$ absorbed PAR at optimum temperatures across a range of biomes. At a 50\% fraction of PAR relative to global radiation (Jones 1992) this points at a fraction of absorbed radiation of at least $55 \%$ at the Cabauw site in this study. It can be expected that an optimum irradiance use efficiency of $2.20 \mathrm{~g} \mathrm{CO}_{2} \mathrm{MJ}^{-1}$ holds under a wide range of weather conditions.

The annual gross assimilatory $\mathrm{CO}_{2}$ flux $\left(F_{\mathrm{a}}\right)$ at site Cabauw in 1993 amounted to 6553 $\mathrm{g} \mathrm{CO}_{2} \mathrm{~m}^{-2}$. July 1994 was missing from the measurements, but assuming a monthly irradiance of $500 \mathrm{MJ} \mathrm{m}^{-2}$ and a non-limiting incident radiation use efficiency of $2.20 \mathrm{~g}$ $\mathrm{CO}_{2} \mathrm{MJ}^{-1}$ it can be seen that $F_{\mathrm{a}}$ in 1994 is unlikely to have exceeded $6100 \mathrm{~g} \mathrm{CO}_{2} \mathrm{~m}^{-2}$. Annual $F_{\mathrm{a}}$ values of of 6000-6500 $\mathrm{g} \mathrm{CO}_{2} \mathrm{~m}^{-2}$ are in the upper reaches of levels observed in other studies in peat grasslands. Jacobs et al. (2007) measured $\mathrm{CO}_{2}$ fluxes at site Cabauw from 2002 to 2005 primarily at easterly incident wind angles, ranging from approximately 4500 to $6180 \mathrm{~g} \mathrm{CO}_{2} \mathrm{~m}^{-2}$. Veenendaal et al. (2007) found $F_{\mathrm{a}}$ values of 5660 and $5360 \mathrm{~g}$ $\mathrm{CO}_{2} \mathrm{~m}^{-2}$ in two peat grasslands in the Netherlands in 2004 and 2005. Higher values of $F_{\mathrm{a}}$ were measured in a mowed grassland on an alluvial clay soil, approximately $50 \mathrm{~km}$ east of site Cabauw. Here, Jacobs et al. (2007) arrived at a 4-year average annual $F_{\mathrm{a}}$ of $7370 \mathrm{~g} \mathrm{CO}_{2} \mathrm{~m}^{-2}$, whereas Lantinga (1985) calculated an annual $F_{\mathrm{a}}$ of $7390-7970 \mathrm{~g} \mathrm{CO}_{2}$ $\mathrm{m}^{-2}$ using crop enclosures under various management regimes. Gilmanov et al. (2007) re-evaluated multiple eddy covariance measurements and calculated annual $F_{\mathrm{a}}$ values of 3970-6810 $\mathrm{g} \mathrm{CO}_{2} \mathrm{~m}^{-2}$ in a range of intensively managed European grasslands. In Japanese intensively managed grasslands on loam soils Hirata et al. (2013) measured annual $F_{\text {a }}$ values of $3825-9820 \mathrm{~g} \mathrm{CO}_{2} \mathrm{~m}^{-2}$ at various fertiliser application regimes. In peat grassland ecosystems drainage canals can reduce the actual vegetation surface cover and therefore the apparent primary productivity. A delayed warming of the moist soil in spring may have limited early productivity, although active water management aims to prevent this. 
The range of annual $F_{a}$ values shows the variability in grassland primary productivity. Irradiance is an important factor in this variation (Gilmanov et al. 2007), but other factors also affect productivity. Low temperatures limit grass sward assimilatory activity (Wilson \& Cooper 1969, Woledge \& Dennis 1982, Woledge \& Parsons 1986) by slowing down metabolism. After scaling the flux measurements the effect of low temperature also emerged at the ecosystem level on a seasonal scale in this study. In the drained peat grassland ecosystem $F_{\mathrm{a}}$ was clearly limited at monthly average air temperatures $\left(T_{\mathrm{a}}\right)$ below $10^{\circ} \mathrm{C}$. Yuan et al. (2007) found an optimum daily temperature of approximately $20^{\circ} \mathrm{C}$ across multiple biomes. However, the effect on the annual $\mathrm{CO}_{2}$ flux was modest as low $T_{\mathrm{a}}$ correlates with low $R_{s}$. At the opposite end of the temperature spectrum high aerial vapour pressure deficit is known to directly limit assimilatory activity, an effect sometimes attributed to high temperature (Woledge et al. 1989). The effect of high vapour pressure also emerged at the ecosystem level in this study. $F_{\mathrm{a}}$ was limited at monthly average aerial vapour pressure deficits $(D)$ exceeding $350 \mathrm{~Pa}$, either as a measure for a low soil moisture content or through a direct effect on stomatal conductance. Its impact on the annual $\mathrm{CO}_{2}$ flux was higher than for low $T_{\mathrm{a}}$ as high $D$ correlates with high $R_{\mathrm{s}}$. The annual radiation use efficiency at site Cabauw of $1.67 \mathrm{~g} \mathrm{CO}_{2} \mathrm{MJ}^{-1}$ fell well below its maximum value of $2.20 \mathrm{~g} \mathrm{CO}_{2} \mathrm{MJ}^{-1}$ and was shown to be primarily reduced by several months in which $D$ exceeded $400 \mathrm{~Pa}$. Qi et al. (2017) found a clear relationship between evapotranspiration and dry matter yield across multiple grassland ecosystems. Polley et al. (2011) found the radiation use efficiency in Great Plains grasslands to decrease with increasing levels of evapotranspiration. The measurements at site Zegveld show a limiting effect at levels of $D$ exceeding $300 \mathrm{~Pa}$.

Combining the annual gross assimilatory $\mathrm{CO}_{2}$ fluxes $\left(F_{\mathrm{a}}\right)$ measured by Jacobs $e t$ al. (2007) from 2002 to 2005 and independent site weather data provided by the Royal Netherlands Meteorological Institute (KNMI) corroborates the observation from this study that vapour pressure deficit $(D)$ correlates negatively with productivity. From these data it can be calculated that the annual radiation use efficiencies in the study by Jacobs et al. (2007) were 1.50-1.60 $\mathrm{g} \mathrm{CO}_{2} \mathrm{MJ}^{-1}$ in 2002 and 2005, but decreased to $1.20 \mathrm{~g} \mathrm{CO}_{2}$ $\mathrm{MJ}^{-1}$ in 2003 and 2004. The weather data show that, at comparable levels of irradiance, $D$ was substantially higher in 2003 and 2004 than in 2002 and 2005. The decrease in annual radiation use efficiency which can be calculated from the data by Jacobs et al. (2007) and KNMI thus clearly correlates with higher levels of $D$. Reichstein et al. (2007) noted that 2003 was characterised by European-wide low primary productivity as a result of drought. It demonstrates that the effect of high $D$ observed in this study on a monthly time scale can also emerge on an annual basis. Differences in irradiance are thus strongly mediated by differences in radiation use efficiency related to limiting factors. The effect of high vapour pressure deficit was higher than the effect of low temperature, as high vapour pressure deficit is more probable to occur at high irradiance. 


\subsubsection{Respiratory $\mathrm{CO}_{2}$ flux}

The grassland's respiratory $\mathrm{CO}_{2}$ flux represents the ecosystem's gross $\mathrm{CO}_{2}$ loss. It is heterogeneous as it consists of respiratory activity by the cattle, vegetation's maintenance and growth respiration, and soil microbial respiration associated with the decomposition of both soil organic matter and peat in the aerobic soil profile. A differential response to an otherwise heterogeneous environment of temperature and moisture makes that its quantitative characteristics don't compare instantly to those of other respiratory systems.

The multiple components do not occur evenly distributed in time, which particularly applies to growth respiration. Growth respiration is physiologically part of the assimilation rather than respiration (Lawlor 1987) and continues well after the daylight period has ceased, although progressively decreases over time. It could be argued that growth respiration is to be excluded from the respiratory $\mathrm{CO}_{2}$ flux by restricting the analysis to the measurements made during the $2^{\text {nd }}$ half of the night-time period, where the growth respiration is minimised. However, the measurements show that the $\mathrm{CO}_{2}$ flux at a given air temperature is actually higher during the $2^{\text {nd }}$ half than during the $1^{\text {st }}$ half of the nighttime period. This may be related to the phase shift between soil and air temperature becoming more pronounced during the $2^{\text {nd }}$ half of the night-time period. The heat capacity of the soil causes it to retain much of its energy over longer periods of time and therefore the soil temperature to increase relative to the air temperature as the dark period progresses. The composite respiratory temperature - air and soil temperature - is relatively high at low air temperatures, possibly causing the respiratory $\mathrm{CO}_{2}$ flux to be higher than if expected solely on basis of air temperature. The $2^{\text {nd }}$ half of the night-time period is therefore the most atypical in terms of temperature and night-time $\mathrm{CO}_{2}$ flux and thus unsuitable as an exclusive basis for the relationship between air temperature and respiratory $\mathrm{CO}_{2}$ flux.

The ecosystem's assimilatory $\mathrm{CO}_{2}$ flux showed a primary response to irradiance only mediated by temperature and air humidity. It can be seen that the interaction of the ecosystem with a homogeneous radiative environment taking place only at its surface contributes to the instant and distinct nature of this response. The respiratory system's heterogeneity in both space and time as well as its heterogeneous environment preclude such distinct dynamics for the respiratory $\mathrm{CO}_{2}$ flux. Adding to the complexity of the response of the respiratory $\mathrm{CO}_{2}$ flux to its environment is the correlated response to both temperature and biomass.

A $Q_{10}$ type of relationship with value 2.2 was observed for the response of the instantaneous night-time $\mathrm{CO}_{2}$ flux to air temperature (Kruse et al. 2011, Lloyd \& Taylor 1994), which was particularly evident in the increasing response with increasing temperature. Its annual pattern may include the effect of biomass, thereby elevating the response 
level. The grassland ecosystem's monthly respiratory $\mathrm{CO}_{2}$ flux $(F)$ responded linearly to monthly average air temperature, but this includes the effect of increasing biomass per unit of surface area. As seasonal temperature increases, so does the composite biomass consisting of living biomass, litter and soil microbial biomass in the aerobic soil profile at seasonally decreasing groundwater levels. The effect of biomass interacting was visible in those months which were characterised by a strongly impaired primary productivity as a consequence of drought, resulting in a clearly reduced response of the respiratory $\mathrm{CO}_{2}$ flux to temperature. Indeed, Reichstein et al. (2007) found ecosystem respiratory activity to follow assimilatory activity also under conditions where the latter is severely impaired by drought. This reduced response to temperature at drought and low primary productivity despite a potentially higher respiratory $\mathrm{CO}_{2}$ flux from the aerobic soil profile - a consequence of limited lateral diffusivity to water - indicates that the instant respiratory $\mathrm{CO}_{2}$ flux from living biomass and litter exceeded the instant respiratory $\mathrm{CO}_{2}$ flux from the decomposition of peat by a wide margin.

The reference value of the monthly respiratory $\mathrm{CO}_{2}$ flux $(F)$ aims to eliminate the effect of temperature and is determined by the vegetation's biomass, the soil microbial biomass and the soil organic matter substrate. It is shown to exhibit a distinct seasonal course. A composite measure for the ecosystem's biomass is the assimilatory $\mathrm{CO}_{2}$ flux $\left(F_{\mathrm{a}}\right)$ itself. Higher assimilatory activity correlates with more shoot and root biomass and thus a higher maintenance respiration as well as more organic matter added to the soil profile which in turn correlates with more soil microbial biomass and a higher soil organic matter decomposition rate per unit of surface area. However, whereas part of the respiratory response to $F$ is instant, another part of the response will occur with a delay. The decomposition of assimilated organic matter will be gradual and be apparent only in the course of time. Tails of gradually decreasing decomposition in time each originating from the organic matter senesced at a particular point in time - the historic component of organic matter - cumulate and contribute to an indistinct response of $F_{\mathrm{r}}$ to $F_{\mathrm{a}}$. This will explain at least part of the hysteresis observed in this response, $F_{\mathrm{r}}$ relative to $F_{\mathrm{a}}$ being substantially higher in the later part of the growing season. But cumulated litter as the growing season progresses also correlates with (particularly composite) temperature. Both higher levels of organic matter substrate and higher temperatures thus contribute to higher absolute levels of $F_{\mathrm{r}}$ and of levels of $F_{\mathrm{r}}$ relative to $F_{\mathrm{a}}$ towards the end of the growing season. Tenhunen et al. (1995) found the seasonal pattern of the respiratory $\mathrm{CO}_{2}$ flux in tundra to follow aerated soil volume (i.e. soil microbial biomass), whereas its diurnal pattern followed temperature. However, the effect of aerated soil volume may well have included a seasonal effect of temperature.

The annual respiratory $\mathrm{CO}_{2}$ flux $\left(F_{\mathrm{r}}\right)$ at site Cabauw in 1993 was $7473 \mathrm{~g} \mathrm{CO}_{2} \mathrm{~m}^{-2}$. Assuming a maximum assimilatory $\mathrm{CO}_{2}$ flux of $1100 \mathrm{~g} \mathrm{CO}_{2} \mathrm{~m}^{-2}$ in July 1994, it can be 
seen that $F_{\mathrm{r}}$ in 1994 probably did not exceed $6800 \mathrm{~g} \mathrm{CO}_{2} \mathrm{~m}^{-2}$. The annual respiratory $\mathrm{CO}_{2}$ flux relative to the annual assimilatory $\mathrm{CO}_{2}$ flux amounted to $1.12-1.14 \mathrm{~g} \mathrm{CO}_{2}$ $\mathrm{g}^{-1} \mathrm{CO}_{2}$, which indicates that biomass was the most important factor in the difference between both annual $F_{\mathrm{r}}$ values. The annual respiratory activity outside the grassland ecosystem associated with dairy produce of approximately $200 \mathrm{~g} \mathrm{CO}_{2} \mathrm{~m}^{-2}$ does not greatly affect the annual respiratory $\mathrm{CO}_{2}$ flux or the ratio between respiratory and assimilatory $\mathrm{CO}_{2}$ flux. Gilmanov et al. (2007) derived annual $F_{\mathrm{r}}$ values of $3450-5620 \mathrm{~g} \mathrm{CO}_{2} \mathrm{~m}^{-2}$ for multiple intensively managed grasslands throughout Europe and found a strong positive correlation between assimilatory and respiratory $\mathrm{CO}_{2}$ flux. In their measurement of the $\mathrm{CO}_{2}$ fluxes in the drained peat grassland ecosystem of this study Jacobs et al. (2007) found annual $F_{\mathrm{r}}$ values between 2002 and 2005 to range from approximately 4900 to $6200 \mathrm{~g}$ $\mathrm{CO}_{2} \mathrm{~m}^{-2}$. Their measurements indicate an annual relative respiratory $\mathrm{CO}_{2}$ flux ranging from 0.90 to $1.11 \mathrm{~g} \mathrm{CO}_{2} \mathrm{~g}^{-1} \mathrm{CO}_{2}$. A relative respiratory $\mathrm{CO}_{2}$ flux of $0.90 \mathrm{~g} \mathrm{CO}_{2} \mathrm{~g}^{-1} \mathrm{CO}_{2}$ - the assimilatory $\mathrm{CO}_{2}$ flux unusually exceeding the respiratory $\mathrm{CO}_{2}$ flux - was observed in 2005 as the assimilatory $\mathrm{CO}_{2}$ flux increased sharply from its lows in 2003 and 2004 and the increase in the respiratory $\mathrm{CO}_{2}$ flux lagged behind. Where we observed an annual pattern of the respiratory $\mathrm{CO}_{2}$ flux trailing behind the assimilatory $\mathrm{CO}_{2}$ flux - reflected in the hysteresis in the response of former to the latter - the data provided by Jacobs et al. (2007) suggest that a similar pattern can be seen across years. Annual assimilatory activity follows environmental conditions instantly, whereas respiratory activity as a consequence of the decomposition of assimilated organic matter trails behind. It seems almost by coincidence to be the unusual wetter pattern in the 2002-2005 period which allowed this observation. This effect across multiple years is somewhat reminiscent of the observations done by Ma et al. (2007) where abundant litter from one year caused a late start of the growing season in the next year, thereby temporarily switching the ecosystem between exhibiting $\mathrm{CO}_{2}$ sink and $\mathrm{CO}_{2}$ source behaviour. Veenendaal et al. (2007) measured annual $F_{\mathrm{r}}$ values of 5650 and $5850 \mathrm{~g} \mathrm{CO}_{2} \mathrm{~m}^{-2}$ and relative respiratory $\mathrm{CO}_{2}$ fluxes of 1.00 and $1.09 \mathrm{~g} \mathrm{CO}_{2} \mathrm{~g}^{-1} \mathrm{CO}_{2}$ in an extensively and intensively managed peat grassland respectively. The relative respiratory $\mathrm{CO}_{2}$ fluxes in this study and the studies by Jacobs et al. (2007) and Veenendaal et al. (2007) show that the respiratory activity in intensively managed peat grasslands leans towards exceeding the assimilatory activity, but also that individual years may distort this tendency as a result of an unusually low or high assimilatory activity in the preceding year.

\subsubsection{Net $\mathrm{CO}_{2}$ flux}

Ecosystems with undisturbed root zones - both on non-organic soils and undrained organic soils - tend to exhibit net $\mathrm{CO}_{2}$ sink behaviour as sequestered $\mathrm{C}$ decomposes increasingly slowly (Ågren \& Bosatta 1998, Janssen 1984). Disturbance of the root zone as a result of increased aeration or fertilisation can increase the decomposition rate of soil organic matter relative to the net primary productivity. C sequestration in grasslands 
can be relatively high as the biome is characterised by low physiological maintenance requirements, a high allocation of biomass to the root system which is more resistant to decomposition than the shoot and particular qualities of its soil organic matter (Jones \& Donnelly 2004). In a grassland ecosystem on an alluvial clay soil approximately $50 \mathrm{~km}$ east of the site in this study Jacobs et al. (2007) measured an annual $\mathrm{CO}_{2}$ sequestration of $763 \mathrm{~g} \mathrm{CO}_{2} \mathrm{~m}^{-2}$ averaged over 4 successive years, which equalled $14 \%$ of the annual gross assimilatory $\mathrm{CO}_{2}$ flux. Hirata et al. (2013) measured net $\mathrm{CO}_{2}$ exchange rates in intensively managed mown grasslands on volcanic soils across Japan and arrived at annual net $\mathrm{CO}_{2}$ sequestration rates ranging from 172 to $1621 \mathrm{~g} \mathrm{CO}_{2} \mathrm{~m}^{-2}$ (equating $4-24 \%$ of the annual gross assimilatory $\mathrm{CO}_{2}$ flux). However, in their study harvested biomass exceeded this difference between assimilatory and respiratory $\mathrm{CO}_{2}$ flux and after accounting for $\mathrm{C}$ removal all sites exhibited an annual net $\mathrm{CO}_{2}$ release, even if $25 \%$ of the removed biomass were to be retained as manure (Langeveld et al. 1997). This $\mathrm{CO}_{2}$ release may be the consequence of a disturbance of the root zone by increased levels of fertilisation during the multi-year experiment, which appears to be reflected in a steady decrease in soil organic matter content. The experiment by Hirata et al. (2013) may thus have interfered with longer-term $\mathrm{CO}_{2}$ exchange patterns.

Grasslands on organic soils are characterised by more complex $\mathrm{CO}_{2}$ exchange patterns than grasslands on non-organic soils, depending on the level of drainage. On undrained organic soils productivity tends to be low as a result of low soil fertility, low soil temperature and anaerobic conditions in the root zone. However, as senesced biomass in the anaerobic soil profile is largely protected from decomposition these ecosystems can sequester much of their net primary production, a process which typifies many wetlands. Partial drainage results in a net $\mathrm{CO}_{2}$ release once the decomposition of the drained organic soil starts exceeding the sequestration elsewhere in the grassland system (Beetz et al. 2013). The drained peat grassland ecosystem in this study exhibited a ratio of the annual respiratory to assimilatory $\mathrm{CO}_{2}$ flux of 1.12-1.14 $\mathrm{g} \mathrm{CO}_{2} \mathrm{~g}^{-1} \mathrm{CO}_{2}$. This shows that the ecosystem was an annual net $\mathrm{CO}_{2}$ source. On distinguishing between the grassland ecosystem and the drained organic soil profile, the annual net $\mathrm{CO}_{2}$ release of 623 to $920 \mathrm{~g}$ $\mathrm{CO}_{2} \mathrm{~m}^{-2}$ represents the lower boundary of decomposition of organic matter in the drained organic soil profile. The ratio of annual respiratory to assimilatory $\mathrm{CO}_{2}$ flux increases to 1.17 when accounting for an annual $\mathrm{C}$ removal through dairy produce of $200 \mathrm{~g} \mathrm{CO}_{2}$. Over centuries many grasslands on organic soils have been subject to increasing levels of drainage to enhance productivity. Veenendaal et al. (2007) found nearly balanced annual assimilatory and respiratory $\mathrm{CO}_{2}$ fluxes in an extensively managed peat grassland and an annual net $\mathrm{CO}_{2}$ release of $493 \mathrm{~g} \mathrm{CO}_{2} \mathrm{~m}^{-2}$ in an intensively managed peat grassland, the latter of which the result of the decomposition of peat in the aerobic soil profile. The drained peat grassland system at site Cabauw in this study showed an annual net $\mathrm{CO}_{2}$ release of $920 \mathrm{~g} \mathrm{CO}_{2} \mathrm{~m}^{-2}$ in 1993 (12 months) and $623 \mathrm{~g} \mathrm{CO}_{2} \mathrm{~m}^{-2}$ in 1994 (11 months). 
This net release amounted to $11-12 \%$ of the total respiratory $\mathrm{CO}_{2}$ flux, which in turn corresponded to $22-32 \%$ of the observed annual subsidence of the peat soil. Minor fluctuations in the ratio between respiratory and assimilatory $\mathrm{CO}_{2}$ flux can have large consequences for the net $\mathrm{CO}_{2}$ exchange. Whereas Jacobs et al. (2007) measured an average annual net $\mathrm{CO}_{2}$ release of $29 \mathrm{~g} \mathrm{CO}_{2} \mathrm{~m}^{-2}$ at the same site from 2002 to 2005 , the annual values varied from a net $\mathrm{CO}_{2}$ release to a net $\mathrm{CO}_{2}$ sequestration of both $620 \mathrm{~g} \mathrm{CO}_{2} \mathrm{~m}^{-2}$.

Although in the drained peat grassland ecosystem the respiratory $\mathrm{CO}_{2}$ flux responded strongly to the assimilatory $\mathrm{CO}_{2}$ flux, the fluxes' dependencies on irradiance, temperature and air humidity caused the ratio between both $\mathrm{CO}_{2}$ flux components to vary. The monthly net $\mathrm{CO}_{2}$ exchange $\left(F_{\mathrm{n}}\right)$ itself could to a large extent $\left(r^{2}=0.70\right)$ be explained by monthly average air temperature $\left(T_{\mathrm{a}}\right)$ and the monthly assimilatory $\mathrm{CO}_{2}$ flux $\left(F_{\mathrm{a}}\right)$. The effect of $T_{\mathrm{a}}$ on $F_{\mathrm{n}}$ is multifold. The ecosystem responds to a composite temperature of which $T_{\mathrm{a}}$ is only an approximation. Depending on atmospheric conditions and surface characteristics canopy temperature can be higher than $T_{\mathrm{a}}$. Soil temperature follows $T_{\mathrm{a}}$ with delay, more so with increasing depth and water content. $T_{\mathrm{a}}$ has a positive effect on both the respiratory and the assimilatory $\mathrm{CO}_{2}$ flux, but $F_{\mathrm{n}}$ tended towards a $\mathrm{CO}_{2}$ release with increasing temperatures. This shows that the effect of $T_{\mathrm{a}}$ on the respiratory $\mathrm{CO}_{2}$ flux exceeded the effect on the assimilatory $\mathrm{CO}_{2}$ flux. In the average response of $F_{\mathrm{n}}$ to the assimilatory $\mathrm{CO}_{2}$ flux, higher $F_{\mathrm{a}}$ resulted in an $F_{\mathrm{n}}$ which tended towards $\mathrm{CO}_{2}$ sequestration. A higher primary productivity thus leads the ecosystem to sequester more $\mathrm{CO}_{2}$. In the drained peat grassland ecosystem in this study this pattern results in a shift in the ratio between monthly $F_{\mathrm{r}}$ and $F_{\mathrm{a}}$ towards $F_{\mathrm{a}}$ resulting a lower net $\mathrm{CO}_{2}$ release.

The intra-annual course of $F_{\mathrm{n}}$ was characterised by an ambiguous pattern, reflected in the hysteresis in the response of the respiratory to the assimilatory $\mathrm{CO}_{2}$ flux. In the course of the season the respiratory $\mathrm{CO}_{2}$ flux increased substantially relative to the assimilatory $\mathrm{CO}_{2}$ flux. A deeper aerobic soil profile exposing more soil organic matter to conditions conducive to decomposition may have contributed to this relative increase of the respiratory $\mathrm{CO}_{2}$ flux (Kechavarzi et al. 2007). However, this would only explain part of the relative increase as it was noted that the decomposition of the peat soil in the aerobic soil profile amounted to approximately $11-12 \%$ of the total respiratory $\mathrm{CO}_{2}$ flux. It can be seen that the seasonal increase of the respiratory relative to the assimilatory $\mathrm{CO}_{2}$ flux was an instant consequence of increased air and soil temperatures, but also of an increasing amount of litter originating from preceding growth. It illustrates how the net $\mathrm{CO}_{2}$ exchange in a particular time interval is affected by the primary productivity in preceding time intervals. A pattern where the primary productivity affects subsequent $\mathrm{CO}_{2}$ exchange patterns can even be observed at an inter-annual time scale as data provided by Jacobs et al. (2007) and Ma et al. (2007) suggest. A growing season with a decidedly low or high primary productivity can tip the balance of net $\mathrm{CO}_{2}$ exchange in the following 
season. Although such deviations from longer-term exchange patterns are only temporary, $\mathrm{CO}_{2}$ flux measurements surrounding such an event may provide a distorted image of more average net $\mathrm{CO}_{2}$ exchange values. As primary productivity varies substantially among years, this effect should even occur without actually changing the direction of the net $\mathrm{CO}_{2}$ exchange. It is thus conceivable that in the longer run a meta $\mathrm{CO}_{2}$ exchange pattern could emerge converging from highly variable annual net $\mathrm{CO}_{2}$ exchange values.

The drained peat grassland ecosystem in this study was characterised by two successive years of net $\mathrm{CO}_{2}$ emissions, a pattern which can often be observed in grasslands on drained organic soils in general (Beetz et al. 2013, Hooijer et al. 2010, Jacobs et al. 2007, Veenendaal et al. 2007). However, this study also demonstrates that this ecosystem's $\mathrm{CO}_{2}$ exchange patterns followed the same logic as grasslands on non-organic soils, where $\mathrm{CO}_{2}$ sequestration increases with primary productivity and decreases with temperature. The decomposition of organic matter in the aerobic soil profile largely represents an additional respiratory $\mathrm{CO}_{2}$ flux component, which could thus be mitigated by reducing the depth of the groundwater table. 


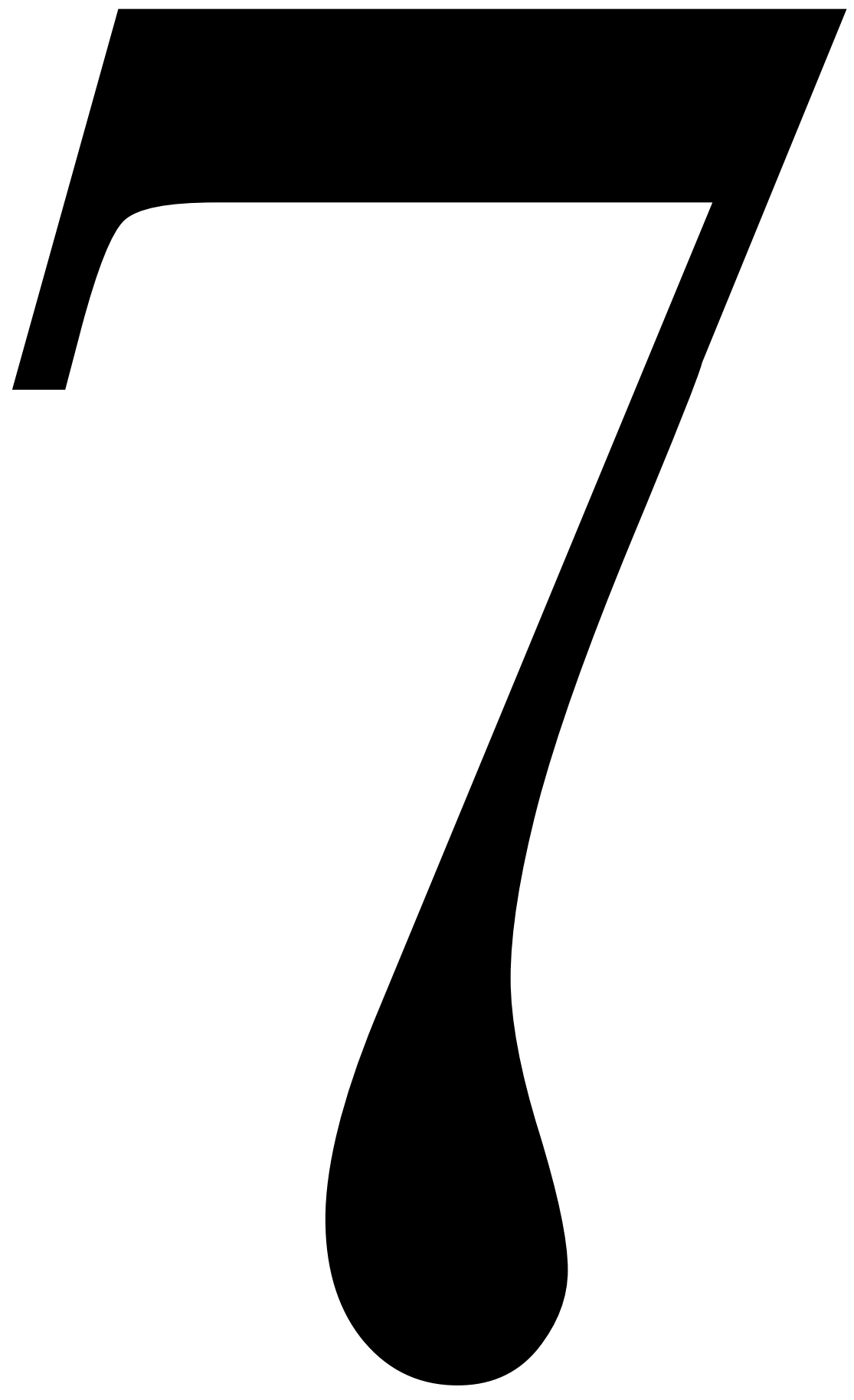


Chapter 7

General discussion 


\subsection{A PERSPECTIVE}

This thesis demonstrates how an annual net $\mathrm{CO}_{2}$ exchange in a grassland can emerge from its components, with emphasis on a drained peat grassland ecosystem. Global ecosystem net $\mathrm{CO}_{2}$ exchange lies at the heart of the observation that the atmospheric $\mathrm{CO}_{2}$ concentration does not increase as fast as could be expected on basis of anthropogenic $\mathrm{CO}_{2}$ emissions. On average the increase equates approximately $50 \%$ of the annual emissions, although the percentage varies strongly among years. The difference between $\mathrm{CO}_{2}$ emissions and atmospheric $\mathrm{CO}_{2}$ points to the existence of a substantial global net $\mathrm{CO}_{2}$ sink, sequestering approximately $3 \mathrm{Gt} \mathrm{C}$ annually. Whereas the contribution of tropical rainforests is ambiguous, a strong terrestrial $\mathrm{C}$ sink has been identified in the temperate latitudes of the Northern Hemisphere. Temperate forests have been considered to be an important factor in this net $\mathrm{CO}_{2}$ sequestration, not in the least because of their volume of aboveground biomass. However, grasslands have equally been proposed to significantly contribute to this net $\mathrm{CO}_{2}$ sink. Grasslands are characterised by relatively low metabolic maintenance requirements and a high fraction of root biomass. As root litter decomposes more slowly than shoot litter (Freschet et al. 2013), this favours its relative accumulation in the soil profile. It has been shown that structure and size distribution of organic soil aggregates in grasslands play an important role in this stable soil C pool (Jones \& Donnelly 2004). Grassland ecosystems thus keep their C largely belowground and volumes of soil organic matter are relatively high as compared to other biomes (Dass et al. 2018, Ojima et al. 1993, Schlesinger \& Bernhardt 2013). Grasslands on organic soils constitute a special case as their soil profiles are partially anaerobic and thus characterised by particularly low decomposition rates. Many grasslands on organic soils or peat grasslands have been subject to varying degrees of drainage. The $\mathrm{C}$ flow in these drained peat grasslands is more complex than in grasslands on mineral soils as any $\mathrm{C}$ sequestration in the anaerobic part of the soil profile is now complemented by the decomposition of organic matter in the aerobic part of the soil profile. This makes the $\mathrm{C}$ balance in a peat grassland the most complex but to some extent process-wise also the most generic in grasslands. The $\mathrm{C}$ balance processes in grasslands on organic soils bear resemblance to processes in wetlands in general. Whereas undisturbed ecosystems tend towards a net $\mathrm{CO}_{2}$ sequestration, drainage of a soil profile rich in organic matter often results in a net $\mathrm{CO}_{2}$ release.

This thesis aims to analyse the dynamics of the atmospheric-biospheric $\mathrm{CO}_{2}$ exchange in peat grasslands and how its constituent processes converge into an annual net $\mathrm{CO}_{2}$ exchange. It subsequently uses the processes to consider the role of grasslands in the global C cycle. This study considers successive levels of system aggregation, in which processes at one level help explain processes at a higher level. An understanding of how process dynamics at one level of aggregation emerge from the process dynamics at lower 


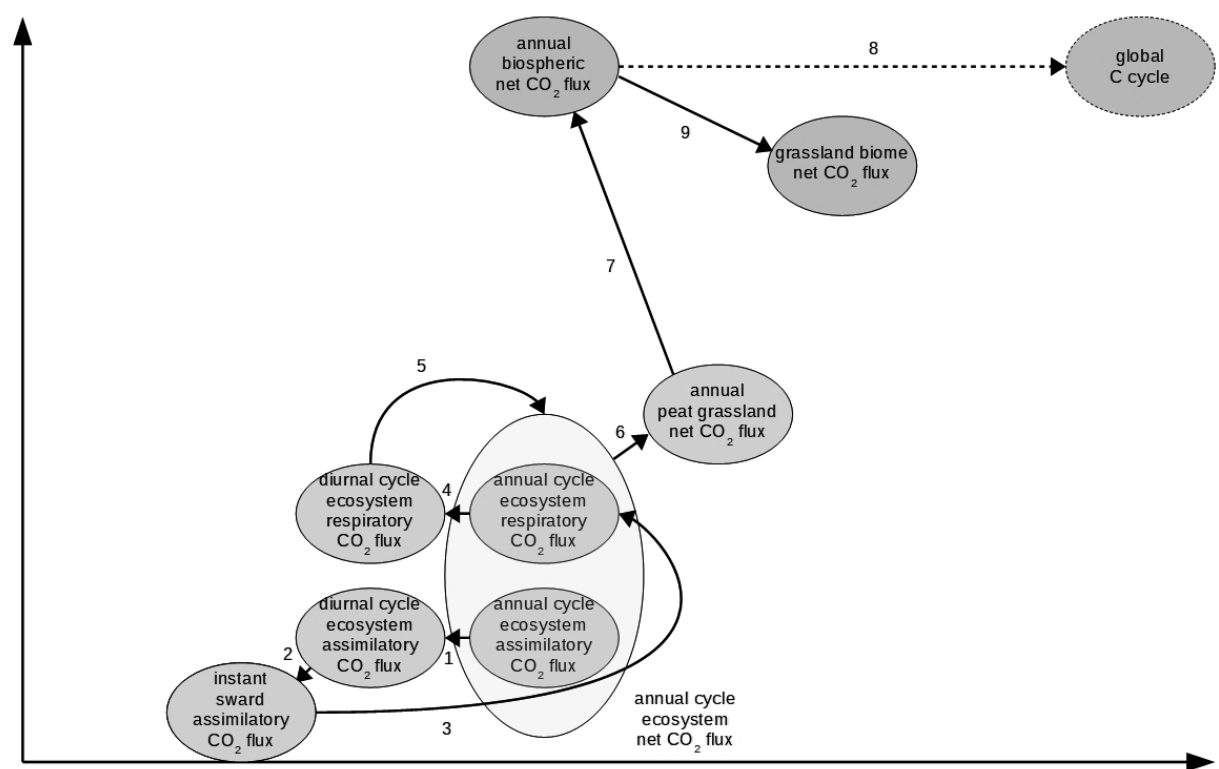

Figure 7.1. The general discussion navigates through a sequence of processes at increasing levels of aggregation in space and time. The first half follows the course of the processes analysed in the preceding chapters. It discusses how the annual cycle of the assimilatory and respiratory processes emerges from diurnal and instant patterns (1-4). It then shows how the annual cycle of ecosystem net $\mathrm{CO}_{2}$ exchange as such is explained from its constituent processes (5). It discusses the annual $\mathrm{CO}_{2}$ exchange in grasslands on organic soils (6). It subsequently looks to which extent annual and long-term patterns of atmospheric-biospheric $\mathrm{CO}_{2}$ exchange may be explained by annual ecosystem patterns (7-8). It concludes with a discussion of the potential role of the grassland biome in these annual patterns of atmospheric-biospheric $\mathrm{CO}_{2}$ exchange (9).

levels of aggregation supports assertions about system behaviour at higher levels of aggregation. Figure 7.1 summarises the structure of this discussion and how it navigates its way up through dimensions of space and time. After a reflection on the used research methodologies (Section 7.2), it continues with the differentiation between the ecosystem's gross assimilatory and respiratory $\mathrm{CO}_{2}$ fluxes (Section 7.3), which represent its processes of $\mathrm{CO}_{2}$ absorption and $\mathrm{CO}_{2}$ release. It discusses how the annual cycle of ecosystem assimilatory $\mathrm{CO}_{2}$ exchange is the aggregated result of the measured diurnal cycle of ecosystem assimilatory $\mathrm{CO}_{2}$ exchange. The diurnal cycle of the ecosystem assimilatory $\mathrm{CO}_{2}$ exchange in turn follows from the processes of photosynthetic activity in the grass sward. It is subsequently discussed how the annual cycle of the ecosystem respiratory $\mathrm{CO}_{2}$ exchange aggregates from the measured diurnal cycle of ecosystem respiratory $\mathrm{CO}_{2}$ exchange. It is discussed how the annual cycles of assimilatory and respiratory $\mathrm{CO}_{2}$ exchange result in an annual cycle of ecosystem net $\mathrm{CO}_{2}$ exchange, which determines the 
ecosystem's annual $\mathrm{CO}_{2}$ balance. Based on general process insights and the measurements in the various peat grassland ecosystems in this study it is then discussed which effect various drainage levels could have on the $\mathrm{CO}_{2}$ balance in grasslands on organic soils (Section 7.4). The processes underlying ecosystem net $\mathrm{CO}_{2}$ exchange are then used to match annual patterns observed in the global atmospheric $\mathrm{CO}_{2}$ concentration and to explore whether annual biospheric net $\mathrm{CO}_{2}$ exchange could explain part of these patterns (Section 7.5). It follows a qualitative exploration of a role for the grasslands in the biospheric net $\mathrm{C}$ sequestration based on identified processes while progressing through the successive levels of aggregation (Section 7.6). It concludes with a brief speculation on the role of biospheric $\mathrm{C}$ storage in the $\mathrm{C}$ cycle (Section 7.7).

The characterisation of the ecosystem's annual net $\mathrm{CO}_{2}$ flux requires the analysis of the mass and energy fluxes at the appropriate temporal and spatial resolutions. All $\mathrm{CO}_{2}$ flux measurements - the ecosystem's instantaneous net $\mathrm{CO}_{2}$ exchanges - done in a single year can be added to arrive at the ecosystem's annual net $\mathrm{CO}_{2}$ flux. However, the annual $\mathrm{CO}_{2}$ flux obtained this way can be distorted as it easily incorporates a weather bias, a phenomenon which was demonstrated in the analysis of the ecosystem's $\mathrm{CO}_{2}$ fluxes in Chapter 6. An over-representation of measurements done under weather conditions conducive to growth could overestimate the ecosystem's actual $\mathrm{CO}_{2}$ sequestration. Even in a homogeneous distribution of incident wind angles and flux measurements, an annual net $\mathrm{CO}_{2}$ exchange calculated directly from the instantaneous measurements is a number for that particular year but fails to characterise the ecosystem's net $\mathrm{CO}_{2}$ flux. The net $\mathrm{CO}_{2}$ flux is therefore instead to be analysed as the result of the discrepancy between both ecosystem $\mathrm{CO}_{2}$ flux components and their dependence on environmental factors.

\subsection{REFLECTION ON THE RESEARCH METHODOLOGY}

\subsubsection{Measurement methodologies}

Measurements of ecosystem net $\mathrm{CO}_{2}$ exchange are generally done using either micrometeorological methods (e.g. Ammann et al. 2020, Heimsch et al. 2020, Zeeman et al. 2010) or closed chambers (e.g. Hoffmann et al. 2015, Spielmann et al. 2020, Weideveld et al. 2020).

The closed chamber has the advantage of being a less costly and less complex experimental setup than micrometeorological measurement and measuring a well defined (if small) ecosystem surface area. Its disadvantages are in a difficult interpretation of the measurement data (Kutzbach et al. 2007, Pavelka et al. 2018, Zhao et al. 2018), a potential overestimation of fluxes during conditions of low atmospheric turbulence (Schneider et al. 2009) and the non-representative character of measurement plots relative 
to the entire ecosystem (Rochette et al. 1997, Waldo et al. 2019). Particularly grasslands on drained peat soils are characterised by a large and complex spatial heterogeneity, such as the interaction between distance to drainage ditches, lateral conductivity and weather conditions. Such ecosystems require a careful selection of closed chamber measurement locations (Weideveld et al. 2020) and even then it remains difficult to scale the measurements.

Micrometeorological measurement methods have the advantage of a much larger footprint (or fetch) than closed chambers, thereby integrating ecosystem surface heterogeneity. In addition, micrometeorological methods avoid interference with the boundary layer, which may distort fluxes under conditions of low turbulence. The aerodynamic method relies on the relations between fluxes and gradients of momentum, heat, water vapour and gas under conditions of neutral stability, whereas the eddy covariance method is based on the covariance between fluctuating components of vertical wind and gas concentration (Monteith \& Unsworth 1990). The Netherlands Energy Research Foundation (ECN) applied both techniques in this study, for the experimental setups at Cabauw and Zegveld, respectively (Hensen et al. 1997). The use of the eddy covariance method has gradually overtaken the use of the aerodynamic method in a strive for homogeneity in methodology in measuring ecosystem $\mathrm{CO}_{2}$ exchange (Baldocchi 2003, Baldocchi 2020, Loubet et al. 2013, Meyers \& Baldocchi 2005) and because it is often considered to require fewer assumptions about the structure of the boundary layer. The aerodynamic method has nevertheless retained its applicability in uniform stands of level vegetation (Monteith \& Unsworth 1990) and the measurement of trace gas fluxes (Kamp et al. 2020, Meredith et al. 2014). In comparing $\mathrm{O}_{3}$ fluxes over grassland using both techniques, Muller $e$ a al. (2009) found the aerodynamic gradient and eddy covariance techniques to return similar results. Zhao et al. (2019) came to the same conclusion while comparing $\mathrm{CO}_{2}$ fluxes over small ponds using eddy covariance and several flux gradient techniques.

Analysis of the aerodynamic gradient measurements done at site Cabauw (Hensen et al. 1997) shows a distinct response of the respiratory and assimilatory $\mathrm{CO}_{2}$ flux components to primary environmental factors, both at shorter and longer time scales. Mediating effects of secondary environmental factors at various time scales were clearly observed and assigned. Instant and aggregated $\mathrm{CO}_{2}$ flux values were in the order of magnitude as observed in other studies. Whereas the eddy covariance $\mathrm{CO}_{2}$ flux measurements at site Zegveld were limited to a single growing season, the $\mathrm{CO}_{2}$ flux responses to primary and secondary environmental factors were comparable to those at site Cabauw. These observations and the agreement in the order of magnitude of the $\mathrm{CO}_{2}$ fluxes in this and other studies add to the confidence in the measurements, their treatment and their compliance with more recent studies. This is demonstrated in detail in Chapters 3 to 6 and their addenda in Appendix A, and is further discussed in the following paragraphs. 
Both micrometeorological measurement approaches make assumptions about the boundary layer and have remained open to improvement in technique and data interpretation (Luyssaert al. 2009, Meredith et al. 2014). At the time of the research the aerodynamic gradient technique as applied here by ECN at site Cabauw qualified as state-of-the-art. Whereas the eddy covariance technique has grown into the de facto standard for measuring $\mathrm{CO}_{2}$ fluxes in a wide range of ecosystems, the aerodynamic gradient technique still finds application in flux studies, albeit less so for $\mathrm{CO}_{2}$ exchange (Kamp et al. 2020, Laubach et al. 2016, Waldo et al. 2019, Zhao et al. 2019).

\subsubsection{Statistical analysis and process-based modelling}

The argument of this thesis revolves around the processes which constitute the net $\mathrm{CO}_{2}$ exchange in this particular grassland ecosystem through successive levels of aggregation. It attempts to illustrate how processes at one level of aggregation on a certain scale in space and time can be explained on basis of processes at lower levels of aggregation. This is also topic of discussion in Section 7.3. Chapter 6 also calculates and discusses the ecosystem's annual net $\mathrm{CO}_{2}$ exchange, however emphasises its potentially large inter-annual variation over a statistical treatment of the net $\mathrm{CO}_{2}$ exchange value as such. Monthly values of $\mathrm{CO}_{2}$ fluxes and environmental factors were limited to those time intervals with actual measurements, implicitly applying simple extrapolation as a gap-filling technique for the calculation of the annual net $\mathrm{CO}_{2}$ exchange. For the processes as such this plays much less a role as it does not affect the response of a $\mathrm{CO}_{2}$ flux component to an environmental factor. Görres et al. (2014) illustrate the difficulty in identifying a gap-filling technique by showing how equally suitable models result in clearly different values of ecosystem net $\mathrm{CO}_{2}$ exchange. Luo and Schuur (2020) point at the general necessity to account for system characteristics changing in time and with environmental conditions, even in analytical approaches with more detail.

Statistical analysis was applied in those cases where differences between treatments were investigated (the in vivo experimentation in Chapter 2) and where the difference in the ecosystem respiratory $\mathrm{CO}_{2}$ flux between drainage levels was assessed (addendum to Chapter 5 in Appendix A). Yet, interpretation of statistical analyses in such complex systems can at times be cumbersome, while it can also be limited in causality and explanatory power. Jones et al. (2017) measured net $\mathrm{CO}_{2}$ exchange in an intensively managed grassland on mineral soil during 9 consecutive years. The average annual net $\mathrm{CO}_{2}$ sequestration of $799 \mathrm{~g} \mathrm{CO}_{2} \mathrm{~m}^{-2} \mathrm{y}^{-1}$ was characterised by a large inter-annual variation (reflected in its confidence interval of $568 \mathrm{~g} \mathrm{CO}_{2} \mathrm{~m}^{-2} \mathrm{y}^{-1}$ ) but nevertheless significant. The cause for this variation is of particular interest as the time series shows how unrepresentative singular values of ecosystem annual net $\mathrm{CO}_{2}$ exchange can be but would also allow for the identification of the most important drivers for this inter-annual variation (Piao et al. 2019). After correcting for lateral C flows to and from the system the 
average annual net $\mathrm{CO}_{2}$ sequestration decreased to $598 \mathrm{~g} \mathrm{CO}_{2} \mathrm{~m}^{-2} \mathrm{y}^{-1}$ but was stopped from being significant. However, it could be argued that this is a problematic conclusion as the ecosystem was clearly exhibiting a $\mathrm{CO}_{2}$ sequestration, however obscured by factors unaccounted for.

A similar dilemma can be found in the interpretation of the difference in the ecosystem respiratory $\mathrm{CO}_{2}$ flux between two drainage levels at site Zegveld in this study (addendum to Chapter 5 in Appendix A). Although this difference was not significant, the $\mathrm{CO}_{2}$ flux values found complied with the difference in drainage level and the $\mathrm{CO}_{2}$ flux values measured at site Cabauw. The minor fraction of the $\mathrm{CO}_{2}$ flux related to the decomposition of organic soil in the total ecosystem respiratory $\mathrm{CO}_{2}$ flux (in the order of magnitude of $5-10 \%)$ may have contributed to the difficulty in identifying statistically significant differences. Weideveld et al. (2020) measured a similar difference in respiratory $\mathrm{CO}_{2}$ flux between two drainage levels in a drained peat grassland. They equally had to conclude that there was no statistically significant difference in $\mathrm{CO}_{2}$ flux between both drainage levels, possibly related to the very same high background ecosystem respiratory $\mathrm{CO}_{2}$ flux. These cases seem to indicate too that in the case of more complex systems with multiple interacting factors it may not necessarily be enough to stop at differences which are not statistically significant.

The approach in this thesis emphasises mechanistic explanation on basis of constituent processes over statistical characterisation. It seeks to explore why an annual $\mathrm{CO}_{2}$ balance attains a certain value and how it differs among years. Without explicit consideration of ecosystem processes, $\mathrm{CO}_{2}$ flux studies may be at risk to remain isolated in space and time, although recent exceptions in scope have emerged (Moreaux et al. 2020). It cannot provide a definitive answer, but chooses a path which allows for a meaningful inter-annual comparison and which constitutes a basis for a more numerical approach in understanding causality in systems behaviour.

\subsection{PROCESSES IN CYCLES OF ECOSYSTEM CO EXCHANGE}

\subsubsection{Assimilatory $\mathrm{CO}_{2}$ exchange}

Chapter 6 shows that the ecosystem assimilatory $\mathrm{CO}_{2}$ flux in this study primarily responded to irradiance. In the annual cycle and under conditions non-limiting to growth, the monthly gross assimilatory $\mathrm{CO}_{2}$ flux responded linearly to monthly irradiance at 2.20 $\mathrm{g} \mathrm{CO}_{2} \mathrm{MJ}^{-1}$. Whereas the instant assimilatory $\mathrm{CO}_{2}$ flux in the diurnal cycle exhibited an asymptotic response to irradiance, no light saturation was observed at the aggregated level in the annual cycle. Straightforward calculations applying the diurnal course of 
solar irradiance (Goudriaan \& Van Laar 1994) and a constant asymptotic response of the instant assimilatory $\mathrm{CO}_{2}$ flux to irradiance show that the linear aggregated response can be largely explained by the distribution of irradiance over longer daylength as levels of irradiance increase. The midday saturation of the assimilatory response is compensated for by longer periods where there is less light saturation. The linearity of the aggregated response emerging from the calculations is affected neither by latitude (i.e. the course of the daylength and solar irradiance) nor by the exact characteristics of the instant asymptotic response. The analysis of the instant assimilatory $\mathrm{CO}_{2}$ flux in Chapter three identified an increase in ecosystem assimilatory capacity towards late spring and summer. However, the same calculation shows that this increase contributed only modestly to the dominating pattern of a linear response of the monthly assimilatory $\mathrm{CO}_{2}$ flux to monthly irradiance.

Chapter 3 shows that the instant ecosystem gross assimilatory $\mathrm{CO}_{2}$ flux at sites Cabauw and Zegveld in 1993 and 1994 at a shortwave irradiance of $350 \mathrm{~W} \mathrm{~m}^{-2}$ amounted to 0.41 $0.87 \mathrm{mg} \mathrm{CO}_{2} \mathrm{~m}^{-2} \mathrm{~s}^{-1}$ in summer and $0.58-0.94 \mathrm{mg} \mathrm{CO}_{2} \mathrm{~m}^{-2} \mathrm{~s}^{-1}$ in autumn. Low ecosystem assimilatory rates in summer were associated with conditions of drought in August 1994. On converting the in vivo sward measurement values from 1995 provided in Chapter 2 at a photosynthetically active radiation equivalence of $4.57 \mu \mathrm{mol} \mathrm{J}^{-1}$ (Jones 1992) and a shortwave irradiance of $350 \mathrm{~W} \mathrm{~m}^{-2}$, the leaf photosynthetic rates were $0.46-0.53 \mathrm{mg} \mathrm{CO}_{2}$ $\mathrm{m}^{-2} \mathrm{~s}^{-1}$ in summer and $0.37-0.46 \mathrm{mg} \mathrm{CO}_{2} \mathrm{~m}^{-2} \mathrm{~s}^{-1}$ in autumn. This shows that the canopy gross assimilatory $\mathrm{CO}_{2}$ flux at a shortwave irradiance of $350 \mathrm{~W} \mathrm{~m}^{-2}$ was $80-100 \%$ higher than the leaf gross photosynthetic rate. Successive levels of detail in assimilatory activity thus aggregate across space and time. The instant asymptotic response of leaf assimilatory activity to irradiance in Chapter 2 translates into a similarly instant asymptotic response of ecosystem assimilatory activity in Chapter 3, which is approximately twice as high. The instant asymptotic ecosystem response to irradiance subsequently aggregates to a linear response on an annual scale in Chapter 6 as more irradiance coincides with longer daylength and therefore longer periods of sustained photosynthetic activity.

The primary response of the assimilatory $\mathrm{CO}_{2}$ flux to radiation was limited by both low temperature and conditions of drought. Chapter 6 shows for the annual cycle of the assimilatory $\mathrm{CO}_{2}$ flux that months having an average air temperature below $10^{\circ} \mathrm{C}$ were characterised by an irradiance use efficiency below its maximum of $2.20 \mathrm{~g} \mathrm{CO}_{2} \mathrm{MJ}^{-1}$. The response of the instantaneous ecosystem assimilatory $\mathrm{CO}_{2}$ flux in Chapter 3 was equally limited by low temperature, as the inclusion of a linear effect of temperature in the hyperbolic response of the assimilatory $\mathrm{CO}_{2}$ flux to irradiance generally resulted in a clear increase in the initial radiation use efficiency $\varepsilon$. The simultaneous decrease in the asymptotic value of the assimilatory $\mathrm{CO}_{2}$ flux was the result of the modification of the curve's initial slope and largely apparent as its value was rarely actually attained. The 
instantaneous ecosystem $\mathrm{CO}_{2}$ flux measurements show that limiting temperatures at low irradiance occurred throughout much of the growing season. For the characterisation of the instantaneous response of the assimilatory $\mathrm{CO}_{2}$ flux to irradiance the limiting effect of temperature appears to be relevant as it greatly affects the shape of the response curve. However, the annual cycle of $\mathrm{CO}_{2}$ exchange shows that its effect on the annual gross assimilatory $\mathrm{CO}_{2}$ flux was modest as low temperature is generally associated with low irradiance. This pattern is not symmetrical in time, i.e. effects of low temperature will be most pronounced early in both diurnal and annual cycles. This asymmetry is reflected in the hysteresis in the response of assimilatory activity to irradiance. A negative effect of increasing temperature, particularly on the initial radiation use efficiency and to a lesser extent on the asymptotic value of the response curve, was shown in Chapter 2 in the in vivo measurements of the response of leaf photosynthetic activity to irradiance in a grass sward. However, the applied temperatures in the in vivo experiment exceeded the temperatures generally observed in situ in the earlier part of the diurnal cycles in Chapter 3. Both observations indicate that the grassland ecosystem's assimilatory activity is subject to a temperature optimum. The effect of low temperature is discernible in its limiting effect on the initial radiation efficiency in the ecosystem's assimilatory $\mathrm{CO}_{2}$ flux where it coincides with low irradiance. The effect of high temperature observed in leaf photosynthetic activity is less apparent in the ecosystem assimilatory $\mathrm{CO}_{2}$ flux as it is associated with higher irradiance and therefore less with the initial slope of the response curve. To some extent, a negative effect of high temperature on assimilatory activity may be implicit in the slope of the linear response of the monthly assimilatory $\mathrm{CO}_{2}$ flux to monthly irradiance.

Alternatively, a negative effect of high temperature may be confounded with the observed effect of drought. Woledge et al. (1989) even suggested that it may be drought which obscures a sustained positive effect of temperature on photosynthetic activity in grass swards. However, comparison of the effect of temperature and drought on the assimilatory $\mathrm{CO}_{2}$ flux in Chapter 6 shows that the effect of drought as such was real. The annual cycle of assimilatory $\mathrm{CO}_{2}$ exchange showed a clear limiting effect at a monthly average air vapour pressure deficit exceeding $350 \mathrm{~Pa}$. Whether this is a direct effect of aerial vapour pressure on canopy surface conductance or a measure for low soil moisture cannot be inferred from this study. However, other observations have shown that high vapour pressure deficit as such can have a limiting effect on stomatal conductance. As high vapour pressure deficit is typically felt at high irradiance, vapour pressure deficit proved to impose a major limitation on the annual ecosystem assimilatory $\mathrm{CO}_{2}$ flux in both years of measurement. In the instant assimilatory $\mathrm{CO}_{2}$ flux in Chapter 3 the effect of drought was not evident, particularly because the analysis considered measurements at westerly to southwesterly wind angles only, thereby foregoing drier weather conditions. This was clearly demonstrated in Chapter 6 in the annual cycle of $\mathrm{CO}_{2}$ exchange when 
comparing both incident wind angle ranges. Westerly to southwesterly incident wind angles resulted in a narrower and more optimal response to irradiance than the full incident wind angle range.

Aggregated assimilatory activity in this study thus responded linearly to irradiance, a pattern which can be largely explained by the correlation between irradiance and daylength. Daylength is therefore an important factor in seasonal assimilatory activity, scaling in time being non-linear. A linear response of the monthly gross assimilatory $\mathrm{CO}_{2}$ flux to monthly irradiance at site Cabauw of $2.20 \mathrm{~g} \mathrm{CO}_{2} \mathrm{MJ}^{-1}$ under conditions of nonlimiting temperature and air humidity is thought to be a value which can be extrapolated beyond the measurement period of two years. Indeed, measurements at site Zegveld show a similar value in a different year. The monthly assimilatory $\mathrm{CO}_{2}$ flux responded to monthly average temperature in an optimum, whereas an average aerial vapour pressure deficit exceeding $350 \mathrm{~Pa}$ had a limiting effect.

Pastureland in North-western Europe is untypical for grasslands in general. It grows under conditions of temperature, precipitation and nutrient availability which usually lead to a climax vegetation of forest (Stiling 2015). Chapter 6 already shows that drought can seriously affect a linear response to irradiance even under temperate climate conditions. Sala et al. (1988) and Polley et al. (2011) found primary productivity in Great Plains grasslands to be particularly constrained by precipitation. Natural grasslands in general are characterised by complex and limiting nutrient relationships (Vitousek 2015). Productivity of most grasslands has been known to be particularly restricted by the availability of nitrogen and phosphorus (Sattari et al. 2016). Nonetheless, none of this necessarily precludes the existence of a baseline response of assimilatory activity to irradiance under non-limiting conditions of temperature and moisture in natural grasslands. Such a response can at times be difficult to discern as these non-limiting conditions are relatively rare, but even under limiting conditions an effect of radiation can appear. If such a baseline response were to be identified, its slope could be hypothesised to be dependent on nutrient availability and be well below a value of $2.20 \mathrm{~g} \mathrm{CO}_{2} \mathrm{MJ}^{-1}$ as proposed for the Netherlands.

\subsubsection{Respiratory $\mathrm{CO}_{2}$ exchange}

The response of the ecosystem assimilatory $\mathrm{CO}_{2}$ flux to irradiance is distinct as it is a primarily instant relationship. Canopy photosynthetic capabilities develop seasonally along with levels of irradiance. The instantaneous assimilatory $\mathrm{CO}_{2}$ fluxes showed that the asymptotic value of its response to irradiance correlated with seasonal levels of irradiance. The response of these photosynthetic capabilities to irradiance, temperature and air humidity is instant. The course of the ecosystem respiratory $\mathrm{CO}_{2}$ flux is less distinct as it relates to a body of heterogeneous organic matter which is exposed to a heterogeneous 
physical environment. Root and shoot biomass have different chemical compositions and therefore different base levels of maintenance respiration (Goudriaan \& Van Laar 1994). Dead organic matter is characterised by an age continuum ranging from highly decomposable litter to soil organic matter in age fractions with increasing resistance to decomposition by soil microbial biomass. Drained organic soils increase the complexity as the aerobic soil profile too consists of organic matter age fractions ranging from recent exposure to aerobic conditions in the downward adjustment of the drainage depth to exposure at the start of drainage. The expression of the assimilatory $\mathrm{CO}_{2}$ flux per unit of surface area clearly relates the $\mathrm{CO}_{2}$ flux to a canopy and its absorbed irradiance. However, the surface area is much less a measure for both mass and nature of the organic matter underneath. Not even a homogeneous physical environment - primarily temperature and soil humidity - would incite a distinct response from such an aggregated volume of organic matter. The actual vertical profile of soil temperature and moisture cannot be properly represented by conditions at the soil surface. This adds to a less distinct response of soil respiratory processes to air temperature. Drained organic soils are moreover often characterised by a concave ground water level, which introduces short-distance horizontal variations in the aerobic soil profile.

Analysis of the instant respiratory $\mathrm{CO}_{2}$ flux in monthly cohorts in Chapter 6 shows a clear response to temperature, although its exact shape - linear or any $Q_{10}$ type of relationship - in these cohorts could not be identified because of the limited range of night temperatures. However, a clear $Q_{10}$ type of relationship emerges from the slopes of the monthly linear responses, increasing with temperature levels. Whereas the instant response reveals this $Q_{10}$ type of relationship, the aggregated response of monthly values shows a linear relationship between monthly average air temperature and monthly respiratory $\mathrm{CO}_{2}$ flux in the form of an inverted Blackman curve. But this Blackman curve also corresponds to the rapid transition from low to high activity observed in any $Q_{10}$ type of response, which makes both curves analogous. This does not mean that the entire response of the respiratory $\mathrm{CO}_{2}$ flux to temperature can actually be attributed to temperature. Monthly aggregated flux values in both Chapter 3 and 6 hint at a clear dependence of the respiratory $\mathrm{CO}_{2}$ flux on the assimilatory $\mathrm{CO}_{2}$ flux, which includes both maintenance respiratory activity in living biomass and the decomposition of litter. The observed hysteresis in this response - relative respiratory activity being higher in the $2^{\text {nd }}$ half of the year - could have been caused by both higher temperature and higher amounts of living biomass and litter. The effect of biomass on respiratory activity is also reflected in its response to temperature, which was much lower in months with impeded assimilatory activity. Whereas the compound slopes of the monthly instant responses of the night-time $\mathrm{CO}_{2}$ flux to temperature show a $Q_{10}$ type effect of temperature on metabolic processes, the base level of these responses may include an effect of biomass. 
A physiological basis exists for independent effects of both biomass and temperature. Both were observed in this study. However, as both are correlated in these measurements it is not possible to statistically separate their effects on the respiratory $\mathrm{CO}_{2}$ flux. As the respiratory $\mathrm{CO}_{2}$ flux stems from a volume of assimilated compounds it could even be argued that its decomposition in time can be characterised by a meta pattern which transcends seasonal and annual variations in temperature. The slowdown of the decomposition at low temperature is thus compensated for by an acceleration at subsequently higher temperature.

\subsubsection{Net $\mathrm{CO}_{2}$ exchange}

The analysis in Chapter 6 shows that in the investigated drained peat grassland ecosystems the aggregated assimilatory $\mathrm{CO}_{2}$ flux is determined by a distinct linear effect of irradiance which was constant during the two years of measurement. This linear effect is mediated by conditions of low humidity and, to a lesser extent, by conditions of low temperature. The respiratory $\mathrm{CO}_{2}$ flux responds to biomass linearly, whereas its response to air temperature follows a $Q_{10}$ type of path (on an aggregated scale appearing as a linear response at air temperatures exceeding $5^{\circ} \mathrm{C}$ ). Both factors simultaneously determine the respiratory $\mathrm{CO}_{2}$ flux. In combination with the heterogeneity of organic matter and temperature in the vertical soil profile they contribute to a less distinct response of the respiratory $\mathrm{CO}_{2}$ flux to temperature. This illustrates how the ecosystem net $\mathrm{CO}_{2}$ flux - the difference between assimilatory and respiratory $\mathrm{CO}_{2}$ flux - at any time depends on biomass, irradiance, temperature and air humidity. The annual course of the monthly net $\mathrm{CO}_{2}$ exchange in drained peat grassland shows a recurring pattern, in which a net $\mathrm{CO}_{2}$ sequestration in spring and early summer is followed by a net release in autumn and winter. Spring is characterised by both long daylength and irradiance increasing ahead of temperature. This results in a rapid increase of the assimilatory $\mathrm{CO}_{2}$ flux over the respiratory $\mathrm{CO}_{2}$ flux. In summer, daylength decreases and temperature catches up, which causes the respiratory $\mathrm{CO}_{2}$ flux to gradually increase over the assimilatory $\mathrm{CO}_{2}$ flux. Short daylength and low levels of irradiance and air temperature in autumn result in a low assimilatory $\mathrm{CO}_{2}$ flux, but trailing soil temperatures still maintain a relatively high respiratory $\mathrm{CO}_{2}$ flux. Winter sees a low respiratory $\mathrm{CO}_{2}$ flux and a negligible assimilatory $\mathrm{CO}_{2}$ flux. Net $\mathrm{CO}_{2}$ sequestration was observed only in spring and early summer, whereas the remaining period was characterised by a net $\mathrm{CO}_{2}$ release. The annual net $\mathrm{CO}_{2}$ release of 623 to 920 $\mathrm{g} \mathrm{CO}_{2} \mathrm{~m}^{-2}$ found in this study amounted to $12-14 \%$ of the annual assimilatory $\mathrm{CO}_{2}$ flux, which explains how minor shifts in the annual course of the assimilatory and respiratory $\mathrm{CO}_{2}$ fluxes could produce very different net $\mathrm{CO}_{2}$ exchanges. This illustrates how a $\mathrm{CO}_{2}$ balance calculated as the sum of net $\mathrm{CO}_{2}$ exchange measurements - done over a limited period of time - is insufficient to assess an ecosystem's pattern of $\mathrm{CO}_{2}$ exchange. The complexity of differential responses of both $\mathrm{CO}_{2}$ flux components to environmental factors is compounded by the decomposition of senesced biomass which takes place over 
a much longer period of time than the time in which it was assimilated. This in part decouples assimilatory and respiratory $\mathrm{CO}_{2}$ fluxes. The effect can be observed in some monthly time cohorts in this study, in which low assimilatory activity in one month leads to lower respiratory activity in the subsequent month. Other studies (e.g. Jacobs et al. 2007, Ma et al. 2007) retrospectively suggest that this effect can be noticed even across annual cycles. One year with an assimilatory $\mathrm{CO}_{2}$ flux which strongly deviates from average patterns may temporarily revert the $\mathrm{CO}_{2}$ balance in the subsequent year as the respiratory $\mathrm{CO}_{2}$ flux responds to the deviation with delay.

Many grassland and forest ecosystems are open and characterised by substantial C flows across system boundaries. In grasslands they primarily concern harvested biomass - either grass or dairy produce - and manure. Chapter 6 describes how the annual net $\mathrm{CO}_{2}$ exchange will get distorted if these $\mathrm{C}$ flows remain unaccounted for. Beyond experimental sites these numbers can be estimated for intensively managed pastureland. However, Chapter 6 also discusses how it may not be possible to arrive at a closed C balance. The harvested biomass remains of relevance to the $\mathrm{C}$ balance even if removed from the ecosystem. The harvested biomass will be subject to direct or indirect further decomposition elsewhere and it is difficult to draw a system boundary in space and time. Harvested grass will be fed possibly outside the measured ecosystem, where it will be converted into livestock products, respiratory $\mathrm{CO}_{2}$ and manure - still of relevance to the ecosystem's $\mathrm{C}$ balance. In case of grazing the conversion of grass into dairy produce takes place inside the ecosystem, which captures the respiratory $\mathrm{CO}_{2}$ flux. This then leaves the question what is to be held of the dairy produce processed outside the system. The drained peat pastureland in this study was grazed, which implies that the largest $\mathrm{C}$ flow across the ecosystem boundary was constituted by dairy produce. In Chapter 6 it was calculated that this $\mathrm{C}$ flow amounted to an equivalent of approximately $200 \mathrm{~g} \mathrm{CO}_{2} \mathrm{~m}^{-2} \mathrm{y}^{-1}$. This potentially additional respiratory $\mathrm{CO}_{2}$ flux has been kept apart from the calculated net respiratory $\mathrm{CO}_{2}$ flux of $623-920 \mathrm{~g} \mathrm{CO}_{2} \mathrm{~m}^{-2} \mathrm{y}^{-1}$. The extent to which this additional respiratory $\mathrm{CO}_{2}$ flux - respired outside of ecosystem boundaries - needs to be added to the ecosystem flux proper is subject to discussion, but this will be up to $200 \mathrm{~g} \mathrm{CO}_{2} \mathrm{~m}^{-2}$ $\mathrm{y}^{-1}$. This further increases the net $\mathrm{CO}_{2}$ release from this drained peat grassland ecosystem.

Effects of irradiance, vapour pressure deficit and temperature on the ecosystem's monthly net $\mathrm{CO}_{2}$ exchange are reflected in a simple linear regression $\left(n=23, r^{2}=0.76\right)$. All independent variables contributed to the variation $(P<0.05)$ even though irradiance and vapour pressure deficit were subject to multi-collinearity. It shows that irradiance was correlated with a tendency towards net $\mathrm{CO}_{2}$ sequestration, whereas vapour pressure deficit and temperature were correlated with a tendency towards net $\mathrm{CO}_{2}$ release. Every ${ }^{\circ} \mathrm{C}$ increase in air temperature thus results in a monthly net $\mathrm{CO}_{2}$ release of $23 \mathrm{~g} \mathrm{CO}_{2}$ $\mathrm{m}^{-2}$. On replacing irradiance and vapour pressure deficit by the assimilatory $\mathrm{CO}_{2}$ flux 
itself $\left(n=23, r^{2}=0.70\right)$ the tendency is similar, with every ${ }^{\circ} \mathrm{C}$ increase in temperature resulting in a monthly net $\mathrm{CO}_{2}$ release of $30 \mathrm{~g} \mathrm{CO}_{2} \mathrm{~m}^{-2}$. This illustrates how an increase in primary productivity results in a net $\mathrm{CO}_{2}$ exchange which tilts towards a higher net $\mathrm{CO}_{2}$ sequestration. The effect of temperature on the respiratory activity exceeds its effect on assimilatory activity and an increase results in a net $\mathrm{CO}_{2}$ exchange which tilts towards a higher net $\mathrm{CO}_{2}$ release. This indicates that ecosystems in environments with levels of temperature in the lower optimum for primary productivity and long days which enhance primary productivity should be characterised by a relatively high net $\mathrm{CO}_{2}$ sequestration. This applies to biomes in the temperate and boreal rather than tropical climate zones.

\subsection{ECOSYSTEM CO 2 EXCHANGE ON ORGANIC SOILS}

\subsubsection{Effects of drainage}

Ecosystems on organic soils behave differently as the instant immobilisation of $\mathrm{C}$ in the anaerobic soil profile results in a more lasting net $\mathrm{CO}_{2}$ sequestration while protecting assimilated organic matter from most respiratory activity (although methanogenesis can sustain a certain level of decomposition of organic matter). This immobilisation has the potential for a substantial $\mathrm{CO}_{2}$ sequestration as it immediately removes most senesced biomass from decomposition. However, the additional $\mathrm{C}$ sink remains susceptible to environmental and managerial change. It may be caught up by drainage at a later point in time in a delayed decomposition of senesced biomass, as is the case for the drained peat grassland ecosystems in this study. Basic processes underlying the $\mathrm{C}$ cycle are shown to be the same for a drained peat grassland ecosystem and a grassland on mineral soil. The autotrophic biomass assimilates $\mathrm{CO}_{2}$ and respires assimilated organic components, resulting in a net primary productivity. This autotrophic subsystem includes the root zone. Much of the senesced shoot biomass decomposes as litter before being transformed into soil organic matter. However, the greater part of the senesced root biomass enters the aerobic soil profile where it is subject to transformation (and decomposition) by soil microbial bacteria. Soil organic matter consists of a continuum of age fractions, where the relative decomposition rate of organic matter progressively decreases in time as a result of easily degradable fractions being decomposed first. This tail of age fractions reflects the history of the autotrophic biomass. It is still tightly linked to that biomass as its original source. More recent age fractions contribute most to the decomposition of soil organic matter, reinforcing the bond between biomass and respiratory $\mathrm{CO}_{2}$ flux from decomposing soil organic matter. Drainage of organic soil in peat grasslands exposes part of the anaerobic soil profile to aerobic conditions. This organic matter is much older and hardly linked to the current autotrophic biomass, if at all. Particularly in peat grasslands this organic matter often originates from different vegetation types predating the grassland vegetation. The exposure of the anaerobic soil profile to aerobic conditions 
is done in incremental downward adjustments of the water level, each year adding a layer of approximately 0.5 to $1 \mathrm{~cm}$ depth of new organic soil to aerobic conditions. This incremental drainage creates a similar pattern of age fractions in the drained organic soil as in the soil organic matter, with the deepest part of the aerobic soil profile conceivably exhibiting the highest decomposition rates. This distinction between the three subsystems for the $\mathrm{C}$ cycle in a drained peat grassland is instrumental to the differentiation between the $\mathrm{CO}_{2}$ fluxes associated with the different processes.

The complexity of the $\mathrm{C}$ balance in peat grasslands has been demonstrated by Veenendaal et al. (2007), who measured one year of $\mathrm{CO}_{2}$ exchange in two peat grasslands both drained at $60 \mathrm{~cm}$ depth. From a measured annual net $\mathrm{CO}_{2}$ sequestration of $22 \mathrm{~g} \mathrm{CO}_{2} \mathrm{~m}^{-2}$ at a bird reserve site the authors subtracted a biomass removal of $430 \mathrm{~g} \mathrm{C} \mathrm{m}^{-2} \mathrm{y}^{-1}$ to arrive at an annual net $\mathrm{CO}_{2}$ release of $1,555 \mathrm{~g} \mathrm{CO}_{2} \mathrm{~m}^{-2}$. Though numerically correct, it can be argued whether the removed biomass should be entirely accounted for as $\mathrm{CO}_{2}$ release. Off-site the biomass will partly transform to manure, being returned to another site. Were the biomass to remain on-site, the senesced organic matter would partly decompose and partly be transferred to the soil profile. At an intensive dairy farming site the authors measured an annual net $\mathrm{CO}_{2}$ release of $491 \mathrm{~g} \mathrm{CO}_{2} \mathrm{~m}^{-2}$, but in a pattern of mowing, grazing and application of manure it proves to be difficult to settle on a $\mathrm{CO}_{2}$ balance which does justice to the open nature of this ecosystem.

Annual net $\mathrm{CO}_{2}$ releases from the drained peat grasslands as calculated in Chapter 6 and from those documented in other studies - particularly those by Jacobs et al. (2007) - clearly show that the decomposition of peat from the aerobic part of the soil profile tends to exceed any net $\mathrm{CO}_{2}$ sequestration by the autotrophic biomass and its soil organic matter. Grasslands on mineral soils tend towards a net $\mathrm{CO}_{2}$ sequestration largely because of the chemical composition characteristics of the grassland's biomass. This means that the measured net $\mathrm{CO}_{2}$ release in the intensively managed drained peat grassland in this study of 620-920 $\mathrm{g} \mathrm{CO}_{2} \mathrm{~m}^{-2} \mathrm{y}^{-1}$ can be considered as the lower boundary of the decomposition of peat. An additional respiratory $\mathrm{CO}_{2}$ flux can be included of up to $200 \mathrm{~g} \mathrm{CO}_{2} \mathrm{~m}^{-2} \mathrm{y}^{-1}$ related to dairy produce. The basic processes underlying the intraannual net $\mathrm{CO}_{2}$ exchange were shown to respond strongly to irradiance, air humidity and temperature. This net $\mathrm{CO}_{2}$ release accounted for approximately $25 \%$ of the total annual soil subsidence of $13 \mathrm{~mm}$, which adds to the argument that soil subsidence (Couwenberg 2009) is not necessarily an adequate measure for the decomposition of drained organic soil (Christensen et al. 2004, Kuikman et al. 2005). In comparison to net $\mathrm{CO}_{2}$ sequestration values of $330 \mathrm{~g} \mathrm{CO}_{2} \mathrm{~m}^{-2} \mathrm{y}^{-1}$ in a grassland on mineral soil in the Netherlands (Jacobs et al. 2007), $598 \mathrm{~g} \mathrm{CO}_{2} \mathrm{~m}^{-2} \mathrm{y}^{-1}$ in a grassland on mineral soil in Scotland (Jones et al. 2017) and $381 \mathrm{~g} \mathrm{CO}_{2} \mathrm{~m}^{-2} \mathrm{y}^{-1}$ as an average in multiple European grasslands (Soussana et al. 2007) the net $\mathrm{CO}_{2}$ release in this drained peat grassland at 
location Cabauw is substantial. Yet this part of the ecosystem's respiratory $\mathrm{CO}_{2}$ flux accounted for only $11-12 \%$ of the total respiratory $\mathrm{CO}_{2}$ flux. The relatively minor share in the total respiratory $\mathrm{CO}_{2}$ flux explains how no directly evident differences were observed between the two different drainage levels at peat grassland site Zegveld, particularly as the difference between both levels probably amounted to only about half this percentage. A weather bias in the flux measurements related to different incident wind angles may have further obscured any detectable differences in the respiratory $\mathrm{CO}_{2}$ flux. The $\mathrm{CO}_{2}$ flux emanating from the decomposition of organic matter in the aerobic soil profile is thus small relative to the entire respiratory $\mathrm{CO}_{2}$ flux, but very large relative to any net $\mathrm{CO}_{2}$ flux. This shows how the decomposition of soil organic matter in drained peat grasslands can easily reverse the direction of a net $\mathrm{CO}_{2}$ exchange

The annual net $\mathrm{CO}_{2}$ exchange - whether release or sequestration - thus only accounts for a minor part of the gross $\mathrm{CO}_{2}$ fluxes. The course of the monthly $\mathrm{CO}_{2}$ flux components shows how it evolves from the response of these components to intra-annual variations in environmental conditions and from a history of biomass senescence during preceding time intervals. Nature and magnitude of an ecosystem's net $\mathrm{CO}_{2}$ exchange become evident only after the completion of a full seasonal cycle of growth. Whereas the two years of measurement at site Cabauw resulted in similar annual net $\mathrm{CO}_{2}$ releases of approximately $600-900 \mathrm{~g} \mathrm{CO}_{2} \mathrm{~m}^{-2}$ - the year exhibiting the lowest value was missing one month of data probably characterised by a net $\mathrm{CO}_{2}$ release - this consistency needs not be the rule. Measurements done by Jacobs et al. (2007) at the same site revealed strongly varying annual net $\mathrm{CO}_{2}$ exchanges, including one year exhibiting a net $\mathrm{CO}_{2}$ sequestration. This variation has in this thesis been hypothesised to be related to the occurrence of an unusually warm and dry season, its effect spilling over into the following years. Seasonal weather conditions appear to exert a substantial influence on the annual net $\mathrm{CO}_{2}$ exchanges in any ecosystem, also in grasslands in general and grasslands on organic soils in particular. Grasslands on drained organic soils may be extra sensitive to fluctuations in temperature in view of their large aerobic soil organic matter volume. Seasonal weather in general may well explain part of the variation in net $\mathrm{CO}_{2}$ exchange values in a range of European grassland sites (Gilmanov et al. 2007, Hörtnagl et al. 2018, Soussana et al. 2007) and even in a range of grasslands on organic soils in the Netherlands (Jacobs et al. 2007).

It thus requires sustained process-based measurements at at a few well documented sites rather than shorter measurement campaigns at many sites to determine and understand the longer-term $\mathrm{CO}_{2}$ balance in grasslands, even more so for drained peat grasslands because of their complex system of soil organic matter. 


\subsubsection{Prospects for reduced drainage}

Mitigation of $\mathrm{CO}_{2}$ emissions from drained peat grasslands in the Netherlands has attracted substantial attention in view of their contribution to anthropogenic $\mathrm{CO}_{2}$ fluxes and a commitment to the targets set in the 2016 Paris Agreement within the United Nations Framework Convention on Climate Change (UNFCC). Raising groundwater levels in the aerobic soil profile has been proposed to reduce the decomposition of peat soils. It would turn anaerobic that part of the peat soil profile which, from a logical perspective, exhibits the highest decomposition rate, i.e. those layers which have become exposed to aerobic conditions most recently. Higher ground water levels in general would reduce soil subsidence and therefore decrease the annual downward adjustment of water levels required to compensate for this subsidence. This consequentially reduces the amount of peat in the anaerobic soil profile which becomes newly exposed to aerobic conditions. Multiple approaches to raising groundwater levels have been proposed and already implemented. Raised drainage levels in the pasture waterways raise groundwater levels throughout the soil profile. This approach is the rationale for the experimental setup at site Zegveld in this study, although strictly speaking there were no (recently) changed water levels but only already existing differences in drainage level. However, limited lateral diffusivity to water in these soils may result in a less than proportional effect on the groundwater level. The issue of a concave water meniscus - most noticeable where equidistant to both waterways - continues to persist at least to some extent. At the far end of the measure scale is raising the drainage level to ground level, thereby turning most of the soil profile anaerobic. This measure has the potential to entirely halt the decomposition of the organic soil, but also severely impacts grassland management and land use options. An alternative measure of more recent date is the application of lateral drainage, which particularly addresses the problem with limited lateral diffusivity and a persistent concave groundwater surface (e.g. Hoving et al. 2008, Weideveld et al. 2020). Lateral drainage evens out large differences in groundwater depth and raises the groundwater level during the growing season when the aerobic organic soil profile is deepest and decomposition of peat highest. Incidentally, lateral drainage has the potential to increase the annual assimilatory $\mathrm{CO}_{2}$ flux and primary productivity by lowering groundwater levels at the start of the growing season - enabling an earlier start of sward growth - and by raising groundwater levels during the growing season - leading to higher soil moisture content. Higher primary productivity in peat grasslands in turn results in a higher $\mathrm{CO}_{2}$ sequestration.

Raising groundwater levels in drained peat grasslands has the potential to decrease the decomposition of peat from the organic soil profile. However, its decomposition dynamics are complex - consisting of a continuum of age fractions subject to a heterogeneous physical and biological environment - and quantitatively dwarfed by much larger $\mathrm{CO}_{2}$ fluxes related to sward processes. The initial effect of raising groundwater levels may 
predominantly be a shallower aerobic soil profile and a lower decomposition of organic matter. Comparison of the instantaneous $\mathrm{CO}_{2}$ flux measurements at drainage depths 30 and $60 \mathrm{~cm}$ at site Zegveld in Chapter 5 shows that the respiratory $\mathrm{CO}_{2}$ flux at a temperature of $15^{\circ} \mathrm{C}$ was $0.012 \mathrm{mg} \mathrm{CO} \mathrm{m}^{-2} \mathrm{~s}^{-1}$ higher at the low than at the high groundwater table, even though the difference was not statistically significant. A not uncontentious extrapolation translates this into an annual value of $375 \mathrm{~g} \mathrm{CO}_{2} \mathrm{~m}^{-2}$ as the respiratory flux difference between drainage depths 30 and $60 \mathrm{~cm}$. This again compares to an average annual $\mathrm{CO}_{2}$ emission of $772 \mathrm{~g} \mathrm{CO}_{2} \mathrm{~m}^{-2}$ measured at a drainage depth of $60 \mathrm{~cm}$ at site Cabauw. This suggests a proportionality between drainage depth and $\mathrm{CO}_{2}$ emissions (and thus decomposition of organic matter in the aerobic soil profile). A further rise of the groundwater table may gradually include a reverse process of peat formation if groundwater levels are high enough. Where $\mathrm{CO}_{2}$ fluxes associated with active sward processes intertwine with $\mathrm{CO}_{2}$ fluxes associated with peat decomposition and formation, it requires very specific experimentation to derive any relationship between drainage levels and $\mathrm{CO}_{2}$ fluxes in drained peat grasslands. The potential of raising drainage levels for the $\mathrm{CO}_{2}$ balance in peat grasslands could be explored by comparing peat soil $\mathrm{CO}_{2}$ fluxes in well-drained peat grasslands - predominantly related to decomposition - and in peat grasslands where groundwater levels have been raised to ground level - predominantly related to peat formation. The surface area of peat grasslands in the Netherlands amounts to 200,000-270,000 ha. Most of these grasslands are currently drained to such an extent that they exhibit a net $\mathrm{CO}_{2}$ release. Hendriks et al. (2007) measured the $\mathrm{CO}_{2}$ exchange for 3 consecutive years in a wetland restored from an abandoned peat grassland and found an average annual net $\mathrm{CO}_{2}$ sequestration of $1,209 \mathrm{~g} \mathrm{CO}_{2} \mathrm{~m}^{-2}$. The annual net $\mathrm{CO}_{2}$ sequestration increased with the length of the growing season, illustrating again how a higher annual assimilatory activity results in a higher net $\mathrm{CO}_{2}$ sequestration. This is particularly evident in their experiment, as there is hardly any biomass removal and most of its assimilated biomass is immobilised in the anaerobic soil profile. Hendriks et al. (2007) measured an efflux of C dissolved in lateral water flows, but this could be considered an anomaly as the studied wetland effectively represented an island of water surrounded by drained peat grasslands. In comparison to the net $\mathrm{CO}_{2}$ sequestration in other ecosystems a value of $1,200 \mathrm{~g} \mathrm{CO}_{2} \mathrm{~m}^{-2} \mathrm{y}^{-1}$ can be considered very high, a direct consequence of a largely absent respiration from the ecosystem's root zone. It compares to an average annual net $\mathrm{CO}_{2}$ sequestration of $330 \mathrm{~g} \mathrm{CO}_{2} \mathrm{~m}^{-2}$ measured by Jacobs et al. (2007) in multiple grasslands on mineral soils during 4 consecutive years. Peat formation in an anaerobic organic soil profile thus appears to have the potential to result in a strong $\mathrm{CO}_{2}$ sink. This $\mathrm{CO}_{2}$ sink contrasts with the $\mathrm{CO}_{2}$ source of $772 \mathrm{~g} \mathrm{CO}_{2} \mathrm{~m}^{-2} \mathrm{y}^{-1}$ in a drained peat grassland with a drainage depth of $60 \mathrm{~cm}$ as calculated in Chapter 6. Jacobs et al. (2007) found a $\mathrm{CO}_{2}$ release of approximately $730 \mathrm{~g} \mathrm{CO}_{2} \mathrm{~m}^{-2} \mathrm{y}^{-1}$ in their first year of measurement in the same drained peat grassland, the subsequent years being characterised by unusual weather conditions. Indiscriminately averaging annual net $\mathrm{CO}_{2}$ exchange 
values in a range of grasslands on organic soils at varying levels of drainage, Jacobs et al. (2007) found an average net $\mathrm{CO}_{2}$ release of $807 \mathrm{~g} \mathrm{CO}_{2} \mathrm{~m}^{-2} \mathrm{y}^{-1}$.

It could then be estimated that the restoration of peat grassland drained up to a depth of $60 \mathrm{~cm}$ to a wetland could reverse a source of $700 \mathrm{~g} \mathrm{CO}_{2} \mathrm{~m}^{-2} \mathrm{y}^{-1}$ into a sink of 1,200 $\mathrm{g} \mathrm{CO}_{2} \mathrm{~m}^{-2} \mathrm{y}^{-1}$, i.e. a difference of $1,900 \mathrm{~g} \mathrm{CO}_{2} \mathrm{~m}^{-2} \mathrm{y}^{-1}$ (or 19 ton $\mathrm{CO}_{2} \mathrm{ha}^{-1} \mathrm{y}^{-1}$ ). Methane emissions from wetlands are of relevance as $\mathrm{CH}_{4}$ has a strong global warming potential, corresponding to approximately 23 equivalents of $\mathrm{CO}_{2}$ (Ciais et al. 2013). $\mathrm{CH}_{4}$ emissions from drained peat grasslands are negligible as compared to $\mathrm{CH}_{4}$ emissions from wetlands. Part of the effect of sequestered $\mathrm{CO}_{2}$ in restored wetlands is thus lost by increasing $\mathrm{CH}_{4}$ emissions. Hendriks et al. (2007) measured $\mathrm{CH}_{4}$ efflux from the same restored wetland and after accounting for its global warming potential found the ecosystem to sequester the equivalent of $65 \%$ of the amount of $\mathrm{CO}_{2}$ actually sequestered, i.e. $780 \mathrm{~g} \mathrm{CO}_{2}$ eq. $\mathrm{m}^{-2} \mathrm{y}^{-1}$. This reduces the difference between the $\mathrm{CO}_{2}$ source of a drained peat grassland and the $\mathrm{CO}_{2}$ sink of a restored wetland to $1,480 \mathrm{~g} \mathrm{CO}_{2} \mathrm{~m}^{-2} \mathrm{y}^{-1}$ (or 14.8 ton $\mathrm{CO}_{2} \mathrm{ha}^{-1} \mathrm{y}^{-1}$ ). In this model peat formation and ceasing peat decomposition each contribute $50 \%$ to a reversed $\mathrm{CO}_{2}$ balance. But the measurements at sites Cabauw and Zegveld in this study show that reduction of drainage levels stopping short of complete wetland restoration can also contribute to a $\mathrm{CO}_{2}$ balance which favours $\mathrm{CO}_{2}$ sequestration. Various degrees of wetland restoration align closely with the biogeochemical $\mathrm{C}$ cycle and restore part of its processes which were lost as a result of the exploitation. The process of peat formation is sustainable as there is no practical limit to the amount of $\mathrm{C}$ sequestered in the anaerobic soil profile. The global $\mathrm{C}$ balance indicates that the biosphere constitutes an incomparably strong $\mathrm{CO}_{2}$ sink, which has even been gaining in strength. A pattern of increasing biospheric net $\mathrm{CO}_{2}$ sequestration suggests that these natural processes still contain much potential to further absorb and sequester $\mathrm{CO}_{2}$. Effective and sustainable measures to mitigate anthropogenic $\mathrm{CO}_{2}$ emissions add to these processes of primary productivity, rather than emphasise the development of artificial inert $\mathrm{CO}_{2}$ reservoirs. Drainage on a global scale during the past centuries has substantially decreased both the surface area of wetlands and the biome's $\mathrm{C}$ storage capacity. A reduction of the $\mathrm{CO}_{2}$ emissions from drained organic soils or even the entire restoration of wetlands reverse this process of degradation and further reinforce the global C cycle.

\subsection{PATTERNS OF ANNUAL ATMOSPHERIC-BIOSPHERIC $\mathrm{CO}_{2}$ EXCHANGE}

On basis of these processes of $\mathrm{CO}_{2}$ exchange in grassland ecosystems, a parallel to some extent may be drawn with the net $\mathrm{CO}_{2}$ exchange patterns of the biosphere-ocean system as a whole. Although it is one great leap coming from a single ecosystem, it 
may be argued that the biosphere merely is a composite ecosystem of high complexity simultaneously subject to a broad range of environmental conditions, whereas the oceans internalise characteristics of both ecosystem and physical solubility. Biosphere and oceans appear to annually sequester a net amount of $\mathrm{CO}_{2}$ equivalent to approximately $50 \%$ of anthropogenic emissions (Ciais et al. 1995, Levin 2012). As already illustrated in Figure 1.1 this net $\mathrm{CO}_{2}$ sequestration is the net result of much larger biological and physical process fluxes between atmosphere, biosphere and oceans. However, the actual percentage varies greatly among years, ranging from 20 to $80 \%$. This variation offers the possibility to speculate on some of the main drivers of these global $\mathrm{CO}_{2}$ exchange processes (Piao et al. 2019). Aggregating complex processes and environmental parameters, all characterised by a high degree of temporal and spatial variability, into single annual values is an inherently perilous activity. Each such value is inevitably subject to a vast array of geophysical and methodological assumptions and can therefore in principle be easily disputed. And yet, at this particular spatial scale the annual time increments may represent the most suitable temporal scale, with the growing season coming full circle. Shorter time scales include the complexity of a heterogeneous environment which does not exhibit a distinct response to shorter-term averaged environmental conditions. An attempt is made for the period 19592017 using annual data on atmospheric $\mathrm{CO}_{2}$ concentration, temperature and $\mathrm{C}$ balance from established sources, which find their way to a range of other research applications. The annually averaged atmospheric $\mathrm{CO}_{2}$ concentration on Hawaii's Mauna Loa volcano as measured first by the Scripps Institute of Oceanography (Keeling at SIO 2019) and later by the National Oceanic \& Atmospheric Administration (Tans at NOAA/ESRL 2019) is taken to represent the global atmospheric $\mathrm{CO}_{2}$ concentration, even though Ciais et al. (2019) noted that the ratio between the atmospheric $\mathrm{CO}_{2}$ concentrations on Hawaii and South Pole has shifted probably as a result of differential changes in $\mathrm{CO}_{2}$ sinks in Northern and Southern Hemispheres. The globally aggregated annual land and ocean surface temperature anomaly (relative to base period 1951-1980) as calculated by the Goddard Institute for Space Studies (GISTEMP Team 2019, Lenssen et al. 2019) is taken as a measure for global temperature. Le Quéré et al. (2018) consolidated calculations of global $\mathrm{C}$ emissions from industrial processes and the combustion of fossil fuels (Boden et al. 2017, B.P. 2018) and land-use change (Hansis et al. 2015, Houghton \& Nassikas 2017) as well as the global increase in atmospheric $\mathrm{CO}_{2}$ (Dlugokencky \& Tans 2018). The annual net $\mathrm{C}$ sequestration by both biosphere and oceans is here calculated as the difference between the annual $\mathrm{C}$ emissions and the annual increase in atmospheric $\mathrm{CO}_{2}$ (Le Quéré et al. 2018).

Figure 7.2B plots the iconic gradual increase of the atmospheric $\mathrm{CO}_{2}$ concentration, increasing from $316 \mu \mathrm{mol} \mathrm{mol}^{-1}$ in 1959 to $407 \mu \mathrm{mol} \mathrm{mol}^{-1}$ in 2017. The drawn line in Figure 7.2A plots the course of the global annual net $\mathrm{C}$ sequestration by biosphere and oceans as calculated from the data provided by Le Quéré et al. (2018), showing both its 

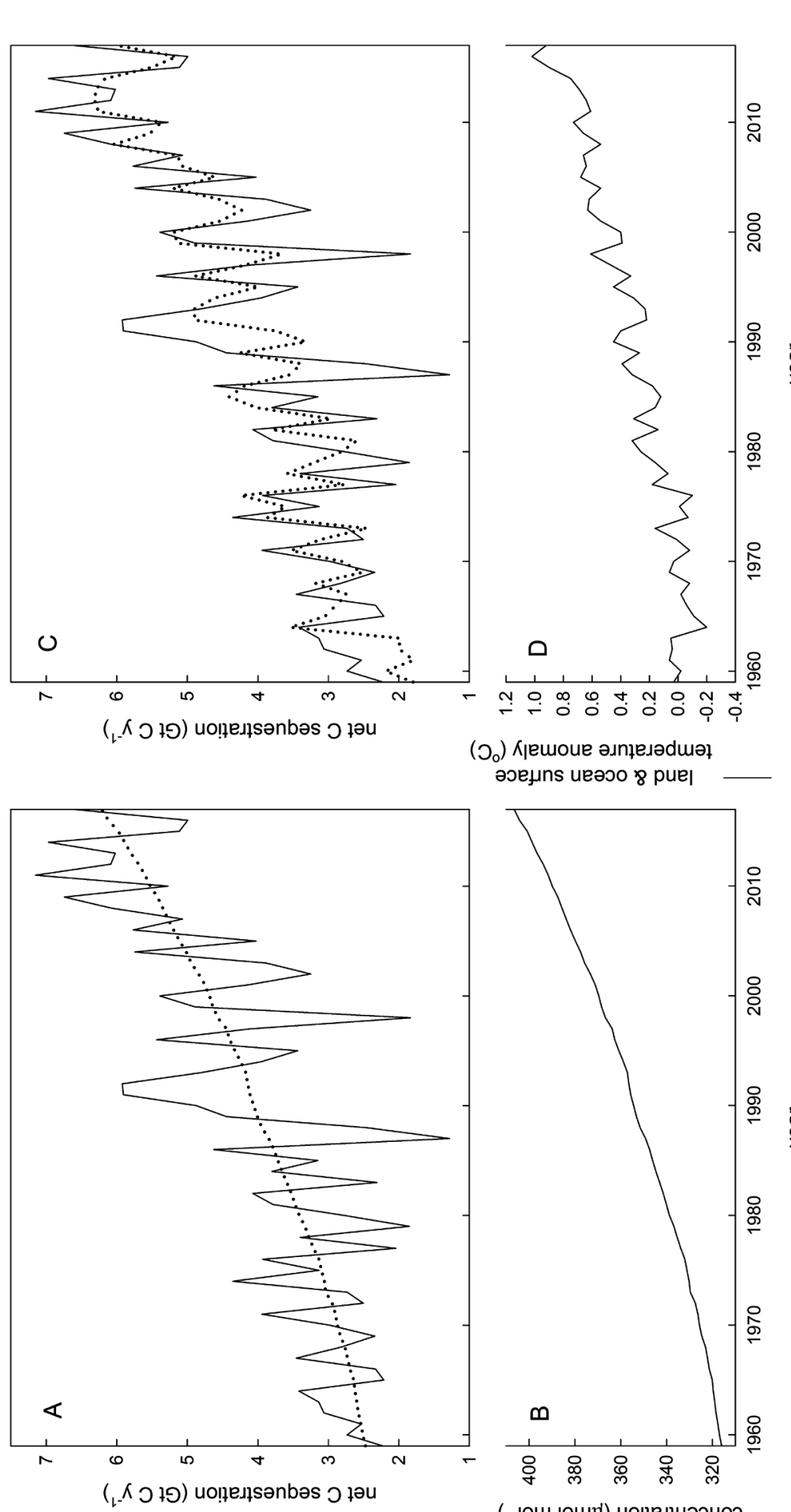

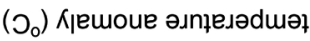
әэедns ueəэо \& pue।

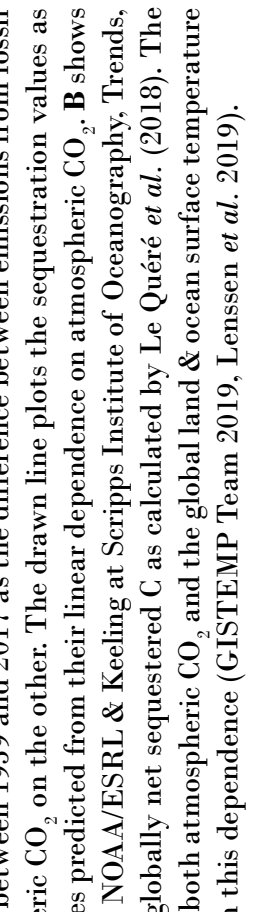

已 $\frac{0}{5} \div$

$\stackrel{\Xi}{\Xi}$.

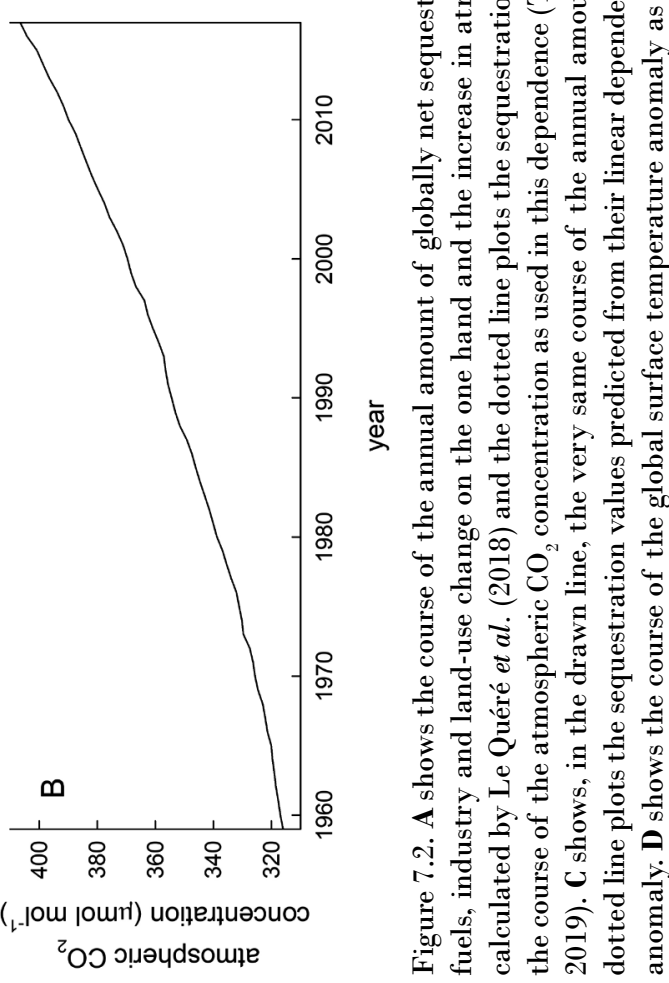


increase in time and its large inter-annual variation. In the period under consideration the absorption relative to anthropogenic emissions ranged from 18 to $80 \%$. The dotted line in Figure 7.2A plots the net $\mathrm{C}$ sequestration if it were to respond linearly to the atmospheric $\mathrm{CO}_{2}$ concentration, at a slope of $\left.0.041 \mathrm{Gt} \mathrm{C} \mathrm{y}^{-1}(\mu \mathrm{mol} \mathrm{mol})^{-1}\right)^{-1}\left(r^{2}=0.57\right.$, $n=59$ ). Although primary productivity in $\mathrm{C}_{3}$ plants is well known to respond to the ambient $\mathrm{CO}_{2}$ concentration, part of the increase in the net $\mathrm{C}$ sequestration with increasing atmospheric $\mathrm{CO}_{2}$ is likely to be related to a global increase in the length of the growing season instead. Figure 7.2D shows the gradual increase in global surface temperature, which is reflected in a progressively earlier start of the growing season. Whereas irradiance and daylength are shown to have an important role in the intra-annual pattern of ecosystem primary productivity, it is temperature, the length of the growing season and their gradual increase which may contribute to much of the inter-annual dynamics of biospheric primary productivity. The drawn line in Figure 7.2C shows the same course of the global annual net $\mathrm{C}$ sequestration by biosphere and oceans as in Figure 7.2A. The dotted line in Figure 7.2C plots the net $\mathrm{C}$ sequestration if it were to respond linearly to both atmospheric $\mathrm{CO}_{2}$ concentration and the temperature anomaly $\left(r^{2}=0.70\right.$, $n=59)$. As both independent parameters are characterised by a high degree of multicollinearity - temperature and atmospheric $\mathrm{CO}_{2}$ are strongly correlated - a confident assertion about the individual contributions is statistically not possible. However, it does indicate that, in combination, a higher atmospheric $\mathrm{CO}_{2}$ concentration is correlated with a higher net $\mathrm{C}$ sequestration and that a higher temperature anomaly is correlated with a lower net $\mathrm{C}$ sequestration. A visual comparison of observed and predicted responses in Figure 7.2C further underlines this conclusion, with the predicted $\mathrm{C}$ sequestration generally following the variations in the observed $\mathrm{C}$ sequestration, albeit in a slightly damped fashion. The increase in $\mathrm{C}$ sequestration with atmospheric $\mathrm{CO}_{2}$ is retained whereas inter-annual temperature peaks - modest as they may seem - correspond to lower net $\mathrm{C}$ sequestration rates and temperature troughs correlate with higher net $\mathrm{C}$ sequestration. This response raises the question how two potentially opposing effects of increasing temperature can be reconciled, i.e. a higher net $\mathrm{C}$ sequestration in its correlation with atmospheric $\mathrm{CO}_{2}$ and a lower $\mathrm{C}$ sequestration in its response to the temperature anomaly. This dichotomy seems to indicate that two separate temperature signals may be at work. The increasing atmospheric $\mathrm{CO}_{2}$ concentration would correlate with an increasing background temperature and length of the growing season, where a rise in the absorptive $\mathrm{C}$ flux in its effect exceeds a rise in the desorptive $\mathrm{C}$ flux. The variation in the temperature anomaly surrounding this gradual increase would thus contribute less to the length of the growing season but more to changing the desorptive $\mathrm{C}$ flux.

This pattern of global $\mathrm{C}$ exchange corresponds to the process dynamics observed in the grassland ecosystem in this study (and those inferred from other studies), where conditions conducive to growth increase and higher temperatures decrease net $\mathrm{CO}_{2}$ sequestration. 
However, unlike the analysis of the grassland ecosystem where the constituent processes of gross assimilation and respiration explicitly result in a net $\mathrm{CO}_{2}$ exchange, the global data merely show a net exchange whereas its components can only be guessed at. The data from GISTEMP Team (2019), Keeling (2019), Le Quéré et al. (2018) and Tans (2019) show a strong correlation between inter-annual variations in temperature and the net $\mathrm{CO}_{2}$ sequestration. The root cause can be in both processes of absorption (reduced absorption by warmer surface water and reduced assimilatory activity as a consequence of lower precipitation) and processes of desorption (increased respiratory activity as a consequence of higher temperatures). Satellite measurements show that El Niño events have a strong effect on both $\mathrm{CO}_{2}$ uptake and respiratory activity of the terrestrial biosphere and on biomass burning (Chatterjee et al. 2017, Keeling et al. 2001, Liu et al. 2017). The differential effect of temperature suggests that the gradual increase in background temperature has a positive effect on the absorptive $\mathrm{C}$ flux exceeding a likely positive effect on the desorptive $\mathrm{C}$ flux, but that bouts of high temperature in the temperature anomaly primarily increase the desorptive $\mathrm{C}$ flux. The general trend in the time interval considered thus seems to be one where increasing temperature has a dominant effect depending on its intra-annual distribution. It gradually increases both absorptive and desorptive $\mathrm{C}$ fluxes and simultaneously accounts for large fluctuations in the fraction of $\mathrm{CO}_{2}$ sequestered relative to anthropogenic emissions. Jet Propulsion Laboratory's ongoing OCO-2 satellite measurements (Crisp et al. 2004) could provide more insight into global $\mathrm{CO}_{2}$ fluxes, provided the mission is maintained over a sufficiently long period of time.

These observations also illustrate the complexity of the interaction between atmospheric $\mathrm{CO}_{2}$ and temperature. Whereas the global $\mathrm{C}$ cycle as such is characterised by consistent negative feedbacks on atmospheric $\mathrm{CO}_{2}$, these feedbacks seem to partially loose their coherence when considering an effect of atmospheric $\mathrm{CO}_{2}$ on temperature (Archer 2010, Ciais et al. 2013, Schlesinger \& Bernhardt 2013). Higher temperatures both decrease the solubility of $\mathrm{CO}_{2}$ in water and increase biospheric respiratory activity, which implies a positive feedback on atmospheric $\mathrm{CO}_{2}$. Such feedback mechanism would seriously reduce predictability of both $\mathrm{C}$ cycle and atmospheric temperature. However, the global $\mathrm{CO}_{2}$ data over the period 1959-2017 indicate that a higher biospheric respiratory $\mathrm{CO}_{2}$ flux as a consequence of higher temperatures can still concur with an increasing net $\mathrm{CO}_{2}$ sequestration, thereby retaining a negative feedback mechanism. From 1959 to 2017 the annual biospheric net $\mathrm{CO}_{2}$ sequestration has thus increased from approximately 2 to 7 Gt C (Le Quéré et al. 2018), a process probably driven by both increasing temperature and rising atmospheric $\mathrm{CO}_{2}$ concentration. Biospheric primary productivity has thus been a strong net $\mathrm{CO}_{2}$ sink and acted as a powerful negative feedback mechanism on atmospheric $\mathrm{CO}_{2}$ (Ciais et al. 2019). In fact, the net $\mathrm{CO}_{2}$ sequestration will continue after any abatement of anthropogenic $\mathrm{CO}_{2}$ emissions as it responds not to emissions but to atmospheric $\mathrm{CO}_{2}$ and temperature. Underneath an average net sequestration equating 
$50 \%$ of anthropogenic emissions hides the fact that the absolute net $\mathrm{CO}_{2}$ sequestration from the atmosphere has been increasing strongly. It underlines the strength of this $\mathrm{CO}_{2}$ sink, which has exceeded a mere proportionality to the $\mathrm{CO}_{2}$ concentration. The global data fail to reveal the biospheric net $\mathrm{CO}_{2}$ sequestration's constituent components, but it can be seen that a net absorption of $50 \%$ is the result of a much larger gross absorption which in turn concurs with a larger desorption.

\subsection{A ROLE FOR GRASSLANDS IN BIOSPHERIC C SEQUESTRATION}

Whereas drainage has reduced the $\mathrm{C}$ storage of grasslands on organic soils, grasslands in general remain the world's dominating biome and have the potential to explain a substantial part of the identified biospheric net $\mathrm{CO}_{2}$ sink. Ecophysiological characteristics of grasslands and their soil organic matter cause them to be particularly effective in sequestering $\mathrm{C}$. An estimate of the biome's contribution to the biosphere's net $\mathrm{CO}_{2}$ sequestration could be made by extensive $\mathrm{CO}_{2}$ exchange measurements, although the observed variation in space and time make them less compatible with questions on a biospheric scale. Instead, $\mathrm{CO}_{2}$ exchange measurements provide the basis for a generalisation of $\mathrm{CO}_{2}$ exchange processes through model-based analysis (Ciais et al. 2010).

One global approach applies patterns in the relative net $\mathrm{CO}_{2}$ sequestration (i.e. the net $\mathrm{CO}_{2}$ sequestration relative to gross primary productivity) as also observed in this study. Gilmanov et al. (2007) found the annual net $\mathrm{CO}_{2}$ exchange in European grasslands to exhibit large fluctuations, but it also to be causally related to assimilatory activity. Average relative net $\mathrm{CO}_{2}$ exchange in European grasslands on mineral soils as analysed by Gilmanov et al. (2007) amounted to a net $\mathrm{CO}_{2}$ sequestration of $0.10 \mathrm{~g} \mathrm{CO}_{2}$ for each $\mathrm{g}$ of assimilated $\mathrm{CO}_{2}$. Such value does not apply uniformly to all climate zones as temperature, humidity, chemical composition of the biomass and microbial biomass will affect assimilatory and respiratory activity differently. Gibson (2009) divided the grassland biome into high-, mid- and low-latitude grasslands and estimated the total soil C storage at 28.7, 8.9 and $11.1 \mathrm{~kg} \mathrm{C} \mathrm{m}^{-2}$, respectively. Ma et al. (2016) aggregated the soil C content in the top $100 \mathrm{~cm}$ of the soil profile in grassland ecosystems across China on basis of measurements in other studies. They eventually categorised the ecosystems into steppe, meadow, desert and shrub-tussock with an average $\mathrm{C}$ storage of $6.5,11.6,5.6$ and 7.3 $\mathrm{kg} \mathrm{C} \mathrm{m}{ }^{-2}$, respectively, although the constituent values ranged from 1.1 to $32.0 \mathrm{~kg} \mathrm{C} \mathrm{m}^{-2}$. Amundson (2001) showed how temperature and moisture determine the ratio of primary productivity and organic matter decomposition across climate zones and vegetation types, as also noted by Gibson (2009) and Schlesinger and Bernhardt (2013). High latitudes 
are thus characterised by a high soil $\mathrm{C}$ content and a low primary productivity, which is reflected in long residence times. Whereas low latitudes also have a relatively high soil $\mathrm{C}$ content, this concurs with much higher levels of primary productivity. This translates into relatively short residence times of organic matter. This suggests higher relative net $\mathrm{CO}_{2}$ sequestration rates under conditions of low primary productivity, drought and low temperature than under warm and humid conditions, possibly by lower respiratory activity as also reflected in parts of this study.

Natural grasslands are generally located on soils relatively poor in nutrients and not subject to fertilisation (Fay et al. 2015, Sattari et al. 2016). The effect of growth-limiting nutrient availability on the absolute $\mathrm{CO}_{2}$ sequestration can conceptionally be seen to appear in both the net $\mathrm{CO}_{2}$ sequestration rate relative per unit of primary productivity and the primary productivity as such. A nutrient-limiting effect on primary productivity thus results in a lower absolute net $\mathrm{CO}_{2}$ sequestration. On the other hand, nutrientlimited growth can also result in organic matter characterised by lower decomposition rates (Liu et al. 2006, Paz-Ferreiro et al. 2012) and soil nutrient immobilisation (Wedin 1996). This effect is reflected in the relative net $\mathrm{CO}_{2}$ sequestration rate, which follows from the soil organic matter residence time. Lower decomposability of soil organic matter as a consequence of lower nutrient content (i.e. a high $\mathrm{C} / \mathrm{N}$ ratio) will result in a higher relative net $\mathrm{CO}_{2}$ sequestration rate, although the effect is compounded by other factors which affect soil organic matter decomposition such as soil moisture and temperature. It could then be inferred that the relative net $\mathrm{CO}_{2}$ exchange rate would be highest in ecoregions characterised by low temperature or precipitation. A low relative net $\mathrm{CO}_{2}$ exchange rate in savannah grasslands at the other end of the spectrum could result from the ecoregion's high net primary productivity, with its soil organic matter decomposing relatively fast.

A contribution of the grassland biome to net $\mathrm{C}$ sequestration in the terrestrial biosphere is reinforced by the biome's large surface cover and the ecophysiological characteristics of vegetation and soil organic matter. Within the grassland biome, this clearly does not apply to all ecosystems as many intensively used grasslands are effectively net $\mathrm{CO}_{2}$ sources, such as the drained peat pastures typified in this thesis. Natural grasslands typically occur in regions where annual patterns of temperature and precipitation prevent tree growth, concurring with conditions which limit soil microbial activity and thus enhance the accumulation of soil organic matter. Net $\mathrm{C}$ sequestration under conditions less conducive to high primary productivity can continue for a long period of time as is reflected in the large amounts of soil $\mathrm{C}$ in natural grasslands.

The terrestrial biosphere's $\mathrm{CO}_{2}$ absorption - accelerated by conditions of higher atmospheric $\mathrm{CO}_{2}$ concentration and a longer growing season as a result of rising 
temperature - acts as an instant negative feedback on the atmospheric $\mathrm{CO}_{2}$ concentration. This natural negative feedback mechanism on the atmospheric $\mathrm{CO}_{2}$ concentration absorbs the equivalent of approximately half the anthropogenic $\mathrm{CO}_{2}$ emissions, which makes various technical solutions to reduce $\mathrm{CO}_{2}$ emissions or capture $\mathrm{CO}_{2}$ from the atmosphere relatively ineffective in comparison - both in terms of volume and costs. Processes of autotrophic $\mathrm{C}$ sequestration and heterotrophic cycling seem to be capable of an effective biogeochemical response to an increasing atmospheric $\mathrm{CO}_{2}$ concentration. Mitigation of biospheric degradation - as observed in large-scale deforestation, conversion of natural grasslands into agricultural land and drainage of wetlands - could further strengthen this feedback mechanism. More specifically, grasslands on drained organic soils have been shown to constitute a substantial $\mathrm{CO}_{2}$ source, releasing amounts of $\mathrm{CO}_{2}$ which potentially far exceed the amount of $\mathrm{CO}_{2}$ sequestered in grasslands on mineral soils. Measures to reduce drainage levels to limit decomposition of soil organic matter range from raising water levels in drainage canals to lateral drainage to even out concave groundwater surfaces. Both measures have shown to substantially reduce levels of soil subsidence, which suggests lower levels of decomposition of soil organic matter. The relationship between drainage, soil subsidence and actual soil organic matter decomposition still requires further analysis, but this and other studies do indicate that lower levels of drainage reduce decomposition of soil organic matter. At the far end of the scale of reducing $\mathrm{CO}_{2}$ emissions from drained organic soils, calculations show that restoring wetlands could even have a larger impact on these ecosystems' net $\mathrm{CO}_{2}$ exchange, as minimisation of the aerobic soil profile resuscitates processes of peat formation.

\subsection{A TIMELINE TO BIOSPHERIC C SEQUESTRATION}

The biosphere has been exhibiting a substantial net $\mathrm{CO}_{2}$ sequestration from the atmosphere, most likely accumulating as organic matter in its soil profiles as living biomass itself has limited capacity to absorb additional C. Observations also show an annual net $\mathrm{CO}_{2}$ sequestration in a wide range of grassland ecosystems (Gilmanov et al. 2007, Jacobs et al. 2007, Soussana et al. 2007). Dass et al. (2018) indicate that grasslands are probably more resilient in sequestering $\mathrm{C}$ than forests under conditions of an evolving warmer and drier climate. However, the question could be posed whether such sequestration is sustainable in time. It can be approached from two different time perspectives, thereby considering (1) a long-term role of the biosphere in the global C cycle and (2) short-term observations on organic matter in grasslands.

Although soil organic matter can be of high age even in aerobic soil profiles (e.g. Howlett et al. 2013) it is different from geological C sediments (Schlesinger \& Bernhardt 2013). Soil organic matter is subject to decomposition by soil microbial bacteria (albeit at vastly 
different rates) and thus metabolic activity. This implies that at least under hypothetical constant environmental conditions any ecosystem's net $\mathrm{CO}_{2}$ sequestration could in the very long run theoretically approach zero asymptotically. With the ecosystem's $\mathrm{CO}_{2}$ absorption remaining constant, the ecosystem's mass of soil organic matter grows in time and so consequentially does its decomposition. At an indistinct point in time $\mathrm{CO}_{2}$ absorption and $\mathrm{CO}_{2}$ loss would come to largely even each other out. A simple analogy to such an balance between the ecosystem's $\mathrm{CO}_{2}$ absorption and $\mathrm{CO}_{2}$ loss may be found in a canister with a small perforation in the bottom and a constant supply of water to the top. The supply of water initially exceeds the loss through the perforation and the amount of water in the canister will increase. As the amount of water in the canister grows so does the pressure of the water column on the perforation, with the loss rate of water increasing as to eventually balance the supply rate of water. In line with such a model of dynamic C storage, Smith (2014) expresses the opinion that a net $\mathrm{CO}_{2}$ sequestration in grasslands very much depends on their history and gradually decreases in time after sowing or recovery from poor land management.

However, any change in the ecosystem's $\mathrm{CO}_{2}$ absorption (change in primary productivity) or $\mathrm{CO}_{2}$ loss characteristics (soil microbial matter characteristics or physical soil environment) will take aim at a new balance, which means that such a balance will never be attained. In the perforated canister analogy this is represented by a change of water supply or a different diameter of the perforation. The global $\mathrm{C}$ cycle cannot settle as it is experiencing a sustained increase in both $\mathrm{CO}_{2}$ absorption (increasing primary productivity as a result of higher $\mathrm{CO}_{2}$ concentration and temperature) and $\mathrm{CO}_{2}$ loss characteristics (increasing decomposition as a result of higher temperature). A dynamic exchange of $\mathrm{CO}_{2}$ absorption and $\mathrm{CO}_{2}$ loss also implies that in the long run the direction of the net $\mathrm{CO}_{2}$ exchange may reverse. It can thus be hypothesised that on a much longer time scale and at varying environmental conditions the biosphere acts as a $\mathrm{C}$ buffer rather than a permanent $\mathrm{C}$ storage. Biospheric $\mathrm{C}$ storage thus contributes to the regulation, through the atmosphere, of true but slower $\mathrm{C}$ sedimentation at the ocean floors and at the surface of the lithosphere. The dynamic biospheric $\mathrm{C}$ storage (primarily its soil organic matter) is then where the autotrophic $\mathrm{C}$ cycle with its small time coefficient meets the $\mathrm{C}$ cycles of the lithospheric weathering $\mathrm{CO}_{2}$ thermostat and the oceanic $\mathrm{CaCO}_{3} \mathrm{pH}$-stat with their much larger time coefficients.

On a much shorter time scale uncertainty about further increases in grassland soil organic matter content per unit of surface area may originate from measurements in the soil profile. A comparison of annual ecosystem $\mathrm{CO}_{2}$ flux measurements and shortterm measurements of grassland soil organic matter is difficult because of largely incompatible spatial and temporal scales. $\mathrm{CO}_{2}$ flux measurements do not take into account specific soil profile depths, whereas organic matter measurements in the soil 
profile are almost inevitably limited to certain depths. Soil organic matter is subject to constant transformation (Jenkinson 1988), which means that it can migrate to parts of the soil profile beyond measurement depth. The top layer of the soil profile is the primary subject of measurement and may, in the course of time, also grow or shrink vertically, meaning that the top $50 \mathrm{~cm}$ at different points in time may not be the same. This spatial incompatibility goes along with a temporal incompatibility. $\mathrm{CO}_{2}$ sequestration from the atmosphere is a slow process, on a short time scale very significant to the atmospheric $\mathrm{CO}_{2}$ concentration but much less so to the organic matter content in the soil because of the large pool of the latter. This can be easily seen by comparing the amounts of $\mathrm{C}$ involved. An annual net $\mathrm{CO}_{2}$ sequestration in grasslands on mineral soil of $300 \mathrm{~g} \mathrm{CO}_{2}$ $\mathrm{m}^{-2} \mathrm{y}^{-1}$ corresponds to an annual C sequestration of $82 \mathrm{~g} \mathrm{C} \mathrm{m}^{-2} \mathrm{y}^{-1}$. Hoogsteen (2020) measured C contents of 19.8 and $29.9 \mathrm{~kg} \mathrm{C} \mathrm{m}^{-2}$ in the upper $60 \mathrm{~cm}$ of the soil profile in two grasslands on sandy soils in the Netherlands. This illustrates how an annual net $\mathrm{CO}_{2}$ sequestration will be dwarfed by the order of magnitude of the soil's $\mathrm{C}$ content and accordingly difficult to observe.

\subsection{TOWARDS AN EFFECTIVE MITIGATION OF ANTHROPOGENIC $\mathrm{CO}_{2}$ EMISSIONS}

The strength of the natural $\mathrm{C}$ cycle is reflected in both the magnitude of the net $\mathrm{CO}_{2}$ sequestration by the biospheric-oceanic system and its annual variation. The size of even its net $\mathrm{CO}_{2}$ fluxes dwarfs any $\mathrm{CO}_{2}$ sequestration by industrial means. The efficiency of natural ecosystems in sequestering $\mathrm{CO}_{2}$ from the atmosphere while being part of the natural $\mathrm{C}$ cycle make artificial solutions of $\mathrm{C}$ capture - no $\mathrm{C}$ sequestration in the sense of the $\mathrm{C}$ cycle - less effective, relatively costly and to some extent even illogical methods to mitigate anthropogenic $\mathrm{CO}_{2}$ emissions. A kaleidoscope of minute efforts to mitigate emissions can often be deduced from the current debate on climate change. However well-meant, they sometimes seem to reflect a somewhat erroneous understanding of atmospheric $\mathrm{CO}_{2}$ as a static entity which is almost exclusively determined by anthropogenic $\mathrm{CO}_{2}$ emissions. Capture of $\mathrm{CO}_{2}$ in parallel to the natural $\mathrm{C}$ cycle may even be only moderately effective as it ignores the natural $\mathrm{CO}_{2}$ exchange processes which may partly counteract such capture.

Enhanced $\mathrm{CO}_{2}$ sequestration could therefore focus on strengthening the natural $\mathrm{C}$ cycle as it appears to respond well to an increasing atmospheric $\mathrm{CO}_{2}$ concentration. The response of the biosphere is instant and in line with increasing $\mathrm{CO}_{2}$ concentration and even temperature. A stronger response of the biosphere could be attained by the restoration of degraded ecosystems (Griscom et al. 2017), such as grasslands on drained organic soils. Decreased levels of drainage up to wetland restoration offer large potential for sustained net $\mathrm{CO}_{2}$ sequestration. As natural ecosystems prove to be very effective 
in $\mathrm{CO}_{2}$ sequestration their large scale conversion into agricultural land should be of particular concern. It can be seen that less productive forms of agriculture, although often hypothesised to be of general benefit to environmental parameters, could thus in fact lead to an increased conversion of natural ecosystems to agricultural ecosystems which are less effective in sequestering $\mathrm{CO}_{2}$.

Efforts to increase the $\mathrm{CO}_{2}$ sequestration in the natural $\mathrm{C}$ cycle are to be supported by more systemic research which emphasises the basic processes which ultimately lead to a net $\mathrm{CO}_{2}$ exchange (Ciais et al. 2010). More extended periods of experimentation are required to correctly interpret the effect of inter-annual variations in weather (Piao et al. 2019) in combination with a thorough characterisation of the timeline of the soil C. Zeeman et al. (2010) also point at a strong interaction between weather and grassland management at ecosystem level. Such systemic research includes both ecosystems and regional and global processes, all at proper time scales.

\subsection{CONCLUSIONS}

This thesis shows how the net ecosystem $\mathrm{CO}_{2}$ exchange in a temperate drained peat grassland ecosystem is the result of its main constituent processes at successive levels of space and time and how these processes are driven by environmental factors. The ecosystem assimilatory $\mathrm{CO}_{2}$ flux shows a seasonally linear relationship with irradiance under conditions of non-limiting temperature and air humidity. The seasonal assimilatory $\mathrm{CO}_{2}$ flux was particularly affected by low air humidity and less so by low temperature. The seasonal course of the ecosystem respiratory $\mathrm{CO}_{2}$ flux followed the assimilatory $\mathrm{CO}_{2}$ flux, but was also shown to respond strongly to temperature instantly. The drained peat grassland ecosystem in this study was characterised by an annual net $\mathrm{CO}_{2}$ release. Its flux processes were reflected in the net $\mathrm{CO}_{2}$ exchange, where an increase in the assimilatory $\mathrm{CO}_{2}$ flux decreases the net $\mathrm{CO}_{2}$ release and an increase in temperature increases the net $\mathrm{CO}_{2}$ release. A strong indication was found that deeper levels of drainage result in a higher net $\mathrm{CO}_{2}$ release as a result of an enhanced decomposition of organic matter in the aerobic soil profile. At a much larger spatial scale, this general dynamic of ecosystem $\mathrm{CO}_{2}$ exchange is reflected in the atmospheric-biospheric $\mathrm{CO}_{2}$ exchange, thereby potentially explaining the large annual variation in the amount of $\mathrm{CO}_{2}$ sequestered from the atmosphere. It thus highlights a large role for the biosphere in the mitigation of anthropogenic $\mathrm{CO}_{2}$ emissions. On basis of physiological characteristics of grassland ecosystems and the climatic conditions typical for natural grasslands it can then be seen that grasslands could already contribute substantially to a net $\mathrm{CO}_{2}$ sequestration by the biosphere. A potentially even larger role can follow from reduced levels of drainage in 
currently drained peat grasslands, thereby possibly reverting a net $\mathrm{CO}_{2}$ release to a further net $\mathrm{CO}_{2}$ sequestration. 


\section{References}

Ågren, G.I., \& E. Bosatta., 1998. Theoretical Ecosystem Ecology. Cambridge University Press, Cambridge Albergel, C., J.-C. Calvet, A.-L. Gibelin, S. Lafont, J.-L. Roujean, C. Berne, O. Traullé \& N. Fritz, 2010. Observed and modelled ecosystem respiration and gross primary production of a grassland in southwestern France. Biogeosciences 7: 1657-1668

Ammann, C., C.R. Flechard, J. Leifeld, A. Neftel \& J. Fuhrer, 2007. The carbon budget of newly established temperate grassland depends on management intensity. Agriculture, Ecosystems and Environment 121: $5-20$

Ammann, C., A. Neftel, M. Jocher, J. Fuhrer \& J. Leifeld, 2020. Effect of management and weather variations on the greenhouse gas budget of two grasslands during a 10-year experiment. Agriculture, Ecosystems and Environment, https://doi.org/10.1016/j.agee.2019.106814

Amundson, R., 2001. The carbon budget in soils. Annual Review of Earth and Planetary Sciences 29: $535-562$

Anderson, D.E., \& S.B. Verma, 1986. Carbon dioxide, water vapor and sensible heat exchanges of a grain sorghum canopy. Boundary-Layer Meteorology 34: 317-331

Anderson, D.E., S.B. Verma \& N.J. Rosenberg, 1984. Eddy correlation measurements of $\mathrm{CO}_{2}$, latent heat, and sensible heat fluxes over a crop surface. Boundary-Layer Meteorology 29: 263-272

Archer, D., M. Eby, V. Brovkin, A. Ridgwell, L. Cao, U. Mikolajewicz, K. Caldeira, K. Matsumoto, G. Munhoven, A. Montenegro \& K. Tokos, 2009. Atmospheric life time of fossil fuel carbon dioxide. Annual Review of Earth and Planetary Sciences 37: 117-134

Archer, D., 2010. The global carbon cycle. Princeton University Press, Princeton etc., 205 pp.

Asner, G.P., G.V.N. Powell, J. Mascaro, D.E. Knapp, J.K. Clark, J. Jacobson, T. Kennedy-Bowdoin, A. Balaji, G. Paez-Acosta, E. Victoria, L. Secada, M. Valqui \& R.F. Hughes, 2010. High-resolution forest carbon stocks and emissons in the Amazon. Proceedings of the National Academy of Science 107: $16738-16742$

Avissar, R., P. Avissar, Y. Mahrer \& B.A. Bravdo, 1985. A model to simulate response of plant stomata to environmental conditions. Agricultural and Forest Meteorology 34: 21-29

Avissar, R., R.A. Pielke, 1991. The impact of plant stomatal control on mesoscale atmospheric circulations. Agricultural and Forest Meteorology 54: 353-372

Bacastow, R.B., C.D. Keeling \& T.P. Whorf, 1985. Seasonal amplitude increase in atmospheric $\mathrm{CO}_{2}$ concentration at Mauna Loa, Hawaii, 1959-1982. Journal of Geophysical Research 90D: 1052910540

Baccini, A., W. Walker, L. Carvalho, M. Farina, D. Sulla-Menashe \& R.A. Houghton, 2017. Tropical forests are a net carbon source based on aboveground measurements of gain and loss. Science 358: 230-234

Baldocchi, D., 1994. A comparative study of mass and energy exchange over a closed $\mathrm{C}_{3}$ (wheat) and an open $\mathrm{C}_{4}$ (corn) canopy: I. The partitioning of available energy into latent and sensible heat exchange. Agricultural and Forest Meteorology 67: 191-220 
Baldocchi, D., 1994. A comparative study of mass and energy exchange rates over a closed $\mathrm{C}_{3}$ (wheat) and an open $\mathrm{C}_{4}$ (corn) crop: II. $\mathrm{CO}_{2}$ exchange and water use efficiency. Agricultural and Forest Meteorology 67: 291-321

Baldocchi, D.D., 2003. Assessing the eddy covariance technique for evaluating carbon dioxide exchange rates of ecosystems: past, present and future. Global Change Biology 9: 1-14

Balcocchi, D.D., 2020. How eddy covariance flux measurements have contributed to our understanding of Global Change Biology. Global Change Biology 26: 242-260

Baldocchi, D.D., R.J. Luxmoore \& J.L. Hatfield, 1991. Discerning the forest from the trees: an essay on scaling canopy stomatal conductance. Agricultural and Forest Meteorology 54: 197-226

Baldocchi, D.D., S.B. Verma \& N.J. Rosenberg, 1981. Mass and energy exchanges of a soybean canopy under various environmental regimes. Agronomy Journal 73: 706-710

Batjes, N.H., \& W.G. Sombroek, 1997. Possibilities for carbon sequestration in tropical and subtropical soils. Global Change Biology 3: 161-173

Beetz, S., H. Liebersbach, S. Glatzel, G. Jurasinski, U. Buczko \& H. Höper, 2013. Effects of land use intensity on the full greenhouse gas balance in an Atlantic peat bog. Biogeosciences 10: 1067-1082

Boden, T.A., D.P. Kaiser, R.J. Sepanski \& F.W. Stoss, 1994. Trends '93: a compendium of data on global change. Carbon Dioxide Information Analysis Center, Oak Ridge. 984 pp.

Box, E.O., 1988. Estimating the seasonal carbon source-sink geography of a natural, steady-state terrestrial biosphere. Journal of Applied Meteorology 27: 1109-1124

Brooks, A., \& G.D. Farquhar, 1985. Effect of temperature on the $\mathrm{CO}_{2} / \mathrm{O}_{2}$ specificity of ribulose-1,5biphosphate carboxylase/oxygenase and the rate of respiration in the light. Estimates from gas-exchange measurements on spinach. Planta 165: 397-406

Buchmann, N., \& E.-D. Schulze, 1999. Net $\mathrm{CO}_{2}$ and $\mathrm{H}_{2} \mathrm{O}$ fluxes of terrestrial ecosystems. Global Biogeochemical Cycles 13: 751-760

Burton, K.L, W.R. Rouse \& L.D. Boudreau, 1996. Factors affecting the summer carbon dioxide budget of subarctic wetland tundra. Climate Research 6: 203-213

Byrne, K.A., G. Kiely \& P. Leahy, 2005. $\mathrm{CO}_{2}$ fluxes in adjacent new and permanent temperate grasslands. Agricultural and Forest Meteorology 135: 82-92

Caemmerer, S. von, \& G.D. Farquhar, 1981. Some relationships between the biochemistry of photosynthesis and the gas exchange of leaves. Planta 153: 376-387

Campbell, D.I., A.M. Wall, J.P. Nieveen \& L.A. Schipper, 2015. Variations in $\mathrm{CO}_{2}$ exchange for dairy farms with year-round rotational grazing on drained peatlands. Agriculture, Ecosystems \& Environment 202: 68-78

Campbell, D.I., G.L. Glover-Clark, J.P. Goodrich, C.P. Morcom, L.A. Schipper \& A.M. Wall, 2020. Large differences in $\mathrm{CO}_{2}$ emissions from two dairy farms on drained peatland driven by contrasting respiration rates during seasonal dry conditions. Science of the Total Environment, https://doi. org/10.1016/j.scitotenv.2020.143410

Campbell, J.E., J.A. Berry, U. Seibt, S.J. Smith, S.A. Montzka, T. Launois, S. Belviso, L. Bopp \& M. Laine, 2017. Large historical growth in global terrestrial gross primary production. Nature 544: 84-87

Canfield, D.E., 2014. Oxygen, a four billion year history. Princeton University Press, Princeton. 196 pp. 
Casella, E., J.F. Soussana \& P. Loiseau, 1996. Long-term effects of $\mathrm{CO}_{2}$ enrichment and temperature increase on a temperate grass sward. I. Productivity and water use. Plant and Soil 182: 83-99

Chapman, S.J., \& M. Thurlow, 1996. The influence of climate on $\mathrm{CO}_{2}$ and $\mathrm{CH}_{4}$ emissions from organic soils. Agricultural and Forest Meteorology 79: 205-217

Chatterjee, A., M.M. Gierach, A.J. Sutton, R.A. Feely, D. Crisp, A. Eldering, M.R. Gunson, C.W. O’Dell, B.B. Stephens \& D.S. Schimel, 2017. Influence of El Niño on atmospheric $\mathrm{CO}_{2}$ over the tropical Pacific Ocean: findings from NASA's OCO-2 mission. Science 358: eaam 5776

Chen, D.E., H.W. Hunt \& J.A. Morgan, 1994. Responses of a C3 and C4 perennial grass to $\mathrm{CO}_{2}$ enrichment and climate change: comparison between model prediction and experimental data. Ecological Modelling 87: 11-27

Christensen, T.R., T. Friborg, K.A. Byrne, B. Chojnicki, T.R. Christensen, M. Drösler, A. Freibauer, T. Friborg, S. Frolking, A. Lindroth, J. Mailhammer, N. Malmer, P. Selin, J. Turunen R. Valentini, L. Zetterberg \& M. Vandewall, 2004. EU peatlands: Current carbon stocks and trace gas fluxes, Report 4/2004 to 'Concerted action: Synthesis of the European Greenhouse Gas Budget', GeosphereBiosphere Centre, University of Lund, Sweden

Ciais, P., P.P. Tans, M. Trolier, J.W.C. White \& R.J. Francey, 1995. A large Northern Hemisphere terrestrial $\mathrm{CO}_{2}$ sink indicated by the ${ }^{13} \mathrm{C} /{ }^{12} \mathrm{C}$ ratio of atmospheric $\mathrm{CO}_{2}$. Science 269: 1098-1102

Ciais, P., J. F. Soussana, N. Vuichard, S. Luyssaert, A. Don, I. A. Janssens, S. L. Piao, R. Dechow, J. Lathière, F. Maignan, M. Wattenbach, P. Smith, C. Ammann, A. Freibauer, E. D. Schulze \& the

CARBOEUROPE Synthesis Team, 2010. The greenhouse gas balance of European grasslands. Biogeosciences Discussions 7: 5997-6050

Ciais, P., C. Sabine, G. Bala, L. Bopp, V. Brovkin, J. Canadell, A. Chhabra, R. DeFries, J. Galloway, M. Heimann, C. Jones, C. Le Quéré, R.B. Myneni, S. Piao \& P. Thornton, 2013. Carbon and other biogeochemical cycles. In: T.F. Stocker, D. Qin, G.-K. Plattner, M. Tignor, S.K. Allen, J. Boschung, A. Nauels, Y. Xia, V. Bex \& P.M. Midgley (eds.). Climate Change 2013: The Physical Science Basis. Contribution of Working Group I to the Fifth Assessment Report of the Intergovernmental Panel on Climate Change. Cambridge University Press, Cambridg etc., pp. 465-570

Ciais, P., J. Tan, X. Wang, C. Roedenbeck, F. Chevallier, S.-L. Piao, R. Moriarty, G. Broquet, C. Le Quéré, J.G. Canadell, S. Peng, B. Poulter, Z. Liu \& P. Tans, 2019. Five decades of northern land carbon uptake revealed by the interhemispheric $\mathrm{CO}_{2}$ gradient. Nature 568: 221-224

Cleveland, W.S., N.J. Freeny \& T.E. Graedel, 1983. The seasonal component of atmospheric $\mathrm{CO}_{2}$ : information from new approaches to the decomposition of seasonal time series. Journal of Geophysical Research 88C: 10934-10946

Collatz, G.J., J.T. Ball, C. Grivet \& J.A. Berry, 1991. Physiological and environmental regulation of stomatal conductance, photosynthesis and transpiration: a model that includes a laminar boundary layer. Agricultural and Forest Meteorology 54: 107-136

Combe, M., J. Vilà-Guerau de Arellano, H.G. Ouwersloot, C.M.J. Jacobs \& W. Peters, 2015. Two perspectives on the coupled carbon, water and energy exchange in the planetary boundary layer. Biogeosciences 12: 103-123 
Conant, R.T., K. Paustian \& E.T. Elliott, 2001. Grassland management and conversion into grassland: effects on soil carbon. Ecological Applications 11: 343-355.

Corrall, A.J., \& J.S. Fenlon, 1978. A comparative method for describing the seasonal distribution of production from grasses. Journal of Agricultural Science 91: 61-67

Couwenberg, J., 2009. Emission factors for managed peat soils - an analysis of IPCC default values. Wetlands International, Ede, $14 \mathrm{pp}$.

Criddle, R.S., M.S. Hopkin, E.D. McArthur \& L.D. Hansen, 1994. Plant distribution and the temperature coefficient of metabolism. Plant Cell and Environment 17: 233-243

Crisp, A., R.M. Atlas, F.-M. Breon, L.R. Brown, J.P. Burrows, P. Ciais, B.J. Connor, S.C. Doney, I.Y. Fung, D.J. Jacob, C.E. Miller, D. O’Brien, S. Pawson, J.T. Randerson, P. Rayner, R.J. Salawitch, S.P. Sander, B. Sen, G.L. Stephens, P.P. Tans, G.C. Toon, P.O. Wennberg, S.C. Wofsy, Y.L. Yung, Z. Kuang, B. Chudasama, G. Sprague, B. Weiss, R. Pollock, D. Kenyon \& S. Schroll, 2004. The Orbiting Carbon Observatory (OCO) mission. Advances in Space Research 34: 700-709

Dass, P., B.Z. Houlton, Y. Wang \& D. Warlind, 2018. Grasslands may be more reliable carbon sinks than forests in California. Environmental Research Letters 13: 074027

Davies, A., 1988. The regrowth of grass swards. In: M.B. Jones \& A. Lazenby (eds.) The Grass Crop - The Physiological Basis of Production. Chapman and Hall, London etc., pp. 85-127

Denning, A.S., I.Y. Fung \& D. Randall, 2002. Latitudinal gradient of atmospheric $\mathrm{CO}_{2}$ due to seasonal exchange with land biota. Nature 376: 240-243

De Pury, D.G.G., \& G.D. Farquhar, 1997. Simple scaling of photosynthesis from leaves to canopies without the errors of big-leaf models. Plant Cell and Environment 20: 537-557.

Dirks, B.O.M., \& A. Hensen, 1999. Surface conductance and energy exchange in an intensively managed peat pasture. Climate Research 12: 29-37

Dirks, B.O.M., A. Hensen \& J. Goudriaan, 1999. Surface $\mathrm{CO}_{2}$ exchange in an intensively managed peat pasture. Climate Research 13: 115-123

Dirks, B.O.M., A. Hensen \& J. Goudriaan, 2000. Effect of drainage on $\mathrm{CO}_{2}$ exchange patterns in an intensively managed peat grassland. Climate Research 14: 57-63

Dirks, B.O.M., M. van Oijen, A.H.C.M. Schapendonk, J. Goudriaan \& J. Wolf, 2002. Temperature sensitivity of photosynthesis in Lolium perenne swards: A comparison of two methods for deriving photosynthetic parameters from in vivo measurements. Photosynthetica 40: 405-413

Dlugokencky, E., \& P. Tans, 2018. Trends in atmospheric carbon dioxide, National Oceanic \& Atmospheric Administration, Earth System Research Laboratory (NOAA/ESRL). www.esrl.noaa.gov/gmd/ccgg/ trends/global.html

Drake, B.G., \& F.B. Salisbury, 1972. After effects of low and high temperature pretreatments on leaf resistance, transpiration and leaf temperature in Xanthium. Plant Physiology 50: 572-575

Dunin, F.X., W.S. Meyer, S.C. Wong \& W. Reyenga, 1989. Seasonal change in water use and carbon assimilation of irrigated wheat. Agricultural and Forest Meteorology 45: 231-250

Edwards, P.N., 2010. A vast machine: computer models, climate data, and the politics of global warming. MIT Press, Cambridge etc., 518 pp. 
Eldering, A., P.O. Wennberg, D. Crisp, D.S. Schimel, M.R. Gunson, A. Chatterjee, J. Liu, F.M. Schwandner, Y. Sun, C.W. O’Dell, C. Frankenberg, T. Taylor, B. Fisher, G.B. Ostermann, D. Wunch, J. Hakkarainen, J. Tamminen \& B. Weir, 2017. The Orbiting Carbon Observatory-2 early science investigations of regional carbon dioxide fluxes. Science 358: eaam 5745

Fan, S.-C., S.C. Wofsy, P.S. Bakwin \& D.J. Jacob, 1990. Atmosphere-biosphere exchange of $\mathrm{CO}_{2}$ and $\mathrm{O}_{3}$ in the Central Amazonian forest and the atmosphere. Journal of Geophysical Research 95: 16825-16838

Farquhar, G.D., \& S. von Caemmerer, 1982. Modelling of photosynthetic response to environmental conditions. In: O.L. Lange, P.S. Nobel, C.B. Osmond \& H. Ziegler (eds.). Physiological Plant Ecology II - Water Relations and Carbon Assimilation. Springer Verlag, Berlin. pp. 549-587

Fay, P.A., S.M. Prober, W.S. Harpole, J.M.H. Knops, J.D. Bakker, E.T. Borer, E.M. Lind, A.S. MacDougall, E.W. Seabloom, P.D. Wragg, P.B. Adler, D.M. Blumenthal, Y.M. Buckley, C. Chu, E.E. Cleland, S.L. Collins, K.F. Davies, G. Du, X. Feng, J. Firn, D.S. Gruner, N. Hagenah, Y. Hautier, R.W. Heckman, V.L. Jin, K.P. Kirkman, J. Klein, L.M. Ladwig, Q. Li, R.L. McCulley, B.A. Melbourne, C.E. Mitchell, J.L. Moore, J.W. Morgan, A.C. Risch, M. Schütz, C.J. Stevens, D.A. Wedin \& L.H. Yang, 2015. Grassland productivity limited by multiple nutrients. Nature Plants, DOI https://doi.org/10.1038/ nplants. 2015.80

Feely, R.A., C.L. Sabine, K. Lee, W. Berelson, J. Kleypas, V.J. Fabry \& F.J. Millero, 2004. Impact of anthropogenic $\mathrm{CO}_{2}$ on the $\mathrm{CaCO}_{3}$ system in the oceans. Science 305: 362-366

Feng, Y., 2009. Fundamental considerations of soil organic carbon dynamics: a new theoretical framework. Soil Science 174: 467-481

Field, C.B., 2001. Plant physiology of the 'missing' carbon sink. Plant Physiology 125: 25-28

Fisher, M.J., I.M. Rao, M.A. Ayarza, C.E. Lascano, J.I. Sanz, R.J. Thomas \& R.R. Vera, 1994. Carbon storage by introduced deep-rooted grasses in the South American savannas. Nature 371: 236-238

Foley, J.A., I.C. Prentice, N. Ramankutty, S. Levis, D. Pollard, S. Sitch \& A. Haxeltine, 1996. An integrated biosphere model of land surface processes, terrestrial carbon balance, and vegetation dynamics. Global Biogeochemical Cycles 10: 603-628

Forster, P., V. Ramaswamy, P. Artaxo, T. Berntsen, R. Betts, D.W. Fahey, J. Haywood, J. Lean, D.C. Lowe, G. Myhre, J. Nganga, R. Prinn, G. Raga, M. Schulz \& R. Van Dorland, 2007. Changes in atmospheric constituents and in radiative forcing. In: S. Solomon, D. Qin, M. Manning, Z. Chen, M. Marquis, K.B. Averyt, M. Tignor \& H.L. Miller (eds.). Climate Change 2007: The Physical Science Basis. Contribution of Working Group I to the Fourth Assessment Report of the Intergovernmental Panel on Climate Change. Cambridge University Press, Cambridge

Fox, E., J. Kuo, L. Tilling \& C. Ulrich, 1994. SigmaStat User's Manual. Jandel Scientific, Erkrath

Francez, A.J., \& H. Vasander, 1995. Peat accumulation and peat decomposition after human disturbance in French and Finnish mires. Acta Oecologica 16: 599-608

Freschet, G.T., W.K. Cornwell, D.A. Wardle, T.G. Elumeeva, W. Liu, B.G. Jackson, V.G. Onipchenko, N.A. Soudzilovskaia, J. Tao \& J.H.C. Cornelissen, 2013. Linking litter decomposition of above- and below-ground organs to plant-soil feedbacks worldwide. Journal of Ecology 101: 943-952 
Fung, I., K. Prentice, E. Matthews, J. Lerner \& G. Russell, 1983. Three-dimensional tracer model study of atmospheric $\mathrm{CO}_{2}$ : response to seasonal exchanges with the terrestrial atmosphere. Journal of Geophysical Research 88C: 1281-1294

Fung, I.Y., C.J. Tucker \& K.C. Prentice, 1987. Application of advanced very high resolution radiometer vegetation index to study atmosphere-biosphere exchange of $\mathrm{CO}_{2}$. Journal of Geophysical Research 92D: 2999-3015

Funk, D.W., E.R. Pullman, K.M. Peterson, P.M. Crill \& W.D. Billings, 1994. Influence of water table on carbon dioxide, carbon monoxide, and methane fluxes from taiga bog microcosms. Global Biogeochemical Cycles 8: 271-278

Gardner, R.H., \& J.B. Mankin, 1981. Analysis of biomass allocation in forest ecosystems of the IBP. In: P.D. Reichle. Dynamic properties of forest ecosystems. Cambridge University Press, Cambridge, pp. 451-497

Gibson, D.J., 2009. Grasses \& grassland ecology. Oxford University Press, Oxford. 305 pp.

Gifford, R.M., 2003. Plant respiration in productivity models: conceptualization, representation and and issues for global terrestrial carbon-cycle research. Functional Plant Biology 30: 171-186

Gilmanov, T.G., J.F. Soussana, L. Aires, V. Allard, C. Amman, M. Balzarolo, Z. Barcza, C. Bernhofer, C.L. Campbell, A. Cernusca, A. Cescatti, J. Clifton-Brown, B.O.M. Dirks, S. Dore, W. Eugster, J. Fuhrer, C. Gimeno, T. Gruenwald, L. Haszpra, A. Hensen, A. Ibrom, A.F.G. Jacobs, M.B. Jones, G. Lanigan, T. Laurila, A. Lohila, G. Manca, B. Marcolla, Z. Nagy, K. Pilegaard, K. Pinter, C. Pio, A. Raschi, N. Rogiers, M.J. Sanz, P. Stefani, M. Sutton, Z. Tuba, R. Valentini, M.L. Williams \& G. Wohlfahrt, 2007. Partitioning European grassland net ecosystem $\mathrm{CO}_{2}$ exchange into gross primary productivity and ecosystem respiration using light response function analysis. Agriculture, Ecosystems and Environment 121: 93-120

Gioli, B., F. Miglietta, B. De Martino, R.W.A. Hutjes, H.A.J. Dolman, A. Lindroth, M. Schumacher, M.J. Sanz, G. Manca, A. Peressotti \& E.J. Dumas, 2004. Comparison between tower and aircraft-based eddy covariance fluxes in five European regions. Agricultural and Forest Meteorology 127: 1-16

GISTEMP Team, 2019. data.giss.nasa.gov/gistemp/. GISS Surface Temperature Analysis (GISTEMP), version 4. NASA Goddard Institute for Space Studies. Dataset accessed 2019-07-31

Glenn, S., A. Heyes \& T. Moore, 1993. Carbon dioxide and methane fluxes from drained peat soils, southern Quebec. Global Biogeochemical Cycles 7: 247-257

Goudriaan, J., 1977. Crop micrometeorology: a simulation study. Centre for Agricultural Publishing and Documentation, Wageningen

Goudriaan, J., 1979. A family of saturation type curves, especially in relation to photosynthesis. Annals of Botany 43: 783-785

Goudriaan, J., 1994. Biosphere structure, carbon sequestering potential and the atmospheric ${ }^{14} \mathrm{C}$ carbon record. Journal of Experimental Botany 43: 1111-1119

Goudriaan, J., \& H.H. Van Laar, 1994. Modelling potential crop growth processes. Kluwer, Dordrecht. $238 \mathrm{pp}$. 
Goulden, M.L., J.W. Munger, S.-M. Fan, B.C. Daube \& S.C. Wofsy, 1996. Measurements of carbon sequestration by long-term eddy covariance: methods and a critical evaluation of accuracy. Global Change Biology 2: 169-182

Grace, J., J. Lloyd, J. McIntyre, A.C. Miranda, P. Meir, H.S. Miranda, C. Nobre, J. Moncrieff, J. Massheder, Y. Malhi, I. Wright \& J. Gash, 1995. Carbon dioxide uptake by an undisturbed tropical rain forest in Southwest Amazonia, 1992 to 1993. Science 270: 778-780

Grassini, P., K.M. Eskridge \& K.G. Cassman, 2013. Distinguishing between yield advances and yield plateaus in historical crop production trends. Nature Communications 4: 2918 doi: 10.1038/ncomss3918

Griffiths, H., 1993. Carbon isotope discrimination. In: D.O. Hall, J.M.O. Scurlock, H.R. BolhárNordenkampf, R.C. Leegood \& S.P. Long (eds.). Photosynthesis and production in a changing environment. Chapman \& Hall, London etc. pp. 181-191

Griscom, B.W., J. Adams, P.W. Ellis, R.A. Houghton, G. Lomax, D.A. Miteva, W.H. Schlesinger, D. Shoch, J.V. Siikamäki, P. Smith, P. Woodbury, C. Zganjar, A. Blackman, J. Campari, R.T. Conant, C. Delgado, P. Elias, T. Gopalakrishna, M.R. Hamsik, M. Herrero, J. Kiesecker, E. Landis, L. Laestadius, S.M. Leavitt, S. Minnemeyer, S. Polasky, P. Potapov, F.E. Putz, J. Sanderman, M. Silvius, E. Wollenberg \& J. Fargione, 2017. Natural climate solutions. PNAS 114: 11645-11650

Görres, C.-M., L. Kutzbach \& L. Elsgaard, 2014. Comparative modelling of annual $\mathrm{CO}_{2}$ flux of temperate peat soils under permanent grassland management. Agriculture, Ecosystems and Environment 186: 64-76

Hammerle, A., A. Haslwanter, M. Schmitt, M. Bahn, U. Tappeiner, A. Cernusca \& G. Wohlfahrt, 2007. Eddy covariance measurements of carbon dioxide, latent and sensible energy fluxes above a meadow on a mountain slope. Boundary Layer Meteorology 122: 397-416

Hansis, E., S.J. Davis \& J. Pongratz, 2015. Relevance of methodological choices for account of land use change carbon fluxes. Global Biogeochemical Cycles 29: 1230-1246

Hanson, P.J., S.D. Wullschleger, S.A. Bohlman \& D.E. Todd, 1993. Seasonal and topographic patterns of forest floor $\mathrm{CO}_{2}$ efflux from an upland oak forest. Tree Physiology 13: 1-5

Harley, P.C., J.D. Tenhunen \& O.L. Lange, 1986. Use of an analytical model to study limitations on net photosynthesis in Arbutus unedo under field conditions. Oecologia 70: 393-401

Harley, P.C., R.B. Thomas, J.F. Reynolds \& B.R. Strain, 1992. Modelling photosynthesis of cotton grown in elevated $\mathrm{CO}_{2}$. Plant Cell and Environment 15: 271-282

Harley, P.C., J.A. Weber \& D.M. Gates, 1985. Interactive effects of light, leaf temperature, $\mathrm{CO}_{2}$ and $\mathrm{O}_{2}$ on photosynthesis in soybean. Planta 165: 249-263

Haxeltine, A., \& I.C. Prentice, 1996. BIOME3: an equilibrium terrestrial biosphere model based on ecophysiological constraints, resource availability, and competition among plant functional types. Global Biogeochemical Cycles 10: 693-709

Heimsch, L., A. Lohila, J.-P. Tuovinen, H. Vekuri, J. Heinonsalo, O. Nevalainen, M. Korkiakoski, J. Liski, T. Laurila \& L. Kulmala, 2020. Carbon dioxide fluxes and carbon balance of an agricultural grassland in southern Finland. Biogeosciences Discussions, https://doi.org/10.5194/bg-2020-422

Hendriks, D.M.D., J. van Huissteden, A.J. Dolman \& M.K. van der Molen, 2007. The full greenhouse gas balance of an abandoned peat meadow. Biogeosciences 4: 411-424 
Hensen, A., W.C.M. van den Bulk, A.T. Vermeulen \& G.P. Wyers, 1997. $\mathrm{CO}_{2}$ exchange between grassland and the atmosphere - results over a four year period of $\mathrm{CO}_{2}$ measurements at Cabauw, the Netherlands. Report ECN-C--97-032. Netherlands Energy Research Foundation, Petten

Hensen, A., W.M. Kieskamp, A.T. Vermeulen, W.C.M. van den Bulk, D.F. Bakker, B. Beemsterboer, J.J. Möls, A.C. Veltkamp \& G.P. Wyers, 1995. Determination of the Relative Importance of Sources and Sinks of Carbon Dioxide. Netherlands Energy Research Foundation, Petten.

Hirata, R., A. Miyata, M. Mano, M. Shimizu, T. Arita, Y. Kouda, S. Matsuura, M. Niimi, T. Saigusa, A. Mori, M. Hojito, O. Kawamura \& R. Hatano, 2013. Carbon dioxide exchange at four intensively managed grassland sites across different climate zones of Japan and the influence of manure application on ecosystem carbon and greenhouse gas budgets. Agricultural and Forest Meteorology 177: 57-68

Hiyama, T., M. Sugita \& I. Kayane, 1995. Variability of surface fluxes within a complex area observed during TABLE 92. Agricultural and Forest Meteorology 73: 189-207

Hoffmann, M., N. Jurisch, E. Albiac Borraz, U. Hagemann, M. Drösler, M. Sommer \& J. Augustin, 2015. Automated modeling of ecosystem $\mathrm{CO}_{2}$ fluxes based on periodic closed chamber measurements: A standardized conceptual and practical approach. Agricultural and Forest Meteorology 200: 30-45

Holmén, K., 1992. The global carbon cycle. In: S.S. Butcher, R.J. Charlson, G.H. Orians \& G.V. Wolfe (eds.). Global Biogeochemical Cycles. Academic Press, pp. 239-262

Hoogsteen, M.J.J, 2020. Soil organic matter dynamics in Dutch production grasslands. PhD thesis. Wageningen University \& Research. 196 pp.

Hooijer, A., S. Page, J.G. Canadell, M. Silvius, J. Kwadijk, H. Wösten \& J. Jauhiainen, 2010. Current and future $\mathrm{CO}_{2}$ emissions from drained peatlands in Southeast Asia. Biogeosciences 7: 1505-1514

Houghton, J.T., L.G. Meira Filho, B.A. Callander, N. Harris, A. Kattenberg \& K. Maskell, 1996. Climate Change 1995: The Science of Climate Change. Cambridge University Press, Cambridge

Houghton, R.A., \& A.A. Nassikas, 2017. Global and regional fluxes of carbon from land use and land cover change 1850-2015. Global Biogeochemical Cycles 31: 456-472

Hoving, I.E., G. André, J.J.H. van den Akker \& M. Pleijter, 2008. Hydrological and agricultural effects of the use of submerged drains on peatsoil. Report 102. Wageningen UR Animal Sciences Group, Lelystad. 68 pp.

Howlett, D.S., Y. Toma, H. Wang, S. Sugiyama, T. Yamada, A. Nishiwaki, F. Fernandez \& J.R. Stewart, 2013. Soil carbon source and accumulation over 12,000 years in a semi-natural Miscanthus sinensis grassland in southern Japan. Catena 104: 127-135

Hörtnagl, L., M. Barthel, N. Buchmann, W. Eugster, K. Butterbach-Bahl, E. Diaz-Pines, M. Zeeman, K. Klumpp, R. Kiese, M. Bahn, A. Hammerle, H. Lu, T. Ladreiter-Knauss, S. Burri \& L. Merbold, 2018. Greenhouse gas fluxes over managed grasslands in Central Europe. Global Change Biology 24: $1843-1872$

Hudson, R.J.M., S.A. Gherini \& R.A. Goldstein, 1994. Modeling the global carbon cycle: nitrogen fertilization of the terrestrial biosphere and the 'missing' $\mathrm{CO}_{2}$ sink. Global Biogeochemical Cycles 8: $307-333$

Huylenbroeck, J.M. van, P. Lootens \& E. van Bockstaele, 1999. Photosynthetic characteristics of perennial ryegrass and red fescue turf-grass cultivars. Grass and Forage Science 54: 267-274 
Ingersoll, A.P., 2013. Planetary climates. Princeton University Press, Princeton etc., 278 pp.

Imer, D., L. Merbold, W. Eugster \& N. Buchmann, 2013. Temporal and spatial variations of soil $\mathrm{CO}_{2}, \mathrm{CH}_{4}$ and $\mathrm{N}_{2} \mathrm{O}$ fluxes at three differently managed grasslands. Biogeosciences 10: 5931-5945

Jacobs, A.F.G., B.G. Heusinkveld \& A.M. Holtslag, 2003. Carbon dioxide and water vapour flux densities over a grassland area in the Netherlands. International Journal of Climatology 23: 1663-1675

Jacobs, C.M.J, A. Jacobs, F.C. Bosveld, D.M.D. Hendriks, A. Hensen, P.S. Kroon, E.J. Moors, L. Nol, A. Schrier-Uijl \& E.M. Veenendaal, 2007. Variability of annual $\mathrm{CO}_{2}$ exchange from Dutch grasslands. Biogeosciences 4: 803-816

Janssen, B.H., 1984. A simple method for calculating decomposition and accumulation of 'young' soil organic matter. Plant and Soil 76: 297-304

Janssen, B.H., 1996. Nitrogen mineralization in relation to C: $\mathrm{N}$ ratio and decomposability of organic materials. Plant and Soil 181: 39-45

Janssens, I.A., A. Freibauer, P. Ciais, P. Smith, G.-J. Nabuurs, G. Folberth, B. Schlamadinger, R.W.A. Hutjes, R. Ceulemans, E.-D. Schulze, R. Valentini \& A.J. Dolman, 2003. Europe's terrestrial biosphere absorbs 7 to $12 \%$ of European anthropogenic $\mathrm{CO}_{2}$ emissions. Science 300: 1538-1542

Jarvis, P.G., \& K.G. McNaughton, 1986. Stomatal control of transpiration: scaling up from leaf to region. Advances in Ecological Research 15: 1-49

Jarvis, P.G., 1981. Stomatal conductance, gaseous exchange and transpiration. In: P.G. Jarvis, J. Grace \& E.D. Ford (eds.) Plants and Their Atmospheric Environment - the $21^{\text {st }}$ Symposium of The British Ecological Society, Edinburgh 1979. Blackwell, Oxford etc., pp. 175-204

Jarvis, P.G., 1995. The role of temperate trees and forests in $\mathrm{CO}_{2}$ fixation. Vegetatio 121: 157-174

Jenkinson, D.S., 1988. Soil organic matter and its dynamics. In. A. Wild (ed.) Russell's Soil Conditions \& Plant Growth. Longman, Harlow, pp. 564-607

Jenkinson, D.S., \& J.H. Rayner, 1977. The turnover of soil organic matter in some of the Rothamsted classical experiments. Soil Science 123: 298-305

Jones, H.G., 1992. Plants and microclimate, $2^{\text {nd }}$ ed. Cambridge University Press, Cambridge

Jones, M.B., \& A. Donnelly, 2004. Carbon sequestration in temperate grassland ecosystems and the influence of management, climate and elevated $\mathrm{CO}_{2}$. New Phytologist 164: 423-439

Jones, S.K., C. Helfter, M. Anderson, M. Coyle, C. Campbell, D. Famulari, C. Di Marco, N. van Dijk, Y.S. Tang, C.F.E. Topp, R. Kiese, R. Kindler, J. Siemens, M. Schrumpf, K. Kaiser, E. Nemitz, P.E. Levy, R.M. Rees, M.A. Sutton \& U.M. Skiba, 2017. The nitrogen, carbon and greenhouse gas budget of a grazed, cut and fertilised temperate grassland. Biogeosciences 14: 2069-2088

Kaduk, J. \& M. Heimann, 1996. A prognostic phenology scheme for global terrestrial carbon cycle models. Climate Research 6: 1-19

Kamp, J.N., C. Häni, T. Nyord, A. Feilberg \& L.L. Sørensen, 2020. The aerodynamic gradient method: implications of non-simultaneous measurements at alternating heights. Atmosphere 11: 1067-1072

Kecharvarzi, C., Q. Dawson, P.B. Leeds-Harrison, J. Szatyłowycz \& T. Gnatowski, 2007. Water-table management in lowland UK peat soils and its potential impact on $\mathrm{CO}_{2}$ emission. Soil Use and Management 23: 359-367 
Keeling, C.D., J.F.S. Chin \& T.P. Whorf, 1996. Increased activity of northern vegetation inferred from atmospheric $\mathrm{CO}_{2}$ measurements. Nature 382: 146-149

Keeling, C.D., S.C. Piper, R.B. Bacastow, M. Wahlen, T.P. Whorf, M. Heiman \& H.A. Meijer, 2001. Exchanges of atmospheric $\mathrm{CO}_{2}$ and ${ }^{13} \mathrm{CO}_{2}$ with the terrestrial biosphere and oceans from 1978 to 2000. I. Global aspects. Scripps Institution of Oceanography, SIO Reference 01-06: 1-28

Keeling, C.D., S.C. Piper, R.B. Bacastow, M. Wahlen, T.P. Whorf, M. Heimann \& H.A. Meijer, 2005. Atmospheric $\mathrm{CO}_{2}$ and ${ }^{13} \mathrm{CO}_{2}$ exchange with the terrestrial biosphere and oceans from 1978 to 2000: observations and carbon cycle implications. In: J.R. Ehleringer, T. Cerling \& M.D. Dearing (eds.). A history of atmospheric $\mathrm{CO}_{2}$ and its effects on plants, animals, and ecosystems. Springer, New York, pp. $83-113$

Keeling, R.F., 2019. www.scrippsco2.ucsd.edu/. Scripps Institution of Oceanography.

Kelliher, F.M., R. Leuning \& E.-D. Schulze, 1993. Evaporation and canopy characteristics of coniferous forests and grasslands. Oecologia 95: 153-163

Kelliher, F.M., R. Leuning, M.R. Raupach \& E.-D. Schulze, 1995. Maximum conductances for evaporation from global vegetation types. Agricultural and Forest Meteorology 73: 1-16

Kim, J., \& S.B. Verma (1990) Components of surface energy balance in a temperate grassland ecosystem. Boundary-Layer Meteorology 51: 401-417

Kim, J., S.B. Verma \& N.J. Rosenberg, 1989. Energy balance and water use of cereal crops. Agricultural and Forest Meteorology 48: 135-147

Kim, J., S.B. Verma \& R.J. Clement, 1992. Carbon dioxide budget in a temperature grassland ecosystem. Journal of Geophysical Research 97D: 6057-6063

King, A.W., W.R. Emanuel, S.D. Wullschleger \& W.M. Post, 1995. In search of the missing carbon sink: a model of terrestrial biospheric response to land-use change and atmospheric $\mathrm{CO}_{2}$. Tellus 47B: 501-519

Kirschbaum, M.U.F., \& G.D. Farquhar, 1984. Temperature dependence of whole-leaf photosynthesis in Eucalyptus pauciflora Sieb. ex Spreng. Australian Journal of Plant Physiology 11: 519-538

Klein Goldewijk, K., J.G. van Minnen, G.J.J. Kreileman, M. Vloedbeld \& R. Leemans, 1994. Simulating the carbon flux between the terrestrial environment and the atmosphere. Water, Air, and Soil Pollution 76: 199-230

Kohlmaier, G.H., E.-O. Siré, A. Janececk, C.D. Keeling, S.C. Piper \& R. Revelle, 1989. Modelling the seasonal contribution of a $\mathrm{CO}_{2}$ fertilization effect of the terrestrial vegetation to the amplitude increase in atmospheric $\mathrm{CO}_{2}$ at Mauna Loa Observatory. Tellus 41B: 487-510

Kolenbrander, G.J., 1974. Efficiency of organic manure in increasing soil organic matter content. In: Transactions of $10^{\text {th }}$ International Congress for Soil Science, Moscow, pp. 129-136

Krishnan, P., T.P. Meyers, R.L. Scott, L. Kennedy \& M. Heuer, 2012. Energy exchange and evapotranspiration over two temperate semi-arid grasslands in North America. Agricultural and Forest Meteorology 153: 31-44

Kruse, J., H. Rennenberg \& M.A. Adams, 2011. Steps towards a mechanistic understanding of respiratory temperature responses. New Phytologist 189: 659-677

Kuikman, P.J., J.J.H. van den Akker \& F. de Vries, 2005. Emission of $\mathrm{N}_{2} \mathrm{O}$ and $\mathrm{CO}_{2}$ from organic agricultural soils. Alterra, Wageningen. Alterra-rapport 1035-2: 66 pp. 
Kutzbach, L., J. Schneider, T. Sachs, M. Giebels, H. Nykänen, N.J. Shurpali, P.J. Martikainen, J. Alm \& M. Wilmking, 2007. $\mathrm{CO}_{2}$ flux determination by closed-chamber methods can be seriously biased by inappropriate application of linear regression. Biogeosciences 4: 1005-1025

Laiho, R., J. Laine \& H. Vasander, 1996. Northern Peatlands in Global Climatic Change - Proceedings of the International Workshop held in Hyytiälä, Finland, 8-12 October 1995. Edita, Helsinki

Langeveld, C.A., R. Segers, B.O.M. Dirks, A. van den Pol-van Dasselaar, G.L. Velthof \& A. Hensen, 1997. Emissions of $\mathrm{CO}_{2}, \mathrm{CH}_{4}$ and $\mathrm{N}_{2} \mathrm{O}$ from pasture on drained peat soils in the Netherlands. European Journal of Agronomy 7: 35-42

Lantinga, E.A., 1985. Productivity of grasslands under continuous and rotational grazing. PhD thesis. Landbouwhogeschool Wageningen.

Laubach, J., M. Barthel, A. Fraser, J.E. Hunt \& D.W.T. Griffith, 2016. Combining two complementary micrometeorological methods to measure $\mathrm{CH}_{4}$ and $\mathrm{N}_{2} \mathrm{O}$ fluxes over pasture. Biogeosciences 13: 1309-1327

Lauenroth, W.K., A.A. Wade, M.A. Williamson, B.E. Ross, S. Kumar \& D.P. Cariveau, 2006. Uncertainty in calculations of Net Primary Production for grasslands. Ecosystems 9: 843-851

Lawlor, D., 1987. Photosynthesis: metabolism, control and physiology. Longman, Harlow. 262 pp.

Le Quéré, C., R.M. Andrew, P. Friedlingstein, S. Sitch, J. Hauck, J. Pongratz, P. A. Pickers, J.I. Korsbakken, G.P. Peters, J.G. Canadell, A. Arneth, V.K. Arora, L. Barbero, A. Bastos, L. Bopp, F. Chevallier, L.P. Chini, P. Ciais, S.C. Doney, T. Gkritzalis, D.S. Goll, I. Harris, V. Haverd, F.M. Hoffman, M. Hoppema, R.A. Houghton, G. Hurtt, T. Ilyina, A.K. Jain, T. Johannessen, C.D. Jones, E. Kato, R.F. Keeling, K. Klein Goldewijk, P. Landschützer, N. Lefèvre, S. Lienert, Z. Liu, D. Lombardozzi, N. Metzl, D.R. Munro, J.E.M.S. Nabel, S. Nakaoka, C. Neill, A. Olsen, T. Ono, P. Patra, A. Peregon, W. Peters, P. Peylin, B. Pfeil, D. Pierrot, B. Poulter, G. Rehder, L. Resplandy, E. Robertson, M. Rocher, C. Rödenbeck, U. Schuster, J. Schwinger, R. Séférian, I. Skjelvan, T. Steinhoff, A. Sutton, P.P. Tans, H. Tian, B. Tilbrook, F.N. Tubiello, I.T. van der Laan-Luijkx, G.R. van der Werf, N. Viovy, A.P. Walker, A.J. Wiltshire, R. Wright, S. Zaehle \& B. Zheng, 2018. Global Carbon Budget 2018. Earth System Science Data 10: 2141-2194

Leiber-Sauheitl, K., R. Fuss, C. Voigt \& A. Freibauer, 2014. High $\mathrm{CO}_{2}$ fluxes from grassland on histic Gleysol along soil carbon and drainage gradients. Biogeosciences 11: 749-761

Lenssen, N., G. Schmidt, J. Hansen, M. Menne, A. Persin, R. Ruedy \& D. Zyss, 2019. Improvements in the GISTEMP uncertainty model. Journal of Geophysical Research: Atmospheres 124: 6307-6326

Levin, I., 2012. The balance of the carbon budget. Nature 488: 35-36

Leuning, R., 1995. A critical appraisal of a combined stomatal-photosynthesis model for $\mathrm{C}_{3}$ plants. Plant Cell and Environment 18: 339-355

Lhomme, J.-P., 1991. The concept of canopy resistance: historical survey and comparison of different approaches. Agricultural and Forest Meteorology 54: 227-240

Lindroth, A., \& S. Halldin, 1986. Numerical analysis of pine forest evaporation and surface resistance. Agricultural and Forest Meteorology 38: 59-79

Liu, J., K.W. Bowman, D.S. Schimel, N.C. Parazoo, Z. Jiang, M. Lee, A.A. Bloom, D. Wunch, C. Frankenberg, Y. Sun, C.W. O’Dell, K.R. Gurney, D. Menemenlis, M. Gierach, D. Crisp \& A. 
Eldering, 2017. Contrasting carbon cycle responses of the tropical continents to the 2015-2016 El Nińo. Science 358: eaam 5690

Liu, P., J. Huang, X. Han, O.J. Sun \& Z. Zhou, 2006. Differential responses of litter decomposition to increased soil nutrients and water between contrasting grassland plant species of Inner Mongolia, China. Applied Soil Ecology 34: 266-275

Lloyd, J., \& J.A. Taylor, 1994. On the temperature dependence of soil respiration. Functional Ecology 8: 315-323

Lohila, A., M. Aurela, J.-P. Tuovinen \& T. Laurila, 2004. Annual $\mathrm{CO}_{2}$ exchange of a peat field growing spring barley or perennial forage grass. Journal of Geophysical Research 109: D18116 doi:10.1029/2004JD004715

Long, S.P., 1991. Modification of the response of photosynthetic productivity to rising temperature by atmospheric $\mathrm{CO}_{2}$ concentrations: has its importance been underestimated? Plant Cell and Environment 14: 729-739

Long, S.P., \& J.-E. Hällgren, 1993. Measurement of $\mathrm{CO}_{2}$ assimilation by plants in the field and the laboratory. In: D.O. Hall, J.M.O. Scurlock, H.R. Bolhár-Nordenkampf, R.C. Leegood \& S.P. Long (eds.). Photosynthesis and production in a changing environment. Chapman \& Hall, London etc. pp. 129-167

Loubet, B., P. Cellier, C. Fléchard, O. Zurfluh, M. Irvine, E. Lamaud, P. Stella, R. Roche, B. Durand, D. Flura, S. Masson, P. Laville, D. Garrigou, E. Personne, M.Chelle \& J.-F. Castell, 2013. Investigating discrepancies in heat, $\mathrm{CO}_{2}$ fluxes and $\mathrm{O}_{3}$ deposition velocity over maize as measured by the eddycovariance and the aerodynamic gradient methods. Agricultural and Forest Meteorology 169: 35-50

Luo, Y., \& E.A.G. Schuur, 2020. Model parameterization to represent processes at unresolved scales and changing properties of evolving systems. Global Change Biology 26: 1109-1117

Luo, Z., G. Wang \& E. Wang, 2019. Global subsoil organic carbon turnover times dominantly controlled by soil properties rather than climate. Nature Communications, DOI https://doi.org/10.1038/s41467019-11597-9

Luyssaert, S., M. Reichstein, E.-D. Schulze, I. A. Janssens, B. E. Law, D. Papale, D. Dragoni, M. L. Goulden, A. Granier, W. L. Kutsch, S. Linder, G. Matteucci, E. Moors, J. W. Munger, K. Pilegaard, M. Saunders $\&$ E. M. Falge, 2009. Towards a consistency cross-check of eddy covariance flux-based and biometric estimates of ecosystem carbon balance. Global Biogeochemical Cycles 23: doi:10.1029/2008GB003377

Lynn, B.H., \& T.N. Carlson, 1990. A stomatal resistance model illustrating plant vs. external control of transpiration. Agricultural and Forest Meteorology 52: 5-43

Lüscher, A., U.A. Hartwig, D. Suter \& J. Nösberger, 2000. Direct evidence that symbiotic $\mathrm{N}_{2}$ fixation in fertile grassland is an important trait for a strong response of plants to elevated atmospheric $\mathrm{CO}_{2}$. Global Change Biology 6: 655-662

Lüscher, A., B. Jeangros, W. Kessler, O. Huguenin, M. Lobsiger, N. Millar \& D. Suter, 2004. Land use systems in grassland dominated regions. Organising Committee of the $20^{\text {th }}$ General Meeting of the European Grassland Federation, Zürich. 1229 pp.

Luyssaert, S., M. Reichstein, E.-D. Schulze, I.A. Janssens, B.E. Law, D. Papale, D. Dragoni, M.L. Goulden, A. Granier, W.L. Kutsch, S. Linder, G. Matteucci, E. Moors, J.W. Munger, K. Pilegaard, M. 
Saunders \& E.M. Falge, 2009. Toward a consistency cross-check of eddy covariance flux-based and biometric estimates of ecosystem carbon balance. Global Biogeochemical Cycles 23: GB3009, doi: 10.1029/2008GB003377

Ma, A., N. He, G. Yu, D. Wen \& S. Peng, 2016. Carbon storage in Chinese grassland ecosystems: influence of different integrative methods. Nature Scientific Reports 6: 21378, doi: 10.1038/srep21378

Ma, S.Y., D. Baldocchi, L. Xu \& T. Hehn, 2007. Inter-annual variability in carbon dioxide exchange of an oak/grass savanna and open grassland in California. Agricultural and Forest Meteorology 147: 157-171

Manabe, S., R.J. Stouffer, M.J. Spelman \& K. Bryan, 1991. Transient responses of a coupled oceanatmosphere model to gradual changes of atmospheric $\mathrm{CO}_{2}$. Part I: annual mean response. Journal of Climate 4: 785-818

Mascart, P., O. Taconet, J.-P. Pinty \& M. Ben Mehrez, 1991. Canopy resistance formulation and its effect in mesoscale models: a HAPEX perspective. Agricultural and Forest Meteorology 54: 319-351

McGinn, S.M., \& K.M. King, 1990. Simultaneous measurements of heat, water vapour and $\mathrm{CO}_{2}$ fluxes above alfalfa and maize. Agricultural and Forest Meteorology 49: 331-349

Meredith, L.K., R. Commane, J.W. Munger, A. Dunn, J. Tang, S.C. Wofsy \& R.G. Prinn, 2014. Atmospheric Measurement Techniques 7: 2787-2805

Meyers, T.P., \& D.D. Baldocchi, 2005. Current micrometeorological flux methodologies with applications in agriculture. In: J.L. Hatfield \& J.M. Baker (eds.). Micrometeorology in agricultural systems. Agronomy Monograph 47. American Society of Agronomy, pp. 381-396

Mokma, D.L., 2005. Organic soils. In: D. Hillel (ed.). Encyclopedia of Soils in the Environment, Elsevier, pp. 118-129

Monna, W.A.A., \& J.G. Van der Vliet, 1987. Facilities for Research and Weather Observations on the $213 \mathrm{~m}$ tower at Cabauw and at remote Locations. Koninklijk Nederlands Meteorologisch Instituut. Scientific Report WR-nr87-5. 27 pp.

Monteith, J.L., 1994. Validity of the correlation between intercepted radiation and biomass. Agricultural and Forest Meteorology 68: 213-220

Monteith, J.L., \& M.H. Unsworth, 1990. Principles of Environmental Physics, $2^{\text {nd }}$ Ed. Arnold, London etc. $291 \mathrm{pp}$.

Moreaux, V., B. Longdoz, D. Berveiller, N. Delpierre, E. Dufrêne, J.-M. Bonnefond, C. Chipeaux, R. Joffre, J.-M. Limousin, J.-M. Ourcival, K. Klumpp, O. Darsonville, A. Brut, T. Tallec, E. Ceschia, G. Panthou \& D. Loustau, 2020. Environmental control of land-atmosphere $\mathrm{CO}_{2}$ fluxes from temperate ecosystems: a statistical approach based on homogenized time series from five land-use types. Tellus B: Chemical and Physical Meteorology 72: 1-25

Mott, K.A., \& D.F. Parkhurst, 1991. Stomatal responses to humidity in air and helox. Plant Cell and Environment 14: 509-515

Muller, J.B.A., M. Coyle, D. Fowler, M.W. Gallagher, E.G. Nemitz \& C.J. Percival, 2009. Comparison of ozone fluxes over grassland by gradient and eddy covariance technique. Atmospheric Science Letters 10: $164-169$ 
Nemry, B., L. François, P. Warnant, F. Robinet \& J.-C. Gérard, 1996. The seasonality of the $\mathrm{CO}_{2}$ exchange between the atmosphere and the land biosphere: a study with a global mechanistic vegetation model. Journal of Geophysical Research 101D: 7111-7125

Nepstad, D.C., C.R. de Carvalho, E.A. Davidson, P.H. Jipp, P.A. Lefebvre, G.H. Negreiros, E.D. da Silva, T.A. Stone, S.E. Trumbore \& S. Vieira, 1994. The role of deep roots in the hydrological and carbon cycles of Amazonian forests and pastures. Nature 372: 666-669

Nijs, I., I. Impens \& T. Behaeghe, 1989. Leaf and canopy responses of Lolium perenne to long-term elevated atmospheric carbon-dioxide concentration. Planta 177: 312-320

Nykänen, H., J. Alm, K. Lång, J. Silvola \& P.J. Martikainen, 1995. Emissions of $\mathrm{CH}_{4}, \mathrm{~N}_{2} \mathrm{O}$ and $\mathrm{CO}_{2}$ from a virgin fen and a fen drained for grassland in Finland. Journal of Biogeography 22: 351-357

Oades, J.M., 1988. The retention of organic matter in soils. Biogeochemistry 5: 35-70

Ojima, D.S., B.O.M. Dirks, E.P. Glenn, C.E. Owensby \& J.O. Scurlock, 1993. Assessment of C budget for grasslands and drylands of the world. Water, Air, and Soil Pollution 70: 95-109

Ojima, D.S., W.J. Parton, M.B. Coughenour, J.M.O. Scurlock, T.B. Kirchner, T.G.F. Kittel, D.O. Hall, D.S. Schimel, E. Garcia Moya, T.G. Gilmanov, T.R. Seastedt, Apinan Kamnalrut, J.I. Kinyamario, S.P. Long, J.-C. Menaut, O.E. Sala, R.J. Scholes \& J.A. van Veen, 1996. Impact of climate and atmospheric carbon dioxide changes on grasslands of the world. In: Scope 56, Global Change: Effects on Coniferous Forests and Grasslands

Parton, W.J., D.S. Schimel, C.V. Cole \& D.S. Ojima, 1987. Analysis of factors controlling soil organic matter levels in Great Plains grasslands. Soil Science Society of America Journal 51: 1173-1179

Pavelka, M., M. Acosta, R. Kiese, N. Altimir, C. Brümmer, P. Crill, E. Darenova, R. Fuss, B. Gielen, A. Graf, L. Klemedtsson, A. Lohila, B. Longdoz, A. Lindroth, M. Nilsson, S. Maraňón Jiménez, L. Merbold, L. Montagnani, M. Peichl, M. Pihlatie, J. Pumpanen, P. Serrano Ortiz, H. Silvennoinen, U. Skiba, P. Vestin, P. Weslien, D. Janous \& W. Kutsch, 2018. Standardisation of chamber technique for $\mathrm{CO}_{2}$, $\mathrm{N}_{2} \mathrm{O}$ and $\mathrm{CH}_{4}$ fluxes measurements from terrestrial ecosystems. International Agrophysics 32: 569-587

Paz-Ferreiro, J., E. Medina-Roldán, N.J. Ostle, N.P. McNamara \& R.D. Bardgett, 2012. Grazing increases the temperature sensitivity of soil organic matter decomposition in a temperate grassland. Environmental Research Letters 7: 014027

Pearcy, R.W., \& O. Björkman, 1983. Physiological effects. In: E.R. Lemon (ed.). $\mathrm{CO}_{2}$ and Plants - the Response of Plants to Rising Levels of Atmospheric $\mathrm{CO}_{2}$. Westview Press, Boulder. pp. 65-105

Peisker, M., \& P. Apel, 1981. Influence of oxygen on photosynthesis and photorespiration in leaves of Triticum aestivum L. 4. Oxygen dependence of apparent quantum yield of $\mathrm{CO}_{2}$ uptake. Photosynthetica 15: 435-441

Piao, S., X. Wang, K. Wang, X. Li, A. Bastos, J.G. Canadell, P. Ciais, P. Friedlingstein \& S. Sitch, 2019. Interannual variation of terrestrial carbon cycle: issues and perspectives. Global Change Biology 26: 300-318

Piper, S.C., C.D. Keeling, M. Heimann \& E.F. Stewart, 2001. Exchanges of atmospheric $\mathrm{CO}_{2}$ and ${ }^{13} \mathrm{CO}_{2}$ with the terrestrial biosphere and oceans from 1978 to 2000. II. A three-dimensional tracer inversion model to deduce regional fluxes. Scripps Institution of Oceanography, SIO Reference 01-07: 1-18 
Pleijter, M., \& J.J.H. van den Akker, 2007. Onderwaterdrains in het veenweidegebied. Alterra-rapport 1586. Alterra, Wageningen. 59 pp.

Polley, H.W., R.L. Phillips, A.B. Frank, J.A. Bradford, P.L. Sims, J.A. Morgan \& J.R. Kiniry, 2011. Variability in light-use efficiency for gross primary productivity on Great Plains grasslands. Ecosystems 14: 15-27 Prentice, I.C., W. Cramer, S.P. Harrison, R. Leemans, R.A. Monserud \& A.M. Solomon, 1992. A global biome model based on plant physiology and dominance, soil properties and climate. Journal of Biogeography 19: 117-134

Price, D.T., \& T.A. Black, 1990. Effects of short-term variation in weather on diurnal canopy $\mathrm{CO}_{2}$ flux and evapotranspiration of a juvenile douglas-fir stand. Agricultural and Forest Meteorology 50: 139-158

Proctor, J., S. Hsiang, J. Burney, M. Burke \& W. Schlenker, 2018. Estimating global agricultural effects of geoengineering using volcanic eruptions. Nature 560: 480-483

Qi, A., P.J. Murray \& G.M. Richter, 2017. Modelling productivity and resource use efficiency for grassland ecosystems in the UK. European Journal of Agronomy 89: 148-158

Raich, J.W., \& W.H. Schlesinger, 1992. The global carbon dioxide flux in soil respiration and its relationship to vegetation and climate. Tellus 44B: 81-99

Raven, P.H., R.F. Evert \& H. Curtis, 1981. Biology of plants. Worth, New York, 686 pp.

Reichstein, M., E. Falge, D. Baldocchi, D. Papale, M. Aubinet, P. Berbigier, C. Bernhofer, N. Buchmann, T. Gilmanov, A. Granier, T. Grünwald, K. Havránkova, H. Ilvesniemi, D. Janous, A. Knohl, T. Laurila, A. Lohil, D. Loustau, G. Matteucci, T. Meyers, F. Miglietta, J.-M. Ourcival, J. Pumpanen, S. Rambal, E. Rotenberg, M. Sanz, J. Tenhunen, G. Seufert, F. Vaccari, T. Vesala, D. Yakir \& R. Valentini, 2005. On the separation of net ecosystem exchange into assimilation and ecosystem respiration: review and improved algorithm. Global Change Biology 11: 1424-1439

Reichstein, M., P. Ciais, D. Papale, R. Valentini, S. Running, N. Viovy, W. Cramer, A. Granier, J. Ogée, V. Allard, M. Aubinet, C. Bernhofer, N. Buchmann, A. Carrara, T. Grünwald, M. Heimann, B. Heinesch, A. Knohl, W. Kutsch, D. Loustau, G. Manca, G. Matteucci, F. Miglietta, J.M. Ourcival, K. Pilegaard, J. Pumpanen, S. Rambal, S. Schaphoff, G. Seufert, J.-F. Soussana, M.-J. Sanz, T. Vesala $\&$ M. Zhao, 2007. Reduction of ecosystem productivity and respiration during the European summer 2003 climate anomaly: a joint flux tower, remote sensing and modelling analysis. Global Change Biology 13: 634-651

Retallack, G.J., 2001. Cenozoic expansion of grasslands and climatic cooling. Journal of Geology 109: 407-426

Revelle, R., \& H.E. Suess, 1957. Carbon dioxide exchange between atmosphere and ocean and the question of an increase of atmospheric $\mathrm{CO}_{2}$ during the past decades. Tellus IX (1): 18-27

Ripley, E.A., \& R.E. Redmann, 1976. Grassland. In: J.L. Monteith (ed.) Vegetation and the Atmosphere, Volume 2. Academic Press, London etc., pp. 349-398

Robson, M.J., G.J.A. Ryle \& J. Woledge, 1988. The grass plant - its form and function. In: M.B. Jones $\&$ A. Lazenby (eds.) The Grass Crop - The Physiological Basis of Production. Chapman and Hall, London etc., pp. 27-83

Rochette, P., R.L. Desjardins \& E. Pattey, 1991. Spatial and temporal variability of soil respiration in agricultural fields. Canadian Journal of Soil Science 71: 189-196 
Rochette, P., B. Ellert, E.G. Gregorich, R.L. Desjardins, E. Pattey, R. Lessard \& B.G. Johnson, 1997. Description of a dynamic closed chamber for measuring soil respiration and its comparison with other techniques. Canadian Journal of Soil Science 77: 195-203

Rogiers, N., F. Conen, M. Furger, R. Stöckli \& W. Eugster, 2008. Impact of past and present landmanagement on the C-balance of a grassland in the Swiss Alps. Global Change Biology 14: 2613-2625

Rowntree, P.R., \& L. Dümenil, 1995. Hydrology in climate models and effects on climate. In: H.R. Oliver $\&$ S.A. Oliver (eds.). The role of water and the hydrological cycle in global change. NATO ASI Series I: Global Environmental Change 31: 59-104

Ruimy, A., P.G. Jarvis, D.D. Baldocchi \& B. Saugier, 1995. $\mathrm{CO}_{2}$ fluxes over plant canopies and solar radiation: a review. Advances in Ecological Research 26: 1-68

Ryu, Y., D.D. Baldocchi, S. Ma \& T. Hehn, 2008. Interannual variability of evapotranspiration and energy exchange over an annual grassland in California. Journal of Geophysical Research 113: D09104

Saigusa, N., T. Oikawa \& S. Liu, 1998. Seasonal variations of the exchange of $\mathrm{CO}_{2}$ and $\mathrm{H}_{2} \mathrm{O}$ between a grassland and the atmosphere: an experimental study. Agricultural and Forest Meteorology 89: 131-139

Sala, O.E., W.J. Parton, L.A. Joyce \& W.K. Lauenroth, 1988. Primary production of the central grassland region of the United States. Ecology 69: 40-45

Salinger, M.J., 2007. Agriculture's influence on climate during the Holocene. Agricultural and Forest Meteorology 142: 96-102

Sattari, S.Z., A.F. Bouwman, R. Martinez Rodríguez, A.H.W. Beusen \& M.K. van Ittersum, 2016. Negative global phosphorus budgets challenge sustainable intensification of grasslands. Nature Communications 7, 10696, doi:10.1038/ncomms10696(2016)

Saugier, B., \& N. Katerji, 1991. Some plant factors controlling evapotranspiration. Agricultural and Forest Meteorology 54: 263-277

Scafetta, N., A. Mirandola \& A. Bianchini, 2017. Natural climate variability, part 1: observations versus the modeled predictions. International Journal of Heat and Technology 35: 9-17

Schapendonk, A.H.C.M., P. Dijkstra, P. Groenwold, J. Pot \& C.S. van de Geijn, 1997. Carbon balance and water use efficiency of frequently cut Lolium perenne L. Swards at elevated carbon dioxide. Global Change Biology 3: 207-216

Schimel, D.S., 1995. Terrestrial ecosystems and the carbon cycle. Global Change Biology 1: 77-91

Schlesinger, W.H. \& E.S. Bernhardt, 2013. Biogeochemistry, an analysis of global change. Elsevier, Amsterdam etc., 672 pp.

Schneider, J., L. Kutzbach, S. Schulz \& M. Wilmking, 2009. Overestimation of $\mathrm{CO}_{2}$ respiration fluxes by the closed chamber method in low-turbulence nighttime conditions. Journal of Geophysical Research 114, doi:10.1029/2008JG000909

Schothorst, C.J., 1982. Drainage and behaviour of peat soils. In: H. de Bakker \& M.W. van den Berg (eds.) Proceedings of the Symposium on Peat Lands Below Sea Level. International Institute for Land Reclamation and Improvement, Wageningen, pp. 130-163

Schulze, E.-D., R. Leuning \& F.M. Kelliher, 1995. Environmental regulation of surface conductance for evaporation from vegetation. Vegetatio 121: 79-87 
Schwandner, F.M., M.R. Gunson, C.E. Miller, S.A. Carn, A. Eldering, T. Krings, K.R. Verhulst, D.S. Schimel, H.M. Nguyen, D. Crisp, C.W. O’Dell, G.B. Ostermann, L.T. Iraci \& J.R. Podolske, 2017. Spaceborne detection of localized carbon dioxide sources. Science 358: eaam 5782

Scurlock, J.M.O., K. Johnson \& R.J. Olson, 2002. Estimating net primary productivity from grassland biomass dynamics measurements. Global Change Biology 8: 736-753

Segal, M., R. Avissar, M. McCumber \& R.A. Pielke, 1988. Evaluation of vegetation effects on the generation and modification of mesoscale circulations. Journal of Atmospheric Sciences 45: 2268-2292

Sellers, P.J., Y. Mintz, Y.C. Sud \& A. Dalcher, 1986. A Simple Biosphere model (SiB) for use within General Circulation Models. Journal of Atmospheric Science 43: 505-531

Šesták, Z., J. Čatský \& P.G. Jarvis (eds.), 1971. Plant photosynthetic production. Dr. W. Junk N.V. Publishers, The Hague. 818 pp.

Silvola, J., J. Alm, U. Ahlholm, H. Nykänen \& P.J. Martikainen, 1996. $\mathrm{CO}_{2}$ fluxes from peat in boreal mires under varying temperature and moisture conditions. Journal of Ecology 84: 219-228

Smit, H.J., M.J. Metzger \& F. Ewert, 2008. Spatial distribution of grassland productivity and land use in Europe. Agricultural Systems 98: 208-219

Smith, P., 2014. Do grasslands act as a perpetual sink for carbon? Global Change Biology 20: 2708-2711

Sonneveld, M.P.W., \& E.A. Lantinga, 2011. The contribution of mineralization to grassland $\mathrm{N}$ uptake on peatland soils with anthropogenic A horizons. Plant and Soil 340: 357-368

Soussana, J.F., V. Allard, K. Pilegaard, P. Ambus, C. Ammann, C. Campbell, E. Ceschia, J. Clifton-Brown, S. Czobel, R. Domingues, C. Flechard, J. Fuhrer, A. Hensen, L. Horvath, M. Jones, G. Kasper, C. Martin, Z. Nagy, A. Neftel, A. Raschi, S. Baronti, R.M. Rees, U. Skiba, P. Stefani, G. Manca, M. Sutton, Z. Tuba \& R. Valentini, 2007. Full accounting of the greenhouse gas $\left(\mathrm{CO}_{2}, \mathrm{~N}_{2} \mathrm{O}, \mathrm{CH}_{4}\right)$ budget of nine European grassland sites. Agriculture, Ecosystems and Environment 121: 121-134

Spencer, R.W., 2008. The discovery of global warming. Harvard University Press, $240 \mathrm{pp}$.

Spielmann, F.M., A. Hammerle, F. Kitz, K. Gerdel \& G. Wohlfahrt, 2020. Seasonal dynamics of the COS and $\mathrm{CO}_{2}$ exchange of a managed temperate grassland. Biogeosciences 17: 4281-4295

Stiling, P.D., 2015. Ecology: global insights \& investigations. McGraw-Hill, New York, 566 pp.

Sullivan, M., S. Lewis, K. Affum-Baffoe, C. Castilho, F. Costa, A. Cuni Sanchez, C. Ewango, W. Hubau, B. Marimon, A. Monteagudo-Mendoza, L. Qie, B. Sonké, R. Vásquez Martínez, T. Baker, R. Brienen, T. Feldpausch, D. Galbraith, M. Gloor, Y. Malhi \& O. Phillips, 2020. Long-term thermal sensitivity of Earth's tropical forests. Science 368: 869-874

Sun, Y., C. Frankenberg, J.D. Wood, D.S. Schimel, M. Jung, L. Guanter, D.T. Drewry, M. Verma, A. Porcar-Castell, T.J. Griffis, L. Gu, T.S. Magney, P. Köhler, B. Evans \& K. Yuen, 2017. OCO-2 advances photosynthesis observation from space via solar-induced chlorophyll fluorescence. Science 358: eaam 5747

Sundquist, E.T., 1993. The global carbon dioxide budget. Science 259: 934-941

Suter, D., M. Frehner, B.U. Fischer, J. Nösberger \& A. Lüscher, 2002. Eleved $\mathrm{CO}_{2}$ increases carbon allocation to the roots of Lolium perenne under free-air $\mathrm{CO}_{2}$ enrichment but not in a controlled environment. New Phytologist 154: 65-75 
Tan, Z., Y. Zhang, G. Yu, L. Sha, J. Tang X. Deng \& Q. Song, 2010. Carbon balance of a primary tropical seasonal rain forest. Journal of Geophysical Research 115: D00H26

Tans, P.P., I.Y. Fung \& T. Takahashi, 1990. Observational constraints on the global atmospheric $\mathrm{CO}_{2}$ budget. Science 247: 1431-1438

Tans, P.P., 2019. www.esrl.noaa.gov/gmd/ccgg/trends/. National Oceanic and Atmospheric Administration, Earth System Research Laboratory.

Tenhunen, J.D., C.T. Gillespie, S.F. Oberbauer, A. Sala \& S. Whalen, 1995. Climate effects on the carbon balance of tussock tundra in the Philip Smith Mountains, Alaska. Flora 190: 273-283

Thom, A.S., 1972. Momentum, mass and heat exchange of vegetation. Quarterly Journal of the Royal Meteorological Society 98: 124-134

Thom, A.S., 1975. Momentum, mass and heat exchange of plant communities. In: Monteith J.L. (ed.) Vegetation and the Atmosphere. Academic Press, London etc, pp. 57-109

Thornley, J.H.M., 1998. Grassland dynamics. An ecosystem simulation model. CAB International, Wallingford, $241 \mathrm{pp}$.

Thornley, J.H.M., 2011. Plant growth and respiration re-visited: maintenance respiration defined - it is an emergent property of, not a separate process within, the system - and why the respiration : photosynthesis ratio is conservative. Annals of Botany 108: 1365-1380

Turner, D.P., S. Urbanski, D. Bremer, S.C. Wofsy, T. Meyers, S.T. Gower \& M. Gregory, 2003. A crossbiome comparison of daily light use efficiency for gross primary production. Global Change Biology 9: 383-395

Van den Pol-van Dasselaar, A., M.L. van Beusichem \& O. Oenema, 1999. Methane emissions from wet grasslands on peat soil in a nature reserve. Biogeochemistry 44: 205-220

Van Dijk, A.I.J.M., \& A.J. Dolman, 2004. Estimates of $\mathrm{CO}_{2}$ uptake and release among European forests based on eddy covariance data. Global Change Biology 10: 1445-1459

Van Huissteden, J., R. van den Bos \& I. Marticorena Alvarez, 2006. Modelling the effect of water-table management on $\mathrm{CO}_{2}$ and $\mathrm{CH}_{4}$ fluxes from peat soils. Netherlands Journal of Geosciences 85: 3-18

Van Zandvoort, A., D.R. Lapen, I.D. Clark, C. Flemming, E. Craiovan, M.D. Sunohara, R. Boutz \& N. Gottschall, 2017. Soil $\mathrm{CO}_{2}, \mathrm{CH}_{4}$, and $\mathrm{N}_{2} \mathrm{O}$ over and between tile drains on corn, soybean, and forage fields under tile drain management. Nutrient Cycling in Agroecosystems 109: 115-132

Veenendaal, E.M., O. Kolle, P.A. Leffelaar, A.P. Schrier-Uijl, J. Van Huissteden, J. Van Walsem, F. Möller $\&$ F. Berendse, 2007. $\mathrm{CO}_{2}$ exchange and carbon balance in two grassland sites on eutrophic drained peat soils. Biogeosciences 4: 1027-1040

Velthof, G.L., \& O. Oenema, 1995. Nitrous oxide fluxes from grassland in the Netherlands: II. effects of soil type, nitrogen fertilizer application and grazing. European Journal of Soil Science 46: 541-549

Verberne, E.L.J., J. Hassink, P. de Willigen, J.J.R. Groot \& J.A. van Veen, 1990. Modelling organic matter dynamics in different soils. Netherlands Journal of Agricultural Science 38: 221-238

Verhoef, A., S.J. Allen, H.A.R. de Bruin, C.M.J. Jacobs \& B.G. Heusinkveld, 1996. Fluxes of carbon dioxide and water vapour from a Sahelian savanna. Agricultural and Forest Meteorology 80: 231-248

Verma, S.B., \& N.J. Rosenberg, 1976. Carbon dioxide concentration and flux in a large agricultural region of the Great Plains of North America. Journal of Geophysical Research 81: 399-405 
Verma, S.B., D.D. Baldocchi, D.E. Anderson, D.R. Matt \& R.J. Clement, 1986. Eddy fluxes of $\mathrm{CO}_{2}$, water vapor, and sensible heat over a deciduous forest. Boundary-Layer Meteorology 36: 71-91

Vitousek, P., 2015. Grassland ecology: complexity of nutrient constraints. Nature Plants 1: 15098.

Waldo, S., E.S. Russell, K. Kostyanovsky, S.N. Pressley, P.T. O’Keeffe, D.R. Huggins, C.O. Stöckle, W.L. Pan \& Brian K. Lamb, 2019. $\mathrm{N}_{2} \mathrm{O}$ emissions from two agroecosystems: high spatial variability and long pulses observed using static chambers and the flux-gradient technique. Journal of Geophysical Research: Biogeosciences 124: 1887-1904

Warnant, P., L. François, D. Strivay \& J.-C. Gérard, 1994. CARAIB: a global model of terrestrial biological productivity. Global Biogeochemical Cycles 8: 255-270

Watson, R.T., I.R. Noble, B. Bolin, N.H. Ravindranath, D.J. Verardo \& D.J. Dokken (eds.), 2000. Land use, land-use change and forestry. IPCC Special Report. Cambridge University Press, Cambridge, 375 pp.

Wedin, D.A., 1996. Nutrient cycling in grasslands: an ecologist's perspective. In: R.E. Joost \& C.A. Roberts (eds.). Nutrient cycling in forage systems. Potash and Phosphate Institute, Manhattan KS, pp. 29-44.

Weideveld, S.T.J., W. Liu, M. van den Berg, L.P.M. Lamers \& C. Fritz, 2020. Sub-soil irrigation does not lower greenhouse gas emission from drained peat meadows. Biogeosciences Discussions, https://doi. org/10.5194/bg-2020-230

Wilson, D., \& J.P. Cooper, 1969. Effect of temperature during growth on leaf anatomy and subsequent light-saturated photosynthesis among contrasting Lolium genotypes. New Phytologist 68: 1115-1123

Woledge, J., \& W.D. Dennis, 1982. The effect of temperature on photosynthesis of ryegrass and white clover leaves. Annals of Botany 50: 25-35

Woledge, J., \& A.J. Parsons, 1986. The effect of temperature on the photosynthesis of ryegrass canopies. Annals of Botany 57: 487-497

Woledge, J., J.A. Bunce \& V. Tewson, 1989. The effect of air humidity on photosynthesis of ryegrass and white clover at three temperatures. Annals of Botany 63: 271-279

Wolf, J., \& L.H.J.M. Janssen, 1991. Effects of changing land use in the Netherlands on net carbon fixation. Netherlands Journal of Agricultural Science 39: 237-246

Wood, S., K. Sebastian \& S.J. Scherr, 2000. Pilot Analysis of Global Ecosystems. World Resources Institute, Washington, $125 \mathrm{pp}$.

Wu, J., P.E. Jansson, L. van der Linden, K. Pilegaard, C. Beier \& A. Ibrom, 2013. Modelling the decadal trend of ecosystem carbon fluxes demonstrates the important role of functional changes in a temperature deciduous forest. Ecological Modelling 260: 50-61

Yang, H.S., \& B.H. Janssen, 2000. A mono-component model of carbon mineralization with a dynamic rate constant. European Journal of Soil Science 51: 517-529

Yuan, W., S. Liu, G. Zhou, G. Zhou, L.L. Tieszen, D. Baldocchi, C. Bernhofer, H. Gholz, A.H. Goldstein, M.L. Goulden, D.Y. Hollinger, Y. Hu, B.E. Law, P.C. Stoy, T. Vesala \& S.C. Wofsy, 2007. Deriving a light use efficiency model from eddy covariance flux data for predicting daily gross primary production across biomes. Agricultural and Forest Meteorology 143: 189-207

Zeeman, M.J., R. Hiller, A. K. Gilgen, P. Michna, P. Plüss, N. Buchmann, W. Eugster, 2010. Management and climate impacts on net $\mathrm{CO}_{2}$ fluxes and carbon budgets of three grasslands along an elevational gradient in Switzerland. Agricultural and Forest Meteorology 150: 519-530 
Zhang, Y., M. Xu, H. Chen \& J. Adams, 2009. Global pattern of NPP to GPP ratio derived from MODIS data: effects of ecosystem type, geographical location and climate. Global Ecology and Biogeography 18: 280-290

Zhao, J., M. Zhang, W. Xiao, W. Wang, Z. Zhang, Z. Yu, Q. Xiao, Z. Cao, J. Xu, X. Zhang, S. Liu \& X. Lee, 2019. An evaluation of the flux-gradient and the eddy covariance method to measure $\mathrm{CH}_{4}, \mathrm{CO}_{2}$, and $\mathrm{H}_{2} \mathrm{O}$ fluxes from small ponds. Agricultural and Forest Meteorology 275: 255-264

Zhao, P., A. Hammerle, M. Zeeman \& G. Wohlfahrt, 2018. On the calculation of daytime $\mathrm{CO}_{2}$ fluxes measured by automated closed transparent chambers. Agricultural and Forest Meteorology 263: $267-$ 275 


\section{Summary}

This thesis begins from the observation that the increase in the atmospheric $\mathrm{CO}_{2}$ concentration has not been increasing as fast as could be expected on basis of anthropogenic $\mathrm{CO}_{2}$ emissions. Close examination shows that the terrestrial biosphere exhibits a large annual $\mathrm{CO}_{2}$ sink of approximately $12.5 \mathrm{Gt} \mathrm{CO}_{2}$. This equates approximately $50 \%$ of anthropogenic $\mathrm{CO}_{2}$ emissions, which implies that without this biospheric sink the atmospheric $\mathrm{CO}_{2}$ concentration could have increased to well over $500 \mu \mathrm{mol} \mathrm{mol}^{-1}$ instead of its current $410 \mu \mathrm{mol} \mathrm{mol}^{-1}$. The study aims to explore to which extent the grassland biome could play a role in this biospheric net $\mathrm{CO}_{2}$ sink. It starts by analysing how a $\mathrm{CO}_{2}$ balance in grassland ecosystems emerges from its constituent processes. Its successive chapters develop how diurnal cycles of assimilatory and respiratory activity aggregate to an annual cycle of $\mathrm{CO}_{2}$ exchange between atmosphere and grassland ecosystem. It establishes why the annual net $\mathrm{CO}_{2}$ exchange or $\mathrm{CO}_{2}$ balance differs strongly among years.

Particular attention in this analysis is given to drained peat grassland ecosystems. Undrained peat grasslands and associated types of wetlands used to be very common and are characterised by large amounts of $\mathrm{C}$ immobilised in an anaerobic soil profile. Many of these peat grasslands have been drained to improve agricultural productivity and now have a partially aerobic soil profile rich in organic matter. This aerobic soil profile is characterised by the accelerated decomposition of peat. This decomposition of peat results in a release of $\mathrm{CO}_{2}$, which has a potentially large effect on the ecosystem's annual $\mathrm{CO}_{2}$ balance. The annual $\mathrm{CO}_{2}$ balance in a grazed drained peat grassland ecosystem in the Netherlands is determined and the effect of different levels of drainage on this annual $\mathrm{CO}_{2}$ balance is evaluated. It is demonstrated that the restoration of peat grassland ecosystems harbours great potential for $\mathrm{CO}_{2}$ sequestration.

The succession of chapters in the thesis follows a logic in which the temporal and spatial scales of the $\mathrm{CO}_{2}$ exchange processes increase. It navigates from instant grass sward processes to instant ecosystem processes, which then aggregate to annual patterns of $\mathrm{CO}_{2}$ exchange in grassland ecosystems. These annual patterns are subsequently used to explore the potential role of the biosphere in general and the grassland biome in particular in a net $\mathrm{CO}_{2}$ sequestration from the atmosphere.

In Chapter one, the general introduction lays out the processes in the global $\mathrm{C}$ cycle at successively smaller time scales, which constitute a complex system of negative feedbacks working towards a stabilisation of the atmospheric $\mathrm{CO}_{2}$ concentration. Since the start of measurements on the atmospheric $\mathrm{CO}_{2}$ concentration a discrepancy has 
been observed with anthropogenic $\mathrm{CO}_{2}$ emissions. This discrepancy shows a consistent net $\mathrm{CO}_{2}$ sequestration from the atmosphere, although the magnitude of this net $\mathrm{CO}_{2}$ sequestration varies strongly among years. An indication for a role of the biosphere follows from the annual cycle of the atmospheric $\mathrm{CO}_{2}$ concentration, which concurs with the growing season. This annual cycle shows that the atmospheric $\mathrm{CO}_{2}$ concentration sees a sharp drop around spring and gradually increases again afterwards. The relative occurrence of different $\mathrm{C}$ isotopes in the atmosphere shows that a particularly large net $\mathrm{CO}_{2}$ sink can be observed in the northern latitudes during the growing season, which supports a clear role for the terrestrial biosphere. Measurements of $\mathrm{CO}_{2}$ exchange in tropical rainforests suggest a net $\mathrm{CO}_{2}$ sequestration which is largely driven by regrowth after prior deforestation. Measurements in temperate forests show a more consistent net $\mathrm{CO}_{2}$ sequestration depending on climate conditions. However, grassland ecosystems can be seen as particularly suited to the sequestration of $\mathrm{CO}_{2}$ because of their physiological characteristics and the nature of their soil organic matter. Measurements of $\mathrm{CO}_{2}$ exchange in grasslands on mineral soils support such a role, even when characterised by large interannual variations. Grasslands on drained organic soils generally exhibit a net $\mathrm{CO}_{2}$ release because of the decomposition of organic matter in the aerobic soil profile.

Chapter two starts at the lowest level of process aggregation in this thesis. It introduces an experiment in which the photosynthetic activity in an in vivo grown grass sward was measured under laboratory conditions in summer and autumn. This opens a perspective on the seasonal course of photosynthetic characteristics. Photosynthetic rate was measured as a function of irradiance, temperature $\left(15-30{ }^{\circ} \mathrm{C}\right.$ and $\left.10-25^{\circ} \mathrm{C}\right)$ and ambient $\mathrm{CO}_{2}$ concentration $\left(200-700 \mu \mathrm{mol} \mathrm{mol}^{-1}\right)$. The dynamics in the response of photosynthetic activity were analysed by applying a process description where photosynthetic rate is determined by both electron transport rate in the thylakoid membrane and carboxylation at low irradiance. However, it shows that it is difficult to apply these essentially biochemical processes to in vivo leaf area. It proved to be not possible to consistently parametrise the underlying equations. Aggregated hyperbolic response functions instead show that the initial leaf photosynthetic rate at zero irradiance consistently decreased with temperature; the initial rate consistently increased with ambient $\mathrm{CO}_{2}$ concentration. The photosynthetic rate at saturating irradiance was never actually attained and therefore rather was a hypothetical value resulting from the response at lower irradiance. In general, photosynthetic rate appeared to decrease with temperature in summer and show a temperature optimum in autumn.

Chapter three reports on aerodynamic gradient $\mathrm{CO}_{2}$ flux measurements done in a grazed drained peat grassland during a period of two years. The measured instantaneous net $\mathrm{CO}_{2}$ flux was separated into a respiratory and a gross assimilatory $\mathrm{CO}_{s}$ flux. The respiratory $\mathrm{CO}_{2}$ flux responded to temperature in a $Q_{10}$ type of relationship, whereas the assimilatory 
$\mathrm{CO}_{2}$ flux primarily responded to irradiance hyperbolically. Low temperature appeared to be strongly limiting the initial response of the assimilatory $\mathrm{CO}_{2}$ flux to irradiance during a substantial part of the growing season. This is a consequence of the concurrence of low irradiance and low temperature in the early periphery of the day. An effect of aerial vapour pressure deficit and calculated surface conductance on the assimilatory $\mathrm{CO}_{2}$ flux could not be detected, possibly as a result of the relatively maritime weather conditions during measurement. A clear correlation was found between the assimilatory $\mathrm{CO}_{2}$ flux at saturating irradiance (a measure for ecosystem photosynthetic capacity) and the respiratory $\mathrm{CO}_{2}$ flux at reference temperature (a measure for metabolically active biomass). The respiratory $\mathrm{CO}_{2}$ flux responded stronger to temperature than the assimilatory $\mathrm{CO}_{2}$ flux. The diurnal cycle of the instant assimilatory and respiratory $\mathrm{CO}_{2}$ fluxes shows that net $\mathrm{CO}_{2}$ sequestration was enhanced under conditions of high primary productivity and moderate temperatures. Moderate temperatures suppress respiratory activity more than assimilatory activity. These are conditions typically found in the higher latitudes.

Chapter four reports on aerodynamic gradient energy flux measurements done in the same grazed drained peat grassland during the same two consecutive years as in Chapter three. It is measured how the downward net irradiance dissipates into an upward latent heat flux (associated with evapotranspiration) and an upward sensible heat flux (conductive heat flux from the surface). The latent heat flux is strongly influenced by the ecosystem's surface conductance (much derived from its stomatal conductance). Both upward heat fluxes more or less function as communicating vessels. If the latent heat flux is impaired because of low surface conductance, the surface temperature increases. The increased difference between surface and air temperature subsequently increases the sensible heat flux. Their interrelation is reflected in the Bowen ratio, which is the ratio of the sensible heat flux to the latent heat flux. A high Bowen ratio thus points at an impaired latent heat flux and a reduced ecosystem surface conductance. Several months during the growing season were identified with an increased Bowen ratio, thus pointing at a limiting ecosystem surface conductance and thereby suppressing the assimilatory $\mathrm{CO}_{2}$ flux more than the respiratory $\mathrm{CO}_{2}$ flux.

Chapter five reports on eddy correlation $\mathrm{CO}_{2}$ flux measurements done during a growing season in a grazed peat grassland at two different drainage levels. The measured instantaneous net $\mathrm{CO}_{2}$ flux was again separated into a respiratory and a gross assimilatory $\mathrm{CO}_{2}$ flux. The experiment aims to measure the difference in the respiratory $\mathrm{CO}_{2}$ flux between both drainage levels, which is a measure for the difference in decomposition of peat in both aerobic soil profiles. Direct comparison of the respiratory $\mathrm{CO}_{2}$ fluxes was not possible because by far the greatest part of these fluxes are associated with living biomass and not with the decomposition of peat. Relative differences were too small to 
be detectable. A different approach was thus chosen in which the instantaneous net $\mathrm{CO}_{2}$ flux was treated as a process as such, responding to the gross assimilatory $\mathrm{CO}_{2}$ flux and temperature. The ecosystem net $\mathrm{CO}_{2}$ flux tended towards sequestration at an increasing assimilatory $\mathrm{CO}_{2}$ flux and towards release at increasing temperature. Comparison of the net $\mathrm{CO}_{2}$ fluxes at both drainage levels at zero assimilatory activity and a temperature of $15{ }^{\circ} \mathrm{C}$ indicated that the net $\mathrm{CO}_{2}$ release from the peat grassland with deep drainage was higher by $0.012 \mathrm{mg} \mathrm{CO}_{2} \mathrm{~m}^{-2} \mathrm{~s}^{-1}$ than the net $\mathrm{CO}_{2}$ release from the peat grassland with a more shallow drainage. At a hypothetically constant temperature of $15^{\circ} \mathrm{C}$ this translates into an annual difference of $375 \mathrm{~g} \mathrm{CO}_{2} \mathrm{~m}^{-2} \mathrm{y}^{-1}$ or 3.75 ton $\mathrm{CO}_{2}$ ha $^{-1} \mathrm{y}^{-1}$.

Chapter six aggregates the instantaneous $\mathrm{CO}_{2}$ fluxes and their environmental parameters from Chapters three and five to monthly values. This results in the annual cycle of $\mathrm{CO}_{2}$ exchange at a time resolution where effects of differences in weather conditions on the $\mathrm{CO}_{2}$ flux components and the annual net $\mathrm{CO}_{2}$ exchange can be properly assessed. It shows that the annual cycle of the gross assimilatory $\mathrm{CO}_{2}$ flux responded strongly to irradiance with a baseline response of $2.20 \mathrm{~g} \mathrm{CO}_{2} \mathrm{MJ}^{-1}$. The baseline response was mediated by limiting effects of low temperature and high vapour pressure deficit. Low temperature had relatively little impact on the annual assimilatory $\mathrm{CO}_{2}$ flux as it generally concurred with low irradiance. High vapour pressure deficit appeared to be a major limiting factor in the annual assimilatory $\mathrm{CO}_{2}$ flux as it was felt at high irradiance. The annual cycle of the respiratory $\mathrm{CO}_{2}$ flux responded to both temperature and assimilatory $\mathrm{CO}_{2}$ flux, although the effects could not be really separated. The response to temperature followed a $Q_{10}$ type of relationship, sharply increasing beyond monthly average temperatures of $5^{\circ} \mathrm{C}$. In its response to the assimilatory $\mathrm{CO}_{2}$ flux the respiratory $\mathrm{CO}_{2}$ flux showed clear hysteresis, with higher values in the $2^{\text {nd }}$ half of the growing season. This can be related both to higher temperatures and to an increase in amount of decomposing senesced organic matter as the season progresses. For the grazed drained peat grassland ecosystem annual net $\mathrm{CO}_{2}$ releases of 623 and $920 \mathrm{~g} \mathrm{CO}_{2} \mathrm{~m}^{-2} \mathrm{y}^{-1}$ were calculated, which are considered to be a lower boundary for the decomposition of peat in the aerobic soil profile. An export of $\mathrm{C}$ in dairy produce which is calculated to be equivalent to approximately $200 \mathrm{~g} \mathrm{CO}_{2}$ $\mathrm{m}^{-2} \mathrm{y}^{-1}$ should be added to the ecosystem respiratory $\mathrm{CO}_{2}$ flux depending on the degree to which this $\mathrm{C}$ is considered to be respired outside the ecosystem.

In Chapter seven, the general discussion reflects on the research methodology and weaves together the processes at the successive levels of aggregation as explored in Chapters two to six. It demonstrates how patterns of photosynthetic activity in the grass sward re-appear in instant ecosystem $\mathrm{CO}_{2}$ exchange and how patterns of instant ecosystem $\mathrm{CO}_{2}$ exchange translate into an annual cycle of $\mathrm{CO}_{2}$ exchange. In the annual cycle of $\mathrm{CO}_{2}$ exchange higher levels of assimilatory activity lead to a higher net $\mathrm{CO}_{2}$ sequestration whereas higher temperature through its dominating effect on respiratory activity leads to a lower 
net $\mathrm{CO}_{2}$ sequestration. This emphasises the significance of the climate of an ecoregion, where a moderately warm but productive growing period and low temperatures outside the growing period enhance net $\mathrm{CO}_{2}$ sequestration. Such conditions particularly apply to ecosystems in the temperate and boreal climate zones.

Drained grasslands on organic soils are generally characterised by a net $\mathrm{CO}_{2}$ release originating in the decomposition of organic matter in the aerobic soil profile. In this study an annual net $\mathrm{CO}_{2}$ release of at least $600-900 \mathrm{~g} \mathrm{CO}_{2} \mathrm{~m}^{-2} \mathrm{y}^{-1}$ was found. It was also shown that drainage depth has a possible effect on the $\mathrm{CO}_{2}$ release. Further calculations on basis of literature indicate that the restoration of drained peat grasslands to undrained conditions could ultimately result in extraordinarily high levels of net $\mathrm{CO}_{2}$ sequestration as a result of new peat formation.

The observed pattern of ecosystem net $\mathrm{CO}_{2}$ exchange in response to assimilatory activity and temperature returns in the annual fluctuations in the biospheric net $\mathrm{CO}_{2}$ sequestration from the atmosphere. Although this net sequestration on average equals $50 \%$ of the anthropogenic $\mathrm{CO}_{2}$ emissions, the actual percentage varies among years between 20 and $80 \%$. Closer observation shows that much of this fluctuation concurs with fluctuations in global temperature. Warmer years are characterised by a lower net $\mathrm{CO}_{2}$ sequestration than cooler years. The absolute net $\mathrm{CO}_{2}$ sequestration has been increasing consistently since the start of structured measurement of the atmospheric $\mathrm{CO}_{2}$ concentration. This shows that the negative feedback from the biosphere on atmospheric $\mathrm{CO}_{2}$ has been responding well to an increasing atmospheric $\mathrm{CO}_{2}$ concentration and a longer growing season as a result of rising temperature. It is discussed how grasslands could have a substantial role in this biospheric net $\mathrm{CO}_{2}$ sequestration. It can be argued that the biospheric processes of $\mathrm{C}$ capture and $\mathrm{C}$ loss in general support a regulating role for the biosphere in between atmospheric $\mathrm{CO}_{2}$ and long-term $\mathrm{C}$ sedimentation. Whereas this annual sequestration has a large impact on the course of the atmospheric $\mathrm{CO}_{2}$ concentration, it is of a minute size relative to the soil $\mathrm{C}$ content. This makes its direct observation in measurements of soil C content very improbable.

This thesis shows how processes of grassland $\mathrm{CO}_{2}$ exchange result in an annual $\mathrm{CO}_{2}$ balance. It highlights the causes for fluctuations in this $\mathrm{CO}_{2}$ balance. It illustrates how the biosphere as a whole exerts a strong and direct influence on the atmospheric $\mathrm{CO}_{2}$ concentration by instantly sequestering large amounts of $\mathrm{CO}_{2}$. It discusses why grasslands could have a large role in this biospheric $\mathrm{CO}_{2}$ sequestration, even though the Dutch pastureland in this study is in multiple respects uncharacteristic of natural grasslands. It is argued that reinforcing the natural role of the biosphere by restoration of degraded ecosystems such as peatlands is an effective and efficient approach to mitigating anthropogenic $\mathrm{CO}_{2}$ emissions. 


\section{Acknowledgments}

Along the elongated time line of this thesis many people were directly or indirectly involved, many of them in its earlier phase. I thank the many colleague $\mathrm{PhD}$ candidates in the Department of Theoretical Production Ecology, the C.T. de Wit Graduate School for Production Ecology \& Resource Conservation and the Research Institute for Agrobiology and Soil Fertility for discussions on a wide range of topics, many sharing in methodological approaches. I am much indebted to the contributions of particularly Jan Goudriaan, Arjan Hensen, Joost Wolf, Marcel van Oijen, Ad Schapendonk, Peter van Leeuwen, Gon van Laar, Rob Dierckx and Willem Tonk.

I thank Egbert Lantinga for the substantive discussions on the subject matter and for acting as co-promotor. I want to express particular gratitude to Martin van Ittersum for his role as promotor, for the methodological reflection and sharpening the line of reasoning in the thesis and for skilfully guiding the manuscript towards its completion.

Two persons were present during the entire trajectory of this thesis. Without their trust and encouragement this undertaking would not have been sustained, let alone been completed. I am most grateful to my co-promotor Rudy Rabbinge for his patience, guidance, many reviews and methodological insights and for involving me in various initiatives engaged in the mitigation of $\mathrm{CO}_{2}$ emissions in the Netherlands. I thank my mother for her continued support and confidence, to which I owe so much. 


\section{About the author}

Björn Dirks was born in Heerlen, the Netherlands, on 25 October 1965. After obtaining his secondary education degree at the Gymnasium Augustinianum in Eindhoven in 1984, he enrolled in the BSc/MSc Crop Production programme at Wageningen Agricultural University. Primary focus during the studies was on the fields of crop physiology, plant physiology and systems analytical principles in crop production. After graduation in 1990 , a research project was done on weather-related yield variability in the Sahelian zone. In 1992 he started his PhD project at the Department of Theoretical Production Ecology of Wageningen University on cycles of atmospheric-biospheric $\mathrm{CO}_{2}$ exchange in Dutch peat grasslands. The research was done in cooperation with the Netherlands Energy Research Foundation (ECN) and at that time leaned towards an emphasis on micrometeorological aspects of the measurements. From 1991 to 1996 successive training assignments were taken up on the principles of primary production. He switched from academia to the private sector in 1998 to start working for an international IT service provider. In a role of software developer and analyst, experience as a contractor was gathered in a range of companies in the Netherlands. In 2002 he started working for a small IT solutions provider in Switzerland as an IT consultant to primarily Swiss projects. In part motivated by personal circumstances, a move closer to the Netherlands followed in 2018 when he started working in Belgium for the subsidiary of a Dutch software house. In a dual role of solution architect and technology team lead he has been involved in projects for customers in Belgium, Luxembourg, France and Switzerland. The author has sustained strong interest in the broader thesis subject matter. This period saw the emphasis of the thesis evolve towards an understanding of the annual cycle of $\mathrm{CO}_{2}$ exchange in grasslands and its significance to processes in the global $\mathrm{C}$ cycle. 

This research was financially supported by the National Research Program on Global Air Pollution and Climate Change in the Netherlands (NRP project no. 852076).

Printing: ProefschriftMaken || www.proefschriftmaken.nl 

